\title{
Cultural Values in Selected Southeast Asian Countries As Reflected in Representative Short Stories: Comparative Study
}

\author{
Macasaet, Grace Minerva Q. , Teodoro M. Maranan
}

\begin{abstract}
The study on the "Cultural Values in Selected Southeast Asian Countries As Reflected in Representative Short Stories: A Comparative Study" reveals the intent of the researcher to investigate on the commonalities of cultural values in the community life and lifestyles of some selected Southeast Asian countries based on selected short stories of ASEAN literature. These selections were all written during the period from 1950s - 1990s against a background of profound political, social, and psychological change.
\end{abstract}

The researcher has found out that it is not difficult to understand why the short story has been readily adopted by Southeast Asian countries and has gained prominence in the present-day literature of these countries. The adaptability of the short story has enabled them to encompass a wide range of human experience. For example, social stratification is present in practically all societies. The idea of inequality in power, status, wealth, or all three. In the traditional societies of Southeast Asia, stratification is seen primarily in terms of a social hierarchy which bestows status. This study of the cultural values offer valuable insights into the character and integration of Southeast Asian short stories. The short story, with its immersion in society and its concern for the individual, has continually engaged itself in discovering the patterns that emerge from the relationship between the individual and society. ASEAN literature is important in the society where it is written. People read a great deal of short stories, mostly for entertainment, the effects can be more profound and longer lasting than mere escapism.

Content Analysis is a research technique which involves the objective systematic and qualitative description of the manifest content of communication.

The researcher of this study deciphered the images that could be seen in the short story under study through the chosen literary elements. From these literary elements, she identified the different social realities that are revealed through economy, politics, education and religious life of some selected Southeast Asian countries like Malaysia, Indonesia,
Thailand, Vietnam, Myanmar, Singapore, and the Philippines. The primary focus of this study was the comparative analysis of the commonalities of cultural values in the community life and lifestyles of some selected ASEAN countries as reflected on representative short stories of ASEAN literature.

The outputs of the system were the results, findings, and implications of the selected Southeast Asian countries for peace, unification, and solidarity in the Southeast Asian region. The researcher was also interested to know if there had been any change in the image depiction of the selected Southeast Asian countries in contemporary short stories from 1950 s to 1990s.

List of 35 Short Stories from Seven Southeast Asian Countries

Indonesia

1. Inem by Pramoedya Ananta Toer 1952

2. Sri Sumarah by Umar Kayam 1975

3. The Soldier by Nugroho Notosusanto 1956

4. The Decline and Fall of Our Local Mosque by A.A. Navis 1956

5. Meant For Each Other by Abdul Muis 1956

Malaysia

1. Mariah by Che Husna Azhari 1993

2. Victoria and Her Kimono by M.Shanmughalingam 1984

3. A Question of Dowry by Siew Yue Killingley 1962

4. A Common Story by Kassim Ahmad 1959

5. Grave Harvest by Ajikik 1978

Myanmar

This article is published under the terms of the Creative Commons Attribution License 4.0

Author(s) retain the copyright of this article. Publication rights with Alkhaer Publications.

Published at: http://www.ijsciences.com/pub/issue/2015-10/

DOI: 10.18483/ijSci.631; Online ISSN: 2305-3925; Print ISSN: 2410-4477 
1. This Realm of Humans by Khin Hnin Yu 1962

2. Neighbours by Moe Moe (Inya) 1972

3. Mother's Merit by Thu Maung 1980

4. The Kindergarten Teacher by Aung Thinn 1960

5. The Carat 13-Diamond by Daw Khin Myo Chit 1955

Philippines

1. Children of the City by Amadis Ma. Guerrero 1971

2. Clay by Juan T. Gatbonton 1951

3. The House on Zapote Street by Quijano de Manila 1968

4. The Day the Dancers Came by Bienvenido N. Santos 1967

5. Wedding Dance by Amador T. Daguio 1953

Singapore

1. Bugis by Alfian Sa'at 1997

2. The Martyrdom of Helena Rodrigues by S.Kon 1960

3. The Effect of a Good Dinner by Arthur Yap 1963

4. Monster by Catherine Lim 1966

5. The Tiger by S. Rajaratnam 1978

Thailand

1. As If It Had Never Happened by Witthayakon Chiangkun 1974

2. The Grandmother by K. Surangkhanang 1964

3. Lord Buddha, Help Me? by Suchit Wongthred 1975

4. Michigan Test by Wanit Jarungkit-Anan 1974

5. Thong Proi The Rich Girl by M.R.Kukrit Pramoj 1954

Vietnam

1. New Virtue by Nguyen Ban 1962

2. An Unsound Sleep by Nhat - Tien 1974

3. The Cradles by Mai Ngu 1962(Vietnam)

4. The Blind Alley by Ma Van Khang 1962

5. My Milk Goes Dry by Minh-Quan 1974

This study aimed to compare the cultural values of Southeast Asian countries as reflected in Southeast Asian short stories.

Specifically, this study sought to answer the following questions

1. What elements did the writers use to show cultural values in the chosen short stories?

2. How did these cultural values relate to the prevailing situations conditions, and actual events during the time when the short stories were written?
3. How did the identified cultural values in the short stories reflect the roles of the following aspects in the lives of Southeast Asian people?
3.1 Economy
3.2 Politics
3.3 Education
3.4 Religious life
3.5 Social life

4. How were the cultural values among the selected Southeast Asian countries compared based on the ten motivational types of values as reflected in the short stories?

\section{Conclusions}

1. Six of the thirty-five short stories prioritize achievement, personal success, competent performance, obtaining social approval, intelligence, self - respect, social recognition, and ambition. These short stories are from Indonesia, Philippines, Vietnam, and three masterpiece stories from Myanmar.

2. Four of the thirty - five short stories depict cultural values of self-direction, independent thought, creativity, autonomy, independence, intelligence, and privacy. They come from Singapore, Thailand, and two stories from Vietnam.

3. Four of the thirty - five short stories represent cultural values of Security, safety, harmony, stability of society, national security, social order, family security, national security, reciprocation of favors, and sense of belonging. They are from four the Philippines, Singapore, Thailand, and Vietnam. 4. Four of the thirty - five short stories represent cultural values of Benevolence; enhancing the welfare of the in - group; smooth group functioning; concern for family; primary groups; and for others welfare; helpfulnes, honesty, forgiving, loyal, true friendship, mature love, and spiritual life. They come from Myanmar, Malaysia, Indonesia, and Thailand. 5. Three of the thirty - five short stories describe cultural values of Stimulation, excitement, challenge in life, need for variety, a varied life, and daring life. They come from the Philippines, Thailand, and Vietnam.

6. Three of the thirty - five short stories picture cultural values of Hedonism, gratification for oneself, needs and pleasure, enjoying life, and self-indulgent. They come from are Singapore, Thailand, and Myanmar.

7. Three of the thirty - five short stories represent cultural values of Conformity, restraint of actions, social norms, obedience, self-discipline, politeness, honoring parents and elders, loyalty, and being responsible. They come from Malaysia and two masterpieces from Indonesia.

8. Three of the thirty - five short stories describe cultural values of Tradition, respect, commitment to customs/traditions, culture and religion, devout of 

Study

religious rites/beliefs, and symbols. They come from the Philippines, and two short stories from Malaysia.

9. Three of the thirty - five short stories depict cultural values of Universalism, understanding, tolerance, protection for nature/environment, social justice, equality, world peace, spiritual life, protection for the welfare of all people. They come from the Philippines, Singapore, and Malaysia. 10. Two of the thirty - five short stories depict cultural values of Power, social status, prestige, control and dominance over people and resources, authority, wealth, social power, preservation of public image, and social recognition. They come from Singapore and Indonesia.

\section{Recommendations}

The researcher presents the following recommendations :

1. Reading ASEAN short stories is a major activity of University students who wish to do well in their studies. Proficiency in reading brings about corresponding efficiency in writing because reading stimulates and develops the mind. Reading ASEAN short stories enriches the students' ideas and these ideas stimulate them in writing. University students, therefore, must be encouraged to read in order to write well. The students must stay at least an hour daily in the library reading Southeast Asian translated short stories.

2. Professors should be given as part of their advancement to have many meaningful seminars on how to teach World History, to teach and analyze fiction, and how to teach scientific writing. 3. Venues for communication like small group discussions, debates, and reports should be provided as exercises in the sequential or logical presentation of ideas using Southeast Asian short stories as possible topics highlighting the significant differences in terms of cultural values, social norms, religious perspectives, and political mores.

4. Professors should be encouraged to attend seminars/workshops on writing techniques to increase their Globalization/International knowledge and update their research and teaching methodologies and strategies.

5. Essay type of tests should be included in all subject areas to improve the students' skills in writing effectively.

6. The short stories of seven Southeast Asian countries presented in this study should be tried out by the Professors in order to encourage College students to appreciate the multicultural heritage and values of neighboring countries.

7. School publications and writing contests conducted by different universities should motivate students to write. They should encourage students to contribute creative outputs for publication.

8. Reading and writing must be planned. College students must be properly motivated. Students can write more effectively if they are shown model compositions about diverse Southeast Asian literatures.

9. The International Studies Department must meet the faculty for two purposes: a.) to discuss special problems on International Relations and comparative foreign policies of major powers and colonizers using world literature materials.

10. A conscientious use of the Southeast Asian short stories translated in English will surely make the College students discover further the comparison in their diverse cultural values and to authenticate the validity and practicality of this study.

Keywords: Cultural Values, literature, short story, culture shock 
they believe that learning is valuable. Like other .Asians,...Filipin.os...have.. high...regard...for...education because it is an integral part of their values

Figure 1. Map of Southeast Asia.

Figure 2. Theoretical Model of Relations Among

Ten Motivational Type Values

Figure 3. Paradigm Based on the Schwartz's

Theoretical Model of Relations Among

Ten Motivational Types of Values

\section{LIST OF TABLES}

Tab Cultural Values of 35 Short Stories of

le 1 Selected South East Asian Countries

Based on the Ten Motivational Types of

Values.

28

................

Tab Raw Data of Cultural Values of 35 Short

le 2 Stories of Selected South East Asian

Countries Based on the Ten Motivational

Types of Values

\section{CHAPTER 1}

Introduction

The Problem and Its Background

When people talk about values, they talk about something that is connected to human's practical experience. Where do values come from? What is important in values' development is the moral and ethical bases, which are acquired in the process of socialization. Many people consider important values to be justice, truth, health, happiness, and love. However, values can also be very personal preferences, which are important only to one particular person. Values are concepts or ideas, which are connected to a certain culture and language. Values have been formed through a consensus and according to the norms of the society (Veisson 2010).

Moreover, values are the bases of determining what behavior and attitudes are correct. They are emotion laden. The members of a culture share a value such as religiosity or honor because they feel that they are right. Values indicate the social conscience of the people. Culture's values are organized in a hierarchy or a set of priorities. This hierarchy of values is not always apparent, but it can be observed when there is a conflict of values and a selection between them is to be made.

Consequently, values are broad principles that support beliefs, specific statements that people hold to be true. In other words, values are abstract standards of goodness, and beliefs are particular matters that individuals consider true or false. Like for example, students value their education when orientation......Valuing...education...is...the. belief that schoolwork is both interesting and important (Magno 201.0)................................................ 28

In contrast, cultural values represent the implicitly or .explicitly..shared.abstract. ideas..about..whaB is good, right, and desirable in a society. These cultural values for example are freedom, prosperity, and security are the bases for the specific norms that tell people what is..ap.propriate..in..various..situations.....The..ways that societal institutions like family, education, economic, political, and religious systems function, their goals express cultural value priorities (Cultural Values 2004)

For an understanding of how cultural values influence the meanings that members of different societies attribute to work, culture-level value dimensions rather than individual -level dimensions are appropriate. Smith and Schwartz (1997) have explicated the difference between individual-and culture level value dimensions. The appropriate unit of analysis for assessing the validity of culture-level dimensions is the society or cultural group, not the individual person (Hofstede 1980, 1990; Schwartz 1994).

Possible impacts of individual differences in value priorities on the meanings and importance that different individuals within a society attribute to work values are discussed elsewhere (Ros, Schwartz, \& Surkis). When studying individual differences, an individual-level theory of values, different from the theory explicated here, must be used (Schwartz 1999).

In this study, "Cultural Values in Selected Southeast Asian Countries As Reflected in Representative Short Stories: A Comparative Study", it is possible to follow the trails of many kinds of evidences, each of which, if pursued consistently can illuminate wide areas of the life and circumstances of the peoples of the region. Short stories represent one trail; the study and descriptive analysis of the thirty-five short stories eliciting cultural values provide another richly rewarding exploration into the social traditions of the people whose lives they play a significant role. Along with, literary sources, of course are not a substitute for history, but they contribute something to perceptions of a period - of its cultural values, of what it was like to live through, of its ambiance and character. The essential nature of the short story is that it is an art form which attempts to portray all varieties of human experience through the medium of narrative prose, in a way faithful to the norms of formal realism. It focuses on the personal relations of individuals and the circumstances in which they 

Study

live, and the resulting work as a whole reveals a cultural value (Johns 1979).

Short story presents certain situation, or better a complex of situations was like, as affecting and effected by character under the consistent vision of the author. In this way, the short story can provide at once a picture of society (Johns 1979).

Indeed, the short story, with its immersion in society, is continually discovering the patterns of relationship between the individual and society. These patterns seem relevant to the Southeast Asian experience. Truly, these patterns search for meaning and stability to the changes in the society (Kintanar 1988).

Meanwhile, the themes conveyed in the selected Southeast Asian contemporary short stories are the ill effects of war, child abuse. Slavery, magic realism, and extended family ties are very apparent for Malaysia. Love for humankind, ironic hunting adventure, man's existence in two-worlds, intergenerational gap between father and son, and the evils of war are seen in the stories from Vietnam. The themes conveyed in Singapore's short stories are child abuse, graft and corruption, fascination, life's tricks and homecoming (De Jesus 2006).

Most significantly, a close reading of selected short stories used to show the cultural values of Southeast Asian countries reveals a unique combination of diverse and plural socio- cultural influences from the Confucian Chinese and distinctively Southeast Asian norms as well as Western ideologies as may be gleaned from the experience of the fictional characters in the context of their families and societies.

However, though little translated into other languages and scarcely marketed or noticed in Europe, the Americas, Africa, or China, the modern literature of Southeast Asia expresses "world" culture, the product of global, cross-cultural interactions extending over continents and seas for centuries. Indonesia and Vietnam share some of the characteristics of all four contexts where proletarian literary movements developed. Their modern literatures also display many of the forms and themes of European modernism. The mid $-1950 \mathrm{~s}$, in particular, is an important luminal period in the cultural history of both countries, a period when not only literature and the writer's role in society debated but also violently contested (Liem 2010).

Even greater, are the themes conveyed in the selected Southeast Asian contemporary short stories. Short stories from Indonesia show experiences like deceptive relationships, human rights violations, and violations against women. The Philippines has perennial experiences like women as sex objects, child molestation, environmental protection, alienation between father and son, and cultural preservations. Thailand has favorite themes like women's rights, murder, unrequited love, plight of the elderly and peace and contentment (De Jesus 2006).

Most important, is that a short story is a relatively brief fictional narrative in prose. It depicts one character's inner conflict with others, usually having one thematic focus. Short stories generally produce a single, focused emotional and intellectual response in the reader. The short story form ranges from "flash fiction," which run in length from a sentence to four pages, to novellas that can easily be 100 pages long and exhibit characteristics of both the short story and the novel. Because some works straddle the definitional lines of these three forms of fiction short story, novella, and novel - the terms should be regarded as approximate rather than absolute.

Most significantly, the modern genre of short stories was made popular by the magazines and newspapers where the stories could first be found. Today, many short stories can still be found in magazines and other periodicals, and are still quite popular. Things have changed since the short stories mentioned before though. By the early $20^{\text {th }}$ century into the present the short story had matured as a form (Baritugo et.al.) Background of the Study

The study on the "Cultural Values in Selected Southeast Asian Countries As Reflected in Representative Short Stories: A Comparative Study" reveals the intent of the researcher to investigate on the commonalities of cultural values in the community life and lifestyles of some selected Southeast Asian countries based on selected short stories of ASEAN literature. These selections were all written during the period from 1950s - 1990s against a background of profound political, social, and psychological change.

The researcher has found out that it is not difficult to understand why the short story has been readily adopted by Southeast Asian countries and has gained prominence in the present-day literature of these countries. The adaptability of the short story enabled them to encompass a wide range of human experience. For example, social stratification is present in practically all societies. The idea of inequality in power, status, wealth, or all three. In the traditional societies of Southeast Asia, stratification is seen primarily in terms of a social hierarchy which bestows status (Kintanar 1988).

In fact, in many Southeast Asian societies, the idea of class in the Marxian sense came to be recognized 
only in this century. Even now, in a number of Southeast Asian societies, stratification in terms of traditional status groupings still persists. Alongside this, may be a sharp awareness of social class in the Marxian sense, particularly in those societies where the end of colonialism and/or the rapid pace of globalization has brought to light glaring defects in the social system. Awareness of social inequality and its effects on the individual and society is thus a major theme in the works of many Southeast Asian writers, particularly those who write out of social commitment. This approach assumes that literature and society are closely interrelated, and the study of society as imaged in literature is very much within the province of the student of literature.

Most important, the contact with Western civilization and the opportunity to acquire a modern education which colonization brought to many parts of Southeast Asia in the $19^{\text {th }}$ century proved to be mixed blessing. It resulted in the creation of a Westernized intellectual elite on whom would devolve the task of nation building when the colonizers had finally left. But it also produced within these potential leaders of their peoples conflicts and tensions as they attempted to reconcile the liberal ideas of the West with the traditions and realities in their own countries. They soon realized, first, that though in their minds they may have freed themselves from blind adherence to outmoded traditions, tradition itself remained a dominant force in their societies and, second, that persistent idealism and the will to effect change were not sufficient to cope with the harsh realities of colonial oppression and the structures of colonial power. Such realizations often resulted in trauma as well as anguish over their personal and cultural identities which could not be dissociated (Kintanar 1988).

First, with the attainment of Philippine independence, came the urgent need to rediscover a true Philippine identity. To the middle-class intellectuals, heirs to the ilustrados, who took it upon themselves to redefine this identity, it proved no easy task. They had to cope with the multiple nature of their cultural heritage, derived in part from Spain and in part from the United States and as such representing two diverse cultural traditions, as well as with the fragmented and discontinuous state of their indigenous culture.

Meanwhile, the period from 1946 to 1960 was an era of effective American control of the Philippine economy, political life and military affairs. Culture during this period developed according to the ideological direction set by the United States. This was secured by the Educational Exchange Program, more popularly known as the "Fulbright Program," which was a latter-day version of the pensionado system of the early years of the American Occupation (Lumbera and Lumbera 2005).

Next, in the 1950s depicted the evils of the tenancysystem in Central Luzon. The struggle between the farmer and the landlord takes up the center of the short stories. It implies that the solution to the agrarian problem lies in the reconciliation of conflicting classes by the government. A society in which the peasant remained slave to a tenancy system that gave rich landlords enormous wealth while peasants were mired in debts they inherited from parents and would bequeath to children (Lumbera and Lumbera 2005).

Furthermore, the short stories in the 1960s probe the problem of identity in the experience of the Filipino middle - class intellectual. The Filipino intellectuals failed to harmonize values received from Western education with the hard facts of economic underdevelopment. Many short stories were about old timer Filipinos in the US. As far as the young people were concerned, Tagalog writing had to be put on par with Philippine writing in English which had profited from constant exposure due to what was being done by writers in the US and in Europe.

In contrast, the year 1970 was a turning point for the nationalist movement. Mass rallies, demonstrations and marches in public places reached the living room of urban Filipinos via television, and the terms "US Imperialism," "feudalism," bureaucrat capitalism" and "fascism" became familiar words. Violence and deaths at mass actions were recorded and denounced in the newspapers and on radio and television.

Even greater, in the 1970s, the disparate organizations articulating the struggle of women to assert their role as partners of men in nation building ceased to be the norm in expressing women's aspirations in Philippine society, to harness the power of organized women for revolutionary change with a specifically feminist consciousness.

To Indonesian readers living in the 1950s - the years Pramoedya Ananta Toer wrote and published stories - the period was the summer of popular discontent, an intense time of disillusion to Indonesians who thought that the 1945 independence would deliver a better life and more enthusiasm for their country's future. When the news of Japan's defeat and of the August 17, 1945 proclamation of Indonesian independence by Sukarno and Hatta, Pramoedya made his way back to Djakarta (Anderson and Kahin 2002).

Moreover, A.H. Johns notes that Pramoedya is through and through Javanese in his cultural attitudes. At the same time he finds much in his 
traditional culture repellent. And it is this ambivalence - his isolation from and commitment to his Javanese traditions - that is the source of much of the emotional intensity of his work.

The identity crisis which occurs among the members of the Westernized elite is also seen in the fiction of Indonesia and in the English - language fiction of the Philippines but is not usually found in Malay fiction. This is perhaps because Malay society is more strongly traditional and also because many Malay writers come from the rural areas where tradition prevails. This is not to say that the identity theme does not occur in Malay fiction. The concern of Malay fiction writers is the need to reassert Malay identity by strengthening it, by rediscovering the sources of its past strength and applying them to the present. Only in doing so can Malay society be revitalized and roused from its lethargy.

Alas, literature was the medium of instruction through which the writers could contribute to the intellectual experience of their readers, consistent with the aim of instituting social justice and peace especially after the war was enacted in its constitution. In the different works of its writers, the different forms of social and economic bondage that tied down the Malays, from that of a colonized mind to a dilemma of capitalistic exploitation (Husin and Hussein 1988).

Next, the question of Malay consciousness is very much the concern of Malay fiction, but Malaysia is multiracial nation. It is possible to forge a larger consciousness that goes beyond the narrow limits of ethnic affiliation and takes a total view of Malaysian life and society (Kintanar 1988).

The development of literature and its activities in Brunei Darussalam progressed rather slowly due to a number of factors that could not be avoided. The most important factor is the lack of active patronage. In Brunei Darussalam there were no magazines or newspapers that could exist for long as could be found in the neighbouring countries and contributed a lot to the growth of literature. Another factor is that the literary activities that began in the secondary schools were discontinued when the students left school. The authentic Brunei writers grew not because of any motivation or encouragement but because there was this intrinsic interest in writing and the interest could not survive long for there was no patronage and there was antipathy from a section of the community towards literature (Maxwell 1998).

Identity in Singapore must be seen in a different context. Unlike Malaysia which puts forth Malay language and culture as the bases of a national identity, Singapore encourages the concept of a plural society even though a large segment of its population is Chinese. Given the geopolitical realities of the region, it cannot do otherwise. To create a national identity based on Chinese language and culture would not be acceptable to its immediate neighbors, Indonesia and Malaysia, nor to its non-Chinese population, or even its ethnic Chinese citizens who are Westernized and English educated. Nor does it seem possible to merge elements from the cultures of the various ethnic groups that comprise Singapore society; the cultural traditions of these groups are too disparate and strong to result in a harmonious blending. Sociologists have postulated that the chief components of what may so far be regarded as a Singapore identity are the pragmatic values of efficiency and progress which have been consistently seen as the goals of nation building in Singapore. Moreover, it seems likely that this identity will be increasingly based on the English language as the language which is most useful in the attainment of these values.

Furthermore, it would appear that the concept of Singapore identity is still amorphous, still in the process of taking shape. It is not strange, therefore, that the sense of identity dominates neither background nor theme of the fiction written in Singapore. Much of the fiction portray or comment on various aspects of the plural society that is Singapore but it is difficult to find any unanimity of feeling concerning what it means to be Singaporean. Perhaps this is why Robert Yeo points out in his 1967 collection of Singapore short stories that short story writing had not as yet coalesced into the beginnings of a tradition. Fiction in Malay and in Chinese or Tamil seems to focus on the problems of their specific language communities. Some stories, like those of M. Balakrishnan, a Tamil writer, deal with the theme of inter-racial friendship, but this seems to be based more on the characters' awareness of their common humanity than on their being Singaporeans together (Kintanar 1988).

Most important, such an essentialist view of 'East' versus 'West' in regard to culture and ideology has made the government determined to maintain 'a role model for those who challenge the idea that the Western path to modernization is the only one on offer'. This ideology has been reiterated and inculcated through political campaigns in schools, homes, and workplaces as the Singaporean 'way of life'. However, Singapore's path to modernization is replete with cultural conflicts, ideological tensions and educational paradoxes (Koh 2006).

It is no exaggeration that in the period $1900-1975$ Vietnamese literature reached heights unequalled in all its history. This flowering was no doubt due to a combination of factors- political, economic and 
social; but the most important single cause was the introduction of quoc - ngu( the system of writing literary and colloquial Vietnamese in the Roman alphabet. It slowly but surely superseded the nom system of transliteration in Chinese characters, which had always been cumbrous to use - indeed, it was not officially recognized by the majority of emperors. But if quoc - ngu ushered in a new era in Vietnamese literature, it is because politically the situation was opportune. The French had only recently established themselves in Vietnam (1862, for most historians, marks the end of Vietnamese independence and the beginning of the colonial period); and with the French occupation of the whole of Indochina Western civilization burst with shattering impact into a world long closed to it. The conflict between the two cultures, Chinese and French, was soon to come out into the open and has unforeseen repercussions on literature and politics. Vietnamese literature had acquired respectability in the $18^{\text {th }}$ and early $19^{\text {th }}$ centuries; the introduction of quoc - ngu was to prove a powerful rejuvenating force and trigger off a brilliant revival which has lasted to the present day (Durand and Huan 1985).

Thailand, in contrast to Singapore, Thailand is racially, culturally, and linguistically, a fairly homogenous society. The Thais seem secure in their culture, religion, and history. Predominantly Buddhist, they take pride in a rich cultural heritage developed under a long, unbroken line of Thai kings. Buddhism and the monarchy to this day remain firm symbols of Thai national identity. As the only people in Southeast Asia fortunate enough to escape colonization, they did not have Western culture forcibly imposed on them. When they were exposed to it, they were in a position to pick and choose those elements of Western culture which would augment their own traditional culture and bring them to the modern age. This took place largely during King Chulalongkorn's time $(1868$ - 1910). The process has not been without trauma, of course. As elsewhere, there will always be areas of conflict between Eastern and Western culture, between the traditional and the modern. But they have been spared the additional pain which their colonized neighbours have had to suffer - that of recognizing the value of Western ideas such as freedom, equality, and justice while seeing these very principles violated in their own countries by the same people who espoused them.

As in other Southeast Asian countries, it is the elite in Thailand who have been most exposed to Western ways and values. But secure in his history and culture, the Thai does not suffer an acute identity crisis. The problem for the Thai lies in learning how to take his place in the modern world, drawing on Western culture, yet retaining the best and most distinctive of his own values (Kintanar 1988). Setting of the Study

The researcher has chosen representative short stories in some selected ASEAN countries. The seven countries of Southeast Asia like Malaysia, Thailand, Indonesia, Vietnam, Myanmar, Singapore and the Philippines are presented in Figure 1 and the respective brief description of Southeast Asia.

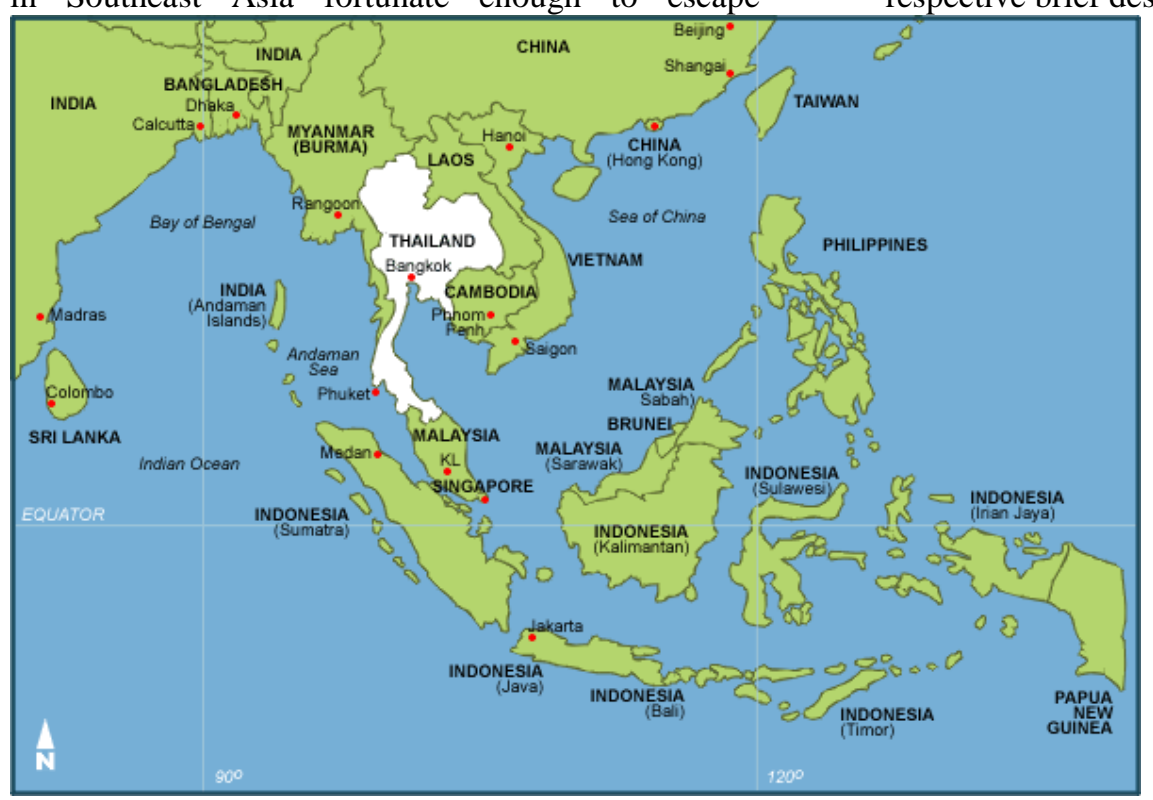

Figure 1. Map of Southeast-Asia

Malaysia

Malaysia sits on the South China Sea in the center of Southeast Asia. The country is crescent- shaped, starting with Peninsular Malaysia (West Malaysia) and extends to another region, Sabah and Sarawak (East Malaysia), located on the island of 
Borneo. The total area of Malaysia is approximately 330,000 square $\mathrm{km}$, with most of it located on the island of Borneo. Peninsular Malaysia only comprises approximately $40 \%$ of the total area.

Malaysia's climate is hot and humid with relative humidity ranging from 80 - 90 percent, except in the highlands. The temperature averages from 70-90 degrees $F$ (20-30 degrees $C)$ throughout the year. The tropical climate is experienced year-round with the rainy season varying on the coasts of Peninsular Malaysia. The west coast has its rainy season from September through December with the east coast (and Sarawak and Sabah) experiencing it from October through February. East Malaysia (the northern slopes) gets up to $5080 \mathrm{~mm}$ of rain a year versus West Malaysia's $2500 \mathrm{~mm}$.

There are forests covering over half of Malaysia, with notable tropical forests in Sabah and Sarawak. Deforestation is a problem the country is dealing with due to logging and hydroelectric projects (Malaysia’s Geography 2010)

\section{Thailand}

Thailand covers an area of 514,000 square kilometers in the centre of the South-East Asian peninsula. It is bordered by Myanmar (Burma), Lao People's Democratic Republic, Cambodia and Malaysia, and has 2,420 kilometers of coast line on the Gulf of Thailand and the Andaman sea. Thailand stretches 1,650 kilometers from north to south, and from east to west 780 kilometers at its widest point. For economic, social and ecological reasons, Thailand is usually classified into four geographical regions. The central region: comprising the basin of the Chao Phrya River which runs from north to south and after crossing Bangkok flows to the Gulf of Thailand. The central region is often called the "rice bowl" of Thailand being the most fertile area of the country. After the Bangkok Metropolitan Region, it enjoys the highest per capita income in the country.

The northern region is mountainous and was traditionally the most heavily forested area of the country. In the recent years, however, overcutting has considerably reduced its forest resources. The main centres of population are in the narrow alluvial valleys along the four north-south flowing rivers which unite in the northern central plain to form the Chao Phraya.

The north-eastern region (Isarn) constitutes approximately one third of the area of the Kingdom and comprises the Korat Plateau which is bounded on the north and east by the Mekong River and the south by the Dongrek escarpment. The region is drained by the Mun and Chi rivers, both tributaries of the Mekong. Largely owing to lower and erratic rainfall and poorer soils than in other parts of the country, the north-eastern provinces have the lowest per capita income in the country. Approximately one third of the population of Thailand lives in the north-east. The south-eastern region: the south-east, which comprises the hilly countryside from Bangkok to the Cambodian border, is characterized by higher rainfall and poorer soils than the adjoining central region. It is an important fruit, maize and cassava-growing area and its coastline offers extensive opportunities for fisheries and tourism. The high rainfall also permits some rubber to be grown.

The southern region: the southern peninsula has the highest rainfall in the country. It is the principal rubber-growing area and contains extensive alluvial deposits of tin. The forests of the south have been seriously overcut as elsewhere in the Kingdom. In recent years, the region has suffered from severe floodings which are believed to have been amplified by deforestation and subsequent soil erosion (United Nations Thailand 2014).

\section{Indonesia}

Indonesia is the largest archipelago in the world. It consists of five major islands and about 30 smaller groups. There are total number of 17,508 islands of which about 6000 are inhabited. Straddling equator, the archipelago is on a crossroads between two oceans, the Pacific and the Indian Ocean, and bridges two continents, Asia and Australia. The territory of the Republic of Indonesia stretches from $6^{\circ} 08^{\prime} \mathrm{N}$ latitude to $11^{\circ} 15^{\prime} \mathrm{S}$ latitude, and from $94^{\circ} 45^{\prime} \mathrm{E}$ to $141^{\circ} 05^{\prime} \mathrm{E}$ longitude. Total Area of Indonesia is 1,919,440 sq km (Land Area: 1,826,440 sq km; Water Area: 93,000 sq km).

The five main islands are: Sumatra $(473,606$ sq. $\mathrm{km}$ ); the most fertile and densely populated islands, Java/Madura (132,107 sq. km); Kalimantan, which comprises two-thirds of the island of Borneo $(539,460 \mathrm{sq} \mathrm{km})$; Sulawesi $(189,216 \mathrm{sq} \mathrm{km})$; and Irian Jaya $(421,981 \mathrm{sq} \mathrm{km})$, which is part of the world's second largest island, New Guinea. Indonesia's other islands are smaller in size. The country is predominantly mountainous with some 400 volcanoes, of which 100 are active. The highest mountain is the perpetually snow-capped Mandala Top (15,300 feet) in the Jaya Wijaya mountain range of Irian Jaya. Many rivers flow throughout the country. They serve as useful transportation routes on certain islands, for example, the Musi, Batanghari, Indragiri and Kampar rivers in Sumatra; the Kapuas, Barito, Mahakam and Rejang rivers in Kalimantan; and the Memberamo and Digul rivers in Irian Jaya (Indonesia's Geography 2010).

\section{Vietnam}

Several district regions make up Vietnam. They are Southern Lowland; the Annam Cordillera; the Coastal Plain; the Tonkin Lowland; and the Northern 
Highlands. The Southern Lowland consists of the densely populated Mekong Delta and the adjacent area to the north. A low, fertile plain only slightly above sea level, it is one of Asia's great riceproducing regions.

The Annam Cordillera is a long mountain chain forming much of the Laos-Vietnam border. In the north the mountains are narrow and have rugged peaks reaching almost 9,000 feet $(2,740 \mathrm{~m})$ above sea level. The southern section spreads out to form the Central Highlands, a wide plateau ranging from 2,000 to 4,000 feet $(610$ to $1,220 \mathrm{~m})$ in altitude, but with peaks up to 7,900 feet $(2,410 \mathrm{~m})$.

The Coastal Plain, lying between the Annam Cordillera and the sea, extends approximately from NhaTrang northward to ThanhHoa. Narrow and in places disappearing altogether toward the south, the plain widens to 40 miles $(60 \mathrm{~km})$ in its northern portion. The Tonkin Lowland is the heart of northern Vietnam. It includes the lower valley and delta of the Red River and the surrounding area. Like its counterpart, the Southern Lowland, it is a broad, flat region, thickly settled and intensively cultivated. The Northern Highlands, bordering the Tonkin Lowland on its landward sides, occupy much of the wide portion of northern Vietnam. The highest peaks, exceeding 10,000 feet $(3,050 \mathrm{~m})$, are in the west and northwest. Most of the region's people live in the deep, narrow valleys of the Red River and its tributaries.

Vietnam has two great river systems: the Mekong in the south and the Red River in the north. Both have large delta plains that are subject to heavy seasonal flooding, and both are crossed by complex canal networks. Of the other rivers, the largest are the $\mathrm{Ca}$ and $\mathrm{Ma}$, in the north, and the Dong Nai, in the south.

A tropical monsoon climate prevails, with warm to hot weather all year and heavy, though seasonal, rainfall. The summer monsoon brings moisture-laden air from the south that drops much rain everywhere except on the Coastal Plain. From June through September Ho Chi Minh City (Saigon) receives 50 inches $(1,270 \mathrm{~mm})$ of rain, Hanoi 45 inches $(1,140$ $\mathrm{mm})$. The heaviest rains of the northeast winter monsoon, which begins in September, occur on the Coastal Plain. Hue, one of the cities on the plain, receives an annual average of 100 inches $(2,540 \mathrm{~mm})$ of rainfall, most of it during this monsoon.

Except in mountainous areas, high temperatures prevail all year. Ho Chi Minh City averages $79^{\circ} \mathrm{F}$. $\left(26^{\circ} \mathrm{C}\right.$.) in December, the coolest month, and $85^{\circ} \mathrm{F}$. $\left(29^{\circ} \mathrm{C}\right.$.) in April, the hottest. Hanoi has a January average of $62^{\circ} \mathrm{F}$. $\left(17^{\circ} \mathrm{C}\right.$. $)$ and a June average of $85^{\circ}$ F. $\left(29^{\circ}\right.$ C. $)$. More than half the original forest that once covered Vietnam has long since vanished, largely because of cutting and burning to create new farmland. The remaining forest, chiefly in the mountains, consists of broadleaf evergreen and deciduous trees. Smaller patches of forest are scattered throughout the lowlands (Vietnam Geography Profile 2008).

Myanmar

Located between Bangladesh and Thailand, with India and China to the north, Myanmar covers an area of about $675,000 \mathrm{sq} \mathrm{km}$ (over 260,000 sq $\mathrm{mi})$. The capital and largest city is Yangon, an important trade center is Mandalay located in central Myanmar.

The country itself is divided into two classifications, Lower Myanmar and Upper Myanmar. Lower Myanmar is comprised of coastal areas with thick tropical forests that have valuable trees in them (teak forests, oil-bearing and timber trees) with Upper Myanmar making up the interior parts of the country.

A major topographical feature of Myanmar is the Irrawaddy River system. Since its deltaic plains are very fertile, it is considered to be the most important part of the country covering about 18,000 sq mi $(47,000 \mathrm{sq} \mathrm{km})$. Hkakabo Razi, the highest peak in Southeast Asia at 19,295 ft $(5,881 \mathrm{~m})$, is located in Myanmar. A barrier between India and Myanmar, the Arakan Yoma range has peaks that range between $915 \mathrm{~m}(3,000 \mathrm{ft})$ and 1,525 $\mathrm{m}(5,000$ $\mathrm{ft})$.

Almost half of Myanmar is covered in forests that are comprised of teak, rubber, cinchona, acacia, bamboo, ironwood, mangrove, coconut, betel palm with northern highlands comprised of oak, pine and many varieties of rhododendron. There are many tropical fruits to be found as well, citrus, bananas, mangoes, and guavas in the coastal region (Myanmar's Geography 2010).

\section{Singapore}

Singapore is an island of 646 sq. km, about the size of Chicago. It is located at one of the crossroads of the world. Singapore's strategic position has helped it grow into a major center for trade, communications, and tourism. Its geographical location is $96 \mathrm{~km}$ north of the equator, between longitude 103 degrees 36' East and 104 degrees 25' East. Singapore is often touted as a concrete jungle with close to $90 \%$ of the population living in flats and an ever-changing skyline of monumental buildings. Government and private enterprises also conduct an orchestra of automation that makes Singapore one of the world's most efficient societies. Yet Singapore has also been known as a green city. There is a 
wealth of flora and fauna here that is beyond one's own imagination.

Two causeway bridges link Malaysia, which is just north of Singapore. The key islands of the Riau Archipelago of Indonesia are also just a quick ferry trip away, whereas Thailand and the Philippines are a short plane journey away. Singapore, with an airport served by more than 69 airlines, is very much the gateway to Southeast Asia

Singapore's climate is warm and humid, with temperatures ranging from 23 degree Celsius to 31 degree Celsius. This makes it ideal for those who enjoy sunbathing, swimming, sailing, and other water sports. For those who do not enjoy the tropical climate, Singapore is sheltered from the worst effects of the sun with air-conditioning in almost all of its buildings, including restaurants. Rain falls throughout the year with more consistent rain during the monsoon season from November to January. Showers are usually sudden and heavy, but brief and refreshing (Singapore's Geograhy 2010).

\section{Philippines}

The archipelago is divided into three groups: Luzon, Visayas, and Mindanao. The Luzon islands include Luzon Island itself, Palawan, Mindoro, Marinduque, Masbate and Batanes Islands. The Visayas is the group of islands in central Philippines, the largest of which are Panay, Negros, Cebu, Bohol, Leyte and Samar. The Mindanao islands include Mindanao itself, plus the Sulu Archipelago, composed mainly of Basilan, Sulu and Tawi-Tawi.

In terms of its political geography, Philippines is divided into a hierarchy of local government units with 81 provinces as the primary unit. The provinces are further subdivided into cities and municipalities, which are in turn, composed of barangays. The barangay is the smallest local government unit. Philippines is also divided into 17 regions with all provinces grouped into one of the 16 regions for administrative convenience. The National Capital Region (NCR) however, is divided into four special districts.

Being part of the Pacific Ring of Fire, the islands of the Philippines are volcanic in origin and mostly are mountainous. Mount Apo in Mindanao is the highest point in the country which is 2,954 meters above sea level. The second highest point is Mount Pulag in Luzon.

Many volcanoes in the country are active. The most devastating eruption was that of Mount Pinatubo in 1991. Mount Mayon is another active volcano and is famous for its perfectly shaped cone. Taal Volcano, on the other hand, is the world's smallest volcano.

The country's most extensive river systems are the Pulangi River which flows into Rio Grande de Mindanao; the Agusan River in Mindanao which flows north into Mindanao Sea; the Cagayan River in northern Luzon which is the longest river in the country; and the Pampanga River, which flows south from east into Manila Bay. The Laguna de Bay, located east of Manila Bay, is the largest freshwater lake in the Philippines.

The Philippines has a tropical climate dominated by rainy and dry seasons. The summer monsoon brings heavy rains to most of the archipelago from May to October, while the winter monsoon brings cooler and drier air from December to February. Manila and most of the lowland areas are hot and dusty from March to May. The country sits astride the typhoon belt, and it suffers an annual attack of dangerous storms from July to October. The areas mostly affected are northern and eastern Luzon, and the Bicol and Eastern Visayas regions, but Manila gets devastated periodically as well (Philippines 2009)

Theoretical/Conceptual Framework

Schwartz value theory has been tested in more than seventy countries, and in most of the samples both the distinctiveness of the ten value types and their circular structure could be confirmed (Schwartz 2006).

In order to test the validity of the theoretical content and structure of cultural value types, the Theoretical Model of Relations among Ten Motivational types of Values was used as basis for finding the commonalities on cultural values of thirty five representative short stories of selected ASEAN countries. The analysis used means of samples that represent cultural values. 


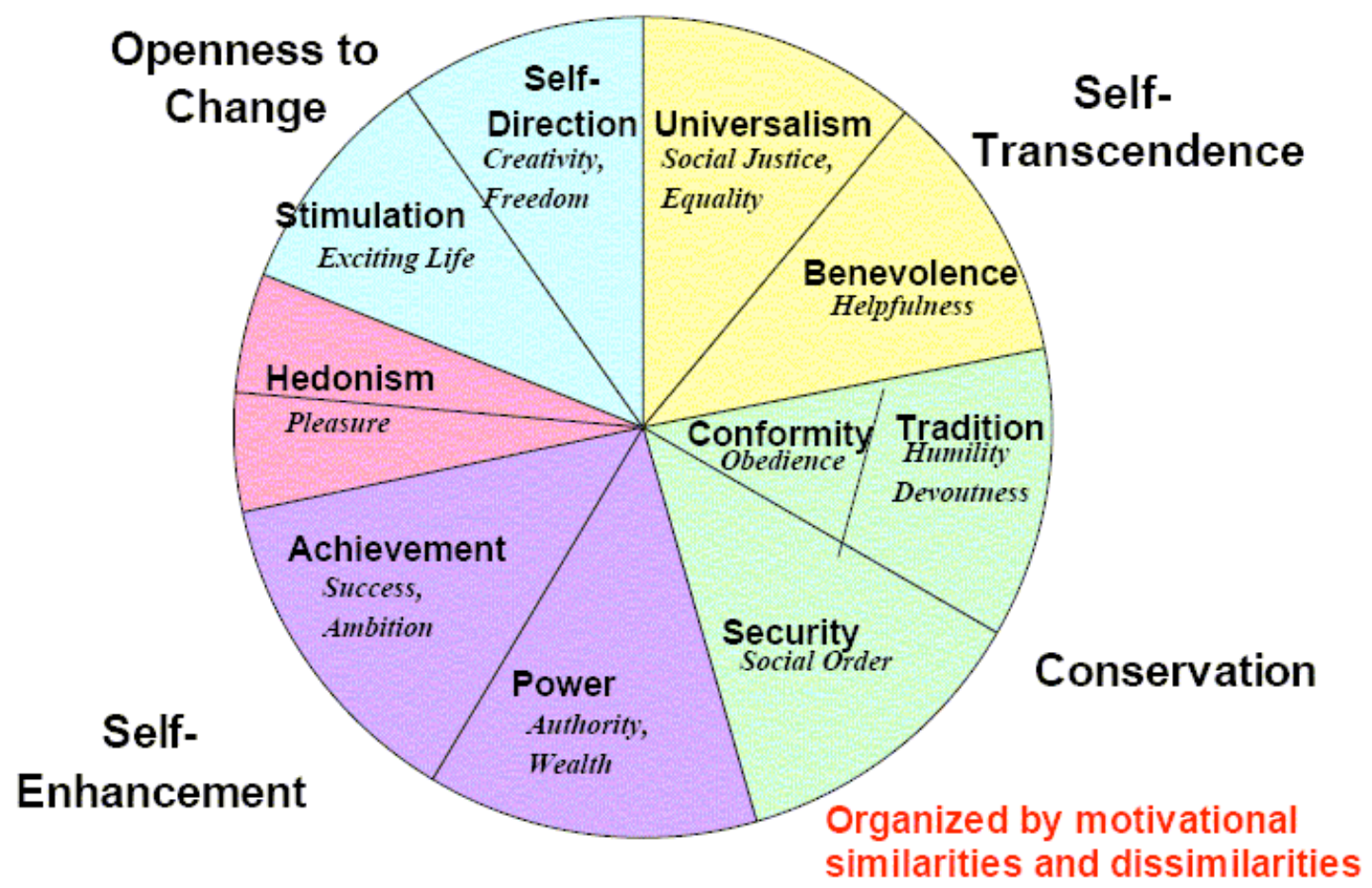

Figure 2

Theoretical Model of Relations Among Ten Motivational Types of Values

The theory identifies ten motivationally distinct value orientations that people in all cultures recognize and it specifies the dynamics of conflict and congruence among these values. It aims to be a unifying theory for the field of human motivation, a way of organizing the different needs, motives, and goals. The ten basic values are intended to include all the core values recognized in cultures around the world (Schwartz 2006).

The Circular Motivational Structure of Ten Values 1. Self-Direction - Independent thought, creativity, autonomy, independence, intelligence, privacy

2. Stimulation - excitement, challenge in life, need for variety and stimulation, a varied life, and daring life

3. Hedonism - gratification for oneself, needs and pleasure, enjoying life, and self-indulgent

4. Achievement - personal success, competent performance, obtaining social approval, intelligence, self - respect, social recognition, and ambitious

5. Power - social status, prestige, control and dominance over people and resources, authority, wealth, social power, preservation of public image, social recognition

6. Security - Safety, harmony, stability of society, national security, social order, family security, national security, reciprocation of favors, sense of belonging
7. Conformity - Restraint of actions, social norms, obedience, self - discipline, politeness, honoring parents and elders, loyalty, and being responsible

8. Tradition - Respect, commitment to customs/traditions, culture and religion, devout of religious rites/beliefs and symbols

9. Benevolence - Enhancing the welfare of the in group; smooth group functioning, concern for family, primary groups, and for others' welfare; helpfulness, honesty, forgiving, loyalty, true friendship, mature love, and spiritual life

10. Universalism - understanding, tolerance, protection for nature/environment, social justice, equality, world of peace, spiritual life, protection for the welfare of all people

The theory concerns the basic values that people in all cultures recognize. It identifies ten broad motivationally distinct value orientations and specifies the dynamics of conflict and congruence among these values.

That is, individuals and groups have different value priorities or hierarchies. Seventy countries around the world have validated both the contents and structure of values postulated by the theory.

This proliferation of behavior, attitude, and personality studies/variables testifies to the fruitfulness of the value theory and its promise for future research (Schwarz 2006).

Based on the aforementioned theories on Cultural Values, the researcher was able to formulate her own framework as going to be explained by the following 
paradigm. It would seem that, given the basic talent and the inclination to write short stories, many Southeast Asian writers have been moved by the urgency of the problem facing their societies and the immediate need to articulate their needs, conflicts, and concerns. For all that, there have emerged ASEAN short story writers, who have successfully fused their cultural values with their artistic skills. Indeed, representative short stories and society are closely interrelated.

The researcher cited all the cultural values mentioned in the thirty five representative ASEAN short stories. These cultural values were based on
Schwartz's Ten Basic Motivational Types of Values that people in all cultures implicitly recognize. The study employed the Expressive Elements of Fiction Guide like character, setting, point of view, plot, conflict, symbol, and theme. Then, the researcher used the art of the short story that employs the technique of writing the actual events from the thirty five representative ASEAN short stories that depict and stimulate emotional, imaginative, and intellectual cultural values. The cultural values have congruence with Schwartz's Ten Motivational Types of Values (Baritugo et.al. 2007).

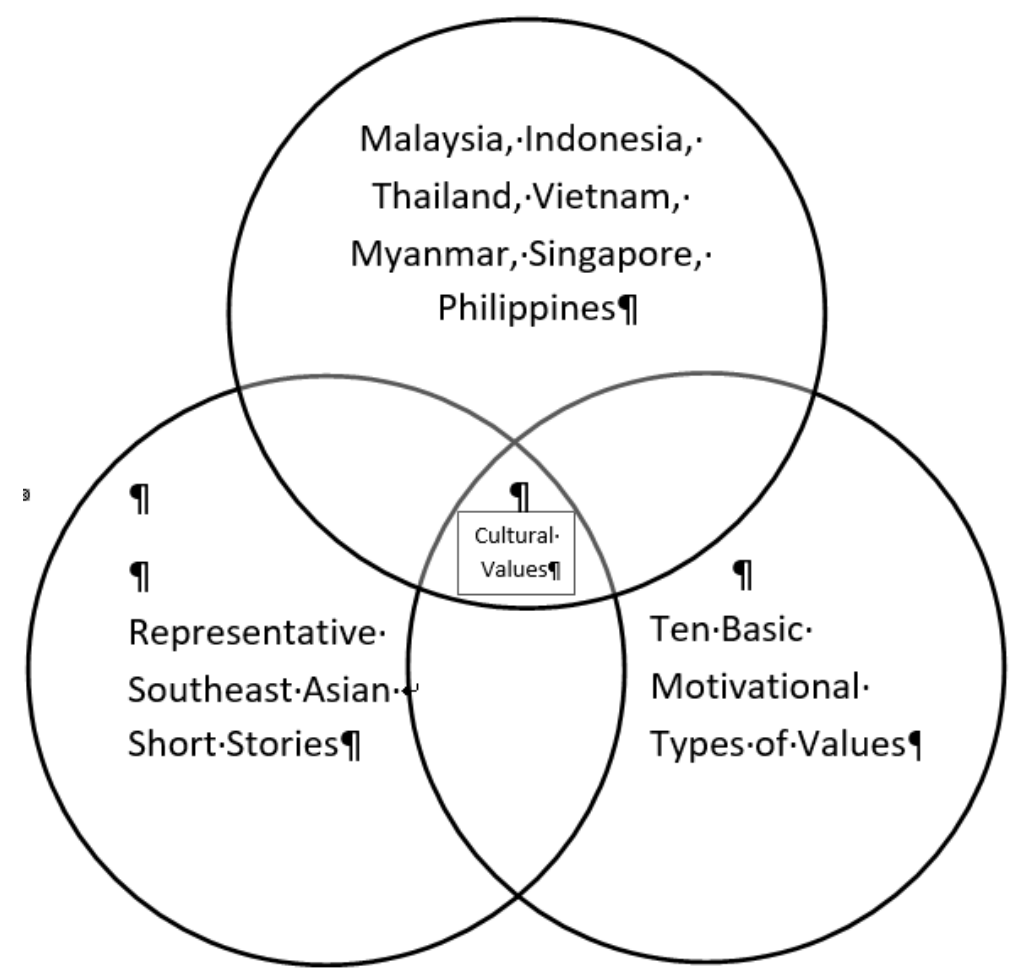

Figure 3. Paradigm Based on the Schwartz's Theoretical Model of Relations Among Ten Motivational Types of Values

Paradigm shows that cultural values are present in all Southeast Asian representative short stories under study. Indeed, common cultural values among the selected Southeast Asians are reflected in the representative ASEAN short stories.

It concerns the cultural values that individuals in all cultures recognize. The paradigm is based on the theory of Schwartz, S. H. (2006) the basic human cultural values. These values common to culturally diverse groups, suggesting a universal organization of human motivations.

Statement of the Problem

This study aimed to compare the cultural values of Southeast Asian countries as reflected in Southeast Asian short stories.

Specifically, this study will sought to answer the following questions

1.What elements did the writers use to show cultural values in the chosen short stories?
2.How did these cultural values relate to the prevailing situations conditions, and actual events during the time when the short stories were written?

3.How did the identified cultural values in the short stories reflect the roles of the following aspects in the lives of Southeast Asian people?
3.1Economy
3.2Politics
3.3Education
3.4Religious life
3.5Social life

4.How were the cultural values among the selected Southeast Asian countries compared based on the ten motivational types of values as reflected in the short stories?

Assumptions of the Study 

Study

The study was anchored on the assumption that short story plays a part in helping people to understand the conditions of society by filling in the gaps in the apprehension of reality, both social and individual, and serving as literary witness to the fullness of a society's life.

The short story, has been readily adopted by countries in Southeast Asia and has gained prominence in the present-day literature of these countries. The flexibility and the adaptability of the short story enable them to encompass a wide range of human experience.

More importantly, in view of its origins and early development, the short story is eminently suited to chronicle the societies in transition as is the case with Southeast Asian societies. The shift from a communal society which is essentially simple and harmonious to a modern one which is more complex, forces the individual to see himself apart from his society; at the same time, he feels even more greatly the need to understand the complex society and to adjust against all odds.

\section{Significance of the Study}

This study of the cultural values offers valuable insights into the character and integration of Southeast Asian short stories. The short story, with its immersion in society and its concern for the individual, has continually engaged itself in discovering the patterns that emerge from the relationship between the individual and society. ASEAN literature is important in the society where it is written. People read a great deal of short stories, mostly for entertainment; the effects can be more profound and longer lasting than mere escapism.

A successful work of fiction can affect people's perceptions of their society, thereby making them more secure in their feelings about their culture or it may challenge their perceptions, causing them to rethink their views or to seek new understanding such as the work itself may provide.

The study gives a deeper understanding of the cultural values of Southeast Asian countries. Short stories of ASEAN literature are beautiful and a creative form of art that helps trace the foundation of a nation. With this study educators like the curriculum planners and teachers, can go back to the past through the reliving of teaching literature, strengthening cognitive, affective and manipulative skills in the social sciences especially and relating it to modern science and technology.

The following may benefit from the study:

Parents and children sustain the cultural identity of the ASEAN family that creates a network of supportive and nurturing communities; the seemingly stable entrenchment of English as the dominant language of the educated. In the Philippines, English is accepted as the language of technology, diplomacy, and trade. Most of the Filipinos of today do not equate nationalism with a non-English medium education and that one can be a genuine Filipino despite an English education.

The Colleges and Universities in the Philippines, the study can provide a deeper understanding of the cultural values of Southeast Asian countries needless to say, culture lies in the fact that in spite of the conflict situations which continually arise within it, the larger movement of society has always been toward harmonization and reconciliation of its individual members.

Similarly, the individual feels the need to relate himself to his fellow men to mitigate his sense of isolation and aloneness. As a social being, it is natural for him to reach out to other men who may have similar needs.

For the faculty members - to go beyond their roles as lecturers in the classrooms and step outside and get involved in the pursuit of new knowledge enhancing their teaching skills. They may teach the students the search for identity. Identity is a universal theme in the individual's attempt to understand himself and his society and that is why it is a compelling and persistent theme in modern fiction.

This is true of fiction in Southeast Asia where multicultural societies and emerging nationalisms often find the individual at Southeast Asia in a confusion of identities.

For the graduate and undergraduate International Studies students to be motivated and inspired to pursue careers in applying the knowledge they learned in their academic training and appreciate education in a new light. In the traditional societies of Southeast Asia, stratification presupposes inequality in social relationships, that is, inequality in power, status, and wealth. Stratification is seen primarily in terms of a social hierarchy which bestows status.

These significant points in the study, when realized will ultimately benefit the teaching community in particular and the entire population in general as answer to their extreme poverty that will gradually be resolved.

Scope, Limitations and Delimitation

This study focused on the comparison and analysis of the commonalities of cultural values in the community life and lifestyles of some selected Southeast Asian countries based on selected short stories of ASEAN literature.

The subjects of the study are representative thirty five contemporary short stories used to show the cultural values of Southeast Asian countries.

The researcher used references published before the year 2000 because the topic needed both primary sources and secondary sources related to ASEAN short stories as a part of the ways of life of man. 

Study

In historical/cultural research, references published before the year 2000 are representatives of the time when the written materials were published and can be used as guide in the analysis and interpretation of data gathered.

\section{Definition of Terms}

For clear and easy understanding of the study, the following terms are defined.

Communitarian. Communitarian in nature is evident in the documents' exhorting Singaporeans to "compromise" their "selfish" individual interests, benefits, and rights for the common good and to perform their duties as members of their family and community. Communitarianism essentially highlights the importance of the community in the formation and shaping of the individual's values, behaviour, and identity (Tan 2012).

Cultural Values. This refers to the commonly held standards of what is acceptable or unacceptable, important or unimportant, right or wrong, workable or unworkable, etc., in a community or society. Cultural Values are also defined as culture - level dimensions that reflect a set of deeply held beliefs that characterize a culture's worldview with respect to humanity and its relationship to nature and time (Schwartz 1999).

Culture. This refers to the values, beliefs, behavior, and material objects that together form a people's way of life. Culture includes what one thinks, how one acts, and what one owns. Culture is both a link to the past and a guide to the future (Kendall 2012).

Culture of Peace. This refers to the culture of social interaction, based on the principles of freedom, justice and democracy, tolerance, and solidarity, and respect for all human rights; a culture that rejects violence and instead, seeks a solution to problems through dialogue and negotiation; a culture of prevention that endeavors to detect the sources of conflict at their very roots, so as to deal with them more effectively and as far as practicable, to avoid them (Boulding 1998).

Culture Shock. This is a feeling of a clash between one's host culture and one's primary culture, possibly leading to feelings of loneliness, alienation, uncertainty, frustration, and/or fear. It is the "driving force that pushes the participant to become interculturally competent in the host culture" but it might just as well tip someone over the edge to the point where he/she feels he is not coping. The consequences of culture shock are not always negative, but neither are they inevitably positive (Chan and Parr 2012).

Ethnocentrism. This is the tendency to view one's own culture as superior and to apply one's own cultural values in judging the behavior and beliefs of people raised in other cultures. Ethnocentrism contributes to social solidarity, a sense of value and community, among people who share a cultural tradition. People everywhere think that their familiar explanations, opinions, and customs are true, right, proper, and moral. They regard a different behavior as strange, immoral, or savage. It is also the belief that one's own patterns of behavior are always natural, good, beautiful, or important, and that strangers, to the extent that they live differently, live by savage, inhuman, disgusting, or irrational standards. It is the practice of judging all other cultures by one's own culture. It implies misunderstandings and conflict that occur when people interpret and judge what they see, according to their own norms, values, and assumptions (Kendall 2008).

Intercultural Competence. This is the key goal of internationalisation because it indicates an awareness and understanding of culturally diverse people and situations, as well as the presence of behaviors that promote productive and effective communication among and across cultures (Andrew 2012).

Internationalisation. This is the awareness and operation of interactions within and between cultures through its teaching, research and service functions, with the ultimate aim of achieving mutual understanding across cultural borders (Andrew 2012).

Literature. This refers to mean compositions designed to tell stories, dramatize situations, express emotions, and analyze and advocate ideas. Works composed before the invention of writing were necessarily spoken or sung, and were retained only as long as living people knew them and performed them. While many of these oral works are lost, many have also been saved and preserved as printed texts. Today, writing and printing give life to most literature. As a result, reading and appreciating literary texts are often a totally private, silent experience (Alaras 1986).

Modernization. This refers to the sequencing of development, though sequencing in this theory is the result of the relationship between variables, rather than a consequence of design. Economic growth starts a chain of events leading eventually and inevitably to political reform: economicreform economic growth - social change -democracy (Elgin 2010).

Multiculturalism. This refers to the learning environment that enhances knowledge, understanding, and insight into cultures and differences throughout the world and preventing racism, hate, and discrimination (Ozturgut 2012).

Shared Values. This refers to the first proposal in 1988 by Deputy Prime Minister GohChok Tong of Singapore, regardless of ethnicity, religion, and other differences. The shared values consist of the following five broad principles: nation before community and society before self, family as the basic unit of society, community support and respect 
for the individual, consensus, not conflict, racial and religious harmony (Kendall 2012).

Short story. This refers to relatively brief fictional narrative in prose. It depicts one character's inner conflict or conflict with others, usually having one thematic focus. Short Stories generally produce a single, focused emotional and intellectual response in the reader. The short story form ranges from "flash fiction", which run in length from a sentence to four pages, to novellas that can easily be 100 pages long and exhibit characteristics of both the short story and the novel (Brooks, Purser and Warren 1975).

Sociological Criticism. This refers to an approach to literature that examines social groups, relationships, and cultural values as they are manifested in literature. Sociological approaches emphasize the nature and effect of the social forces that shape power relationships between groups or classes of people (Baritugo and Caranguian 2007).

The Association of Southeast Asian Nations (ASEAN). This refers to political and economic organization of ten countries located in Southeast Asia, which was formed on August 8 1967 by Indonesia, Malaysia, the Philippines, Singapore and Thailand. Since then, membership has expanded to include Brunei, Burma (Myanmar), Cambodia, Laos, and Vietnam. Its aims include accelerating economic growth, social progress, cultural development among its members, protection of regional peace and stability, and opportunities for member countries to discuss differences peacefully. (Chandler and Owen 2004).

Values. This refers to the culturally defined standards that people use to decide what is desirable, good, and beautiful, and that serve as broad guidelines for social living. Values are standards that people who share a culture use to make choices on how to live. Values are also broad principles that support beliefs, specific statements that people hold to be true. In other words, values are abstract standards of goodness, and beliefs are particular matters that individuals consider true or false (Kendall 2012).

\section{CHAPTER 2}

\section{Review of Related Literature and Studies}

The following are related literatures and studies that provided some of the additional information that were helpful for the in - depth understanding of the study.

Cultural Values

"Cultural values represent the implicitly or explicitly shared abstract ideas about what is good, right, and desirable in a society. These cultural values (e.g. freedom, prosperity, security) are the bases for the specific norms that tell people what is appropriate in various situations. The ways that societal institutions (e.g. the family, education, economic, political, religious systems) function, their goals and their modes of operation, express cultural values and priorities" (Schwartz 1999).

For example, cultural values are emphasized in Singapore. Collectivist societies tend to emphasize identity based on the social network and the extended family. Also associated with collectivism are interdependence, group harmony, strong family ties, filial piety, loyalty to the in-group, indirect communication, conformity, and the belief on collective decision. Proper behavior for a Singaporean includes being prudent, courteous, wellmannered, patient, and "morally upright". Additional work-related values characteristic of Singaporeans include being hardworking, industrious, serious and disciplined. A good citizen in Singapore should participate in multicultural harmony and national solidarity. Singapore is atypical of collectivist countries in that it is a wealthy country and a modern society; Singapore prides itself on being forward thinking and concerned about the 21 st century. Singapore is a fast-moving society and it appears that the younger generation has adopted some distinctive values. Studies of older adolescents have found out that Singaporean youth tend to be materialistic and pragmatic (Yeo \& Chow 1997).

In Singapore, the prime focus is not diversity, as that could lead to cultural fragmentation and ethnic division. Not only does Singapore aim to make its students aware of the global culture in order to fit into the world arena, it also anticipates that cross cultural experiences may enable students to reflect on the difference between cultural values and countries so that they can come to a greater appreciation of the uniqueness of Singapore (Tin Yau Lo 2010).

Multiculturalism

Most importantly, the state's vision of shared citizenship reflects the ideology of multiculturalism promoted by the government in Singapore. Multiculturalism is more accurately described as "multiracialism" in Singapore because the government classifies everyone based on four racial identities according to one's paternal line: Chinese, Malay, Indian, and Others. The state has introduced an ethnic pedagogy of public "recognition" that provides for both the education that fosters national citizenship and the relegation of ethnic identities to the parochial (Tan 2012).

Multiculturalism is a worldview that rejects the global centrality of any single culture or historical perspective (Madigan, 1993). "It is a principle, an approach, or a set of rules of conduct that guides the interactions and influences the perceptions, beliefs, attitudes, and behaviors of people from diverse cultural backgrounds" (Fu 1993 p.40).

Culture 
Culture, as a social construct and a value system, defines social norms and sets priorities in a society. It tends to have more enduring influence over social and educational practices than political ideology and curriculum innovations. This becomes particularly evident when tensions and conflicts arise between cultural values and educational reforms (Christiansen \& Silver 2011).

Culture is the values, beliefs, behavior, and material objects that together form a people's way of life. Culture includes what one thinks, how one acts, and what one owns. Culture is both the link to the past and the guide to the future.

Even greater, to understand all that culture is, one must consider both thoughts and society, ideas that range from art to zen. Material culture, by contrast, is the physical things created by members of a society. Culture shapes not only what one does but also what one thinks and how one feels - elements of what people commonly, but wrongly, describe as human nature. The warlike Yanomamo of the Brazilian rain forest thinks aggression is natural, but halfway around the world, the Semai of Malaysia live quite peaceful. The cultures of the US and Japan both stress achievement and hard work, but members of society typically put a higher value on individualism than do the Japanese who value collective harmony.

Similarly, culture learning is the process of acquiring the culture-specific and culture-general knowledge, skills, and attitudes required for effective communication and interaction with individuals from other cultures. It is a dynamic, developmental, and on-going process which engages the learner cognitively, behaviourally, and affectively (Lee 2012).

Consequently, T.S. Eliot's “Observation on Culture" argues that one of the bases of cultural myths is religious beliefs. Besides religion, culture, and history also influence prevailing myths and beliefs, and its leadership styles. In international management studies, culture sets the context in the development and reinforcements of beliefs. Culture is viewed as a system of shared cognitions or a system of knowledge and beliefs. Culture is seen as a unique system for perceiving and organizing material phenomena, things, events, and behavior. When cultural boundaries become blurred, the significance of the role and functions of mythology in different cultural systems increase. The study contributes to the theoretical development of cultural mythology in international management within a framework of contextual nuancing, cultural bridging, and meaning making (Gopalakrishnan and Kessler 2013).

As a result, as the world becomes a more globalized society, interactions among various cultures will increase. For these interactions to be meaningful and beneficial, an understanding of each culture is required. Through internationalization of the classroom, higher education can play a vital role in fostering this cultural awareness, begin forming cross-cultural relationships, and provide a forum for developing effective interactions that will benefit a globalized society. Additionally, students in a crosscultural classroom will be afforded opportunities to develop and refine various methods of interacting with individuals with different backgrounds and cultures in preparation for jobs and careers that will require interactions in a globalized marketplace (Crose 2011).

For instance, if the world is to be transformed, actions must accompany words. However, the culture of activism is not about fighting, it is exercising one's presence in the world in a way that one believes that the world can transform itself to meet fundamental human rights. Such rights include concerns regarding race, ethnicity, class, diversity, gender, sexual orientation, disabilities, spirituality, justice, equity, marginalization, and caring (Mirci 2010).

Most importantly, most people would agree that culture for tolerance is a task for the family as well as for schools and the wider community. But how should that task be understood? Perhaps the most obvious way would be to follow a chain of reasoning along these lines: culture of tolerance is good, discrimination is bad and children should be brought up by their parents and teachers to respect others, especially those who differ from them in religion, race or culture and, also, perhaps more controversially, those whose way of life at a more personal level differs from that of the majority, for example, in terms of their sexual relationships and their approach to marriage and family life or in their moral views and conduct. Understood in this way, educating for tolerance raises a predominantly practical question about how best to achieve this end. (Almond 2010).

In addition, Asian Indian immigrants often move to other countries with pre immigration beliefs of success and may want to fulfill their dreams of success through their children. Because of these desires, some immigrant parents may give daughters more support in becoming successful. Such Asian Indian immigrant families may encourage women's educational goals and promote independence, making the cultural values of the dominant and traditional culture less conflicting or discrepant for these women. Furthermore, Asian Indian immigrants may recognize their children's struggles in negotiating a bicultural identity and may offer interpersonal family support. Additionally, Asian Indian women with quality family relationships may feel secure in the decisions that they make, knowing that they can rely on their families (Davidson and Inman 2012).

Meanwhile, another examples are Americans who have a lower context culture while the Japanese have a higher context culture. In low 
context culture, people tend to convey their feeling or thoughts with words. In other words, what you are saying is what you are feeling and thinking. In high context culture, people do not use words as a tool to convey their feelings and thoughts, but not always or explicitly. They often rely on the context in which words are spoken.

Southeast Asian Literature and Society

Most important, up to 1954, Vietnam underwent the cultural influence of two great countries: firstly, China which had practically colonized it for over ten centuries, and secondly, France from the end of the $19^{\text {th }}$ century until 1954. Consequently, Vietnamese literature reflects the influence of these two cultures and in 1954 three trends can be distinguished : (1) a truly popular literature of purely Vietnamese tradition; (2) preFrench literature, written in Chinese and highly developed; (3) contemporary literature in which the influence of French culture is clearly seen, particularly in literature (ThamSeong Chee 1981).

Even greater, literature and society are closely interrelated in the context of Southeast Asia. It would appear that social change constitutes the single most important influence on literary development, influencing as it does literary cognition, style, genre, and language. Whether literature is seen from the perspective of the writers or from the perspective of the supporting institutions like the government, there is no disagreement in regard to its place in society. Indeed, the unifying perception is that literature is potent for a number of reasons - social, educational, linguistic, political, and intellectual. Literary works, in all seriousness, are commentaries and reactions to the changing circumstances of life brought about by the confrontation between tradition and modernity. The social equilibrium of the traditional past became disrupted consequent on the colonial experience. In one or two instances, this disequilibrium amounted to no less than a total destruction of the inherited social fabric, particularly when wars of independence had to be fought to secure self-rule. With political conflict came ideological conflict. Perhaps the two most notable developments in this regard have been the cumulative demands for a more rational society based on justice, respect, equality of opportunity, and humanity and the growth of competing ideologies of indigenous or non-indigenous origins in the lives of the Southeast Asian peoples (ThamSeongChee 1981). Most significantly, Southeast Asian literature is in a sense ethnic literature. The literary works exemplify the unfolding of ethnic consciousness of a world undergoing rapid transformation with all its pangs and joys. Whether the writers are Burmese, Malay, Thai, Filipino, Baba, Vietnamese, Cambodian (Kampuchean) - including many of the indigenous and non-indigenous ethnic minorities in Southeast Asia - each is a group with its own ethnic experience. In confronting and resolving the demands and responsibilities of nation-building, writers have thus adopted the way most familiar and understandable to them - from the viewpoint of their experience as members of an ethnic group with its unique cultural and historical past. Hence, the literary products are, to a large extent, exemplifications of both the growing consciousness of each ethnic group in a rapidly changing world and the cognitive consequences arising from the confrontation of the ethnic experience of with the social and political changes taking place. There is no doubt a gradation of intensity of the ethnic element suffusing the literary works. In some instances, it is almost imperceptible; at least it is not overtly expressed and defended. In other instances, it is almost imperceptible; at least it is not overtly expressed and defended. In other instances, it is implied in the manner ethnic sensitivities and meanings are presented. Whatever the case, each group is attempting to express an identity based on ethnic experience (ThamSeongChee 1981).

Even greater, patriarchal norms dominate Indonesian literature. This implies that the position of women is restricted and subservient, one result of which is the depiction of women as socially inferior. In Indonesia, a number of apparatuses sustain a patriarchal gender ideology, religion and the state can be mentioned as the most fundamental. HinduJavanese values, as expressed in the wayang (shadow puppet theater), and Islam justify polygamy that is polygyny, the marriage of one man with more than one wife and double sexual standards, while Christian creeds deny women full autonomy over their bodies in using contraceptives or resorting to abortion. Women's primary role is in the domestic sphere, according to Indonesia's state ideology, which under Suharto's New Order is formulated explicitly in the Panca Darma Wanita (The Five Duties of Women). The state adheres to values which have their roots partly in the religious convictions mentioned and partly in Dutch bourgeois notions. These ideological concepts resonate through all fiction, but it is especially polygamy and double sexual standards are juxtaposed with the Western concepts of monogamy, romantic love, and marital fidelity (Hellwig 1994).

In contrast, women experience time and again that in the patriarchal order their way of acting and communicating is not considered appropriate by men. Different ways of interacting with others come to the fore in a number of the Indonesian tales. For example, women in close mother-daughter bonds which give them the strength to assert themselves and take control over their lives, as in Sri Sumarah, Bawuk, and Burung-Burung Manyar. Keluarga Gerilya is an example of a distorted mother-son relationship, the mother relying completely on her son for her sense of self (Hellwig 1994). 
The period from 1946 to 1960 was an era of effective American control of the Philippine economy, political life and military affairs. Needless to say, culture during this period developed according to the ideological direction set by the U.S. This was secured by the Educational Exchange Program, more popularly known as the Fulbright Program, which was a latter-day version of the pensionado system of the early years of the American Occupation. The Fulbright Program was supposed to have brought about an exchange of cultural influences, but what actually took place was a one-way cultural traffic which only intensified the Americanization of the Filipino intellectual. During the heyday of the program in the $1950 \mathrm{~s}$, practically every artist, writer, musician, critic or academician of any consequence was given a grant to stay in the US - lecturing, observing, travelling, studying or familiarizing himself with the cultural scene in that country. The impact of this cultural campaign to ingratiate the intelligentsia to the U.S. may now be evaluated in terms of artwork and literature produced by Fullbright artists who demonstrated in their output that they were perfectly capable of keeping up with artistic trends in the US and elsewhere in the West (Lumbera and Lumbera 2005).

In addition, in the history of Tagalog literature, Lazaro M. Francisco ranks among the finest since the beginning of the twentieth century. In addition to a deft hand at characterization, Francisco has a supple prose style responsive to the subtlest nuances of ideas and the sternest stuff of passions. A pronounced idealist turn of mind leads him to contrived resolutions for his plots, but his passionate involvement in the problems of the nation, particularly of the oppressed, has given breadth and depth to the totality of his works.

For instance, in the Philippines, komiks has been known as the cheapest form of entertainment. In the literal sense of the word "cheap", komiks have been accepted if not embraced by the Filipino people. Numerous films have been based on komiks stories since the 1950s. In the art scene, an exhibit of the works of Francisco Coching was held at the Cultural Center of the Philippines. The Vargas Museum in the University of the Philippines featured a Mars Ravelo exhibit. However, since the medium failed to develop and evolve (some say it has devolved since the days of Coching), the komiks eventually began to be perceived as cheap in the derogatory way. Aside from Coching, creators such as Alfredo Alcala and Nestor Redondo are hardly recognized in the Philippine cultural scene. Ironically, it is the Americans who paid tribute to Alcala and Redondo when the artists passed away. Currently, the komiks seem to be losing to the pocket romance books in terms of sales.

As a result, there have been some small comics conventions in the Philippines but these were mostly part of collectors' conventions that focus on comics' monetary value and collectivity. The creators of Culture Crash have Comic Book, Anime and Gaming Conventions. While it was a good venue for various comics creators to gather and present their work, the conventions were more of anime shows where very few Filipino creations are involved (unless one counts the uncredited animators who work on Japanese animation). While it may argue that anime is part of Philippine popular culture, it was quite sad to see creators and creations of traditional komiks get virtually ignored amidst the din of cosplay (costume play) and J-pop (Japanese pop). Impacts of Cultural Values of Shalom H. Schwartz

Now, for an understanding of how cultural values influence the meanings that members of different societies attribute to work, culture-level value dimensions rather than individual -level dimensions are appropriate. Smith and Schwartz (1997) have explicated the difference between individual-level value dimensions. The appropriate unit of analysis for assessing the validity of culturelevel dimensions is the society or cultural group, not the individual person (Hofstede 1980, 1990, Schwartz 1994).

Next, possible impacts of individual differences in value priorities on the meanings and importance that different individuals within a society attribute to work values are discussed elsewhere (Ros, Schwartz, and Surkis). When studying individual differences, an individual-level theory of values, different from the theory explicated here, must be used (Schwartz 1999).

Finally, one considers relations of cultural value emphases to national differences in the importance of work values or goals. Work values refer to the goals or rewards people seek through their work. They are expressions of more general human values in the context of the work setting. A review of the literature points to four broad types of work values that are distinguished implicitly by respondents (Surkis, 1992). Listed with their core goals in parentheses, these are: intrinsic (personal growth, autonomy, interest, and creativity), extrinsic (pay and security), social (contact with people and contribution to society), power (prestige, authority, influence). The basic contention is that the types of work goals whose pursuit is encouraged and rewarded, rather than discouraged and sanctioned, depend in part on the prevailing cultural value emphases in a society. Moreover, other things being equal, the goals chosen by managers to motivate workers will be more effective if they are compatible with prevailing cultural emphases. That is, no one type of work goal is likely to be the most effective across all cultures (Schwartz 1999).

In conclusion, people can observe that the Shared Values are communitarian in nature. The communitarian slant is evident in the document's exhorting Singaporeans to "compromise" their 
"selfish" individual interests, benefits, and rights for the common good and to perform their duties as members of their family and community. Communitarianism essentially highlights the importance of the community in the formation and shaping of the individual's values, behavior, and identity. Linked to the importance of community is the communitarian's preference for collectivism over individualism, especially the individual's freedom, right of choice, and right to justice. A number of writers have noted that an Asian version of communitarianism exists in East and Southeast Asian countries such as China, South Korea, Malaysia, Indonesia, and Singapore. This is reflected in their political leaders reminding their fellow citizens to sacrifice a personal right or a civil or political liberty so as to fulfill their duties and responsibilities toward their family and community. In return, the governments of these countries ensure that appropriate social and economic conditions are in place to enable their citizens to fulfill their duties and responsibilities as "good citizens." This explains why, for example, the law mandates that children must provide financial support for their elderly parents in China, Japan, and Singapore; the governments in Korea and Hong Kong also provide tax and housing benefits to make it easier for children to care for their elderly parents at home (Tan 2012).

For example, a number of researchers view traditional Cambodian cultural values as an important aspect for understanding Cambodian American school achievement. In this study, culture refers to acquired values and beliefs that guide people's perspectives. Karmic law, the belief in the predetermination of one's fate, is a central value of Cambodian culture as derived from Theravada Buddhist belief. The Theravada variant of Buddhism is practiced by most Cambodians and serves as explanation for their individual happiness and suffering. Cambodians generally view themselves as Buddhists, both culturally and spiritually. Smith-Hefner (1994) notes that for Cambodians, "to be Khmer is to be Buddhist" (Chhuon and Hudley 2006).

Literature as One Way of Raising Nationalism in Southeast Asia

First, there is no neutrality in writing, whether in literature or history, for all writing contains ideologies that it transmits to the consciousness of each reader. For the longest time, Filipino historians have insisted on the value of writing history from the Filipino perspective and not from the point of view of foreign conquerors. Renato Constantino, a nationalist historian, says that it is necessary to look back into the past in order to see the present clearly. Filipinos' consciousness of the past is twisted: "Much of the blame must be laid at the door of colonial education." (Constantino 1959) He called it the "miseducation" of the Filipino. It was a means of pacifying the people and weakening nationalism. The United States was seen as a "'generous benefactor" and this erased the struggle of the people against colonialism. In his writing of history, Constantino highlights not the views of the ilustrado but the Filipino masses (Ortiz 2008).

Similarly, like in history, literature is one way of raising awareness of a nationalist perspective. In line with the assertions made above, children's literature is not free from ideology. This is the point Dela Cruz made in his article. Children's literature must start once more from the problem of nationhood. It can be said that there are two national problems connected to the context of national literature in the Philippines. First, there is the consciousness that champions Western thinking and turns its back on the beliefs and culture of the Filipino... Second is the continuing domination of former colonizers in the world order. This is caused by the combination of the power of former colonizers and internal problems of the Philippines (Ortiz 2008).

Consequently, the Filipino short stories in English is a reaction against the commercialization of the Filipino's intuitive grasp of his cultural history. Filipinos have seen how the awit and corrido writers reached out to Europe and succeeded in keeping a national community stocked with virtual images of life for its edification. When the Filipino mind, owing to an accident of history, accommodated itself to a unique form of the narrative, the modern short story, a similar performance to be produced by the shaping imagination. This began in the late twenties and early thirties, about the same time that writers in Tagalog were themselves becoming disturbed over the way the literary tradition in the native language was being used. This confluence of awareness by both groups of writers was no coincidence. There was in the maturing Filipino spirit a need for fuller growth.

In fact, literary images do not exist in a vacuum: they are related to what history, psychology, sociology, anthropology and other disciplines - as well as their own experiences. Literature helps create views of images. It is through their preservation in works of art that the stereotypes and archetypes have known (Arellano 1994).

Cultural values represent the implicitly or explicitly shared abstract ideas about what is good, right, and desirable in a society. These cultural values are the bases for the specific norms that tell people what is appropriate in various situations.

This research paper develops among the readers the existence of short stories from Southeast Asia. It points out that the short stories from Southeast Asia show images of societies which are universal in nature. 
Representative short stories from selected Southeast Asian countries have commonalities in terms of cultural values. These are the ordinary life happenings and difficulties which people experience every day.

\section{CHAPTER 3}

\section{Method and Procedure}

This study described the contemporary cultural values of some selected Southeast Asian countries. It also analyzed and interpreted the conditions that brought about the described images of commonalities of cultural values in the community life and lifestyles of some selected Southeast Asian countries based on selected thirty - five contemporary short stories of ASEAN literature. Specifically, it studied the content and messages of the contemporary ASEAN short stories.

Method of Research

The study employed a descriptive method of research. The descriptive method is designed to gather information about the present condition. It describes and interprets what it was. It is concerned with conditions or relationships that exist, opinions that are held, processes that are going on, effects that are evident or trends that are developing. It is primarily concerned with the present although it is often considering past events and influences as they are relating to the current conditions. Descriptive study also is a scientific research consists of a study that collects evidence, is looking for answers to prove the research problem and so as to identify intangible factors. The researher answers more complex and sensitive issues and used case studies and investigated observed groups. It was useful in determining specific information on the values, opinions, and behaviors of a population. Moreover, it focused on a natural setting which problems are most likely to happen. A comparative study was also used by the researcher to show how the commonalities in cultural values among the selected Southeast Asian countries reflected in some representative ASEAN short stories.

The study used the Descriptive Method to describe contemporary events and the research questions and problems were based on findings and understanding of the tradition of the past as part of the people's beliefs and practices expressed in the ASEAN contemporary short stories, and how these skills enhance the culture for peace, tolerance, and unification.

Content Analysis was also used as a research technique which involves the objective systematic and qualitative description of the manifest content of communication.
The researcher of this study deciphered the elements that could be seen in the short story under study through the chosen literary elements. From these literary elements, she was able to identify the different social realities that were revealed through economy, politics, education, religious life and social lives of some selected Southeast Asian countries like Malaysia, Indonesia, Thailand, Vietnam, Myanmar, Singapore, and the Philippines. The primary focus of this study was the comparative analysis of the commonalities of cultural values in the community life and lifestyles of some selected ASEAN countries as reflected on representative short stories of ASEAN literature.

The outputs of the system were the results, findings, and implications of the selected Southeast Asian countries for peace, unification, and solidarity in the Southeast Asian region.

The researcher was also interested to know if there has been any change in the elements depiction in the selected Southeast Asian contemporary short stories from 1950 s to 1990 s.

To relate this study to other studies on the contemporary cultural values of some selected Southeast Asian countries, Content Analysis of representative contemporary short stories of ASEAN literature was cited. This genre was widely disseminated and had an immediate audience, as such they strike contemporary short stories played a major influence in the thinking of people by building images of the sexes which eventually became stereotypes or archetypes.

Sources of Data

Data were gathered from secondary sources. Secondary studies included gathered sources from the library books, scholarly journals, visits to the seven embassies based in Metro Manila, and content analysis. The study was basically descriptive in nature. Sources or data from internet were also included to authenticate, validate and collect reliable information related to the study.

Variables and Measures

The variables considered for the content analysis were divided into two categories. The first category was to provide the necessary background information about the short story. The other category was composed of the contemporary images of ASEAN women and men. Other variables that were considered were demographic characteristics, character representation and images.

Subjects of the Study

The subjects of the study were the thirty - five representative short stories from the Malaysia, Indonesia, Thailand, Vietnam, Myanmar, Singapore, and Philippines.

List of 35 Short Stories from Seven Southeast Asian Countries

Indonesia

1. Sri Sumarah by Umar Kayam 1975 
2. The Decline and Fall of Our Local Mosque by A.A. Navis 1956

3. Meant For Each Other by Abdul Muis 1956

4. Inem by Pramoedya Ananta Toer 1952

5. The Soldier by Nugroho Notosusanto 1956

Malaysia

6. Victoria and Her Kimono by M.Shanmughalingam 1984

7. A Common Story by Kassim Ahmad 1959

8. A Question of Dowry by Siew Yue Killingley 1962

9. Mariah by Che Husna Azhari 1993

10. Grave Harvest by Ajikik 1978

Myanmar

6. The Kindergarten Teacher by Aung Thinn 1960

7. The Carat 13-Diamond by Daw Khin Myo Chit 1955

8. This Realm of Humans by Khin Hnin $\mathrm{Yu}$ 1962

9. Neighbours by Moe Moe (Inya) 1972

10. Mother's Merit by Thu Maung 1980

Philippines

6. The Day the Dancers Came by Bienvenido N. Santos 1967

7. The House on Zapote Street by Quijano de Manila 1968

8. Clay by Juan T. Gatbonton 1951

9. Children of the City by Amadis Ma. Guerrero 1971

10. Wedding Dance by Amador T. Daguio 1953

Singapore

1. The Tiger by S. Rajaratnam 1978

2. The Martyrdom of Helena Rodrigues by S.Kon 1960

3. Bugis by Alfian Sa'at 1997

4. The Effect of a Good Dinner by Arthur Yap 1963

5. Monster by Catherine Lim 1966

Thailand

1. Lord Buddha, Help Me? by Suchit Wongthred 1975

2. Thong Proi The Rich Girl by M.R.Kukrit Pramoj 1954

3. As If It Had Never Happened by Witthayakon Chiangkun 1974

4. Michigan Test by Wanit Jarungkit-Anan 1974

5. The Grandmother by K. Surangkhanang 1964

Vietnam

1. The Cradles by Mai Ngu 1962(Vietnam)
2. New Virtue by Nguyen Ban 1962

3. My Milk Goes Dry by Minh-Quan 1974

4. An Unsound Sleep by Nhat - Tien 1974

5. The Blind Alley by Ma Van Khang 1962

Technique

The techniques used were the textual and documentary analysis. The researcher gathered all materials related to the present study. The primary sources of materials were the texts gathered from different libraries such as CEU - Graduate School Library, Rizal Library of Ateneo de Manila University, UP Diliman Main Library, Philippine Normal University, National Library, Ramon Magsaysay Foundation Library, and other private libraries in the Philippines.

Procedure

The first phase of the study was the borrowing of published books containing short stories from the Philippines.

The second phase of the study was the reading of the short stories from the representative short stories from Southeast Asian countries. This was a long laborious process. From this reading the researcher was able to choose 35 representative short stories from selected countries in ASEAN, which were Malaysia, Indonesia, Thailand, Vietnam, Myanmar, Singapore and Philippines. Due to inadequate English translations of short stories from Brunei Darussalam, Cambodia, Laos and Timor Leste, the researcher did not include works from these four countries anymore.

The third phase of the study was the descriptive analysis of the thirty- five short stories using characterization, point of view, setting, plot, conflict, themes and symbols.

CHAPTER 4

Presentation, Analysis and Interpretation of Data

This chapter presents an analysis and interpretation of data gathered, following the order of succession of the statement of the problems stated in Chapter 1.

1. Elements that Writers Used in the Short Story to Show Cultural Values

Indonesia

1.)Pramoedya Ananta Toer showed the cultural values of conformity, obedience, politeness, and honoring parents and elders using the element of the point of view. The point of view comes from an innocent eye of six years old girl. She was "Inem's" friend and she was six years old. She was the cousin of "Inem" and she could tell everything about Inem from the point of view of an innocent eye. This little girl tried to narrate the sufferings of her cousin from her seventeen year old husband. The point of view even narrated that her mother told Inem that a woman must be loyal to her husband or else her ancestors will curse 
her. She has reminded Inem to prepare his meals always. She must wash his clothes properly and comfort him when he is tired. She must give him medicines when he is sick. The point of view proved to readers the sanctity of the cultural values of conforming and honoring the decisions of parents and elders by the children.

Toer also showed honoring parents and elders using the element of plot. Inem's mother wants the girl to marry Markaban after the harvest is over. Inem is so young, only eight. But Markaban's family has lots of money. Inem's family need the dowry. It's the only way they can get the money ( Aveling 1976).

2.) Umar Kayam explored the cultural values of benevolence, concern for family's welfare, and forgiving using the element of character. The central position occupied by a female character. The device is exceptionally important in that it permits the author to focus on the family and the individual, particularly in the ways they interact. "Sri Sumarah" was an obedient, understanding of her husband's weaknesses, patient, never stubborn and always respectful of his power. Sri Sumarah was a young widow, still attractive, but did not want to remarry anymore. Sri said that seclusion is a good thing for persons approaching middle age. If fate mocked Sri Sumarah about Tun being married at seventeen years of age, then she had to answer fate dramatically. After that she approached Pak Mohammad, the rich farmer, and pawned half of the small plot of rice land to him. Sri Sumarah did other jobs as well like selling fried bananas in schools.

Signs of rising inflation had already been apparent in the subdistrict but suddenly it went out of control. Sri was hit hard. Tun and Yos still did not have much of an income. How was she going to help them? How was she going to come up with the money for the payments on her loan if all she had to live on was her husband's meager pension?

Inspite of the fact that the only child of Sri eloped at a very tender age of seventeen still Sri Sumarah remained benevolent and concerned about the family's welfare. Indeed, she was hurt when Tun was not actually concentrating with her studies. But, still the cultural value of forgiving continually manifest in Sri Sumarah's mother's characterization.

Umar Kayam explored the cultural value of forgiving using the element of plot. If fate mocked "Sri Sumarah" about her only child Tun being married at a tender age of seventeen, then she had to answer fate dramatically. How was she going to help them? After that she approached Pak Mohammad, the rich farmer, and pawned half of the small plot of rice land to him. Sri Sumarah did other jobs as well like selling fried bananas in schools. Very typical of a mothers' cultural value is having a forgiving heart. It doesn't matter if a child commits hundred times of mortal sins against her mother, automatically, the mother will always forgive the mistake of the child. Forgiving is not enough, but the Indonesian mother will help the child survive in this cruel world.

3.) Nugroho Notosusanto exposed the cultural values of achievement, personal success, competent performance, obtaining social approval, self -respect, social recognition, and ambitious using the element of plot in the story "The Soldier" The attack began. A grenade lobbed into the car in the middle of the cutting. Onom threw it out and it exploded behind them. They exchanged shots. Tatang enjoyed the heavy scream of the 12.7 his own tension had gone as soon as he pressed the trigger. He felt very safe behind the walls of the armoured car. They were protected from low-flying bullets. She married a soldier, not a mercenary. The cultural values of achievement and personal success is reflected in the life of a soldier. They have been always prepared to die heroes for their beloved country. They are always more than willing to forget their families for the sake of their love and dedication for their country. A regular soldier sacrifices everything he has for his ideals.

Nugroho Notosusanto showed cultural value of obtaining social approval and ambitious desire using the element of conflict in the story "The Soldier" Man versus the social society. Lance Corporal Tatang or the leading character struggles against ideas, practices, or customs of other people. The "ideal expectation of the society" towards the soldier Tatang to always prioritize his sacred duty towards his beloved country than prioritizing the comfortable life of his own family. Like in this story "The Soldier" his family living with him in the barracks, to the extent that Fatimah his daughter died of malaria. In the end of the story, again, again because of the poor accomodation in the barracks again. A soldier sacrifices everything he has for his ideals. Tatang has been worried about his wife. She is sick for three days already. She looked fragile. There are no doctors in the south. Their daughter Fatimah was as fragile as her mother. She caught tropical malaria in a camp in Jakarta and died. The soldiers of the Indonesian army want to remain loyal to their vocation (dharma). The soldier would place service to his country before anything else. They put duty first before family.

4.) A.A.Navis presented the cultural values power, social status, prestige, control and dominance over people and resources, authority, wealth, social power, preservation of public image, social recognition using the element of plot in the story "The Decline and Fall of Our Local Mosque". Basically, in Indonesia, the imams benefit in the higher status and power of having a key position in the mosque. They guide the ordinary Moslems in contemplating and praying and memorizing Islamic doctrines. But, perhaps unfortunately, to the extent 
of lacking time to advance themselves in the study of proper style of leadership, math, science and technology. The lord said "You didn't mind that your descendants would be poor too ? they may be poor but they know the Koran by heart - It means nothing to you that they are poor. Then why did you remain in poverty, making no provision for those to come ? You let others steal your property, while you fought amongst yourselves, you deceived and oppressed each other. I gave you a rich country. But you were lazy. You preferred contemplation. I told you to work and pray. You only prayed. So you did nothing but praise me and glorify my holy name. you must go back to hell ! Angels - put them back in the lowest pits. You did wrong in spending too much time on the cultivation of your soul. You prayed because you were afraid of going to hell, but you forgot your fellow Moslems and your family. You were put in the world to live as part of a community, but you were too selfish.

A.A. Navis presented the cultural value of preservation of public image using the element of symbolism in the story "The Decline and Fall of Our Local Mosque". Once there was an election. He told us about a frog whose only ambition in life was to be a king. We called one of the politicians "the frog prince." The politician wants to have power and to preserve his public image but he becomes a frog prince... He was religious at the same time enriching himself at the expense of the ordinary religious Moslems. It has been continually indoctrinated to them in the five pillars to give alms to the poor, orphans, and widows. People did wrong in spending too much time on the cultivation of your soul. You prayed because you were afraid of going to hell, but you forgot your fellow Muslims and your family. You were put in the world to live as part of a community, but you were too selfish. It is alright to cultuvate the cultural values of power and to preserve public image but in the true sense of it, but never to the extent of enriching themselves at the expense of ordinary Islamic people.

5.) Abdul Muis showed cultural values of conformity, social norms, restraint of actions, obedience, self-discipline, politeness, honoring parents and elders, loyalty, and being responsible using the element of theme in the story "Meant for Each Other". The researcher has noticed the conservatism and chastity to young people of Indonesia. The young people are always aware of their social values of honoring parents and elders by the willingness to wait for the right time to fall in love seriously. "Love can wait for young people that time in the $19^{\text {th }}$ century." It was already evening, it's only proper that girls in Java be escorted along a road at night. Eighteen year old girls are already responsible of considering social norms and reputation. Besides, the Directress of her dormitory was rigorously conforming to conservative mores.
Suparta asked Ratna if correspondence would interfere with her activities. Ratna answered that they should think of their education and future first, and time will tell if they are really meant for each other.

Abdul Muis presented the cultural value conformity using the element of symbolism in the story "Meant for Each Other" "Do not query much why things are as they are. All is God's will, and in His preordainment alone lies certainty. Live in the fear of Allah, my son! Be firm in your heart. Indeed, Indonesians are religious and loyal to social norms. They do not believe so much in friendly dating of young people to get to know each other better. They are disciplined and very conservative. It is the will of their god Allah that two young people be married truly chaste and virgins. Ratna instructed Suparta to return to Djakarta. She said to him "When we are older we will surely meet again. If we are meant for each other, we will surely meet again."

$\frac{\text { Malaysia }}{1 .) C h e}$ Husna Azhari presented the cultural
values tradition, respect, commitment to customs/traditions, culture and religion, devout of religious rites/beliefs, and symbols using the element of plot in the story "Mariah". It has been explained and narrated in the plot of "Mariah" that they follow a patriarchal society. Men are allowed to be married to four women, provided these men will apply equality in their dwelling place. The man will provide equal amount of financial support, equal amount of time and attention. The man will never practice favoritism and partiality among his beloved four submissive wives. The man should be able to have four wives to maximize the number of population of Moslems in the world, and the widows will be taken cared of. In a small village in Molo, Imam's house in Malaysia. Mashallah! The people in the village all whispered reverently in awe of Cik Yam's virtue and steadfastness in allowing her husband to have a second wife.

He begged Cik Yam's forgiveness, kissed the hem of Cik Yam's sarong and asked for her permission to take Mariah as his second wife. "I love you and will always love you, Yam. Nothing can change that. I will always be your husband" Cik Yam said yes to Imam's request, on condition of equality.

The Imam and Cik Yam have been married for fifteen years and Cik Yam is a model and paragon of virtue. The loving, devoted wife, the model housewife ? Why ? Why? Then of course Cik Yam is childless... voices trailed away.

Che Husna Azhari exposed cultural value of tradition using the element of conflict in the story "Mariah". Man vs. Society (social) - The leading character struggles against ideas, practices, or 
customs of other people. Mariah said yes. The Imam was the man to marry. A man of religion would be the only person worth marrying after all those years of self-imposed celibacy. Truly Cik Yam was an angel, to willingly share her husband with her. Mariah, untutored in religion, in fact untutored in everything except nasi belauk selling. It is all Allah's decree, said Mariah. Cik Yam practices the cultural value of being devout of religious beliefs and rites by struggling to follow her conscience versus or against the customs and practices of Moslem men getting married for the second time or third time or fourth time. This conflict destroys her sanity at first, but eventually, she wants to follow the will of Allah.

2.) M. Shanmughalingam explored the cultural values of benevolence, enhancing the welfare of the in-group, smooth group functioning, concern for family, primary groups, and for others' welfare, helpful, honest, forgiving, loyal, true friendship, mature love, and spiritual life using the element of plot in the story "Victoria and Her Kimono". It was carefully narrated in the plot of the story that the Malaysian wife has tried to be loyal and benevolent towards her husband - although the husband seems to be insensitive and uncaring. The wife knows the value of to be concerned on the welfare of her community by wearing kimono in Malaysian society in order to pacify the ire of the Japanese imperialists. The plot talks about the great Japanese war in Malaysia that drew people together even as it made them suspicious of one another; it provided ample opportunities of intimacy as it did of enmity. (Mukherjee,D., Singh, and Quayum, 2002). Ramanan was on the Japanese military's wanted list as an over-zealous English language teacher to be silenced forever. Instead, Vickneswari the wife who was practicing her Japanese wearing her kimono at that time ran out of the house towards them and went on her angry melodramatic gestures in a Tamil film looking for her husband. She said in Japanese language that they were abandoned by her husband.

The Japanese soldier had never seen a nonJapanese woman in kimono in Malaya. Seeing Vickneswari in her unusual outfit charging towards him made him quite disoriented. He retreated.

Long after that Ramanan who had been crouching in the garden behind the house emerged. For the first time in his life he called his wife "My queen" The British King nearly died... Long live the Asian Queen. The wife literally saved the husband's life. He asked for her forgiveness for underestimating her and not listening to her all these years.

M. Shannughalingam showed benevolence using the element of setting. The couple especially Mrs. Vickneswari showed values of being helpful, true friendship and being loyal to her neighbors by exchanging food and latest information. Mrs. Vickneswari sells cakes or barter them for rice and sugar while wearing her kimono. The Asian bamboo bends with the wind and does not break. The trees that refuse to bend may crack in heavy storm.

Using lateral thinking the Japanese came by land from the north on 8 December 1941. By 12 January 1942 they had occupied Kuala Lumpur and by 15 February impregnable' Singapore. School buildings in the towns were used by the Japanese military as barracks, stores, training centres and as the HQ for the kempetai. Queen Victoria's portrait lurched left down to horizontal as Emperor Hirohito advanced right up to have his picture taken.

Col. Watanabe Wataru had demanded that Malayans who had long submitted to British rule and indulged in the hedonistic and materialistic way of Western life be taught seishin and be trained to endure hardship to get rid of this. Watanabe introduced Nippongo to replace English and Chinese which were abolished in schools. Ramanan continued giving private tuition classes in English language secretly in his house.

Mrs. Vickneswari sells cakes or barter them for rice and sugar while wearing her kimono. The Asian bamboo bends with the wind and does not break. The trees that refuse to bend may crack in heavy storm.

Mr. Ramanan during Japanese invasion observed that this period of subsistence on tapioca, cow herding and petty trading was the good news. The death railway in the north, the reign of terror with the kempeitai informers, spies, physical abuse, brutality, torture or imprisonment for a wide range of misdeeds (including the lesser ones of listening to the $\mathrm{BBC}$ or failure to bow low enough at Japanese sentry points), shortages of food and the hyper - inflation of their "banana" currency which featured bananas on their notes

3.) Siew Yue Killingley presented the cultural values of conformity, restraint of actions, social norms, obedience, self-discipline, politeness, honoring parents and elders, loyalty, and being responsible using the element of plot in the story "A Question of Dowry".

Mrs. Ramachandran tries to remember that her father gave four pieces of land as their dowry in the wedding. She confirms also the fact that they received three pieces of land from the wife of their second son. Mr. and Mrs. Ramachandran like to see a land so they can raise an amount for the dowry. But the land is now too marshy for house-holding unless they can have it drained and improved. Mrs. Ramachandran brags to her husband that her future son-in-law is a doctor. After Thiruchelvam has left for his dispensary, Mr. Ramachandran lets his wife and daughter know about the changed situation.

Mrs. Ramachandran, tries to say stoically "There's more than one doctor in our community, and its up to you, Ramachandran to do your duty as a father." Sivasothie walks to the kitchen, her head bows modestly, innocently, and nonchalantly. 

Study

Siew Yue Killingley showed the cultural values conformity, obedience, honoring parents and elders, and loyalty using the element of symbolism in the story " A Question of Dowry". The necklace represents the dowry in the story. The dowry symbolizes materialism of men in Hindu tradition. The requirement of dowry will make an obedient daughter more loyal to her clan/family. They will provide the dowry to assure the daughter of a decent and respectable husband like a medical doctor. If the family of the daughter has wealth, then they can afford huge amount of dowry. In so doing, Hindu Malaysians men benefit from the cultural value of honoring parents and elders. They will enjoy the security of having a lot of savings and investments. Chauvinism and superiority of men in India is part of their old culture.

Siew Yue Killingley showed conformity using the element of plot. The plot narrates the events of people following the dictates of social norms and being polite to parents and elders. Mrs. Ramachandran, tries to say stoically "There's more than one doctor in our community, and its up to you, Ramachandran to do your duty as a father." Sivasothie walks to the kitchen, her head bows modestly, innocently, and nonchalantly.

4.) Kassim Ahmad showed the cultural values universalism, nationalism, understanding, tolerance, protection for nature/environment, social justice, equality, world of peace, spiritual life, protection for the welfare of all people using the element of character in the story "A Common Story". Yusuf has came back from Singapore. He could have made a fortune in the Malayan Civil Service. But then, he has decided to come back in the life of the rubber tappers in kampong. His father has been discouraged that Yusuf wants to take care of their lands, their kampong, or their people. Yusuf's mother, poor woman, does not understand it either. But his mother has been very happy to be reunited with her son after four years of his university education. Yusuf has been very faithful, nationalistic, and loyal to his Kampong or province. It was in 1963 that Malayan Federation was formed consisted of Malaya, Singapore, Sabah, and Sarawak. But, it was in 1965, that Indonesia became an independent state.

Kassim Ahmad explored the cultural values of universalism and nationalism using the element of setting in the story "A Common Story". He sees his kampong folk - illiterate, rubber - tappers or farmers for generations- with their tattered clothes, their wrinkled faces and their coarse hands, and with nothing on their feet. They have to walk miles, to their work. And they have to walk miles again to the little village town to buy - to borrow on credit - their daily rations of sugar, coffee, salt and oil. They sell the products of their sweat. His father has always been coming back from the sawah, (farm) drenched with sweat, smelly, and dirty. His mother works under the flickering light of the kerosene lamp till late into the night. It proves that no matter what, Yusuf has loved to go back to his native land inspite of the poverty of his native land. The setting proves his loyalty to his beloved motherland.

Then one day, the whole kampong has been fenced and they can not go out anytime they like even to tap their rubber or tend their padi. The Malayan Communist Party wants to conquer their country! But soon enough, life in the village has settled down to its new routine.

Malayan Communist Party was formed in 1930 1989 in Malaya, Singapore, Thailand, Dutch East Indies ( Dutch radicals, trade unions of Chinese Communist Party \& French Indo - China ).

5.) Ajikik exposed cultural values of tradition, respect, commitment to customs/traditions, culture and religion, devout of religious rites/beliefs, and symbols using the element of theme in the story "Grave Harvest". Kiman has been devout of religious rites and beliefs. Highlights the modern values, religious teachings, and to criticize the ills of corrupt humanity in the Malay society. It was so unfortunate that the people in kampong have become so much greedy of the cashew nuts in the cemetery. Everyone wanted to get so much cashew nuts to sell them in the market. They forgot their virtue of being devouts of religious rites and beliefs. This relates also the hardships of the lower class or kampong life. The readers will understand better the Malaysian culture, life styles and problems.

Ajikik presented the cultural values of tradition, culture and religion using the element of symbolism in the story "Grave Harvest". Kiman smiled just for a split second. He looked calm. Nobody knows that Kiman has a dream! Kiman has deamt his father is there in the house. He has asked Kiman to pluck some cashew nuts to give to the people in the mosque. It was Friday. The next morning Kiman died. The symbolism means the people have to remember again the beauty of their tradition, culture, and religion. They must stop their deviant and criminal behavior of being greedy, robbers and selfish.

\section{Myanmar}

1.)Khin $\mathrm{Hnin} \mathrm{Yu}$ presented the cultural values achievement, personal success, competent performance, obtaining social approval, intelligent, self-respect, social recognition, and ambitious using the element of plot in the story "This Realm of Humans" Through the help of the plot, the researcher was able to prove that people from Southeast Asia actually, should be able to economize on expensive things. ASEAN people should be able to save money in the bank for them to be able to buy real properties like house and lot. The wife was able to save 15 gold coins, then she wanted to buy a house of their own. She didn't want to stay in a rented house anymore. So, after ten years of married life, 
they have moved to their own two-storied teak house. Then he kissed his wife out of gratitude. So much so, the wife did not change at all. She was always simple. She has worn the thicker cotton voile or the thinner type of homespun and the five-kyats cotton longyis. Indeed, the wife has lived a poor life! She was not eating well, not dressing up, perhaps almost a miserable life in order to economize a lot. Chit Chit hired a gardener and a maid. She wanted to have a big garden. They have lived happily in their little bungalow. In their old age, they are now living comfortably.

Khin Hnin $\mathrm{Yu}$ showed the cultural value of achievement using the element of symbolism in the story "This Realm of Humans". Buddhist philosophy says that the only way one can free oneself of attachments can one find freedom and peace of spirit. According to Buddha, in their human lives, they have to earn and save and let go of their attachments when they grow old. Man is born to work but also to be peacefully happy both in this life and beyond, and that they can get only through meditation. If the mind is not at peace, the richest man cannot find happiness. Buddhism actually teaches them to detach themselves from materiallism. If they will only learn to detach themselves from the love of materialism. Most likely, people will become focused on cultural values of achievement.

2.) Moe Moe (Inya) showed the cultural values hedonism, gratification for oneself, needs and pleasure, enjoying life, and self-indulgent using the element of characters in the story "Neighbours". Through the careful understanding of the values of the characters, the researcher was able to realize that people from Myanmar want to become hedonists and at the same time to enjoy life also.

Aye Aye - She complained to her husband about the nosey and intrusive neighbours. The husband advised her to relax.

$\mathrm{Ma} \mathrm{Ma} \mathrm{Nu} \mathrm{-} \mathrm{She} \mathrm{calls} \mathrm{her} \mathrm{the} \mathrm{moment} \mathrm{she} \mathrm{sees}$ her going to bazaar to get her a chicken or something else. She does not give back the money in payment for some things when she comes back. In the long run Aye Aye has learned to forget her request to buy things in the market.

Ma Mya Than - They usually go to the Government Shop to get their ration of rice or milk powder. Ma Mya Than has already five children, messing up their things or pulling her son. Aye Aye usually donates some yards of nylon because Ma Mya Than could not afford to buy clothes anymore because of the five children.

Ma Tin Hlaing - She seems to be a quiet neighbor. But she turned out to be a gossiper. She was able to tell her the dark secrets of her neighbours. Like for example, that neighbour's husband does not show up. The husband has a second wife already.

And then the neighbor $\mathrm{Ma} \mathrm{Ma} \mathrm{Nu}$ wants to look young always because she is leaving together with a son or nephew or something but not really has a blood relationship/kinship but something else.

Moe Moe (Inya) explored cultural value of hedonism using the element of setting in the story. Through the setting, the researcher was able to realize that gossipers, nosey, and thick-skinned people are everywhere. Hedonism and enjoying life are positive cultural values in order to avoid stress and inappropriate emotions. They had moved into a new community and definitely they are strangers in the neighbourhood. They loved their privacy but the neighbours seem to be checking on their behavior from afar. They knew that living in a close community would mean everyone getting into everyone's affairs. So they have decided not to be too familiar with them. But, when it comes to social dealings, they could not very well stay away. The first neighborhood was composed of prying, nosey, intrusive, gossiper, thick skinned but just like family members kind of people.

The second neighborhood is composed of uncaring, anti- social, and snobbish people.

3.) Thu Maung presented the cultural values of benevolence, enhancing the welfare of the in-group, smooth group functioning, concern for family, primary groups, and for others' welfare, helpful, honest, forgiving, loyal, true friendship, mature love, and spiritual life using the element of character in the story "Mother's Merit" Mother Nyo - She is a devout Buddhist who does not pray long and loud every night. She does not attend sessions at meditation centres in order to reach a higher status of mind. She is also not the type to gather merit by giving Soon Kyway feasts for monks and guests on a monthly or even a bi-yearly basis. She in her own way lives her life with a charitable nature, a generous heart and a peaceful mind. She has a generous heart that makes her benevolent to many people. The characters in the story were described fully and Buddhist people will have good karma if they have been helpful to monks for example. Mother Nyo has been consistent on having generous heart, charitable disposition, and peaceful attitude. Thu Maung presentation of character gives a simple description of perfect mothers in Myanmar.

Thu Maung showed the cultural values benevolence, concern for family, and for others' welfare using the element of plot in the story "Mothers' Merit" Through the plot, the researcher was able to discover more of the benevolence of the simple mothers of Myanmar. She has concern for her fellowmen. She likes to feed people. This generosity proves to ASEAN countries that it is always better to become benevolent and to have big heart in order to have good karma and to reach Nirvana someday. Ma Khin Nyo answered "Well, I cooked and cleaned I keep my mind on Buddha's teachings . . . that is how she prays. Her family has six members. But all the friends of her children and her husband's crew, 
treat their home as a place to come and go as they please, to eat whatever food there is, or even just to drop in to use the loo at anytime day or night.

His mother loves to feed people, friends or acquaintances happen to pass by their gate. She would invite them to have a taste of what was cooked that day.

Even the two elderly men who sell brooms would often come in their neighborhood and they always look tired, what with the load they carry and the hot sun. She would always insist they come in for a meal. It must be exhausting to walk for hours under the blazing sun with their load. She wants them to save a bit also.

Once his mother called over a vendor in the train station. She bought two large bamboo baskets from the old woman. The mother never bargains when she shops. His mother has appreciated on how the basket has woven. It is worth the handiwork. The mother has been thinking of the family of the old woman also. Because of the mother's generosity, there, with high steps belying her age ran the old woman heading towards a line of huts far beyond the stalks of harvested paddy in the bare fields.

4.) Aung Thinn presented the cultural values achievement, personal success, competent performance, obtaining social approval, intelligent, self-respect, social recognition, and ambitious using the element of plot in the story "The Kindergarten Teacher". The plot guides the reader that Indonesian cultural values like achievement and personal success want well equipped with basic education, good heath, and moral character. To lay the foundations for vocational education. Give priority to the teaching of science. To give priority to the teaching of arts and culture. Lay a firm and sound educational foundation for the pursuance of university education. The teacher can teach Reading and Writing anytime. But as of the moment, he wants his students to enjoy school. They must love coming to school. They should not be afraid.

Like, there was a boy crying out loud. He would often glance out of the window looking at his grandmother, sitting under a nearby Tamarind tree.

The teacher requested the grandmother not to show herself to the boy. The howls of the boy shook the room. The teacher asked the class to cry so that it will be used up quickly. All the kids went into a loud pantomime of crying. The boy stopped crying in amazement, looking around in confusion. U Nyan Sein went on with his tale. The boy started again to cry. And again the whole class has joined him in crying aloud to use it all up. There were no more tears from anyone, real or fake, after that.

Aung Thinn, presented the cultural values achievement and competent performance using the element of theme in the story "The Kindergarten Teacher". U Nyan Sein was an Art teacher. He was also teaching Reading and Writing in the kindergarten. Meaning, the teacher should be willing to teach almost all subjects. Aside from the fact that he knows the art of child-rearing. The theme means all teachers must be willing to sacrifice, must have utmost patience, and must have humility in his heart. Teachers in Myanmar be willing to endure all kinds of pain physically, emotionally, or financially.

5.) Daw Khin Myo Chit presented the cultural values achievement, personal success, competent performance, obtaining social approval, intelligent, self-respect, social recognition, and ambitious using the element of plot in the story "The Carat 13Diamond" The couple found themselves without a home, without job, in fact without anything except a mischievous toddler who was always hungry. They were lost in the great maze of wartime life. It was Japanese time, but the couple is one. Both of them loved their child so much. They were helped by some of their neighbors, they were able to have goods, and they have sold it on a commission basis. The couple was able to become government servants. At least, they are dignified already. They are now people with achievements and self-respect.

Some kind friends tried to help them by giving them goods to be sold on a commission basis. But, all the customers kept on bargaining. . . Their only son enjoyed the fun. They had to laugh at the little rascal every now and then.

After a while they managed to get employment in one of the government offices. By that time the Allied air raids had begun. They settled down in a ramshackle shed in the suburbs. It was close to their office building so they could work and see their son at home. When the air - raid sirens sounded, they would rush home and the little boy to a safe shelter.

In spite of the raids, they were happier because they were no longer unemployed. They had the dignity of being government servants although their joint salaries barely paid for the daily necessities. It was difficult to believe that they had to live on the edge of starvation. Could such things really happen in Burma, a land flowing with milk and honey.

They had rice, but could not secure cooking oil. They had to be contented with animal fat. Ko Latt her husband was wonderful. $\mathrm{He}$ always had something nice to say about her cooking. So, the wife went on creating masterpieces. The couple found themselves without a home, without job, in fact without anything except a mischievous toddler who was always hungry. They were lost in the great maze of wartime life.

Some kind friends tried to help them by giving them goods to be sold on a commission basis. But, all the customers kept on bargaining. . .

Their only son enjoyed the fun. They had to laugh at the little rascal every now and then.

After a while they managed to get employment in one of the government offices. By that time the Allied air raids had begun. They settled down in a 
ramshackle shed in the suburbs. It was close to their office building so they could work and see their son at home. When the air - raid sirens sounded, they would rush home and the little boy to a safe shelter.

In spite of the raids, they were happier because they were no longer unemployed. They had the dignity of being government servants although their joint salaries barely paid for the daily necessities. It was difficult to believe that they had to live on the edge of starvation. Could such things really happen in Burma, a land flowing with milk and honey.

Daw Khin Myo Chit presented the cultural values achievement and intelligence using the element of symbolism in the story "The Carat 13-Diamond". The worm in the ground knows every tooth of the harrow. The butterfly above preaches patience. "Poverty, to say at the least, is very uncomfortable. People have to learn to count their many blessings in life. The symbolism was very very effective. In spite of the grimmy poverty, people of Myanmar have to achieve something better for them to have good life. They must use their blessing of intelligence from Buddha in order to survive comfortably. Philippines

1.)Amadis Ma. Guerrero showed the cultural values stimulation, excitement, challenge in life, need for variety and stimulation, a varied life, and daring life using the element of plot in the story "Children of the City". The plot is already complete. The street children of Manila are supposed to be abused and destroyed by the ruthless society. The abandoned children become newspaper boys, drug addicts, and child prostitutes. They need the miracle of the God in order to survive in cruel world. The story is about the life of Victor, an eight year old boy whose father was involved in a company menace because of unjust salaries and compensations. His father joined the employee's strike and there he met his death when he was shot by the police officers managing the chaos in the strike. Victor was shocked to know the sudden death of his father on a newspaper. He and his mother were in deep pain upon hearing his father's death.

Soon, his mother had a new husband. She left Victor to his older brother. There, he was trained to be a newspaper boy in the dangerous streets of Avenida. He met there many children doing just like what he is. In those dark street he learned how to curse-say bad words and smoke cigarette because he was influenced by a group of unmannered teenagers. He found himself alone in the street, sometimes being beat up by bullies.

The story ended when the author realized how cruel the world is...

"... And Victor, swirled the life of the city: this city, flushed with triumphant charity campaigns, where workers were made to sign statements certifying they received minimum wage, where millionaire politicians received Holy Communion every Sunday, where mothers taught their sons and daughters the art of begging, where orphans and children from broken homes slept on pavements and under darkened bridges, and where best friends fell out and betrayed one another."

Amadis Ma. Guerrero explored the cultural values of stimulation and daring life using the element of symbolism in the story "Children of the City". The social divide symbolizes the grimmy division of the society between the bourgeisie and the proletariat. The class struggle in the Philippines includes also insugency and seccionism. Go bless the survival of the fittest in the jungle of Manila. In this city, flushed with triumphant charity campaigns, where millionaire politicians received Holy Communion every Sunday, where orphans and children from broken homes slept on pavements and under darkened bridges, and where best friends fell out and betrayed one another. This symbolizes poverty and social divide in the Philippines however. Only when we too can cry about the things you said can we come close to answering question. Why do children of the city suffer so much?

2.) Juan T. Gatbonton presented the cultural values of national security, safety, harmony, stability of society, social order, family security, reciprocation of favors, and sense of belonging using the element of plot in the story "Clay". Clay symbolizes this type of person: Somebody who's always laughing and acting like a happy guy. However, the source people, takes advantage of them, uses them like his toys or pets of his laughter is meanness, not friendliness. He laughs at innocent people, takes advantage of them, uses them like his toys or pets. So much so, Filipinos exercise close family ties in order to protect each other's well being. Filipinos also have outpouring Catholic devotion and faith to take care of the stability of the society. The plot was clear on telling it readers, conscious of the problem of national security, President Manuel A. Roxas granted the US control of the military and naval bases at Clark Air Base and Subic Bay Naval Base, in exchange for military aid. The country at this time was also faced with a Communist unrest in the rural areas

Juan T. Gatbonton explored the cultural values of reciprocation of favors and sense of belonging using the element of theme in the story "Clay" Subservience to the dictates of the US, courting political disaster. Needless to say, culture during this period developed according to the ideological direction set by the U.S. As a former colony of the US, the Philippines upheld the line that the salvation of the world lay with free enterprise and American protection against communism.

The theme means the Americans would be given the right to dispose, exploit, develop, and utilize "all agricultural, timber, and mineral lands" in the Philippines. This violated the Constitution of 1935 , which provided that after independence only 
corporations of which $60 \%$ was owned by Filipinos were allowed to exploit, develop, dispose, and utilize the natural resources of the country.

Ms. Rosete is an example of a sweet, pure, good person who is used by Clay. He talks about her as if she is his possession or plaything.

The main character is the most innocent person at all. He is young and at first he thinks that Clay is a true friend. When he overhears how Clay talks about Ms. Rosete, he finally realizes that Clay is bad. After that, he wants nothing more to do with Clay.

3.) Quijano de Manila presented the cultural values of achievement, personal success, competent performance, obtaining social approval, intelligent, self-respect, social recognition, and ambitious using the element of theme in the story "The House on Zapote Street". Love, freedom and sacrifices can also serve as themes of this Filipino masterpiece in 1968. It was too difficult for Lydia Cabading to finish her

Studies in the College of Medicine. She was an achiever but she fell in love with Dr. Leonardo Quitangon. She has wanted to regain her freedom from her father's chain. In the end, she had to sacrifice her life for her love.

Quijano de Manila explored the cultural value of personal success using the element of characters in the story "The House on Zapote Street". Dr. Leonardo Quitangon, a soft-spoken, mild mannered, cool-tempered Caviteno medical doctor.

Lydia Cabading - a medical intern and looked like a sweet unspoiled girl, but there was a slight mystery about her.

Pablo Cabading, Lydia's father was a member of the Manila Police Department. This father had been known to threaten to arrest young men who stared at his daughter Lydia on the streets or pressed too close against her on jeepneys. An Ilocano, he looked every inch an agent of the law, looked younger than his inarticulate wife, who was actually two years younger than him.

Mother Anunciacion Cabading - A mousy woman unable to speak save at her husband's bidding. Apparently, it shows that in the 1960s, Philippines was a very patriarchal society.

4.) Bienvenido N. Santos showed the cultural values universalism, understanding, nationalism tolerance, protection for nature/environment, social justice, equality, world of peace, spiritual life, protection for the welfare of all people using the element of characters in the story "The Day The Dancers Came". The element of characters have revealed the values of universalism and nationalism by the fact that they want to welcome Filipino tourists in America. Fil is very sentimental, florid, and poetic. He thought things wouldn't be changed. Beautiful memories will always be in his mind and heart. Fil is with Tony, another US citizen but bed ridden for almost two years due to leprosy. But they are always together in America in good times and in bad times.

Filemon Acayan - Filipino, fifty years old, a U.S. citizen, He has been a corporal in the US Army, training at San Luis Obispo. In 1945, after his work in the US Army, he worked in a hospital as a menial. He has been in charge of the human embryos inside their bottles. He has always having nightmares because of those fetus and infants. So much so, he decided to look for another pleasant job as a policeman in the post office in 1945 . He has no more immediate family even in the Philippines. Fil wants to join the company of dancers from the Philippines, show them around, walk with them in the snow, answer their questions, tell them about the changing seasons in the US. He enjoys eating adobo and the best stuffed chicken with Tony in their apartment. Fil shows greater mastery in their dialect. He has always been florid, sentimental, and poetic. Fil is also very sentimental... he can not easily let go of the things. He is perhaps stuck in the past that after years of not being able to visit his beloved country, he thought things wouldn't change. But he has been unfortunately wrong in his expectations. The erasure of all the recorded concert will help Fil to accept that time never stops. Beautiful memories will always be in our hearts and minds. It is a kind of sentimentality that he wants to have a record of memories of the Filipino young dancers, but he ends up losing them all instead. But then again, maybe it was for the best.

Tony Antonio Bataller - a retired porter and unfortunately has been bedridden most of the time for the last two years. His face has been healing from severe burns. He has not been feeling alright. He thinks it's cancer or leprosy. He has shared a lot with Fil. They have tried to be merry on Christmas days, most of the times get drunk and they become loud. Fil loves to recite poems in his dialect and Tony curses all the railroad companies of America. But, they didn't talk last Christmas, they have decided not to celebrate last time.

Bienvenido N. Santos presented the cultural values universalism and nationalism using the element of plot in the story "The Day The Dancers Came". Fil wants to ask them: Ilocano ka ? Bicol ka? Paisano? Comusta? But, suddenly he feels that he is an outsider. Suddenly he feels that he doesn't belong there. The age is in his face already. His hands is already horny, Fil doesn't like to shake hands with the boy who stands close to him. He seems to be friendly but Fil has decided to put his hands in his pocket. How he wishes Tony is with him. Tony knows more how to socialize with those young people. Once in a while, Fil hears them talking in their own native dialects. Fil could really feel the nostalgia of the misa de gallo, barrio fiestas and evening on the plazas. Fil smells their fragrance also of camia, ilang-ilang, and dama de noche. 
He wants to invite those young people to have a free tour of Chicago. He wants to take them around the lakeshore drive, gardens and parks, museums, department stores, planetarium. And finally, he wants to offer a dinner at his apartment on West Sheridan Road - to eat pork adobo and chicken relleno. He wants to say "how about it, paisanos?" The element of plot revealed the values of universalism, understanding, and nationalism by having a sort of nostalgia of the misa de gallo, joyous barrio fiestas, and evening on the plazas. They remember the fragrance of camia, ilang-ilang, and dama de noche because of the presence of the young Filipino tourists. Filemon wants to show them around to taste adobo and chicken relleno also. The truth of the matter is, Fil and Tony are old timers in the USA, but they miss so much the good old times in their own native land, the Philippines. They have been home sick for several years already.

5.) Amador T. Daguio exposed the cultural values tradition, respect, commitment to customs/traditions, culture and religion, devout of religious rites/beliefs, and symbols using the element of symbolism in the story "The Wedding Dance". The gongs of the dancers clamorously called in her ears through the walls. The element of symbolism revealed the values of commitment to culture and religion that demand that all their men in their tribe should have a child.

The beads are worth twenty fields given to Lumnay, they stand for the love of Awiyao for Lumnay. Awiyao not long ago, decided to throw his spear on the stairs of her father's house in token of his desire to marry her. The unwritten law demanded that all their men in their tribe must have a child. Before, she would dance like a bird tripping for grains on the ground, beautifully timed to the beat of the gangsas. She would stretch her hands like the wings of the mountain eagle. Was not their love as strong as the river?

Amador T. Daguio explored the cultural values tradition, culture and religion using the element of characters in the story "The Wedding Dance. The element of characters reveal the values of loyalty to tradition. Lumnay and Awiyao have loved each other so much. But, they have to go on separate ways because of the fact that they would never have a child forever... Lumnay - She does not want any other man than Awiyao. She has been a good wife. Awiyao has nothing to say against her. But unfortunately, seven harvests was just too long to wait for a child. She has prayed to Kabunyan so much. Still Kabunyan never blessed her a child. Well in fact, she has sacrificed many chickens during her fervent prayers. One of the best wives in the whole village. She had been very proud of her husband's humour.

Awiyao - He has been a good husband to Lumnay. He does not want any other woman either.
He had a sense of lightness in saying things, which made people laugh. Just like Lumnay, he would always offer pigs to Kabunyan only for them to have a child with Lumnay. But still, Kabunyan does not see them fit to have a child.

Madulimay - She is not as strong as Lumnay in planting beans, not as fast in cleaning jars, not as good in keeping a house clean.

\section{Singapore}

1.)Alfian Sa'at presented the cultural values of self-direction, independent thought, creative, autonomy, independence, intelligent, privacy using the element of conflict in the story "Bugis". The element of conflict has revealed the values of selfdirection. Salmah has to wear her tudung, the scarf to cover her hair. There has been a struggle within herself not to cover her hair anymore. Within a short story there may be only one central struggle, or there may be one dominant struggle with many minor ones. "Bugis" by Alfian Sa'at - Man VS Society; The leading character struggles against ideas, practices, or customs of other people. Salmah, the main protagonist wears her tudung the scarf to cover her hair. In Singapore, good Muslim girls wear tudung. But the truth is, Salmah has never been comfortable wearing tudung. Salmah has always wanted to keep her privacy but she is intelligent enough to use her independence by keeping her chastity and dignity all at the same time.

Alfian Sa'at showed the cultural values of selfdirection and creativeness using the element of plot in the story "Bugis". Self-direction and independence are cultural values that will defend the priorities of young women of 1990s in Singapore. The plot revealed the values of independent thought in the young people of Singapore nowadays. They want to become more fashionable and modern. They want to show and to flaunt their beautiful hair. Islamic tradition demands that women should be concealed when they come out in public. Although a lot of women don't follow these rules, some have still retained the age-old values of the Islamic religion.

2.) S. Kon showed the cultural values of security of families, stability of society, national security, social order, family security, reciprocation of favors, and sense of belonging using the element of conflict in the story "The Martyrdom of Helena Rodrigues". Emotionally, Helena has taken on the safety roles of up-bringing George that should have been his fathers. As a result George's gender role was reversed from the child to care-taker when he grew up to support his mother that eventually led to his death. He also denied his emotional feelings for Caroline to take care of her because to him it would be the ultimate sin to insult his mother or cause her harm.

S. Kon showed the cultural values of safety, stability of society, family security, and reciprocation of favors using the element of symbolism in the story "The Martyrdom of Helena Rodrigues". Christian 
martyrdom, as opposed to simple or unrefined domestic martyrdom, is suffered with sweet forgiveness and under veils of retirement. Helena's strength was that she never complained, nor gave an appearance of complaint. The devoted mother is now a Lady Dracula. The Medusa presence which has dominated the whole life of George makes him crazy now. The day approached, the banns were called. "The martyrdom of Helena" or is it The selfishness of Helena?

3.) Arthur Yap presented the cultural values hedonism, gratification for oneself, needs and pleasure, enjoying life, and self-indulgent using the element of symbolism in the story "The Effect of a Good Dinner". The first wife has to have a cup of tea given and served by the new/second wife. And the new wife will receive one of these three unlegislated things: a poisonous glare, a look of relief, and a look of total resignation.

Arthur Yap showed the cultural values hedonism and gratification for oneself using the element of setting in the story "The Effect of a Good Dinner". The Moon Festival seems more insipid. Marriage in those days was by the process of match-making. The two persons to be married need not know each other, but after a quietly nervous meeting, they should. Their background is uncomplicated. They came over from China at a very early age with their parents. One day, they were married. Gradually, they prospered. They had many children.

4.) Catherine Lim showed the cultural values power, social status, prestige, control and dominance over people and resources, authority, wealth, social power, preservation of public image, social recognition using the element of plot in the story "Monster". The daughter-in-law wants to convert the room as a study and music room for the children. The room will be a study room for Carol and Ricky. She said “ It's so important to have one's children properly educated these days. There's so much competition in society today"

Catherine Lim oresented the cultural values power and control and dominance over people and resources using the element of setting in the story "Monster". Semi-detached house in such a prestigious housing estate of Karen. She says the house is new and lovely. But because of the filthy old grandmother the house looks like a Chinatown slum.

5.) S. Rajaratnam presented the cultural values universalism, protection for nature/environment, understanding, tolerance, social justice, equality, world of peace, spiritual life, protection for the welfare of all people using the element of plot in the story "The Tiger". Fatima did not like to kill the tiger. She explained: "The tiger was not more than twenty yards away from me and it could have sprung at me easily, but it didn't. At first its eyes glared at me but later they were gentle and bored. There was nothing fierce or murderous about it."

S. Rajaratnam resented the cultural values universalism and protection for nature and environment using the element of symbolism in the story "The Tiger". Fatima was against the idea of killing the tiger as she had sympathy for it, on the contrary the villagers are aggressive enough to kill the beast instead of protecting themselves from it, which shows no possible threat. Overall, Fatima experiences a connection with the tiger which leads her to feel compassionate towards the tiger unlike the villagers who find a need to become violent as they did not take the time to analyze the situation for a more rational solution.

Thailand

1.)Witthayakon Chiangkun presented the cultural values are benevolence, enhancing the welfare of the in-group, smooth group functioning, concern for family, primary groups, and for others' welfare, helpful, honest, forgiving, loyal, true friendship, mature love, and spiritual life using the element of plot in the story "As If It Had Never Happened". The plot revealed the values of benevolence and concern for others' welfare. The readers see the relationship between metropolitan and rural Siam during the late 1960 s from a parallel, if contrasting, perspective. It describes the descent on an isolated Northeastern village of a group of idealistic student "volunteers" who come to build a "Community Hall" as part of some government -sponsored rural development program in Thailand. The next day, the young people started to work just as they had promised. The girls helped by hauling earth, carrying wood. As for the boys, some of them began digging holes and planting posts in them, some tapered the posts' heads, while others sawed up wood. Thong Muan had never seen people work this way before. They worked with broad and cheerful smiles on their faces, chatting and teasing one another so happily. They'd come to work very seriously. But here were sixty people coming to build the Community Hall.

Thong Muan heard that the Community Hall would be used as a place where the villagers could get together and have fun. It would help promote recreation. But at least it must be something worthwhile. Otherwise these sixty young people would never have come from far places to build it ( Anderson 1985).

Witthayakon Chiangkun showed the cultural values of benevolence, concern for others' welfare, helpful, honest, true friendship using the element of symbolism in the story "As If It Had Never Happened" The Community Hall was now completely finished. It stood majestically in the middle of the rice-fields, like a monstrous wild animal. The element of symbolism revealed the value of benevolence of the College students helping 
to build Community Hall for the less priviledged elementary students from the countryside.

The rainstorm has now subsided outside. But it has not died down in her heart. Thong Muan feels a sudden wave of loneliness. And from her eyes ooze clear, pure tears. They well up in the sockets of her eyes and trickle down over her cheeks. Then fall to the dark cement floor.

2.) K. Surangkhanang presented the cultural values security, harmony, stability of society, national security, social order, family security, national security, reciprocation of favors, and sense of belonging using the element of characterization in the story "The Grandmother" The Grandmother - a peddler of cooked dumplings. The old woman has a wrinkled face and with hearing difficulty already. She usually sells 50 tapioca dumplings around the village market. She put some golden fried garlic and red and green hot peppers on top of the shining dumplings.

She has a grown - up daughter who had married and had children of her own, on whom she could not depend for anything. Every afternoon, when she gets home, she will mix together whatever left-over for subsistence

The eldest son is a monk. The old woman had to force herself to feel that her son had no more place in her life. The second daughter was married to an orchard owner with two big wooden houses. But Piam required the old mother to cut down weeds in the ditches of the orchards. The daughter said that the old mother should never be treated as princess. The third son, every night this son would come home nearly every evening drunk and start beating his wife and children. If the old woman will intervene, he would push her so hard that she would be sent reeling. The fourth daughter was ashamed and embarrassed to accommodate her old mother in her dwelling house. Her in-laws are all people of blue blood and rich. Phew was her fifth child. She was married to a lazy man who did not like to work. He could never stay long at one job. When they have money, they would quietly spend it themselves without letting her get some share.

K. Surangkhanang showed the cultural values security and reciprocation of favors using the element of theme in the story "The Grandmother" The old grandmother had brought up with all due care her own daughter until she got married. But still had to depend on her old mother. Instead of being cared for, the old mother had to go out to peddle in order to support them all. Life is full of suffering or conflict (thukkhang), life is non - self (anatta). The only way to overcome these earthly cravings and our ignorance can we attain Nirvana, the Awakening or the Enlightenment.

3.) Suchit Wongthred explored the cultural values of self-direction, independent thought, creative, autonomy, independence, intelligence privacy using the element of character in the story "Lord Buddha, Help Me". Mahaa Bunman is trembling from hunger. His last few coins had been spent that morning on a cup of coffee and half a package of Khled Thong cigarettes. His religion degree should have helped him get a job without any difficulty. But it was all wrong. Nowadays, employers want people with university degrees, not with Parien certificates.

Suchit Wongthred explored the cultural values of self-direction and autonomy using the element of plot in the story "Lord Buddha, Help Me". Mahaa Bunman never thought that the life of a layman would be so difficult and miserable. The world is so confusing. It is turmoil, indecency, and without justice. He thought, he might as well become a thief, a terrorist, a bank robber, a purse snatcher. Oh why did he leave the monkhood?

In the end Mahaa Bunman has thrown his four Buddha amulets, various personifications of the Lord Buddha. He feels relieved around his neck. No more obligation. No more faith. Perhaps, he is ready now to commit deviant or criminal behavior in order to survive. The morality has deteriorated in Thai society.

Society is diseased. People compete with each other so much that the poor almost choke to death over their own jealousy. If all the money that is poured into sexual obsessions were used to help poor people then the prosperity of Thailand would increase.

4.) Wanit Jarungkit exposed the cultural values stimulation, excitement, challenge in life, need for variety, a varied life, and daring life using the element of point of view in the story "Michigan Test". Told in the first person by an amiable, empty headed Bangkok student, it describes the absurd misadventures that befall him in his quest for a passport and visa to join his brother and sister-in-law in California. Officials at the American embassy and USIS inform him that the visa is conditional on passing the "Michigan Test" for English language proficiency.

Wanit Jarungkit exposed the cultural values stimulation and challenge in life using the element of setting in the story "The Michigan Test". "Michigan Test" is the story in which individual Americans actually appear. But, interestingly enough, although they are calmly ridiculed, they are marginal to the tale and to Wanit's subversive concerns. The overt target of his satire is Bangkok's new middle class, which, partly because of growing economic and political uncertainty in Siam, and partly because of the semi colonial relationship with the US cemented in the 1960s, was the main contributor to the massive Thai migration to Southern California in the 1970s.

It is not by chance that Wanit makes his hero a luk jin - - the child of a first - generation immigrant from China. This identification is sociologically correct. Much of bangkok's new middle class is 
Sino-Thai, of recent Chinese descent. The contrast between two migrations : the first of hardworking, poverty - stricken men, fleeing famine and oppression, and seeking a productive better life; Second of idle, well-to-do youths, with nothing on their minds but getting "a whiff of snow" and enjoying the comforts of American consumer culture.

5.) M.R. Kukrit presented the cultural values hedonism, gratification for oneself, needs and pleasure, enjoying life, and self-indulgent using the element of plot in the story "Thong Proi The Rich Girl". Thong Proi has decided to observe poor people. Ordinary people have been working all day under the scourging heat of the sun. People have been wearing shabbily torn clothes and they have experiencing hard lives. But in spite of difficult life, true happiness have always been there in their contented faces.

M.R. Kukrit showed the cultural values hedonism and gratification for oneself using the element of theme in the story "Thong Proi The Rich Girl". Her life was like that of a caged bird who does everything to make her happy. She lived a meaningless life. Hinayana Buddhism, to explore the mystery of karma, the sin of Buddhism's philosophy.

\section{Vietnam}

1.)Nguyen Ban showed the cultural values of achievement, personal success, competent performance, obtaining social approval intelligent, self-respect, social recognition, and ambitious using the element of plot in the story "New Virtue". The element of plot revealed the value of achievement and personal success. Vietnam was a war torn country since the struggles in Indochina beginning in the 1940s. (The struggles in indochina beginning in the 1940s were indeed atrocious and involved many countries, including the United States. Ho's strategy relied on an idea, as he told the New York Times in 1946: "We have a weapon every bit as powerful as the most modern cannon: nationalism! Do not underestimate its power." For Indochina war was the main fact of life for some 30 years.) In 1952, she was captured in an enemy raid and fell into the hands of a sergeant of the $2^{\text {nd }}$ bureau. (French Intelligence Service). She was nineteen. Then the sergeant disposed of her to a French lieutenant for three thousand piastres. Later on, she worked at the Hanoi Muc Nam Quan railway construction site and was rewarded many times.

Everybody had suffered the war of the colonialist invaders, though their sufferings were different. She had done her best to get rid of soiled life and to create a new one. She was a new woman, painstaking and active, this was clearly shown in her daily work.

Nguyen Ban showed the cultural values achievement, personal success, competent performance, obtaining social approval, intelligent, self-respect, social recognition and ambition using the element of symbolism in the story "New Virtue"
Why she didn't enjoy a rest, she replied, "I have rested a long time in the past; now I must make up for the lost time; and this is not enough. The protagonist was abused and violated by the French colonizers in the early 1950s. Through the intervention of their divine Buddha, she was able to get her freedom back. From then on, she has tried to rehabilitate her life destroyed by the imperialists. She enjoys the Tet Festival in her native village, with her husband and her child. She has done her best to get rid of soiled life and to create a new one.

2.) Nhat-Tien showed the cultural values of selfdirection, independent thought, creative, autonomy, independence, intelligent, privacy using the element of characters in the story "An Unsound Sleep"

Old Phan - a beggar but a loving father, he would usually buy a small bottle of alcohol and dry shrimps in the afternoon. He used to be a porter who usually carried loads from several storehouses in Cholon

Miss Phan - earned her living as a greengrocer at the city market. Before seven in the afternoon, she came slowly down the street carrying two baskets of fruit. Ms. Phan is eventually the wife of $\mathrm{Su}$, both of them are Buddhist demonstrators in May 1963.

$\mathrm{Su}-\mathrm{He}$ has always been bringing good news of the underground struggles against the government. The youth gives a careful analysis of the situation in Central and South Vietnam. Su gives his assurance that after the revolution, there will be freedom of religion, faith, freedom of press, freedom of speech. The black markets and smuggling of illegal goods will be stopped. All the fraudulent capitalists and profiteers will be exterminated.

Nhat - Tien explored the cultural values of selfdirection, autonomy, and independence using the element of symbolism in the story "An Unsound Sleep". Nhât-Tien's concise but ample prose style is still evident. He conveys the local flavor through vivid and vibrant descriptions of urban life in wartorn towns and cities of Vietnam during the early 1960's. The author favors descriptions of everyday, banal sights and activities, such as beggars eating filthy rice and Old Pham's penchant for rice alcohol with dry shrimps, not to mention his dwindling monetary flow because of that penchant. These details are banal and mundane; however, because they are part of the fabric of Vietnamese life and unfamiliar to Western readers, they may seem exotic. These details are one of the salient features that produce the overall effect of the local and ethnic milieu of "An Unsound Sleep."

As demonstrated by his portrayal of the lowest class of people in war-torn Vietnam, the author's sympathies lie with the common person. His choice of subject is a literary convention or technique used to deliver a larger message that the poor and 

Study

unrepresented are being trampled on by the government, the well-to-do, and the privileged.

3.) Mai - Ngu presented the cultural values selfdirection, independent thought, creative, autonomy, independence, intelligence and privacy using the element of plot in the story "The Cradles". Two years after the restoration of peace, the adopted girl was just twenty years old. She was sent by the village Committee to a midwife training course, and when it was over, she returned to her village to take charge of its maternity house. The brick watchstation behind Old Blind's hut where the dead and dying children had been taken to waiting for their burial, was built a Maternity House.

Everyday the Old Blind he strained his ears listening to the babies' cries and, was able to say that it was a boy or a girl, if strong or weak and could foretell its character. One day the Old Blind got a tender green stemmed bamboo-tree to weave a basket for fishing. The midwife asked him to make cradles for babies. Old Blind wove cradles with all the skill of his fingers and love of his elated heart. Only now that he was on the shady side of seventy was he given a job to his liking.

None of the children in their village is willing to carry the trade of the Old Blind because they want to go all over the land and do bigger work. If the old man disappears, all the cradles will remain. The babies when they grow up, will leave those cradles to other new-born babies.

Mai - Ngu presented the cultural values selfdirection, independent thought, creative, autonomy, independence, intelligent, privacy using the element of symbolism in the story "The Cradles". Like an artist who had reached the summit of his art he was all the time pondering over his work. The sacred cradle was their birthplace, their country, the immense land of their motherland, the cradle which had lulled them to sleep, protected and brought them up. A bamboo - cradle will be swinging in the centre of every house like a boat on the river.

When the Old Blind sat weaving, his hair and beard covered by whittling, he looked like a deity among his little followers in a Chinese painting.

Ma Van Khang presented the cultural values stimulation, excitement, challenge in life, need for variety and stimulation, a varied life, and daring life using the element of plot in the story "The Blind Alley" Thirteen years ago, Ninh left her native village to earn her living elsewhere. Ninh worked hard daily on the stopes. At night she had to sleep under the floor of a house built on piles, full of gadflies, dog-ticks, mosquitoes, and bugs. Every day there were miners who died of ill-treatment and sickness. She left Coc coal -mine for another town. She went from bad to worse. Arrested and raped by the policemen then she was sold to the Mai Huong coffee-house, at that time a prostitute den where she had to work as a waitress. She had to lead a shameful and exhausting life for six years.

Her beauty lost its bloom so she was turned out on the pavement. Just as that time the town was liberated. Through the assistance of the officials and townsfolk, she learnt bamboo weaving. She dared not think of her shameful life. What was the good of thinking of it? It would only make her weep. She was already leading an easy life.

4.) Ma Van Khang presented the cultural values stimulation and challenge in life using the element of symbolism in the story "The Blind Alley" That day, the blind alley was very animated. The neighbors returned one another's call. Cakes, tins of milk, clothes, and medicines given by groups of women, representatives of old men and of the town-quarter administration, filled the little table.

The blind alley has undergone a change. But when the men leave for work, the blind alley is very animated. And the same cat warms herself by the fire.

Minh - Quan presented the cultural values security, safety, harmony, stability of society, national security, social order, family security, national security, reciprocation of favors, sense of belonging using the element of plot in the story "My Milk Goes Dry" Whenever she would held her children to her arms, all her grief receded, all her disappointments disappeared, all the sorrows which lay heavy in her heart seemed to float away. All the hard trials of the past, became unimportant, she became armed to face and overcome all the future difficulties in life.

5.) Minh - Quan presented the cultural values family security and reciprocation of favors using the element of symbolism in the story "My Milk Goes Dry". Unable to turn over a new leaf, even a rag can be used to wipe up dust, but that youth is less useful tan a rag! Rubbish - no more, no less. "It's owing to those three Frenchmen" A customary way of mentioning the French in South Vietnam (riddle). "These three Frenchmen are liars, dishonest, plundering, raping, seizing other people's land. They are merciless beyond imagination, and they never flinch from any cruelty. Why are they so barbarous?"

"Annamite" old name for the Vietnamese tale talked about Emperor T'sin Tche Hwang never sucked his mother's breast, so he remained unmoved even by a river of bloodshed or a mountain of corpses But Mencius and Confucius, the celebrated philosophers, had sucked the milk of their mothers untl four years of age. So had Jesus Christ.

Minh - Quan presented the cultural values family security and reciprocation of favors using the element of plot in the story "My Milk Goes Dry". It's because none of those Frenchmen is allowed to suck the breast of his mother. White men are not human beings: they are all devils. If a child is fed with 
animal milk, he is deprived of all human sentiments when he grows up. These barbarous people were always planning to corrupt the Annamite!

2. How did these cultural values relate to the prevailing situations, conditions, and actual events during the time when the short stories were written? Indonesia

In the story "Sri Sumarah", the cultural value of benevolence was emphasized. The story was written in 1975. First is Sri Sumarah (1975) an Indonesian masterpiece of Umar Kayam. The cultural values are benevolence, concern for family, helpful, forgiving, and loyalty.

Turmoil has been no stranger to modern Indonesia, and twice since the republic's declaration of independence in 1945 the nation has been shaken - and, for better or worse, irreversibly shaped - - by upheavals of genuinely awesome force. The first of these occurred in late 1948 and centered on a sharp internal struggle for POWER and AUTHORITY played out against the backdrop of an extended war for SELF-DIRECTION and INDEPENDENCE from Dutch rule. Generally referred to as the Madiun Affair, this uprising by Communist forces against the established government headed by Sukarno and Hatta was in fact a much broader phenomenon than that term implies. Fighting took place throughout an extended area in Central and East Java, penetrating to the village level; tens of thousands lost their lives, destruction was widespread, and the political and social scars burned for long afterward. The second upheaval, far more devastating and encompassing the entire archipelago, took place in late 1965. This conflict pitted communists against a Military-Moslem Alliance in an extraordinarily bloody contest for POWER, AUTHORITY, UNIVERSALISM, and EQUALITY in state and society. The carnage resulting from this continued polarization was terrifying: perhaps 750,000 persons killed and roughly as many arrested and imprisoned for periods ranging up to fifteen years. (Frederick 1983).

Over-confident of their strength and precipitated by the serious illness of President Soekarno, who was undergoing treatment by a Chinese medical team from Beijing, the Indonesian Communist Party (PKI) attempted another coup on September 30, 1965. The uprising,(UNIVERSALISM, SOCIAL JUSTICE, EQUALITY) however, was abrupt and quickly stamped out by the Armed Forces under Major General Soeharto, then Chief of the Army's Strategic Command.

On the night of September 30, or more precisely in the early hours of October 1, 1965, armed PKI men and members of Cakrabirawa, the President's security guard, set out to kidnap, torture and kill six top Army Generals. Their bodies were dumped in an abandoned well at Lubang Buaya, on the outskirts of Jakarta. The coup was staged in the wake of troop deployments to Kalimantan, at the height of Indonesia's confrontation with Malaysia. Moreover, at the time, many cabinet members were attending a celebration of the Chinese October Revolution in Beijing. It was during this POWER, CONTROL AND DOMINANCE OVER PEOPLE AND RESOURCES, AUTHORITY vacuum that the communists struck again.

Students made for the streets in militant demonstrations to fight for a three-point claim, (SELF-DIRECTION, AUTONOMY, and INDEPENDENCE or "Tritura," that aimed to ban the PKI, replace Soekarno's cabinet ministers, and reduce the prices of basic necessities. They set up a "street parliament" to gather the demands of the people.

Under these explosive conditions, President Soekarno eventually gave in and granted Soeharto full power to restore order and NATIONAL SECURITY in the country. The transfer of SOCIAL POWER was effected by a presidential order known as "the 11th of March order" of 1966. Soon afterwards, on March 12, 1966, General Soeharto banned the PKI. This decision was endorsed and sanctioned by virtue of the Provisional People's Consultative Assembly Decree No XXV/MPRS/1966. He also formed a new cabinet, but Soekarno remained as Chief Executive. This brought dualism into the cabinet, particularly when Soekarno did not show support for the cabinet's program to establish political and economic stability NATIONAL SECURITY, STABILITY OF SOCIETY Hence, a special session of the Provisional People's Consultative Assembly (MPRS) was convened from March 7-12, 1967. The Assembly resolved to relieve Soekarno of his presidential duties and appointed Soeharto as Acting President, pending the election of a new President by an elected People's Consultative Assembly. (Indonesia's History and Background, 2010)

This short story challenges a variety of beliefs, communist and non-communist alike, about the meaning of the rebellions of 1948 and 1965, and about Indonesian society and values . Traditional Javanese culture; (TRADITION, CULTURE, AND RELIGION) a physical and ideological distance from the upheaval of 1965.

In the story "Meant for Each Other" The cultural values that can be depicted here are CONFORMITY, honoring parents and elders, obedience, discipline, restraint of actions, social norms, and being responsible. The story was written in 1956.

Opium smoking was a widespread social custom in nineteenth-century Java, and commercial trade in opium had far-reaching economic and political 
implications. As in many of the Dutch territories in the Indonesian archipelago, the drug was imported from elsewhere and sold throughout the island under a government monopoly - a system of revenue "farms." These monopoly franchises were regulated by the government and operated by members of Java's Chinese elite, who were frequently also local officials appointed by the Dutch. The farms thus helped support large Chinese patronage networks that vied for control of rural markets throughout Java. James Rush explains the workings of the opium farm system during its mature years by measuring the social, economic, and political reach of these monopolies within the Dutch-dominated colonial society. His analysis of the opium farm incorporates the social history of opium smoking in Java and of the Chinese officer elite that dominated not only the opium farming but also the island's Chinese community and much of its commercial economy. He describes the relations among the various classes of Chinese and Javanese, as well as the relation of the Chinese elite to the Dutch, and he traces the political interplay that smuggling and the black market stimulated(STIMULATION, VARIED AND DARING LIFE) among all these elements.

Opium represents and symbolizes the paramount imperial power in the Indonesian archipelago, monopolized the importation and distribution of opium in Java almost continually from the late $17^{\text {th }}$ century until 1942. It abandoned the well-established system of selling opium indirectly region - by region through SOCIAL POWERFUL Java-Chinese opium farmers.

Inspite of the influx of opium in Jakarta in the 1950s, young people are expected to be mindful of the SOCIAL NORMS, CONVENTIONS and TO ALWAYS HONOR THEIR PARENTS and ELDERS.

In the story "The Soldier", the cultural values of achievement, personal success, competent performance, obtaining social approval, intelligent, self-respect, social recognition, and ambition were emphasized. The story was written in 1956. It was in 1950s when The Indonesian leaders Sukarno and Mohammad Hatta declared Indonesia's INDEPENDENCE as a republic in 1945. In 1949 the Dutch finally acknowledged Indonesia's independence. Sukarno's leanings towards the communists led Hatta to resign and displeased the army. Further resentment in the outer islands against increasing centralization by the Javanese sparked off revolts in late 1956 by army commanders who set up independent governments in Sumatra and Sulawesi. MARTIAL LAW (NATIONAL SECURITY) was declared throughout the archipelago in March 1957 (Tarling, 1999).

After the first national election held in 1955, the Indonesian parliamentary system soon disintegrated under the strains of the country's internal dissension and economic chaos. By that time the Indonesian Communist Party was recovering from the consequences of the abortive 1948 revolt, and Soviet President Khrushchev saw potential in Indonesia as part of his general policy of building up Russian influence in the Third World(ACHIEVEMENT, SOCIAL RECOGNITION. In spite of its disasters of 1925 and 1948, the Indonesian Communist Party was still second only to the Chinese Communist Party in Asia.(SOCIAL POWER) President Sukarno remained a revolutionary leader, eager to supplant Western orientation of the Indonesian economy, and he had personal ambitions to become a Third World leader of the movement against Western imperialism (Tarling, 1999).

In the story "The Decline and Fall of Our Local Mosque", the cultural values of POWER, CONTROL AND DOMINANCE OvER PEOPLE AND RESOURCES were emphasized. The story was written in 1956. It was in the elections of 1955 and 1957 remain markers of religious commitments in the country. Masjumi, representing modernist Islam, was strongest in the outer islands, in West Java and in urban areas. The traditionalist Muslim Nahdatul Ulama, the nationalists (PNI) and communists (PKI), all had their roots in the heartlands of Java. After the elections, both Muslims and Christians feared growing PKI strength(DEVOUT OF RELIGIOUS RITES/BELIEFS) and resented Java -oriented economic policies.

The Darul Islam movements had been continuing in Aceh, west Java, the South Sulawesi in 1958 was used to push modernist IslamDEVOUT OF RELIGIOUS RITES/BELIEFS to the political margins. The suppression of Darul Islam, the PRRI and Permesta revolts and nationalization of businesses, all in the late 1950s, drew the military into civilian administration, transforming it also into the primary new vehicle of national integration and reducing Islam's political relevance (Tarling, 1999).

In the story "Inem", the cultural values of conformity, obedience, politeness, honoring parents and elders, loyalty, restraint of actions, social norms, self-discipline, and being responsible were emphasized. The story was written in 1952.

During Indonesia's formative years, 1949 - 1955, there was great instability of government and very little prospect for a smooth functioning of the party system. Matching the chaotic political situation was the rapid decline in the new nation's economy. Inflation soared in the years 1949-1955, doubling the prices in the rural areas and even more in the cities. The threat of nationalization (INDEPENDENCE, AUTONOMY) of industries and trade scared foreign investors, including the overseas Chinese who had financial connections in Singapore and Hong Kong. The salvation of the peasantry was the rich, fertile, volcanic soil of Java, which seemed to hold unlimited potential for feeding its burgeoning population. 
Instead of cleansing the administration and striving for the economic well-being of the people, Sukarno concentrated on projecting Indonesia and himself, (POWER, CONTROL AND DOMINANCE OVER PEOPLE) though not necessarily in that order, dramatically onto the international stage. Such measures helped to divert the people's attention from their pressing daily wants, to weld them into a national front, and to convince them to stand behind their President in fighting the nation's foes.

Huge sums of money (POWER, WEALTH) were diverted to the erection of prestigious monuments and to rebuilding the capital, Jakarta. The country's debt soared, inflation skyrocketed, and production and exports suffered. Corruption among bureaucrats as well as army officials swelled to intollerable proportions - particularly in the government agencies dealing with licensing, police, and taxes. Petty government officials held second jobs, many of them often driving pedicabs. The frustration in the urban centers among the educated and unemployed youth was tapped by the PKI (Partai Kommunis Indonesia),(UNIVERSALISM, SOCIAL JUSTICE and EQUALITY) which by the early 1960s claimed a membership of 3 million, the largest Communist Party in Asia outside of China (SarDesai, 2013).

$\underline{\text { Malaysia }}$

In the story, "Victoria and Her Kimono" (1984), the cultural value of benevolence was emphasized. The story was written in 1984.

In 1948, the British-ruled territories on the Malay Peninsula formed the Federation of Malaya, which became INDEPENDENT in 1957. Malaysia was formed in 1963 when the former British colonies of Singapore and the East Malaysian states of Sabah and Sarawak on the northern coast of Borneo joined the Federation. The first several years of the country's history were marred by a Communist insurgency, Indonesian confrontation with Malaysia, Philippine claims to Sabah, and Singapore's secession from the Federation in 1965. Malaysia, a middle-income country, has transformed itself since the 1970s from a producer of raw materials into an emerging multisector economy. It was indeed an ACHIEVEMENT, OBTAINING SOCIAL APPROVAL for Malaysia. During the 22-year term of Prime Minister Mahathir bin Mohammad (1981-2003), Malaysia was successful in diversifying its economy from dependence on exports of raw materials to expansion in manufacturing, services, and tourism. (ACHIEVEMENT, PERSONAL SUCCESS, AND AMBITION). As an oil and gas exporter, Malaysia has profited from higher world energy prices, although the rising cost of domestic gasoline and diesel fuel, combined with strained government finances, has forced Kuala Lumpur to begin reducing government subsidies. Malaysia became the $17^{\text {th }}$ largest exporter. (POWER, PRESTIGE, AUTHORITY) The government is also trying to lessen its dependence on state oil producer Petronas, which supplies more than $40 \%$ of government revenue.

Global economic slow down, and mounting public sector debts push the economy in negative growth. The Malaysian bubble economy burst dramatically, the ringgit soon fell up to $45 \%$ of its original value.

In the story "Mariah" The cultural values are tradition, respect, commitment to customs, traditions, religion, culture, devout of religious rites/beliefs, and symbols. The story was written in 1993.

It was in 1993 that a husband had the right to practice polygamy, and this was a test of the first wife's TOLERANCE, UNIVERSALISM, and UNDERSTANDING and endurance for this practice. She believed that as a woman she was destined to accept humiliation, pain, and suffering in order to protect an important aspect of Malaysian culture. She felt that as a woman, she had an obligation to care for both her husband and Islamic devotees in their village. She had to sacrifice her own interests and to suppress her feelings. Islam permeates Malaysian culture and society, and a devout Muslim adheres to its guidelines. Since polygamy is allowed for Muslim males, the Imam her husband, was not breaking any law, and in fact had every right to marry another person with or without consent from his first wife.

An area of interest, is the focus on women. Many stories speak of the difficulties women have faced throughout their lives as mothers, sisters, wives, and lovers. The whole issue is complex and fraught with the sufferings that women have always been subjected to. The feminist movement has not sat upon comfortable bodies and minds in Asia. The women of Singapore and Malaysia have had to balance TRADITIONAL VALUE systems and RESPECT with the new impetus provided by their feminist sisters from the West. The result has frequently been a sense of non-belonging and yet having to perform the duties and roles culturally associated with the fairer sex. (Mukherjee, D., Quayum \& Singh, 2002).

In the story "A Question of Dowry", the cultural values are conformity, obedience to social norms, loyalty, politeness, and honoring parents and elders of Hindu women to Indian social norms was emphasized. The story was written in 1962. It was in 1962 when the Hindu women honor and obey the choice of their parents. This OBEDIENCE/CONFORMITY shows their being RESPONSIBLE and LOYAL to the clan. Indians in Malaysia practice traditions of dowry by the Indian communities since the fourth century. Though prohibited by law in 1961, the extraction of dowry from the bride's family prior to marriage still occurs. Children will feel that they are being forced to marry someone that they don't even know the name. 
Dowry system creates a barrier between the rich and poor. Dowry is based on education, background, financial status, and profession. Many girls committed suicide because their families can not afford to pay high dowry. Good heart is supposed to be given priority not money. The writer has a Jane Austenish flair for presenting social mores ironically, but overbalances on occasion into rather facile satire. And her keen analysis of life in an English educated Indian family underscores the curiously static outlook and the comically inbred attitudes which result from a failure to respond fully to the spirit of a multi-racial society.

In the story "A Common Story", the cultural values of universalism, nationalism, social justice, protection for the welfare of all people, understanding, tolerance, protection for nature/environment, equality, world of peace, spiritual life were emphasized. The story was written in 1959. The actual events behind the short story, the Malayan Union, established in 1946 and consisting of all the British possessions in the Malay Peninsula with the exception of Singapore, was quickly dissolved and replaced by the Federation of Malaya, which restored the AUTONOMY AND INDEPENDENCE of the rulers of the Malay states under British protection- During this time, mostly Chinese rebels under the leadership of the Malayan Communist Party launched guerrilla operations designed to force the British out of Malaya. Malayan Communist Party was formed in Malaya, Singapore, Thailand, Dutch East Indies (Dutch radicals, trade unions of Chinese Communist Party \& French Indo China). (EQUALITY and SOCIAL JUSTICE) The Malayan Emergency lasted from 1948 to 1960, and involved a long anti-insurgency campaign by Commonwealth troops in Malaya. The cultural value is UNIVERSALISM and NATIONALISM It presents the ideal of cultural integration which fired so many intellectuals in the early fifties is not, as believed, something to be achieved overnight. Bewildered by conflicting trends, returns to his kampong, stirred by a political faith whose goals lie in the future, and convinced at the same time that the erosion of the original and enduring values of the community must be halted.

In the story "Grave Harvest", the cultural values are tradition, respect, commitment to customs/traditions, culture and religion, devout of religious rites/beliefs were emphasized. The story was written in 1978 . In the 1970 s -1980 s, there was a literary debate about Islamic literature. Some of them insisted that only literary works written by Islamic writers, truly believing and writing for God, could be true Islamic literature, whereas other writers argued that all literary works, which did not contain elements contrary to general Islamic values, could be considered Islamic literature. In the 1980s there was an Islamic revival in Muslim countries in general, and the debate between two leading Malay critics reflects this as well as a felt need among the Malays to strengthen the Malay community in Malaysia. It is a fact, that the ISLAMIC FAITH, DEVOUT OF RELIGIOUS RITES/BELIEFS is an integrated part of Malay life. (Smyth, 2000).

Grave Harvest highlights the modern values, religious teachings, and to criticize also the ills of corrupt humanity in the Malay society. This relates also the hardships of the lower class or kampong life. The readers after reading the short story will understand better the Malaysian culture, lifestyles, and perennial problems.

$\underline{\text { Myanmar }}$

In the story "The Kindergarten Teacher", the cultural values of achievement, personal success, competent performance, obtaining social approval, intelligent, self-respect, social recognition, and ambitious were emphasized. The story was written in 1960. People can say that in the 1950s, Myanmar was not a least-developed country, and, with a GDI/GDP ratio of 19 per cent, it achieved an average annual growth rate of about 6 per cent.

The protagonist in this story is U Nyan Sein, an Art teacher. He teaches Reading and Writing also in the kindergarten. The protagonist has just arrived for the opening of the new semester and fortunately, he has a good evaluation in his teaching career.

In the next two decades (the 1960s and 1970s), as a consequence of command-style economic management under military rule, self-imposed isolation and INDEPENDENCE, AUTONOMY, PRIVACY, the 'Burmese way to socialism', the economy deteriorated. Real GDP growth was reduced to 3-4 per cent per annum, while the GDI/GDP ratio fell to between 12 and 13 per cent.

On 2 March 1962, Ne Win, with sixteen other senior military officers, staged a coup d'état, arrested $\mathrm{U} \mathrm{Nu}$, Sao Shwe Thaik and several others, and declared a socialist state to be run by their Union Revolutionary Council.

A number of protests followed the coup, and initially the military's response was mild. However, on 7 July 1962, a peaceful student protest on Rangoon University campus was suppressed by the military, The next day, the army blew up the Students Union building. Peace talks (UNIVERSALISM AND WORLD OF PEACE) were convened between the $\mathrm{RC}$ and various armed insurgent groups in 1963, but without any breakthrough, and during the talks as well as in the aftermath of their failure, hundreds were arrested in Rangoon and elsewhere from both the right and the left of the political spectrum. All opposition parties were banned on 28 March 1964. (SOCIAL POWER \& AUTHORITY). The Kachin insurgency by the Kachin Independence Organisation (KIO) had 
begun earlier in 1961 triggered by U Nu's declaration of Buddhism as the state religion, and the Shan State Army (SSA), led by Sao Shwe Thaik's wife Mahadevi and son Chao Tzang Yaunghwe, launched a rebellion in 1964 as a direct consequence of the 1962 military coup.

Ne Win quickly took steps to transform Burma into his vision of a 'socialist state' and to isolate the country from contact with the rest of the world. (SELF-DIRECTION \& INDEPENDENCE) A oneparty system was established with his newly formed Burma Socialist Programme Party (BSPP) in complete control. Commerce and industry were nationalized across the board, but the economy did not grow at first if at all as the government put too much emphasis on industrial development at the expense of agriculture.

In the story "The Carat 13 - Diamond" by Daw Khin Myo Chit, the cultural values are achievement, personal success, competent performance, obtaining social approval, intelligent, self-respect, social recognition, and ambitious were emphasized. The story was written in 1955. The first years of Burmese INDEPENDENCE, AUTONOMY, PRIVACY were marked by successive insurgencies by the Red Flag Communists led by Thakin Soe the White Flag Communists led by Thakin Than Tun, the Yèbaw Нруи (White-band PVO) led by Bo La Yaung, a member of the Thirty Comrades, army rebels calling themselves the Revolutionary Burma Army (RBA) led by Communist officers Bo Zeya, Bo Yan Aung and Bo Yè Htut - all three of them members of the Thirty Comrades, Arakanese Muslims or theMujahid, and the Karen National Union (KNU) After the Communist victory in China in 1949 remote areas of Northern Burma were for many years controlled by an army of Kuomintang (KMT) forces under the command of General Li Mi.

Burma accepted foreign assistance in rebuilding the country in these early years, but continued American support for the Chinese Nationalist military presence in Burma finally resulted in the country rejecting most foreign aid, refusing to join the South-East Asia Treaty Organization (SELFDIRECTION, INDEPENDENCE, AND PRIVACY) and supporting the Bandung Conference of 1955. Burma generally strove to be impartial in world affairs and was one of the first countries in the world to recognize Israel and the People's Republic of China.

The worm in the ground knows every tooth of the harrow. The butterfly above preaches PATIENCE, STIMULATION, AND CHALLENGE IN LIFE. "Poverty, to say at the least, is very uncomfortable. People have to learn to count their many blessings in life. In spite of the poverty in the 1950s, the family in the story "The Carat 13Diamond" was dignified of being government servants although their joint salaries barely paid for the daily necessities. It was difficult to believe that they had to live on the edge of starvation. Could such things really happen in Burma, a land flowing with milk and honey.

In the story "This Realm of Humans", the cultural values of achievement, personal success, competent performance, obtaining social approval, intelligent, self-respect, social recognition, and ambition were emphasized. The story was written in 1962. Soon after its birth in July 1962, the Burma Socialist Program Party recruited members at all levels national, state, district, subdistrict, and village - and formed the Peasants and Workers Council on the Soviet model. The party's policies, officially titled the "Burmese Way of Socialism," which led the country down the road to bankruptcy by the end of the 1960s because the intelligentia refused to cooperate with the blatantly militaristic regime, the BSPP came increasingly under the influence of leftwing or Communist army commanders and Marxist theoreticians. They advocated an economy geared TO THE WELFARE OF THE PEASANTS and workers by eliminating the profit motive and the alien (Indian and Chinese) middlemen and establishing state-controlled cooperatives in all sectors of the economy.(UNIVERSALISM, EQUALITY, AND SOCIAL JUSTICE)

The Ne Win government ordered nationalization of almost every economic activity, including the retail trade. Indians and Chinese, who had been active in the Burmese economy as shopkeepers, moneylenders, importers, and exporters, were expelled and their property confiscated. Banks and insurance companies were also nationalized and assets of British-owned trading companies liquidated.(EQUALITY, UNIVERSALISM, SOCIAL JUSTICE)

There were shortages all around, including rice, which was rationed in a country known in the previous century for being a leading exporter of rice to the rest of the world. The scandalous inability of the public sector to manage the distribution of consumer goods through the "people's stores" created a vicious and lucrative black market, with articles of common use smuggled from East Pakistan (now Bangladesh) and India. The policy of isolation from the rest of the world cost Myanmar heavily, as the import-export trade and foreign investment virtually ground to a halt. (SarDesai, 2013). (SELFDIRECTION, INDEPENDENCE, AND AUTONOMY).

In the story "Neighbours," the cultural values of hedonism, gratification for oneself, needs and pleasure, enjoying life, and self-indulgent were emphasized. The story was written in 1972. In the 1970s, the Burma Socialist Program Party (BSPP) 
showed a new vitality in seeking the political, economic, and social transformation of Myanmar. In the political sphere, having failed to enlist the cooperation of $\mathrm{U} \mathrm{Nu}$ and other politicians, Ne Win presented a new constitution in 1974 to the people, who approved it with $90 \%$ of the vote. The constitution stipulated a unitary state in place of the old federal polity. Along with a new citizenship act, it aimed at dismantling the traditional quasi autonomous relationship that had existed between the central government and the multiethnic society in Myanmar for nearly a millenium. (UNIVERSALISM, EQUALITY, SOCIAL JUSTICE)

In the story "Mother's Merit," the cultural values of benevolence, enhancing the welfare of the ingroup, smooth group functioning, concern for family, primary groups, and for others'welfare, helpful, honest, forgiving, loyal, true friendship, mature love, and spiritual life were emphasized. The story was written in 1980.

On the economic front, the progress in the 1970s was spectacular. In 1972, the Burma Socialists Program Party's central committee approved a twenty-year plan to be implemented through five four-year plans, projected to make Myanmar an industrialized, socialist state. Among the reasons for spectacular success was Myanmar's "green revolution" attributable to the Whole Township Special High-Yield Paddy Production Program. A major natural - gas reservoir was also discovered in the

Gulf of

\section{Martaban.(ACHIEVEMENT\&COMPETENT} PERFORMANCE)

The 1980s were, economically, the worst in Myanmar's post-independence history. Although the decade started off well with real GDP growing between 5 per cent and 8 per cent and the GDI/GDP ratio reaching 21-22 per cent, the political turmoil and social disturbances in the latter half of the decade overshadowed the good beginning. For the decade as a whole, therefore, GDP growth averaged only 1.9 per cent per annum-slightly below the 2 per cent growth in population. The GDI/GDP ratio, however, remained relatively high for this period, averaging 16 per cent per annum. We could also recall that in 1987, Myanmar applied for and was granted 'leastdeveloped country' status by the United Nations and, in 1988 , a new regime came to power that abandoned the 'Burmese way to socialism' and adopted a 'market-oriented' approach for the country to become a 'modern developed nation'.(BURMESE WAY TO SOCIALISM- EQUALITY, SOCIAL JUSTICE, UNIVERSALISM)

Philippines
In the story "Clay", the cultural values of national security, safety, harmony, stability of society, social order, family security, reciprocation of favors, and sense of belonging were emphasized. The story was written in 1951. Elpidio Quirino was the second President of a young and shaky Republic. He was the one who approved the RP-US Mutual Defense Treaty on August 30, 1951. The NATIONAL SECURITY has been threatened by the presence of American bases in the Philippines since 1951.

The Quirino administration (1948 1953) focused on two objectives: 1) to regain faith and confidence in the government; and 2) to restore peace and order. He was more successful in the second objective - breaking the back of the Hukbalahap Movement in Central Luzon. In addition, he was credited with sponsoring the growth of industrial ventures, expanding irrigation, improving the road system, and setting up the Central Bank and rural banking. It was also during his term that the RP-US Mutual Defense Treaty was approved on August 30, 1951. As the second President of a young and shaky Republic, Elpidio Quirino, an economist, believed that a country could not be truly independent unless it had achieved economic stability. $\mathrm{He}$ focused on agricultural productivity and industrialization. This was already an ACHIEVEMENT, PERSONAL SUCCESS, AND COMPETENT PERFORMANCE. He signed into law the Magna Carta of Labor and the Minimum Wage Law. He opened diplomatic and trade relations with neighboring countries such as Thailand, South Korea, Nationalist China, India, Indonesia, and Australia. However, the Huk rebellion persisted and continued to disrupt development.

As president, he tried to win over the Huks to the government side by sending his younger brother, to meet with the Huk supremo, Luis Taruc. In the talks, Taruc asked for the following:

- Scrapping of the Bell Trade Act

- No trade with Japan

- Redistribution of large estates to the peasants/tenants

- Release of the Huk prisoners

- Industrialization; and

- Removal of the US bases in the country Luis Taruc wanted to have SELF - 
DIRECTION and INDEPENDENCE away from foreign interventions.

In the story "Children of the City" the cultural values of stimulation, excitement, challenge in life, need for variety and stimulation, a varied life, and self-indulgent were emphasized. The story was written in 1971. Marcos' response to the Huk resurgence was a combined mailed-fist policy and socio-economic programs. He oversaw the major participation of the Philippines in the 1965 sevennation Manila Summit to discuss the Vietnam civil war. He declared Martial Law, ushered in his New Society, and proclaimed the entire county

as land reform area. (POWER, CONTROL AND DOMINANCE OVER PEOPLE AND RESOURCES, AUTHORITY, AND WEALTH WERE MARCOS' CULTURAL VALUES IN THE 1970S). He imposed curfew and instilled discipline among those in government and civilians. $\mathrm{He}$ abolished Congress and ruled by decrees after Charter Change amended the form of government. He put teeth to tax laws to fund infrastructure projects. He initiated the shift in Philippine foreign policy by establishing diplomatic ties with China and the then Soviet Union. Intelligent and eloquent, Marcos knew the persuasive powers of his office and used them to advantage. Marcos knew when to use his statesmanship

when dealing with problematic situation. He could display coolness

and restraint. But the years 1965 to 1972 also witnessed the holding of massive student rallies, transport strikes, farmers, workers, and urban poor demonstrations, as well as protest marches by teachers, doctors, lawyers, and other professionals. All of them were compelling those in authority, to give in to their legitimate demands.

In the story "The Day The Dancers Came," the cultural values of universalism, nationalism, understanding, tolerance, protection for nature/environment, social justice, equality, world of peace, spirituasl life, protection for the welfare of all people were emphasized. The story was written in 1967.

In the late 1960s the internal stability of the Philippines was threatened by Muslim rebels in the South and by the communist New People's Army. The influx of Christian settlers from Luzon into predominantly Moro Mindanao compounded deepseated Muslim hostility to Manila, leading in 1968 to the formation of the Moro National Liberation Front (MNLF). Pledged to fight for independence, the MNLF received material support from Sabah, whose ambitious chief minister, Tun Mustapha, was of Moro extraction. At the same time radical young communists revived the communist party, now renamed the Communist Party of the Philippines Marxist-Leninist, which created the New People's
Army. (SELF-DIRECTION, AUTONOMY, AND INDEPENDENCE)

In the story "The House on Zapote Street," the cultural values of achievement, personal success, competent performance, obtaining social approval, intelligent, self-respect, social recognition, and ambition were emphasized. The story was written in 1968. President Ferdinand E. Marcos of the Philippines was the decisive Head of State from 1965 to 1986 . He was a lawyer, member of the Philippine House of Representatives (1949-1959) and a member of the Philippine Senate (1959-1965). He was Senate President from 1963-1965

While in POWER AND DOMINANCE OVER FILIPINO PEOPLE AND RESOURCES he implemented wide-ranging programs of infrastructure development and economic reform. However, his administration was marred by massive corruption, political repression, and human rights violations. Marcos tried to increase Agricultural Production through a new strain of cereal called "miracle rice" and through modern irrigation systems.

Due to rising agrarian unrest in the countrysides, he intensified the counterinsurgency drive against the renewed Communist Party by Jose Maria Sison and the New People's Army (NPA).

(1966 - 1968) The peace and order situation in the country had deteriorated. The massacre of peasants in Concepcion, Tarlac, the killing in cold blood of 30 members of Lapiang Malaya in Manila, the killing of Muslim trainees in the infamous Jabidah massacre in Corregidor Island. The H U K repression, graft and corruption, carabao rustling, unresolved crimes involving agents of the law, disillusioned the peasants. Thus, when Marcos ran for reelection in 1969 for a second term, events did not agree for him and the nation. (ALL THESE ACTUAL EVENTS WERE DANGEROUS TO THE NATIONAL SECURITY, STABILITY OF SOCIETY, AND SAFETY OF MARCOS' FLOCK.

In the story "The Wedding Dance," the cultural values of tradition, respect, commitment to customs/traditions, culture and religion, devout of religious rites/beliefs, and symbols were emphasized. The story was written in 1953. The Philippines achieved INDEPENDENCE AND FREEDOM from the United States on July 4, 1946, and the U.S. President, Hary Truman, proclaimed in a radio broadcast that the two countries would be closely bound together in a political and economic alliance for many years. But the new nation soon faced problems sustaining its democratic approach. The huge economic gap between rich and poor, regional and ethnic loyalties, and a primary orientation toward the family shaped society and politics. A small group of landowners, and businessmen, often termed the "hundred families" and who had prospered under US rule, manipulated elected governments to preserve their political and 
economic power. The new constitution also protected US economic power. The new constitution also protected US economic interests. Personal and family rivalries, rather than ideological rivalries separated the political parties. Free elections involved enough violence, bribery, and fraud that dissilusioned Filipinos often derided them as mainly decided by "guns, goons, and gold. (IN THE 1950S, POWER, FIERCE AUTHORITY, AND CONTROL/DOMINANCE OVER PEOPLE AND RESOURCES HAVE BEEN PARTS OF THE CULTURAL VALUES OF THE FILIPINOS).

Economic inequality and social divisions have fueled chronic conflict in the Philippines. The leftist Filipino poet Amado Hernandez portrayed the gap between the rich and poor in his poem "The Kingdom of Mammon": "On every side there's pleasure and distraction, fiesta and dancing, night-long who dares whisper than thousands have no roofs their heads that hunger stalks the town. (UNIVERSALISM, EQUALITY, AND SOCIAL JUSTICE HAVE BEEN AT STAKE DURING 1950S IN THE PHILIPPINES).

Impoverished rural areas fostered various insurgencies to bring revolution. The communist led rebellion from 1948 - 1954, led by the hukbalahap (People's Anti Japanese Army) guerilla fighters, capitalized on peasant discontent in Luzon. Only heavy US assistance to the government and promised reforms suppressed the rebellion. However, most of the reforms were never enacted.

Singapore

In the story "The Effect of a Good Dinner by Arthur Yap the cultural values are hedonism, enjoying life, needs and pleasure, self - indulgent, and gratification for oneself were emphasized. The story was written in 1963.

Merger: On 16 September 1963, Malaya, Singapore, North Borneo and Sarawak were formally merged and Malaysia was formed. The PAP Government felt that Singapore's survival as a nation would be difficult. They lacked natural resources and faced a declining entrepot trade and a growing population which required jobs. Therefore, Singapore felt that the merger was thought to benefit the economy by creating a common free market, eliminating trade tariffs, solving unemployment woes and to support new industries. The British government were reluctant to grant full independence to Singapore because they believed it would provide a haven for communism. ( BENEVOLENCE, TRUE FRIENDSHIP, AND HONEST RELATIONSHIPS DEVELOPED AMONG NORTH BORNEO, SARAWAK, MALAYA, AND SINGAPORE, AS PART OF THE MALAYA FEDERATION.

The union was rocky from the start. During the 1963 Singapore state elections, a local branch of
UMNO took part in the election despite an earlier UMNO's agreement with the PAP not to participate in the state's politics during Malaysia's formative years. Although UMNO lost all its bids, relations between PAP and UMNO worsened. The PAP, in a tit-for-tat, challenged UMNO candidates in the 1964 federal election as part of the Malaysian Solidarity Convention, winning one seat in Malaysian Parliament.

Racial tensions increased as the Chinese in Singapore disdained being discriminated against by the federal policies of affirmative action, which granted special privileges to the Malays guaranteed under Article 153 of the Constitution of Malaysia. There were also other financial and economic benefits that were preferentially given to Malays. Lee Kuan Yew and other political leaders began advocating for the fair and equal treatment of all races in Malaysia, with a rallying cry of "Malaysian Malaysia!".

Meanwhile, the Malays in Singapore were being increasingly incited by the federal government's accusations that the PAP was mistreating the Malays. The external political situation was also tense; Indonesian President Sukarno declared a state of Konfrontasi (Confrontation) against Malaysia and initiated military and other actions against the new nation, including the bombing of MacDonald House in Singapore 10 March 1965 by Indonesian commandos, killing three people. Indonesia also conducted sedition activities to provoke the Malays against the Chinese. Numerous racial riots resulted and curfews were frequently imposed to restore order. The most notorious riots were the 1964 Race Riots that first took place on Prophet Muhammad's birthday on 21 July with twenty three people killed and hundreds injured. During the unrest, the price of food skyrocketed when transport system was disrupted, causing further hardship for the people. (RACIAL TENSIONS HAVE STARTED AMONG THE MALAYS, CHINESE, THE INDONESIAN KONFRONTASI THAT BECAME DETRIMENTAL TO VALUES RESPECT OF TRADITION, COMMITMENT TO CUSTOMS/TRADITIONS, CULTURE, AND RELIGION)

The state and federal governments also had conflicts on the economic front. UMNO leaders feared that the economic dominance of Singapore would inevitably shift political power away from Kuala Lumpur. Despite earlier agreement to establish a common market, Singapore continued to face restrictions when trading with the rest of Malaysia. In retaliation, Singapore refused to provide Sabah and Sarawak the full extent of the loans previously agreed 
to for the economic development of the two eastern states. The Bank of China branch of Singapore was closed by the Central Government in Kuala Lumpur as it was suspected of funding communists. The situation escalated to such an extent that talks between UMNO and the PAP broke down, and abusive speeches and writings became rife on both sides. UMNO extremists called for the arrest of Lee Kuan Yew.

Inspite of the racial tension among Chinese, Malay, and confrontation from Indonesian government Singaporeans in 1963 practiced poligamy and cultural values of HEDONISM AND ENJOYING LIFE. Match-making has nothing much to commend it. Though divorces are never heard of, this does not lend evidence to the belief that these married people are happy and contented.

More often than not, the husbands acquire new wives. It is never the policy for the wife to forbid her husband this little whim as long as he does not squeeze her allowance to rice-powder. Men have certainly all the means and women have all the understanding. Her only misgiving might be that she might not feel amiable towards the new wife. The greater and silent misgiving would be that the new wife might not be amiably disposed towards her, and what with her fresher appeal, her comparative youth and his new allegiance, the woman usually stood in mortal dread of a domestic turmoil. Her consolation would be that life itself, like some table game, would still have built-in surprises. (COMMITMENT TO CUSTOMS/TRADITIONS,CULTURE AND RELIGION OF MUSLIM MEN ALLOWED TO MARRY FOUR WIVES)

In the story "The Tiger" by S. Rajaratnam, the cultural values are universalism, protection for nature/ environment, and protection for the welfare of all people, understanding, tolerance, social justice, equality, world of peace, and spiritual life were emphasized. The story was written in 1978.

The Jurong Industrial Estate was developed in the 1960s to industrialise the economy. After gaining INDEPENDENCE AND AUTONOMY abruptly, Singapore faced a future filled with uncertainties. The Konfrontasi was on-going and the conservative UMNO faction strongly opposed the separation; Singapore faced the dangers of attack by the Indonesian military and forcible re-integration into the Malaysia Federation on unfavorable terms. Much of the international media was skeptical of prospects for Singapore's survival. Besides the issue of sovereignty, the pressing problems were unemployment, housing, education, and the lack of natural resources and land. Unemployment was ranging between $10-12 \%$, threatening to trigger civil unrest.(SINGAPORE WAS CONTEMPLATING TO PETITION FOR SELF-DIRECTION, INDEPENDENCE, AND AUTONOMY FROM THE MALAYAN FEDERATION)
Singapore immediately sought international recognition of its SOVEREIGNTY, AUTONOMY, AND SELF-DIRECTION. The new state joined the United Nations on 21 September 1965, becoming the 117th member; and joined the Commonwealth in October that year. Foreign minister Sinnathamby Rajaratnam headed a new foreign service that helped assert Singapore's independence and establishing diplomatic relations with other countries. On 22 December 1965, the Constitution Amendment Act was passed under which the Head of State became the President and the State of Singapore became the Republic of Singapore. Singapore later co-founded the Association of Southeast Asian Nations on 8 August 1967 and was admitted into the Non-Aligned Movement in 1970.

The Economic Development Board had been set up in 1961 to formulate and implement national economic strategies, focusing on promoting Singapore's manufacturing sector. Industrial estates were set up, especially in Jurong, and foreign investment was attracted to the country with tax incentives. The industrialization transformed the manufacturing sector to one that produced higher value-added goods and achieved greater revenue. The service industry also grew at this time, driven by demand for services by ships calling at the port and increasing commerce. This progress helped to alleviate the unemployment crisis. Singapore also attracted big oil companies like Shell and Esso to establish oil refineries in Singapore which, by the mid-1970s, became the third largest oil-refining centre in the world. The government invested heavily in an education system that adopted English as the language of instruction and emphasised practical training to develop a competent workforce well suited for the industry.(ACHIEVEMENT, COMPETENT PERFORMANCE, AND SOCIAL RECOGNITION OF THE SUCCESS OF SINGAPORE)

The Housing Development Board set up before independence continued to be largely successful and huge building projects sprung up to provide affordable public housing to resettle the squatters. Within a decade, the majority of the population had been housed in these apartments. The Central Provident Fund (CPF) Housing Scheme, introduced in 1968, allows residents to use their compulsory savings account to purchase HDB flats and gradually increases home ownership in Singapore. British troops had remained in Singapore following its independence, but in 1968, London announced its decision to withdraw the forces by 1971 . With the secret aid of military advisers from Israel, Singapore rapidly established the Singapore Armed Forces, with the help of a national service program introduced in 
1967. Since INDEPENDENCE, SELFDIRECTION,AND AUTONOMY Singaporean defense spending has been approximately five percent of GDP. Today, the Singapore Armed Forces is among the best-equipped in Asia

In the story "Monster" by Catherine Lim, the cultural values are power, wealth, prestige, control and dominance over people and resources, authority, social power, preservation of public image, social status, and social recognition were emphasized. The story was written in 1966.

On 7 August 1965, Prime Minister Tunku Abdul Rahman, seeing no alternative to avoid further bloodshed, advised the Parliament of Malaysia that it should vote to expel Singapore from Malaysia. Despite last-ditch attempts by PAP leaders, including Lee Kuan Yew, to keep Singapore as a state in the union, the Parliament on 9 August 1965 voted 126-0 in favour of the expulsion of Singapore, with Members of Parliament from Singapore not present. On that day, a tearful Lee announced that Singapore was a SOVEREIGN, INDEPENDENT nation and assumed the role of Prime Minister of the new nation. His speech included this quote: "For me, it is a moment of anguish. All my life, my whole adult life, I have believed in merger and unity of the two territories."

Under constitutional amendments passed in December that year, the new state became the Republic of Singapore, with the Yang di-Pertuan Negara becoming President, and the Legislative Assembly becoming the Parliament of Singapore. These changes were made retroactive to the date of Singapore's separation from Malaysia. The Malaya and British Borneo dollar remained legal tender until the introduction of the Singapore dollar in 1967. Before the currency split, there were discussions about a common currency between the Malaysian and Singaporean Governments. (SELF-DIRECTION, AUTONOMY, AND INDEPENDENCE SHOULD PREVAIL FOR THE SAKE OF THE SUCCESS OF SINGAPORE)

In the story "Bugis," the cultural values of self direction, independent thought, creative, autonomy, independence, intelligent, and privacy were emphasized. The story was written in 1997.

Singapore's supreme political leader since 1959 has been Lee Kuan Yew. Although, he formally retired as prime minister on November 26, 1990, he continued as a Senior Minister in the cabinet until he was given the status of mentor minister. Under his direction, Singapore's communists were suppressed and stronger ties built with fellow Southeast Asian states. Lee Kuan Yew emphasized the plural character of Singapore's society. In 1975, a cabinet minister was given the chance of reorganizing Nanyang University and supervising the introduction of English as a medium of instruction. (EDUCATION HAS BEEN ONE OF THE TOP PRIORITIES OF SINGAPORE'S ACHIEVEMENT, COMPETENT PERFORMANCE, AND SOCIAL RECOGNITION) Its crucial ties with trade and finance centers in the Western world and Japan have been helped by an English-language education. Bugis in Singapore, was renowned internationally from the 1950s to the 1980s for its nightly gathering of trans women, a phenomenon which made it one of Singapore's top tourist destinations during that period.

When transvestites began to rendezvous in the area in the 1950s, they attracted increasing numbers of Western tourists who came for the booze, the food, the pasar malam shopping and the "girls". Business boomed and Bugis Street became an extremely lively and bustling area, forming the heart of Xiao Po. It was one of Singapore's most famous tourist meccas from the 1950s to the 1980s, ( POWER \& WEALTH) renowned internationally for its nightly parade of flamboyantly-dressed transwomen and attracted hordes of Caucasian gawkers who had never before witnessed Asian queens in full regalia.

Others would sashay up and down the street looking to hook half-drunk sailors, American GIs and other foreigners on $R \& R$, for an hour of profitable intimacy. Not only would these clients get the thrill of sex with an exotic oriental, there would be the added spice of transgressing gender boundaries in a seamy hovel. (HEDONISM \& GRATIFICATION FOR ONESELF)

In the story "The Martyrdom of Helena Rodrigues," the cultural values of family security, safety, harmony, stability of society, national security, reciprocation of favors, sense of belonging were emphasized. The story was written in 1960. First, for the People's Action Party, the consolidation of English educated moderates alone. Second, the confrontation between the communal structures of Peninsular Malaya and the non-communal "Malaysian Malaysia group convinced Singapore leaders that (MULTIRACIALISM, BENEVOLENCE, \& TRUE FRIENDSHIP) were the keys to consensus. Changes in the political structure of Singapore could not be implemented without the endorsement of regional neighbours like Malay minority, Sukarno's konfrontasi, and Chinese dominance over trade.

Lee had this to say "If you like good, you've got to oppose bad. If you want honesty, you fight and kill corruption. If you want men with principles, you must destroy men without principles. There are no half-way houses. It was likened to clean, specific, direct, and of course, effective. (ACHIEVEMENT, COMPETENT PERFORMANCE,

AND

AMBITIOUS) 


\section{Thailand}

In the story "The Grandmother", by K. Surangkhanang, the cultural values are family security, safety, harmony, reciprocation of favors, and sense of belonging, stability of society, national security were emphasized. The story was written in 1964. The unstable condition by then was always toppled by several military coup d'etat starting 1951 until 1958. The country was virtually placed under the state of martial law which lasted for a decade. In 1957 a military coup led by Field Marshal Sarit Thanarat overthrew Pibul Songgram and made Gen. Thanom Kittikachorn premier. In 1958, however, with the stated purpose of combating Communism, Sarit deposed his own premier, suspended the constitution, and declared martial law. King Bhumibol Adulyadej proclaimed an interim constitution in 1959 and named Sarit premier. When Sarit died in 1963, Thanom Kittikachorn was returned to power. A new constitution was finally promulgated in 1968. Under Sarit and Thanom the country's economy in the 1960 s continued to boom, spurred by a favorable export market and considerable U.S. aid. (THAILAND'S ECONOMY CONTINUED TO BOOM- ACHIEVEMENT AND COMPETENT PERFORMANCE) Thailand strongly supported the U.S. policy in South Vietnam, providing bases for U.S. troops and airfields for strikes against the North Vietnamese; thousands of Thai troops were sent in support of South Vietnam. The nation's foreign policy was closely geared to the U.S. presence in Southeast Asia and its economy became increasingly dependent upon U.S. military spending and subsidies. Thailand became one of the founding members of the Association of Southeast Asian Nations (ASEAN) in 1967. ( THAILAND HAS BEGUN TO HAVE REFINED INTERNATIONAL/FOREIGN RELATIONS WITH US AND ASEAN THAT MAKES THEM BENEVOLENT, COCERN FOR OTHERS' WELFARE AND HELPFUL)

Economic reversals came in 1970 when the international demand for rice dropped substantially (due in part to improved farming techniques in other countries) and the prices of tin and rubber fell; for the first time since 1933, Thailand suffered a trade deficit. In addition, the security of the country appeared threatened by the spread of the Vietnam War into Cambodia and Laos and by growing insurgencies, chiefly Communist led, in three separate areas within Thailand itself: in the south, where Malaysian Communists used Thailand as a staging base for operations in Malaysia and Thai Malay separatists mounted an insurgency that continued into the 1980s; in the north, where Communists trained in North Vietnam were believed to be organizing the hill peoples; and, most significantly, in the economically backward northeastern provinces, where a discontented minority had been active since the mid1950s.(THAILAND DOESN'T GIVE UP INSPITE OF ALL THE TURMOILS AND ODDS. THEY TAKE ALL THE HARDSHIPS AS STIMULATIONS,CHALLENGE IN LIFE, AND DARING LIFE.

In Thailand, peddlers, especially women, carry their loads in two baskets which hang from the two twisted - up ends of a pole (mai-khan). In the 1960s, poverty has unfortunately felt and experienced in Thailand due to several military coup d'etat, communist insurgencies, and the spread of Vietnam war atrocities.

The old grandmother in the story has always been willing to sacrifice for the security and safety of her family. Life is full of suffering or conflict (thukkhang), life is non - self (anatta). Only by overcoming these earthly cravings and our ignorance can weattainNIRVANA,COMMITMENT TO RELIGION the Awakening or the Enlightenment.

In the story "Thong Proi The Rich Girl”, by M.R. Kukrit Pramoj depicts many cultural values like hedonism, gratification for oneself, needs and pleasure, enjoying life, and self - indulgent were emphasizes. The story was written in 1954. Thong Proi has decided to observe poor people.

Ordinary people have been working all day under the scourging heat of the sun. People have been wearing shabbily torn clothes and they have experiencing hard lives. But in spite of difficult life, true happiness have always been there in their contented faces. Her life was like that of a caged bird who does everything to make her happy. She lived a meaningless life. Hinayana Buddhism, to explore the mystery of karma, the sin of Buddhism's philosophy. (TRADITION AND DEVOUT OF RELIGIOUS RITES/BELIEFS)

Inflation, corruption in government, and the mysterious death (1946) of King Ananda all contributed to the overthrow (1947) of Pridi's government by Pibul. Pridi fled the country and in 1954 appeared in Beijing as the professed leader of the Communist "Free Thai" movement, allegedly representing numerous Thais still in Yunnan, China. Under Pibul's military dictatorship, the name Thailand was again adopted. Bhumibol Adulyadej, Rama IX, was crowned king in 1950 after a four-year regency. King Bhumibol Adulyadej was officially crowned the NINTH King of the Chakri Dynasty in 1950 in an ancient ceremony held at the Grand Palace. The King pledged to reign with righteousness for the benefit and happiness of the Siamese people. Thailand signed (1950) a technical and economic aid agreement with the United States and sent troops in support of the United Nations action in Korea. ( TRUE FRIENDSHIP WITH 
AMERICA, BENEVOLENCE, AND THERAVADA SPIRITUAL LIFE). Thailand has received huge military grants from the United States and was the seat (1954-77) of the Southeast Asia Treaty Organization. The country, apprehensive over its proximity to China, remained consistently proWestern in international outlook.

In the story "Lord Buddha, Help Me," the cultural values of self-direction, independent thought, creative, autonomy, independence, intelligent, and privacy were emphasized. The story was written in 1975. Economic reversals came in 1970 when the international demand for rice dropped substantially (due in part to improved farming techniques in other countries) and the prices of tin and rubber fell; for the first time since 1933, Thailand suffered a trade deficit. In addition, the security of the country appeared threatened by the spread of the Vietnam War into Cambodia and Laos and by growing insurgencies, chiefly Communist led, in three separate areas within Thailand itself: in the south, where Malaysian Communists used Thailand as a staging base for operations in Malaysia and Thai Malay separatists mounted an insurgency that continued into the 1980s; in the north, where Communists trained in North Vietnam were believed to be organizing the hill peoples; and, most significantly, in the economically backward northeastern provinces, where a discontented minority had been active since the mid1950s.(THERAVADA BUDDHISM HAS BEEN TEACHING THAI TO BE RESILLENT LIKE THE BAMBOO INSPITE OF ALL THE PAIN. THE CULTURAL VALUES ARE STIMULATION, CHALLENGE IN LIFE, AND EXCITEMENT)

The increasing economic and security problems prompted a coup in Nov., 1971, by Premier Thanom Kittikachorn and three military aides, in which they abolished the constitution and the parliament and imposed military rule. Guerrilla raids against both Thai government forces and U.S. air bases continued. Economic conditions improved throughout 1972 as large numbers of U.S. military personnel were transferred from South Vietnam to bases in Thailand; by June of that year there were more U.S. forces in Thailand than in South Vietnam.(TRUE FRIENDSHIP WITH AMERICA)

In Oct., 1973, the military regime of Thanom was toppled after a week of student demonstrations and violence in Bangkok. King Bhumibol Adulyadej appointed Sanya Thammasak as Thanom's successor, giving Thailand its first civilian premier in twenty years. The new premier promised to complete a constitution and to hold general elections. In May, 1974, citing the heavy burden of the office and the sharp criticism directed against the government, Sanya resigned, but he was soon persuaded to form a new government. In June he was sworn in as the head of a revamped, all-civilian cabinet. A new constitution was promulgated in Oct., 1974. Over the next few years the civilian government made little headway in establishing its authority. In 1976, the military took control of the government once again. After that, the military held power almost continuously until the early 1990s.( JUST LIKE MYANMAR, THAILAND BELIEVES IN THE POWER, AUTHORITY, AND PRESTIGE OF THE MILITARY JUNTA TO GOVERN THE PEOPLE)

From the late 1970s, Thailand's political concerns were dominated by pressures resulting from warfare in Vietnam, Laos, and Cambodia and serious unrest in Myanmar (Burma); Thailand also experienced a massive influx of refugees from these countries. From 1975 onward, Thailand was a way station for Hmong refugees immigrating to the United States under its resettlement program. The Khmer Rouge used Thailand as a staging area after they were driven out of Cambodia by the Vietnamese, and internal fighting within the Cambodian government in 1997 sent a new flow of refugees into Thailand. (THAILAND HAD A SUPERB FOREIGN RELATIONS WITH NEIGHBOURING ASEAN COUNTRIES BY APPLYING BENEVOLENCE, HELPFUL, AND BEING LOYAL)

In the story "As If It Had Never Happened," the cultural values of benevolence, enhancing the welfare of the in-group, smooth group functioning, concern for family, primary groups, and for others' welfare, helpful, honest, forgiving, loyal, true friendship, mature love, and spiritual life were emphasized. The story was written in 1974 . Thai society has never been rigid, but it promoted respect for those in authority and valued social harmony, and this conservatism contributed to authoritarian governments and bureaucratic inertia. Thailand's political history after 1945 was characterized by long periods of military rule followed by short-lived democratically elected or semidemocratic governments. Coup d'etat by one or another military faction were common, as Thais strove for a balance between order and stability on the one hand and democracy and personal self-determination on the other. In 1970 King Bhumibol reflected the tension between conservatism and change when he warned against the idea that "the destruction of old established things for the sake of bringing about the new would lead to entirely good results, since surely there must be some good in the old-fashioned things(Lockard, 2009). (KING BHUMIBOL HAS NEVER BEEN TIRED TO GUIDE HIS BELOVED 
FLOCK IN THAILAND, SOCIAL POWER, SOCIAL STATUS, AND PRESTIGE)

In the story "Michigan Test," the cultural values of stimulation, excitement, challenge in life, need for variety and stimulation, a varied life, and daring life were emphasized. The story was written in 1974.Not until the 1970s would a true mass politics develop as opposition movements challenged the longentrenched, corrupt, and often repressive military regime. Many Thais resented US influence and the various military bases, mostly in the northeast, that the Americans used to support their military efforts in Laos and Vietnam. The presence of many freespending American soldiers created a false prosperity in Bangkok and the cities near military bases while also posing a challenge to Buddhist morality. Staunch buddhists were outraged by the sleazy bars, gaudy nightclubs, and brothels that often exploited poor Thai women and served the US and foreign visitors but also attracted eager Thai men.( BUDDHIST MORALITY HAS BEEN CHALLENGED BY THE PRESENCE OF BROTHELS BECAUSE OF AMERICAN GIs. CONTRARY TO TRADITIONS, CULTURE AND BUDDHIST RELIGION. Disenchanted with the military regime and their US allies, university students played a particularly large role in confronting the dictatorship. In 1973 the military regime was overthrown after mass demonstrations, bringing political liberalization. One student expressed the feeling of elation: "I sense freedom. . . like many other Thais, I have wanted it for a long time, but now that we seem to have it," Student activists spread out to villages and factories to generate "bottom up" change by engaging peasants and workers in the struggle for change(Lockard, 2009).

Vietnam

In the story "An Unsound Sleep” by Nhat - Tien, the cultural values here are self - direction, independence, independent thought, creative, autonomy, intelligent, and privacy were emphasized. The story was written in 1974. "An Unsound Sleep" takes place in Vietnam during the Vietnam War. The main concern of the story is how people's lives are changed by political censorship and war. The story traces the Phan family's downfall after a daughter and her husband participate in Buddhist demonstrations. Nhat Tien skillfully incorporates descriptions of the local lifestyle and historical facts in his fiction.

As demonstrated by his portrayal of the lowest class of people in war-torn Vietnam, the author's sympathies lie with the common person. His choice of subject is a literary convention or technique used to deliver a larger message that the poor and unrepresented are being trampled on by the government, the well-to-do, and the privileged. (CONTRARY TO UNIVERSALISM, EQUALITY \& SOCIAL JUSTICE)

Old Pham and his daughter are character types that represent their socioeconomic class and the proletariat. The old man and his daughter are not unique and important as individuals but as representatives, as stand-ins, for the masses. The author uses these character types in order to convey his critical view of the political suppression of the Buddhist demonstrations. The reader can see that Nhât is much more sympathetic with the politics of North Vietnam than with the supposedly democratic South Vietnam. (CIVIL WAR BETWEEN CATHOLICS AND BUDDHISTS IN 1963, CONTRARY TO RESPECT OF TRADITION, DEVOUT OF RELIGIOUS RITES/BELIEFS, AND SYMBOLS)

Nhât uses a basic literary convention of a simple family, socioeconomic class, political struggle, and locality to create a profile sketch of the overall sentiment and popular discontentment of the time in a country fighting a civil war. (CLASS STRUGGLE BETWEEN THE PROLETARIAT AND THE BOURGEIOSIE - $\quad$ SELF-DIRECTION, INDEPENDENT THOUGHT, AND AUTONOMY)

The dominant subject matter is war and government oppression. Though not clearly stated by Nhât, the setting is various towns in South Vietnam during the earlier part of the war and during the presidency of Ngo Dinh Diem (1955-1963). "An Unsound Sleep" creates a story around the Buddhist demonstrations that actually took place in South Vietnam during 1963. One of the primary reasons that the Buddhist demonstrations were severely suppressed was because the members of the Diem family (which was similar to the Kennedy family in the United States in terms of fame and fortune) were Roman Catholics who fervently disapproved of the monks' suicides. Catholics were a minority in Vietnam during that time, amounting to no more than 10 percent of the population. However, they predominated in government positions because Diem was Catholic. The Buddhists' resettlement resulted from Diem's severe discrimination against them.(CONTRARY TO EQUALITY, UNIVERSALISM, AND SOCIAL JUSTICE)

Miss Phan and Su are portrayed as taking part in the Buddhist demonstrations. Although Nhât does not identify the demonstrations, they are most likely the May, 1963, demonstrations against Diem. The demonstrators are fired on by police. Miss Phan and $\mathrm{Su}$ are arrested and imprisoned along with thousands of high school and grade school students who are involved in protests against the Diem government. 

Study

Although Diem is never mentioned by name in the story, readers familiar with the history of the Vietnam War will recognize what regime was. . . (TRUE STORY HAPPENED IN 1963 CONTRARY TO VALUES OF INDEPENDENCE AND FREEDOM)

In the story "My Milk Goes Dry" by Minh-Quan, depicts the cultural values of security, safety, harmony, stability of society, social order, family security, national security, reciprocation of favors, sense of belonging were emphasized. The story was written in 1974. The actual event was that the Indochina Peninsula was colonized by the French in the mid $19^{\text {th }}$ century until 1954 . The Frenchmen are merciless beyond imagination. It's because none of those Frenchmen is allowed to suck the breast of his mother. White men are not human beings: they are all devils. If a child is fed with animal milk, he is deprived of all human sentiments when he grows up. (FRENCH COLONIZERS WERE EXPECTED TO PRACTICE BENEVOLENCE, CONCERN FOR PRIMARY GROUPS, AND FOR OTHERS' WELFARE) These barbarous people were always planning to corrupt the Annamite! Thu, the protagonist in the story has been determined to feed all her children with her own milk. She doesn't want them to grow silly, cruel, or inhumane just like their French colonizers. Thu wants to create a safe and nurturing environment for her six children. She wants to promote the welfare of all her children. Just like in the Philippines, there is now full implementation of the Milk Code, the nation must commit that no child will be left behind. (FAMILY SECURITY/NATIONAL SECURITY)

The French and the British entered Southern Vietnam in 1945 to reconquer the Communist territories in that area which they aimed to make their base. War broke out between the Viet Minh and the French in 1946 until 1954. (THE VIETNAMESE ARE FIERCE WARRIORS. THEY WILL FIGHT FOR THEIR FREEDOM, AUTONOMY, AND INDEPENDENCE)

The Communist used continuous military attacks, used small resources to defeat larger and better targets, they used the element of surprise, used different kinds of forces and the total involvement of the population to fight the enemy. The French army was completely surprised. Communism finally succeeded in Vietnam with the earnest efforts of Ho Chi Minh. When he returned to Vietnam in 1941, he founded the Vietnamese Independence Solidarity League which is more popularly known as Viet Minh. This was an organization designed to accommodate anti colonial Vietnamese. They attracted assistance for fighting against Japanese. (SELF-DIRECTION, INDEPENDENT THOUGHT, INTELLIGENT)
The French were eventually defeated in 1954 at the battle of Dienbienphu. French totally withdrew from Indochina with the signing of the 1954 Geneva Agreement. (STABILITY OF SOCIETY, NATIONAL SECURITY, AND SOCIAL ORDER)

The Communist regime existed in the North, the $17^{\text {th }}$ parallel divided the two areas of Vietnam with the Saigon regime in the South. And the American intervention that ended in 1975 (Chandler et.al 2004)

In the story "The Cradles" by Mai Ngu, the cultural values are self-direction, creative, independent thought, autonomy, independence, intelligent, privacy were emphasized. The story was written in 1962.

The most commonly used dates for the conflict are 1959-1975. This period begins with North Vietnam's first guerilla attacks against the South and ends with the fall of Saigon. American ground forces were directly involved in the war between 1965 and 1973. (SELF-DIRECTION, AUTONOMY, AND INDEPENDENCE)

The Vietnam War first began in 1959, five years after the division of the country by the Geneva Accords. Vietnam had been split into two, with a communist government in the north under Ho Chi Minh and a democratic government in the south under Ngo Dinh Diem. Ho launched a guerilla campaign in South Vietnam, led by Viet Cong units, with the goal of uniting the country under communist rule. The United States, seeking to stop the spread of communism, trained the Army of the Republic of Vietnam and provided military advisors to help combat the guerillas. (UNIVERSALISM, SOCIAL JUSTICE, EQUALITY, WORLD OF PEACE)

In 1954, after suffering a decisive defeat at Dien Bien Phu, the French decided to pull out of Vietnam. At the Geneva Conference of 1954, a number of nations met to determine how the French could peacefully withdraw. The agreement that came out of the conference (called the Geneva Accords) stipulated a cease fire for the peaceful withdrawal of French forces and the temporary division of Vietnam along the 17th parallel (which split the country into communist North Vietnam and non-communist South Vietnam). In addition, a general democratic election was to be held in 1956 that would reunite the country under one government. The United States refused to agree to the election, fearing the communists might win.

With help from the United States, South Vietnam carried out the election only in South Vietnam rather than countrywide. After eliminating most of his rivals, Ngo Dinh Diem was elected. His leadership, however, proved so horrible that he was killed in 1963 during a coup supported by the United States. Since Diem had alienated many South Vietnamese during his tenure, communist sympathizers in South 
Vietnam established the National Liberation Front (NLF), also known as the Viet Cong, in 1960 to use guerrilla warfare against the South Vietnamese. (INDEED, THE VIET CONGS WERE POWERFUL, THEY CONTROLLED AND DOMINATED MANY PEOPLE AND RESOURCES. THEY HAD THE AUTHORITY, SOCIAL POWER, AND WEALTH IN THE EARLY 1960S).

First U.S. Ground Troops Sent to Vietnam

As the fighting between the Viet Cong and the South Vietnamese continued, the U.S. continued to send additional advisers to South Vietnam. When the North Vietnamese fired directly upon two U.S. ships in international waters on August 2 and 4, 1964 (known as the Gulf of Tonkin Incident), Congress responded with the Gulf of Tonkin Resolution. This resolution gave the President the authority to escalate U.S. involvement in Vietnam. President Lyndon Johnson used that authority to order the first U.S. ground troops to Vietnam in March 1965.

\section{Johnson's Plan for Success}

President Johnson's goal for U.S. involvement in Vietnam was not for the U.S. to win the war, but for U.S. troops to bolster South Vietnam's defenses until South Vietnam could take over. By entering the Vietnam War without a goal to win, Johnson set the stage for future public and troop disappointment when the U.S. found themselves in a stalemate with the North Vietnamese and the Viet Cong.

From 1965 to 1969 , the U.S. was involved in a limited war in Vietnam. Although there were aerial bombings of the North, President Johnson wanted the fighting to be limited to South Vietnam. By limiting the fighting parameters, the U.S. forces would not conduct a serious ground assault into the North to attack the communists directly nor would there be any strong effort to disrupt the Ho Chi Minh Trail (the Viet Cong's supply path that ran through Laos and Cambodia).

\section{Life in the Jungle}

U.S. troops fought a jungle war, mostly against the well-supplied Viet Cong. The Viet Cong would attack in ambushes, set up booby traps, and escape through a complex network of underground tunnels. For U.S. forces, even just finding their enemy proved difficult. Since Viet Cong hid in the dense brush, U.S. forces would drop Agent Orange or napalm bombs which cleared an area by causing the leaves to drop off or to burn away. In every village, U.S. troops had difficulty determining which, if any, villagers were the enemy since even women and children could build booby traps or help house and feed the Viet Cong. U.S. soldiers commonly became frustrated with the fighting conditions in Vietnam.
Many suffered from low morale, became angry, and some used drugs. (THE STALEMATE BECAME DETRIMENTAL TO BOTH, THE VIET CONG AND THE U.S. SOLDIERS. THE VIETNAM WAR BECAME RUTHLESS TO NATIONAL SECURITY, STABILITY OF SOCIETY, SAFETY/HARMONY OF BOTH POPULATIONS MOST ESPECIALLY TO SOUTH VIETNAM)

In the story "New Virtue by Nguyen Ban, the cultural values that can be reflected here are achievement, personal success, competent performance, obtaining social approval,intelligent, self respect, social recognition and ambitious were emphasized. The story was written in 1962. The major character has done her best to rid herself of a soiled life and to create a new one during the French invasion in 1952.

Final declaration, dated July 21, 1954, of the Geneva Conference on the problem of restoring peace in Indochina, in which the representatives of Cambodia, the Democratic Republic of Viet-Nam, France, Laos, the People's Republic of China, the State of Viet-Nam, the Union of Soviet Socialist Republics, the United Kingdom and the United States of America took part.

The Conference takes note of the agreements ending hostilities in Cambodia, Laos, and Viet-Nam and organizing international control and the supervision of the execution of the provisions of these agreements.

The Conference expresses satisfaction at the ending of hostilities in Cambodia, Laos, and VietNam. The Conference expresses its conviction that the execution of the provisions set out in the present declaration and in the agreements on the cessation of hostilities will permit Cambodia, Laos, and Viet-Nam henceforth to play their part, in full INDEPENDENCE AND SOVEREIGNTY, IN THE PEACEFUL COMMUNITY OF NATIONS.

The Conference takes note of the declaration of the French Government to the effect that it is ready to withdraw its troops from the territory of Cambodia, Laos, and Viet-Nam, at the request of the governments concerned and within a period which shall be fixed by agreement between the parties except in the cases where, by agreement between the two parties, a certain number of French troops shall remain at specified points and for a specified time. Everybody had suffered the war of the colonialist invaders, though their sufferings were different. She had done her best to get rid of soiled life and to create a new one. She was a new woman, painstaking and active, this was clearly shown in her daily work. (IN 
1954, FRENCH TROOPS TRUE TO THEIR WORDS, WITHDREW THEIR TROOPS AWAY FROM INDOCHINA. THEY WERE ABLE TO SHOW BENEVOLENCE, TRUE FRIENDSHIP, AND LOYALTY)

As early as 1959, the Communists were infiltrating the territorial jurisdiction of South Vietnam. They attacked the Diem government and intensified the fighting in the 1960s. By 1965, Saigon was in near collapse. In view of the increasing influence of the Communists, the United States went to the aid of South Vietnam. Successive US presidents beginning with Dwight Eisenhower in 1954 and John F. Kennedy in 1961 granted huge financial assistance to the anticommunist campaign in South Vietnam. It was US President Lyndon Johnson who approved the intensive bombing of North Vietnam. He also ordered the dispatch of US combat troops into the South to back up the government of President Nguyen Van Thieu. In the early phase of the war, the joint US-Vietnamese forces, were scoring victories. The South Vietnamese forces were after the Vietcong, while American troops took the offensive against North Vietnam. From Vietnam, the war escalated to other parts of Indochina. Beginning in 1965, the Communist Pathet Lao fought the Laotian democratic government while the Communist Khmer Rouge were fiercely fighting in Cambodia. (THERE WAS ANOMIE. THE WAR WAS DETRIMENTAL TO NATIONAL SECURITY, FAMILY SECURITY, AND STABILITY NOF SOCIETY)

The Vietnam War was one of the most costly wars fought in modern times. The war had left more than $15 \%$ of the Vietnamese population killed or wounded. An estimate of two million Vietnamese were killed and three million wounded. US casualties were also high with a death toll of 57,685 and 153,303 wounded (Ongsotto, 2002).

Everybody had suffered the war of the colonialist invaders, though their sufferings were different. She had done her best to get rid of soiled life and to create a new one. She the protagonist was a new woman, painstaking and active, this was clearly shown in her daily work.

In the story "The Blind Alley by Ma Van Khang, the appropriate cultural values are stimulation, challenge in life, need for variety, a varied life, and daring life were emphasized. The story was written in 1965 .

A strong and enigmatic leader, Ngo Dinh Diem exerted all efforts to stabilize South Vietnam. However, his anticommunist policy led him to initiate repressive measures for the elimination of all Communists in his jurisdiction. Assured of the diplomatic support from the United States, Diem refused to hold the election for the reunification. Being a Catholic himself, his alleged favoritism toward his own religious sect alienated the Buddhist groups. The South Vietnamese agitating for reforms staged violent riots. Many Buddhists burned themselves as a part of the nationwide protests. (BUDDHIST TRADITION VS NGO DINH DIEM, A CATHOLIC; RESPECT AND COMMITMENT TO CULTURE AND RELIGION SHOULD BE OBSERVED IN VIETNAM) Oppositionists to his rule were given harsh punishment. Civil rights were suppressed. Further discontent arose when his economic and social programs failed. Soon his government turned into a virtual dictatorship. By 1959, Diem's government had become unstable.

On November 1, 1963, Diem was overthrown by a military coup. Diem and Ngo Dinh Nhu, his brother and political adviser, were executed. A revolutionary council headed by Brigadier Duong Van Minh replaced Diem's government. South Vietnam had ten different governments each installed through a military coup d'etat. (POWER, AUTHORITY, AND SOCIAL STATUS NGO DINH DIEM WERE EXECUTED)

In 1965, a military council was created and headed by General Nguyen Van Thieu and General Nguyen Cao Ky. In 1967, an election was held for the presidency and Thieu was reelected. The political condition in South Vietnam continued to worsen in spite of the series of changes made in the leadership of the country. The existing political instability was to the advantage of the Communists within South Vietnam. Soon they gained popular support leading to the radical reunification of Vietnam (Ongsotto, et.al 2002).UNIVERSALISM, NATIONALISM AND SOCIAL JUSTICE WERE AT STAKE. A CIVIL WAS JUST HAVE TO HAPPEN.

3.) How did the identified cultural values in the short stories reflect the roles of the following aspects in the lives of Southeast Asian people?

Economy

Indonesia

Economy plays a big role among the people in Indonesia. It is the root why people value conformity, obedience, and honoring parents and elders. Just like the protagonist Inem in the story "Inem" by Pramoedya Ananta Toer. They have the habit of obeying Javanese traditions like submitting themselves to early marriage in exchange for a dowry that will augment their financial distress in the $1950 \mathrm{~s}$ up to 1970 s.

Sukarno's nationalistic (UNIVERSALISM AND NATIONALISM) but poorly implemented economic policies contributed to a severe economic crisis by the early 1960s, as well as deepening divisions between communist, Islamic, and military forces. 
The Indonesian economy, began the postwar period poorly and achieved sustained growth only after 1965. The revolution forced postponement of reconstruction to the 1950 s, when the young republic had to struggle with problems of high mortality, food shortages, inflation, and the destruction of physical capital. A GNP growth rate of nearly $2 \%$ per capita for much of the decade, though respectable under the circumstances, was disappointing to many Indonesians, particularly Sukarno, who took over effective control of the state apparatus between 1957 and 1959. His answer was NATIONALISM: expropriation of Dutch property; discrimination against the Chinese; major state investment in heavy industry to make Indonesia self sufficient; and a rhetorical barrage levelled against neo-colonialism in all its forms, culminating in confrontations over Irian Jaya and Malaysia that increased military spending and reduced foreign aid and trade.

The results, in economic terms, were disastrous: trade collapsed, industrial production plummeted, and hyper - inflation set in. In 1950 a small group of leading Indonesian writers published a moving declaration promoting "UNIVERSAL HUMANISM" and "HUMAN DIGNITY. Their beliefs were shaped by the nationalist struggle against the Dutch as well as their familiarity with European Enlightenment values such as DEMOCRACY, SELF-DIRECTION, FREE THOUGHT, and TOLERANCE and UNIVERSALISM. GNP per capita actually declined between 1957 and 1965, as did food consumption in this already hungry country. (Lockard 2009).

Between 1965 and 1967, the military wrested control from Sukarno and turned the economy over to the technocrats, who immediately sought and received the foreign aid and investment that had been frightened away in the period of guided democracy. In 1966 - 1998, SUHARTO moved Indonesia in new PRO-WESTERN and AUTHORITARIAN directions. They made it a crime TO SLANDER or show DISRESPECT of the government or officials. The cultural value here is TRADITION and RESPECT. The emphasis was on curbing inflation, promoting rice production, agricultural extension programme, which provided physical inputs and credit, and fostering import-replacing industries often with military participation. By the end of the 1960s the economy was well on the road to recovery, and even before the oil boom, annual growth per capita had climbed to $5 \%$. It maintained this rate for the remainder of the 1970s, despite the Pertamina scandal of 1975 - possibly the largest defalcation in Southeast Asian history - but fell back to around 1\% after the decline of oil prices in 1983 .

$\underline{\text { Malaysia }}$

Economy plays a big role among the people in Malaysia. It is the root why people value conformity, restraint of actions, social norms, obedience, selfdiscipline, politeness, honoring parents and elders, loyalty, and being responsible. Just like the protagonist Sivasothie in the story "A Question of Dowry" by Siew Yue Killingley. Malaysians are born successful also. They conform to their conservative social norms but they have been loyal to Malay heritage, Sabah, and Sarawak and of course Islamic Shariah Law. Most likely, they have been blessed by their Allah and Mohammad so they have always been successful. Most of their cultural values in Malaysia were influenced by their economy in 1950 s to $1990 \mathrm{~s}$. It is about arranged marriages practised and the traditions of dowry by the Indian communities. Malaysia has achieved MUCH MORE POLITICAL STABILITY and ECONOMIC PROGRESS. The Indian-Malaysians conform to their practices, culture, and customs that family of daughters (would be brides) to produce dowry/money to proceed with their marriage proposal to a dashing gentleman. In so doing, would be grooms should be polite enough to follow the whims and requests of elders for them to be married.

Datuk Seri Dr. Mahathir Muhammed, a medical doctor and Malay NATIONALIST (UNIVERSALISM), became prime minister in 1980. A descendant of a Muslim Indian immigrant, was the first non-aristocrat to become the nation's leader. His AUTOCRATIC LEADERSHIP (POWER) style allowed little tolerance for opponents. Indian's people basically follow the arranged marriage traditions, and they consider it as something honored and great. Dating is prohibited by most families in their community. Dowry is the payment in cash or kind by the bride's family to the bridegroom' s family along with the giving away of the bride in Indian marriage. This is an important part of Hindu marital rites. Though prohibited by law in 1961 , the extraction of dowry from the bride's family prior to marriage still occurs.

UMNO Party, came from a Malay party advocating an ISLAMIC STATE (DEVOUT OF RELIGIOUS RITES/BELIEFS), and a mostly Chinese party pursuing a liberalizing agenda. UMNO claimed to be both PRO-ISLAMIC( TRADITION) and PROMODERNIZATION(POWER and WEALTH). (Lockard 2009). Malaysia is a relatively open stateoriented and newly industrialised market economy. The state plays a significant but declining role in guiding economic activity through macroeconomic plans. Malaysia has had one of the best economic records in Asia, with GDP growing an average 6.5 per cent annually from 1957 to 2005. In 2011 the GDP (PPP) was about $\$ 450$ billion, the 3rd largest economy in ASEAN and 29th largest in the world.

In 1991, former Prime Minister of Malaysia, Mahathir bin Mohamad outlined his ideal, Vision 2020 in which Malaysia would become a selfsufficient industrialized nation by 2020 . Tan Sri Nor 
Mohamed, a government minister, said Malaysia could attain developed country status in 2018 if the country's growth remains constant or increases. Viktor Shvets, the managing director of Credit Suisse has said "Malaysia has all the right ingredients to become a developed nation. In the 1970s, Malaysia has enjoyed considerable ECONOMIC PROGRESS (POWER AND SOCIAL STATUS) the predominantly mining and agricultural-based economy began a transition towards a more multisector economy. Since the 1980s the industrial sector has led Malaysia's growth. High levels of investment played a significant role in this. The economy recovered from the 1997 Asian Financial Crisis sooner than neighbouring countries, and has since recovered to the levels of the pre-crisis era with a GDP per capita of $\$ 14,800$. Inequalities exist between different ethnic groups. The Chinese make up about one-third of the population but accounts for 70 per cent of the country's market capitalisation. International trade, facilitated by the adjacent Strait of Malacca shipping route, and manufacturing are key sectors of the country's economy. Malaysia is an exporter of natural and agricultural resources, the most valuable exported resource being petroleum. At one time, it was the largest producer of tin, rubber and palm oil in the world. Manufacturing has a large influence in the country's economy, although Malaysia's economic structure has been moving away from it. Malaysia remains one of the world's largest producers of palm oil.

Benefitting from ABUNDANT NATURAL RESOURCES (POWER AND PRESTIGE)and ENTREPRENEURIAL

TALENT

(ACHIEVEMENT), high annual growth rates into the late 1990s enabled Malaysia to surpass nations like Portugal and Hungary in NATIONAL WEALTH (POWER) and to achieve a high per capita income and considerable export-oriented light industry employing cheap labor. In an effort to diversify the economy and make it less dependent on exported goods, the government has pushed to increase tourism to Malaysia. As a result, tourism has become Malaysia's third largest source of income from foreign exchange, although it is threatened by the negative effects of the growing industrial economy, with large amounts of air and water pollution along with deforestation affecting tourism. The country has developed into a centre of Islamic banking, and is the country with the highest numbers of female workers in that industry. Knowledge-based services are also expanding. In 1970, better irrigation and mechanized equipment benefited many peasants, especially those with more capital, while others without connections faced less security. Many worked in low-paying jobs (STIMULATION, CHALLENGE IN LIFE). Many young women labored in ELECTRONICS and TEXTILE
FACTORIES (SELF-DIRECTION and CREATIVE).

Squatter settlements and countless shabbily dressed street hawkers hoping to sell enough of their cheap wares to buy a meal (STIMULATION AND CHALLENGE IN LIFE).

$\underline{\text { Myanmar }}$

Economy plays a big role among the people in Myanmar. It is the root why people value achievement, personal success, and self-respect. People of Myanmar have always been suffering a lot because of their Socialist form of government, military Junta, imperialists like British and Japanese but they do not loose hope and spirit. They give their best to achieve economic success inspite of all the odds. Just like the protagonist Ma Chit Hpo in the story "This Realm of Humans by Khin Hnin $\mathrm{Yu}$ (1962) They have the habit of spending the very smallest amount possible. It is alright with them to live a parsimonious lifestyle notably lacking in luxuries. They save a lot like eating meals of rice and tiny fish. But alas, they were able to buy their own little brick bungalow in the suburbs with a big garden. Indeed, they detach themselves of worldly goods and see peace through meditation. In order to have the cultural value of achievement and personal success, people of Myanmar undergo a lot of hard work and years of sacrifices also.

The Burmese Way to Socialism refers to the ideology of the Socialist government in Burma, from 1962 to 1988, when the 1962 coup d'état was led by $\mathrm{Ne}$ Win and the military to remove $\mathrm{U} \mathrm{Nu}$ from power. More specifically, the Burmese Way to Socialism is an economic treatise written in April 1962 by the Revolutionary Council, shortly after the coup, as a blueprint for economic development, reducing foreign influence in Burma INDEPENDENCE AND AUTONOMY, and increasing the role of the military OBEDIENCE . Involves SELF-RESTRAINT (CONFORMITY AND SELF-DISCIPLINE), TOLERANCE (UNIVERSALISM, TOLERANCE) and FORBEARANCE (PATIENCE/FORGIVING) three virtues with which, human nature is not richly endowed.

The Burmese Way to Socialism has largely been described by scholars as being xenophobic, superstitious and an "abject failure," turning one of the most prosperous countries in Asia into one of the world's poorest. However, it may have served to increase domestic stability (NATIONAL SECURITY) and keep Burma from being as entangled in the Cold War struggles that affected other Southeast Asian nations. At least, Burma was able to avoid to experience what had happened to Vietnam War and Korean War due to the plagued of the Cold War. (NATIONAL SECURITY) 
The Burmese Way to Socialism, by far, greatly increased poverty, isolation, and is described as "disastrous". In 1988. Various ethnic insurgencies seeking AUTONOMY (SELF-Direction) continued to fight the regime, but the military kept tight control of the political and ECONOMIC system. Just like the Philippines, the Bangsamoros they also want autonomy finally be given to them.

The Socialist coup led by $\mathrm{Ne}$ Win and the Revolutionary Council (RC) in 1962 was done under the pretext of economic, religious and political crises in the country, particularly the issue of federalism and the right of Burmese states from seceding from the Union.

Impacts of the Burmese Way to Socialism were multi-fold, affecting the economy, educational standards, and living standards of the Burmese people. Foreign aid organizations, like the Americanbased Ford Foundation and Asia Foundation, as well as the World Bank, were no longer allowed to operate in the country. (INDEPENDENCE from Imperialism). Only permitted was aid from a government-to-government basis. (STIMULATION AND DARING ECONOMIC LIFE).

The impact on the Burmese economy was extensive. The Enterprise Nationalization Law, passed by the Revolutionary Council in 1963, nationalized all major industries, including importexport trade, rice, banking, mining, teak and rubber on 1 June 1963. In total, around 15,000 private firms were nationalized. Furthermore, industrialists were prohibited from establishing new factories with private capital. This was particularly detrimental to Burmese Indians and the British, who were disproportionately represented in these industries. (SELF-DIRECTION, AUTONOMY, and INDEPENDENCE). The oil industry, which had previously been controlled by American and British companies such as the General Exploration Company and East Asiatic Burma Oil, were forced to end operations. In its place was the government-owned Burma Oil Company, which monopolized oil extraction and production. (POWER and PRESERVATION OF PUBLIC IMAGE) In August 1963, the nationalization of basic industries, including department stores, warehouses and wholesale shops, followed. Price control boards were also introduced.

Economy plays an important role among the ordinary people in Myanmar. It is the reason why people value hedonism, gratification for oneself, needs and pleasure, and appreciate life. Just like the story "Neighbours" by Moe Moe (Inya), 1972, proves Aye Aye has just realized that living in a close community could mean everyone gets intervening with each other's affairs.
HEDONISM, SELF-INDULGENT, and ENJOYING LIFE most of the times will make Southeast Asian countries feel more relaxed and less pressure. They will surely be able to avoid any sort of paranoia, stress, and pressure. In so doing, they will have harmonious life. Although, sometimes HEDONISM will make them also lazy and less achievers.

The main protagonist suffers a lot because of extreme poverty. She doesn't even have a house and a landline telephone of her own.

Food in Daily Life. (NATIONAL SECURITY) Rice is the staple food except among those in highland areas where rice is difficult to grow. In those areas, rice, millet, sorghum, and corn are the staples. Rice is accompanied by a raw salad of leaves, fruit, or vegetables; a soup; and curries of fish, meat, prawns, or eggs. In addition to turmeric and chili, curries are seasoned with fermented fish or shrimp paste. A variety of cultivated vegetables and wild greens are eaten as well as bamboo shoots. Meals often are accompanied by lentils, pickled relishes, and balachaung (made from fried dry prawns). There are a variety of rice-noodle dishes. After a meal, it is common to eat fresh fruit.

It is for the best interest of the ordinary people of Myanmar if they will have all the basic needs like food, housing, and health. The basic needs and services should be given to urban and rural places.

Burmese traditionally eat a morning meal and an evening meal that is taken before dark. (SAFETY AND STABILITY OF SOCIETY) The meals are served in a large platter or on a low table, with members of the household sitting on mats. Food is eaten with the fingers, although sometimes utensils are used. It is common to drink water and eat fruit after the main meal. Throughout the day people eat betel and smoke tobacco. Burmese not only drink tea made from dried tea leaves but also eat pickled tea as a snack. Other snacks include chappatis, fried insects, and Chinese pastries.

Tea shops are found in every city, town, and large village. These establishments are important locales for social gathering. Street stalls sell a variety of foods in the cities and towns. Relatively few restaurants serve Burmese food. (UNIVERSALISM and PROTECTION FOR THE WELFARE OF ALL PEOPLE) The majority serve Indian or Chinese food, and English food is served in many hotels and guest houses.

Food Customs at Ceremonial Occasions. Feasting and sharing food (UNIVERSALISM, EQUALITY, and PROTECTION FOR THE WELFARE OF ALL 
PEOPLE are an important feature of traditional agricultural and religious rites. Often special foods are prepared for those occasions. Htamane, which is served during the rice harvest festival February, is made of glutinous rice mixed with sesame seeds, peanuts, shredded ginger, and coconut. Alcoholic beverages are drunk during some secular festivities but are not drunk during most religious festivals. In urbanized areas, commercial beer and other forms of alcohol are consumed, while in more remote rural areas, locally made alcohol is more common. Alcoholic drinks are made from fermented palm juice and a distilled rice-based solution. Fermented grainbased alcoholic drinks are more commonly consumed among highland groups. (HEDONISM and GRATIFICATION FOR ONESELF)

Basic Economy. The economy is dominated by agriculture, which accounts for over 59 percent of the gross domestic product and employs about two-thirds of the labor force. Rice is the main product. Production declined after independence but increased during the late 1970s and early 1980s because of the introduction of high-yielding varieties, fertilizer, and irrigation. Since that time, production has barely kept pace with population growth, and Burma, once the world's leading exporter of rice, is barely able to meet subsistence needs of its own population. It continues to export some rice to earn foreign exchange. (ACHIEVEMENT AND INTELLIGENCE)

The production of narcotics from poppies and other sources is widespread in the northern highlands, and Burma is the world's leading supplier of opiates. (STIMULATION AND DARING LIFE) By 1987 Burma was ranked by the United Nations as one of the world's ten poorest nations, with an annual per capita income of $\$ 200$ and average life expectancy of 59. By the 1980s, as a result of the military keeping a tight control of the government and economy, ECONOMIC STAGNATION (CHALLENGE IN LIFE/DARING LIFE) and political repression had fostered.

The revolutionary government that seized power in 1962 nationalized the larger commercial and manufacturing establishments, including those of Indian traders. This created a large black market economy as people attempted to circumvent government control of commerce. The revolutionary government(UNIVERSALISM, EQUALITY, and SOCIAL JUSTICE) attempted to remove the landlord class and turned all land over to peasant producers while retaining ultimate ownership for itself. In practice, agricultural tenancy was not eliminated, and producers had the added burden of state intervention. After 1988, the government allowed a greater role for the private sector and foreign investment. While these reforms have allowed greater private ownership, considerable insecurity remains among those who own property. Commercial Activities. Since 1992, the military regimes have emphasized self-sufficiency and tried to limit imports. (UNIVERSALISM, EQUALITY, SOCIAL JUSTICE) The largest companies and financial institutions are state-owned, with the private sector limited mainly to small-scale trading. In recent years, however, more imported goods, especially from China, have appeared in local markets and there has been growth in the private sector. The main cities and many smaller towns have one or more central markets that sell a wide variety of domestic and imported goods, including clothing and cloth, tobacco, food, baskets, jewelry, toiletries, and electronic goods. There are also specialized markets, such as the iron bazaar in Rangoon's Chinatown.

Burma is the world's largest supplier of illegal opiates (opium and heroin), and the export of amphetamines has increased. Money from the illegal narcotics trade plays a crucial role in the national economy and in keeping the regime solvent. Much of the production of illegal narcotics, however, is in the hands of ethnic rebels in Shan State. Recent peace accords between the government and some rebel groups have given the regime access to income from narcotics. Opium grown in the eastern highlands became a major illegal export for both the government and the remaining ethnic armies. (HEDONISM, NEEDS AND PLEASURE, SELFINDULGENT)

Thailand and India are Burma's primary sources of legal and illegal imported goods. Small amounts are also imported from other neighboring countries such as India, Malaysia, and Singapore. (ACHIEVEMENT, PERFORMANCE)

COMPETENT

Division of Labor. There is little specialization in the agricultural sector. Small-scale commercial trading is done by both men and women, with men being primarily responsible for the transportation of goods. Ethnic Indians and Chinese are an important segment in commercial trading, but many Burmese and others are involved in commercial activities. Few tasks or professions are the monopoly of a single ethnic group. There are various forms of traditional craft specialization. This includes making lacquer ware, stone working, fine wood carving, and working with metal. Modern technical professions such as medicine and engineering are related to one's level of education and specialized training. (ACHIEVEMENT, OBTAINING SOCIAL APPROVAL, AMBITIOUS) Those in the higher levels of commerce and administration generally 
come from the families of prominent members of the regime, and connections with the regime are important factors in amassing wealth and power.

Classes and Castes. Not only is poverty widespread, there is marked inequality. (UNIVERSALISM, SOCIAL JUSTICE, EQUALITY) Essentially, the society is divided into a tiny elite, a fairly small middle class, and a large number of very poor people. While there are traditional elites within most of the ethnic groups and new elites in some groups whose wealth comes from smuggling, the national elite is overwhelmingly Burmese. In recent years income from the narcotics trade has been an important source of wealth for members of the elite. Although some segments of the middle class have prospered from the economic reforms of the late 1980s, most have not done well and remain poor.

Burma, a resource - rich country, suffers from pervasive government controls, inefficient economic policies, corruption, and rural poverty.(DEVOUT OF RELIGIOUS RITES/BELIEFS

General Ne Win dominated the government from $1962-1988$, first as military ruler, then as selfappointed President, and later as political kingpin. (POWER, PRESTIGE, CONTROL AND DOMINANCE OVER PEOPLE AND RESOURCES, AUTHORITY, WEALTH) In September 1988, the military deposed NE WIN and established a new ruling junta. Despite multiparty legislative elections in 1990 that resulted in the main opposition party - the National League for Democracy - winning a landslide victory, the junta refused to hand over power. The National League for Democracy Leader and Nobel Peace Prize recipient Aung San Suu Kyi, who was under house arrest from 1989-1995 and 2000 to 2002, was imprisoned in May 2003 and subsequently transferred to house arrest. She was finally released in November 2010

Burma, a resource - rich country suffers from pervasive government controls, inefficient economic policies, corruption, and rural poverty. The economy suffers from serious macroeconomic imbalances including unpredictable inflation, fiscal deficits, and multiple official exchange rates that overvalue the Burmese kyat, a distorted interest rate regime, unreliable statistics, and an inability to reconcile national accounts. (STABILITY OF SOCIETY SHOULD BE HANDLED CAREFULLY THROUGH DECISIVE LEADERSHIP STYLE.

Socialists believe economic inequality is bad for society and the government is responsible for reducing it via programs that benefit the poor. For example, free public education, free or subsidized healthcare, social security for the elderly, higher taxes on the rich. (NATIONAL SECURITY)
Most of the cultural values in Myanmar were influenced by their economy. It is the basis why people value benevolence, concern for family, honesty, and true friendship. Just like the protagonist Mother Nyo in the story "Mother's Merit" by Thu Maung. Mother Nyo is a devout Buddhist who does not pray long and loud every night. She does not attend sessions at meditation centres in order to reach a higher status of mind. She is also not the type to gather merit by giving Soon Kyway feasts for monks and guests on a monthly or even a bi-yearly basis. She in her own way lives her life with a charitable nature, a generous heart and a peaceful mind.

Truly, if only people in Southeast Asia will humble themselves and will learn to become benevolent and helpful, then, everybody will be able to go through the survival of the fittest.

The Burmese Way to Socialism refers to the ideology of the Socialist government in Burma, from 1962 to 1988 , when the 1962 coup d'etat was led by $\mathrm{Ne}$ Win and the military to remove $\mathrm{U} \mathrm{Nu}$ from power.(POWER, PRESTIGE) More specifically, the Burmese Way to Socialism is an economic treatise written in April 1962 by the Revolutionary Council, shortly after the coup, as a blueprint for economic development, reducing foreign influence in Burma, and increasing the role of the military.

The country's chief trade partners are Thailand, China, Singapore, and India. Myanmar's developing economy, depressed by political turmoil, began to recover in the 1980s with increased private activity and foreign investment, but efforts to liberalize the economy stalled in the late 1990s amid new political turmoil and did not resume until the 2010s.(NATIONAL SECURITY)

Amidst political turmoil and inefficient economic policies in the 1980s in Burma, Mother Nyo never reacts with aggression or bitterness to any suffering that she encounters. She faces whatever fate brings with serenity and would smooth things out with unruffled patience. The equanimity in the face of hardship is her way of meditation and her method of seeking a higher state of mind. (COMMITMENT TO CUSTOMS/TRADITIONS, CULTURE and RELIGION)

Although, she does not practice Buddhism religiously, she in her own way lives her life with a charitable nature, a generous heart and a peaceful mind like she loves to feed. A generous mother who loves to feed people, friends or acquaintances happen to pass by, she would almost drag them into the house. "Hey, come in and have a taste of what I cooked today," is something that you will hear from her all the time.(COMMITMENT TO CUSTOMS/TRADITIONS, CULTURE and RELIGION)

$\underline{\text { Philippines }}$

Economy plays a big role among the people in the Philippines. It is the root why people value 
stimulation, excitement, challenge in life, need for variety and stimulation, a varied life, and a daring life. Inspite of the difficulties in life, Filipinos find those hardships as challenges in life. Just like the protagonist Victor in the story "Children of the City" by Amadis Ma. Guerrero. Perhaps, it has always been due to leadership style apparently that Filipinos don't reach the cultural goal of WEALTH and POWER. Those people in power unfortunately enrich themselves at the expense of others.

STIMULATION AND CHALLENGE IN LIFE need to be taken cared by those people in POWER like basic services, quality education, scholarships, infrastructures, decent free hospitalization, roads/bridges, MRTs and so on. The street children suffer from drugs, prostitution, illiteracy, because nobody from the government sector cares for them.

In Manila a tiny minority lived in palatial homes surrounded by high walls topped with bits of broken glass and barbed wire, with the gates manned by armed guards, They worked in air-conditioned highrise office buildings. (POWER, SOCIAL STATUS, PRESTIGE)

But the vast majority of the people lived in improvised housing in slums, building shacks out of bits of bamboo, cardboard, corrugated metal, and a few cement blocks. The countryside remained impoverished. (STIMULATION and CHALLENGE IN LIFE)

Individual Filipinos also benefited from military and civilian pension disbursements from the United States. The Philippine demand for rent for the military bases escalated from the 1970s onward and resulted in AID promises that rose from $\$ 50$ million a yesr in 1979 to nearly ten times that a decade later. (NATIONAL SECURITY)

Impoverished and without the capacity to reconstruct itself after WWII, the Philippines had to accept US aid-financial help with a lot of strings attached.

The green revolution - actually a complex package of new high-yielding variety seeds, irrigation, fertilizers, and pesticides - was the bestknown example of technological innovation in postwar Southeast Asian agriculture. It was developed in the mid 1960s at IRRI and soon communinicated to the rest of the region; within a decade traditional rice - deficit countries such as Indonesia and the Philippines became self-sufficient. Remittances from Filipinos overseas became by the early 1980s the Philippines' largest single source of foreign exchange. (PROTECTION FOR NATURE/ENVIRONMENT)

To find work, and escape poverty, many Filipinos migrated to become domestic worker, factory worker, and do entertainment jobs. (ACHIEVEMENT AND PERSONAL SUCCESS)

Singapore
Economy plays a big role among the people in Singapore. It is the root why people value power, social status, prestige, control and dominance over people and resources, authority, wealth, social power, preservation of public image, social recognition. Just like the protagonist Karen and Sai Khong in the story "Monster" by Catherine Lim.

Singapore mixed economic policies with an autocratic leadership. The country has been like a giant corporation. People pay fine if caught spitting, littering, or even tossing used chewing gum on the street. (CONFORMITY AND DISCIPLINE)

Singapore is highly educated, enterprising population, with policies favoring economic growth and foreign investment. Singapore is a hub of high technology as well as headquarters for many corporations. (ACHIEVEMENT AND COMPETENT PERFORMANCE)

Redistribution policies, inevitably involved increasing the size of the state apparatus and were in practice difficult to combine with openness to foreign trade and investment. Singapore, that was first to establish export-oriented light industries, especially in the 1960s, became known as the newly industrializing countries. The manufacture of textiles, garments, toys, electrical goods and electronic components and the processing of primary products(Tarling, 1999). (POWER, AUTHORITY, WEALTH)

Everyone studied English in school. Picturesque but congested Chinese commercial districts, high rise apartment blocks, shopping complexes, food courts, professional buildings, luxury hotels, and multistory parking garages. (POWER, SOCIAL STATUS, PRESTIGE, WEALTH)

Thailand

Economy plays a big role among the people in Thailand. It is the root why people value family security, safety, harmony, stability of society, national security, social order, reciprocation of favors, and sense of belonging. Just like the protagonist, the Grandmother in the story of $\mathrm{K}$. Surangkhanang.

From the 1970s until the late 1990s, Thailand enjoyed high rates of economic growth. The large Chinese minority still controls much of the POWER AND WEALTH and the top of the economy is mostly dominated by men of Chinese ancestry. Foreign investment played an important economic role in Thailand, the export of commodities such as rice, rubber, tin, and timber remained significant. (ACHIEVEMENT, OBTAINING SOCIAL APPROVAL, SOCIAL RECOGNITION, AND AMBITIOUS.

The Thai government under Sarit Thanarat switched in the 1960s to infrastructural investment on behalf of private import - substitution industry and agriculture. Industry, primaryly Sino - Thai in ownership, did in fact grow rapidly; but the sustained 
growth of the economy as a whole - averaging over $3 \%$ per capita in the $1950 \mathrm{~s}, 5 \%$ in the $1960 \mathrm{~s}$ - was possible only because agriculture, from which most of the population still earned their living, also grew steadily, SUPERB ACHIEVEMENT. Some of this expansion was in traditional crops such as rice and rubber. By 1968, the export value of other crops passed that of rice for the first time in modern Thai history, having quadrupled in value over the previous fifteen years. Thailand also benefited from substantial American aid throughout the 1950s and 1960s. (NATIONAL SECURITY AND STABILITY OF SOCIETY)

The 1970s brought political instability, the oil crisis and the end of most American aid, as well as signs that import substitution was reaching its ceiling. To the surprise of most experts, the Thai economy kept growing, with GNP per capita increasing at an average annual rate of $4 \%$ throughout 1970s and 1980s. Such new exports as textiles, computer components, prawns, and precious stones joined greatly increased tourism to diversify the economy and cushion it against commodity downturns. Thailand also benefited from a population planning programme that slowed demographic increase substantially in the 1970s and 1980s. By the end of the latter decade, per capita income had reached $\$ 1000$, passing the faltering Philippines. (ACHIEVEMENT, COMPETENT PERFORMANCE, OBTAINING SOCIAL APPROVAL) During the entire postwar period, Thailand was second in the region only to Singapore in average rate of growth (Tarling, 1999).

Thailand suffered from environmental problems. Bangkok became one of the most polluted cities in Asia. The Thais have to save the forest from commercial logging in Thailand. (UNIVERSALISM, PROTECTION FOR NATURE/ENVIRONMENT, WORLD OF PEACE)

\section{Vietnam}

Economy

Economy plays a big role among the people in Vietnam. It is the root why people value selfdirection and independence. Just like the protagonist Ms. Phan in the story "An Unsound Sleep" by Nhat Tien, they have the habit of picking up the pieces after the Vietnam War. They tried their best to rehabilitate their war-torn country.

Vietnam's economy had been mostly agrarian, subsistence-based and village-oriented. French colonizers, however, deliberately developed the regions differently as the French needed raw materials and a market for French manufactured goods, designating the South for agricultural production as it was better suited for agriculture, and the North for manufacturing as it was naturally
WEALTHY in mineral resources. (STABILITY OF SOCIETY, NATIONAL SECURITY)

When the North and South were divided politically in 1954, they also adopted different economic ideologies: communism in the North and capitalism in the South(SELF-DIRECTION AND INDEPENDENCE). Destruction caused by the Second Indochina War from 1954 to 1975 seriously strained the economy. The situation was worsened by the country's 1.5 million military and civilian deaths, and the subsequent exodus of 1 million refugees, including tens of thousands of professionals, intellectuals, technicians and skilled workers (CULTURAL VALUES WERE NATIONAL SECURITY AND STABILITY OF SOCIETY). Since reunification in 1975, the economy of Vietnam has been plagued by enormous difficulties in production, imbalances in supply and demand, inefficiencies in distribution and circulation, soaring inflation rates, and rising debt problems.

Vietnam is one of the few countries in modern history to experience a sharp economic deterioration in a postwar reconstruction period. Its peacetime economy is one of the poorest in the world and has shown a negative to very slow growth in total national output as well as in agricultural and industrial production. Vietnam's gross domestic product ( GDP) in 1984 was valued at US\$18.1 billion with a per capita income estimated to be between US\$200 and US\$300 per year. (SELFDIRECTION, PRIVACY, INDEPENDENCE)

Reasons for this mediocre economic performance have included severe climatic conditions that afflicted agricultural crops,(THEY NEEDED PROTECTION FOR NATURE/ENVIRONMENT) bureaucratic mismanagement, elimination of private ownership, extinction of entrepreneurial classes in the South, and military occupation of Cambodia (which resulted in a cutoff of much-needed international aid for reconstruction). (STIMULATION, EXCITEMENT, AND CHALLENGE IN LIFE)

Throughout the 1990s, exports increased significantly, growing by as much as $20 \%$ to $30 \%$ in some years. In 1999, exports accounted for $40 \%$ of GDP, an impressive performance in the midst of the economic crisis which hit other countries in Asia. Vietnam became a member of the World Trade Organization (WTO) in 2007, which freed Vietnam from textile quotas enacted worldwide as part of the Multi Fibre Arrangement (MFA) in 1974. (NATIONAL SECURITY, STABILITY OF SOCIETY, HARMONY)

In 1986, Vietnam launched a political and economic renewal campaign (Đổi Mói i) that introduced reforms to facilitate the transition from a centralized economy to a "socialist-oriented market 
economy". (STIMULATION, AND CHALLENGE IN LIFE)

By the late 1990s, the success of the business and agricultural reforms ushered in under Đổi Mói was evident. More than 30,000 private businesses had been created, the economy was growing at an annual rate of more than $7 \%$, and poverty was nearly halved. (SELF - DIRECTION, INDEPENDENCE)

Politics

Indonesia

Politics plays a crucial role among the people in Indonesia. It is the essential core among the people in Indonesia. It is the heart why people value benevolence, concern for family, helpful, forgiving, and loyalty. Just like the children of "Sri Sumarah" an Indonesian masterpiece of Umar Kayam, they have decided to have an extra-ordinary kind of idealistic political ideology

Turmoil has been no stranger to modern Indonesia, and twice since the republic's declaration of INDEPENDENCE AND SELF-DIRECTION in 1945 the nation has been shaken - - and, for better or worse, irreversibly shaped - - by upheavals of genuinely awesome force. The first of these occurred in late 1948 and centered on a sharp internal struggle for POWER AND AUTHORITY, played out against the backdrop of an extended war for INDEPENDENCE AND SELF-DIRECTION from Dutch rule. Generally referred to as the Madiun Affair, this uprising by Communist forces against the established government headed by Sukarno and Hatta was in fact a much broader phenomenon than that term implies. Fighting took place throughout an extended area in Central and East Java, penetrating to the village level; tens of thousands lost their lives, destruction was widespread, and the political and social scars burned for long afterward. The second upheaval, far more devastating and encompassing the entire archipelago, took place in late 1965. This conflict pitted communists against a Military-Moslem Alliance in an extraordinarily bloody contest for AUTHORITY, POWER, AND PRESERVATION OF PUBLIC IMAGE in state and society. The carnage resulting from this continued polarization was terrifying: perhaps 750,000 persons killed and roughly as many arrested and imprisoned for periods ranging up to fifteen years. (Frederick, W. H. 1983).

This short story challenges a variety of beliefs, communist and non-communist alike, about the meaning of the rebellions of 1948 and 1965, and about Indonesian society and UNIVERSALISM, EQUALITY AND SOCIAL JUSTICE values . Traditional Javanese culture; a physical and ideological distance from the upheaval of 1965.

Politics plays a big role among the people in Indonesia. It is the root why people value achievement. Just like the protagonist Tatang in the story "The Soldier" by Nugroho Notosusanto, the cultural values that represent here are achievement, control and dominance over people and resources and preservation of public image. The Indonesian soldiers give their lives to their country to claim peace. They place service to the people before anything else. Those soldiers put duty first before family.

On the $14^{\text {th }}$ of February 1942, the Japanese attacked and quickly overran South Sumatra. Early on the first of March they landed on Java and within eight days ended three hundred and fifty years of Dutch sovereignty. The three - and -a-half year Japanese occupation of Indonesia destroyed a whole set of illusions and falsehoods and left man as naked as when he was created and walked in the garden of Eden. On the $17^{\text {th }}$ of August 1945, the Republic of Indonesia was proclaimed by Sukarno and Hatta.(SELF-DIRECTION, AUTONOMY \& INDEPENDENCE)

Since then the naked Adam has undergone severe tribulations: four further years of fighting until the Dutch recognized the Republic's INDEPENDENCE, continuous economic difficulties and until recently, galloping inflation, various regional attempts at secession (particularly the attempt to set up a Muslim state in West Java led by the Daru"l - Islam movement in the early fifties and the attempted break-away movements in Sumatra and the Celebes towards the end of the decade), the period of Guided Democracy after 1959, and the so - called "abortive communist coup"(STIMULATION \& CHALLENGE IN LIFE ) of September 30, 1965 which led to the murder of perhaps a million "communists"(CLAMORING FOR EQUALITY AND UNIVERSALISM) and the imprisonment of at least 75,000 individuals.

On the other hand, with their concern with war, men without women, obscure codes of honor, and their succinct, ironic style, suggest Hemingway. The armoured vehicle in "The Soldier" is a symbol of the armour - plated role-playing of the chief protagonist, whose world of action, warmth, light and masculinity is skillfully contrasted with the cold, dark, sick world of his wife. This is indeed dedicated to "The soldiers of the Indonesian Army who remain LOYAL, WITH CONFORMITY AND OBEDIENCE TO SOCIAL NORMS to their vocation (dharma)"

In some instances, social conditions are so overwhelming in their influence on cognition and emotion that the writings of the creative artist can only be understood or appreciated fully by recourse to the social conditions prevailing at the time. It was a time of complete breakdown in law and order, and TRADITIONAL SOCIAL NORMS failed to regulate behavior. Hunger and shortage, disruption and chaos, danger to life and property, disease and suffering(DETRIMENTAL TO NATIONAL SECURITY AND STABILITY OF SOCIETY), all affected the outlook of writers. 

Study

The struggle for independence following the cessation of Japanese rule also influenced the writers' cognition and sense of values. The war of INDEPENDENCE, first against allied forces (British and Dutch) and then against Dutch forces, had pitched friend against friend, family against family, and district against district. The war convulsed all sense of decency and humanity. (Tham Seong Chee, 1981).

In April 1930 the South Seas Communist Party was dissolved and was replaced by the Communist Party of Malaya. While its primary responsibility was Malaya and Singapore, the party was also active in Thailand and the Dutch East Indies, which did not then have their own Communist parties.(UNIVERSALISM, SOCIAL JUSTICE, EQUALITY) Green rice-fields spread out in the valleys below. It was very hot in West Java

Politics plays a big role among the people in Indonesia. It is the root why people value power. Just like the protagonist Ajo Sidi in the story "The Decline and Fall of Our Local Mosque" (1956) by A.A. Navis. This story depicts the cultural values of power, control and dominance over people and resources, and social power. Deals with yet a different world, the world of the rural village and the values of Islam. Navis is satirical, impious in the name of the greater piety, and has a thoroughly modern concern: that religion be rationalized, cleansed of superstition and egotism, and that it explains the present world as well as the next.

Allah gave Indonesia a rich country. But they were lazy. They preferred contemplation. They were told to work and pray. They only prayed. They did nothing but praise Allah and glorify His holy name. They must go back to hell ! Angels - put them back in the lowest pits.

They did wrong in spending too much time on the cultivation of their soul. They prayed because they were afraid of going to hell, but they forgot their fellow Moslems and their families. They were put in the world to live as part of a community, but many of them were too selfish.

Islam, to which ninety percent of the population adheres, generates double standards which underpin universal patriarchal principles. It allows men to be polygamous but demands monogamy and premarital virginity from women. According to Islamic law men can repudiate their wives, but for women it is much more difficult to seek a divorce.(ADHERENCE TO TRADITION, CUSTOMS, CULTURE \& RELIGION Children born out of wedlock and their mothers are condemned, whereas the fathers of such children are not. The religious - based distinction between illegitimate and legitimate children is expressed in the usage of the Arabic adjectives haram (illegitimate) and sah (legitimate) in the Indonesian language. Indonesian men are socially privileged under the Islamic order.(DEVOUT OF RELIGIOUS RITES/BELIEFS) Christianity, on the other hand, does not condone polygamy. However, it imposes the same sexual requirements on women as does Islam. In most Christian societies, women are penalized more severely for adultery than men.(CONFORMITY AND SELF-DISCIPLINE) Some Christian creeds prohibit women from having abortions and from using contraceptives, thus denying them authority over their bodies. (Hellwig,T.1994).

Malaysia

Politics plays a big role among the people in Malaysia. It is the root why people value tradition. Just like the protagonist Cik Yam in the story "Mariah" by Che Husna Azhari.

In 1957 the Malayan Federation became INDEPENDENT, AUTONOMY \& CREATIVE under a government headed by UMNO and its aristocratic leader Tengku Abdul Rahman. Predominantly Chinese, Singapore remained outside the federation as a British colony. The Malayan arrangement favored the Malays politically, since they had the majority, but Chinese were granted liberal citizenship rights and maintained strong economic power. Many Malayans were hopeful that this arrangement would work. As a character in Malay writer Ibrahim Omar's story "Isolated Village" comments, "Now is no longer the time of our ancestors. Now is not the time of the white people. Now we rule ourselves. And we must help each other help ourselves.

British leaders suggested the idea of a Malaysia federation as a way of ending their now burdensome colonial rule over Singapore, Sarawak, and Sabah, even though the various states were historically and ethnically distinct from Malaya. The Malaysian federation, linking Malaya, Singapore, Sabah, and Sarawak, was formed in 1963 essentially as a marriage of convenience. In the years that followed, Malaysia struggled to create national unity out of deep regional and ethnic divisions. The new, hurriedly formed Malaysian nation faced many political problems, including some disenchantment in Sabah and Sarawak over Malayan domination. Singapore left the federation in 1965 , becoming an independent state.

Parliamentary government was restored in 1970. But the crisis, intensified concerns that freedom of speech and press might spark ethnic tensions, prompting the government to ban public discussion of "sensitive issues" such as ethnic relations. After 1970 governments pursued policies designed to reshape Malaysia's society and economy within a modified democratic system.

By the mid-1970s, only Malaysia and Singapore had at least partial democracies. Vietnam, Cambodia, and Laos all had authoritarian communist governments. Indonesia and Burma had been under 
military rule since the 1960 s and, after a brief period of democracy, Thailand was again governed by generals. A dictator also governed in the Philippines. And few of the countries showed much economic dynamism, but seeds of change had been planted. Migrants crowding into cities came into contact with people from different backgrounds, generating some cultural mixing. Expanding educational systems helped foster larger middle classes seeking more influence. INDUSTRIALIZATION AND WEALTH created new kinds of jobs. Nations were slowly being built, in the form of institutions and in people's minds (Lockard 2009).

\section{$\underline{\text { Myanmar }}$}

Politics plays a big role among the people in Myanmar. It is the root why people value achievement. Just like the protagonist Ma Chit Hpo in the story "This Realm of Humans" by Khin Hnin $\mathrm{Yu}$ they have the habit of wanting to achieve a lot of things.

In the elections of 1951-52 the AFPFL triumphed. In 1958 the AFPFL split into two factions; with a breakdown of order threatening, Premier U Nu invited General Ne Win, head of the army, to take over the government (Oct., 1958). After the 1960 elections, which were won by U Nu's faction, civilian government was restored. However, as rebellions among the minorities flared and opposition to U Nu's plan to make Buddhism the state religion mounted, (DEVOUT OF RELIGIOUS RITES/BELIEFS), conditions deteriorated rapidly.

In 1962, Ne Win staged a military coup, (ANOTHER STIMULATION AND DARING LIFE OF THE PEOPLE OF MYANMAR) discarded the constitution, and established a Revolutionary Council, made up of military leaders who ruled by decree. While the federal structure was retained, a hierarchy of workers' and peasants' councils was created. A new party, the Myanmar Socialist Program party, was made the only legal political organization. The Revolutionary Council fully nationalized the industrial and commercial sectors of the economy and imposed a policy of international isolation. (SELF-DIRECTION,

INDEPENDENCE, INTELLIGENT)

Insurgency became a major problem of the $\mathrm{Ne}$ Win regime. Pro-Chinese Communist rebels-the "White Flag" Communists-were active in the northern part of the country, where, from 1967 on, they received aid from Communist China; the Chinese established links with the Shan and Kachin insurgents as well. The deposed $\mathrm{U} \mathrm{Nu}$, who managed to leave Myanmar in 1969, also used minority rebels to organize an anti-Ne Win movement among the Shans, Karens, and others in the east. However, in
1972, U Nu split with minority leaders over their assertion of the right to secede from Myanmar. (UNIVERSALISM, EQUALITY, SOCIAL JUSTICE, WORLD OF PEACE)

By the early 1970s the various insurgent groups controlled about one third of Myanmar. Ne Win and other top leaders resigned from the military in 1972 but continued to retain POWER, PRESTIGE AND AUTHORITY. A new constitution, providing for a unicameral legislature and one legal political party, took effect in Mar., 1974. At that time the Revolutionary Council was disbanded and Ne Win was installed as president. Economic strife and ethnic tensions throughout the $1970 \mathrm{~s}$ and $80 \mathrm{~s}$ led to antigovernment riots in 1988, which caused Ne Win to resign from office. The series of governments that followed failed to restore order (NATIONAL SECURITY, SOCIAL ORDER, AND STABILITY OF SOCIETY) and the military seized control under the name of the State Law and Order Restoration Council (SLORC); some 3,000 were killed when the demonstrations were suppressed. In June, 1989, the military government officially changed the name of the country from Burma to Myanmar.

In elections held in May, 1990, the National League for Democracy (NLD) won a large majority of assembly seats. However, the SLORC declared the election results invalid and arrested many leaders and members of the NLD. Aung San Suu Kyi, the leader of the NLD, had been placed under house arrest in 1989; (STIMULATION AND CHALLENGE IN HER LIFE) she was awarded the Nobel Peace Prize in 1991. In 1992, General Than Shwebecame head of the junta and assumed the position of prime minister; many political prisoners were released,(BENEVOLENCE AND FORGIVING) most martial law decrees were lifted, and plans to draft a new constitution were announced. However, there was little evidence that the army was prepared to return the government to civilian control. A UN General Assembly committee unanimously condemned the military regime for its refusal to surrender POWER, CONTROL AND DOMINANCE OVER PEOPLE AND RESOURCES, AUTHORITY to a democratically elected parliament.

Politics

Philippines

Politics plays a big role among the people in the Philippines. It is the root why people value family security and sense of belonging. Just like the protagonist Ms Rosete in the story "Clay" by Juan T. Gatbonton, they have the habit of teaching the students very well in the 1950 s to secure national security.

Quirino's Liberal government was widely seen as corrupt, and was easily beaten by his former Defense secretary Ramon Magsaysay in the 1953 election. 
Magsaysay, who oversaw the surrender of the longrunning Hukbalahap rebellion would not complete his term, dying in a plane crash in Cebu; Vice President Carlos P. Garcia succeeded him, won the 1957 election, and implemented a "Filipino First" policy(STABILITY OF SOCIETY, NATIONAL SECURITY AND RECPROCATION OF FAVORS) and an austerity program. Garcia was defeated by his Vice President, Diosdado Macapagal of the Liberal Party, in 1961. Macapagal initiated a return to a system of free enterprise not seen since the Quirino administration. However, Macapagal's policies faced a stiff opposition in Congress, where the Nacionalistas hold the majority. Macapagal was defeated in 1965 by Senator Ferdinand Marcos.

Marcos' infrastructure projects was the feature policy of his term, he was the first president to be reelected, in 1969, although the election was tainted by violence and allegations that Marcos used the treasury to fund his campaign. However, significant protests, such as the First Quarter Storm,(UNIVERSALISM, SOCIAL JUSTICE, WORLD OF PEACE) the communist and Moro insurgencies, and civil unrest, heightened. This made Marcos in 1972 to declare martial law (SECURITY, HARMONY, AND SOCIAL ORDER) and suspend the constitution. A new constitution calling for a semi-presidential government was approved in 1973, but Marcos still ruled by decree until 1978, when the Interim Batasang Pambansa was elected. However, opposition groups, whose leaders mostly had already left in exile, boycotted the election, and Marcos still allowed martial law to continue. Marcos did end martial law in 1981, but opposition groups still boycotted the 1981 presidential election, which Marcos easily won. In 1981, the Marcoses had still benefitted in the so-called SOCIAL POWER, CONTROL AND DOMINANCE OVER PEOPLE AND RESOURCES.

\section{$\underline{\text { Singapore }}$}

Politics plays a big role among the people in Singapore. It is the origin why people value self direction and independence. Just like the protagonist Salmah in the story "Bugis" by Alfian Sa'at. Salmah did not want to wear her tudung just to follow the social norms of the society. Basically, the youth of Singapore values independence. Singapore became part of Malaysia on 16 September 1963, Malaysia being a new political entity formed from the merger of the Federation of Malaya with North Borneo, Sarawak and Singapore. This marked the end of a 144-year period of British rule in Singapore, beginning with the founding of modern Singapore by Sir Stamford Raffles in 1819. (INDEPENDENCE, SELF-DIRECTION, AND AUTONOMY)
The union, however, was unstable due to distrust and ideological differences between leaders of the State of Singapore and the Federal Government of Malaysia. Such issues resulted in frequent disagreements relating to economics, finance and politics. The United Malays National Organisation (UMNO), which was the political party in power in the Federal Government, saw the participation of the Singapore-based People's Action Party (PAP) in the Malaysian general election of 1964 as a threat to its Malay-based political system. There were also major racial riots that year involving the majority Chinese community and the Malay community in Singapore. During a 1965 Singaporean by-election, UMNO threw its support behind the opposition Barisan Sosialis candidate. In 1965, Malaysian Prime Minister Tunku Abdul Rahman decided upon the expulsion of Singapore from the Federation, leading to the INDEPENDENCE, AUTONOMY, AND SELF-DIRECTION of Singapore on 9 August 1965.

\section{Thailand}

Politics plays a big role among the people in Thailand. It is the basis why people value stimulation and challenge in life. Just like the protagonist amiable Bangkok student in the story "Michigan Test" by Wanit Jarungkit, Bangkok's new middle class, which, partly because of growing economic and political uncertainty in Siam, and partly because of the semi colonial relationship with the US cemented in the 1960s, was the main contributor to the massive Thai migration to Southern California in the 1970s. (FAMILY SECURITY, STABILITY OF SOCIETY, AND RECIPROCATION OF FAVORS)

Under Pibul's military dictatorship, the name Thailand was again adopted. Bhumibol Adulyadej, Rama IX, was crowned king in 1950 after a four-year regency.People of Thailand practice CONFORMITY, LOYALTY, OBEDIENCE, AND HONOR TO THE ROYAL KING. Thailand signed (1950) a technical and economic aid agreement with the United States and sent troops in support of the United Nations action in Korea. (TRUE FRIENDSHIP WITH BENEVOLENT USA). Thailand has received huge military grants from the United States and was the seat (1954-77) of the Southeast Asia Treaty Organization. The country, apprehensive over its proximity to China, remained consistently proWestern in international outlook.

In 1957 a military coup led by Field Marshal Sarit Thanarat overthrew Pibul Songgram and made Gen. Thanom Kittikachorn premier. In 1958, however, with the stated purpose of combating Communism, Sarit deposed his own premier, suspended the constitution, and declared martial law. King 
Bhumibol Adulyadej proclaimed an interim constitution in 1959 and named Sarit premier. (AUTHORITY AND POWER). When Sarit died in 1963, Thanom Kittikachorn was returned to power. A new constitution was finally promulgated in 1968. Under Sarit and Thanom the country's economy in the 1960s continued to boom, spurred by a favorable export market and considerable U.S. aid. (CULTURAL VALUES ARE ACHIEVEMENT AND SOCIAL APPROVAL). Thailand strongly supported the U.S. policy in South Vietnam, providing bases for U.S. troops and airfields for strikes against the North Vietnamese; thousands of Thai troops were sent in support of South Vietnam. The nation's foreign policy was closely geared to the U.S. presence in Southeast Asia and its economy became increasingly dependent upon U.S. military spending and subsidies. (HEDONISM AND ENJOYING LIFE) Thailand became one of the founding members of the Association of Southeast Asian Nations (ASEAN) in 1967.

Economic reversals came in 1970 when the international demand for rice dropped substantially (due in part to improved farming techniques in other countries) and the prices of tin and rubber fell; for the first time since 1933, Thailand suffered a trade deficit. In addition, the security of the country appeared threatened by the spread of the Vietnam War into Cambodia and Laos and by growing insurgencies, chiefly Communist led, in three separate areas within Thailand itself: in the south, where Malaysian Communists used Thailand as a staging base for operations in Malaysia and Thai Malay separatists mounted an insurgency that continued into the 1980s; in the north, where Communists trained in North Vietnam were believed to be organizing the hill peoples; and, most significantly, in the economically backward northeastern provinces,(SOCIAL JUSTICE, EQUALITY, AND UNIVERSALISM WERE THE CULTURAL VALUES) where a discontented minority had been active since the mid-1950s.

The increasing economic and security problems prompted a coup in Nov., 1971, by Premier Thanom Kittikachorn and three military aides, in which they abolished the constitution and the parliament and imposed military rule. (SOCIAL POWER, AUTHORITY, AND SOCIAL RECOGNITION) Guerrilla raids against both Thai government forces and U.S. air bases continued. Economic conditions improved (NATIONAL SECURITY) throughout 1972 as large numbers of U.S. military personnel were transferred from South Vietnam to bases in Thailand; by June of that year there were more U.S. forces in Thailand than in South Vietnam.
In Oct., 1973, the military regime of Thanom was toppled after a week of student demonstrations and violence in Bangkok. King Bhumibol Adulyadej appointed Sanya Thammasak as Thanom's successor, giving Thailand its first civilian premier (POWER AND AUTHORITY) in twenty years. The new premier promised to complete a constitution and to hold general elections. In May, 1974, citing the heavy burden of the office and the sharp criticism directed against the government, Sanya resigned, but he was soon persuaded to form a new government. In June he was sworn in as the head of a revamped, allcivilian cabinet. A new constitution was promulgated in Oct., 1974. Over the next few years the civilian government made little headway in establishing its AUTHORITY AND SOCIAL POWER. In 1976, the military took control of the government once again. After that, the military held POWER, AUTHORITY, SOCIAL STATUS, DOMINANCE OVER PEOPLE AND RESOURCES AND PRESERVATION OF PUBLIC IMAGE almost continuously until the early 1990s.

From the late 1970s, Thailand's political concerns were dominated by pressures resulting from warfare in Vietnam, Laos, and Cambodia and serious unrest in Myanmar (Burma); Thailand also experienced a massive influx of refugees from these countries. From 1975 onward, Thailand was a way station for Hmong refugees immigrating to the United States under its resettlement program. The Khmer Rouge used Thailand as a staging area after they were driven out of Cambodia by the Vietnamese, and internal fighting within the Cambodian government in 1997 sent a new flow of refugees into Thailand ( A SORT OF THREAT TO THE NATIONAL SECURITY AND STABILITY OF SOCIETY OF THAILAND)

\section{$\underline{\text { Vietnam }}$}

Politics plays a big role among the people in Vietnam. It is the basis why people value selfdirection and independence. Just like the protagonist Ms. Phan in the story "An Unsound Sleep" by Nhat Tien, she has earned her living as a greengrocer at the city market. Ms. Phan is eventually the wife of Su, both of them are Buddhist demonstrators in May 1963. Vietnam is a socialist republic with a oneparty system led by the Communist Party of Vietnam (CPV). The CPV espouses Marxism-Leninism and Hồ Chí Minh Thought, the thoughts of the late Hồ Chí Minh. The two ideologies function as a firm ideological basis and serve as guidance for the activities of the Party and state. According to the Constitution, Vietnam is "in the period of transition to socialism". Marxism-Leninism was introduced to 
Vietnam in the 1920s and 1930s, and Vietnamese culture has been led under the banner of PATRIOTISM, NATIONALISM, AND EQUALITY and MarxismLeninism. Hồ Chí Minh's beliefs were not systematised during his life, nor quickly following his death. Trường Chinh's biography of "Chairman Hồ" in 1973 emphasised his revolutionary policies. The thoughts of Hồ Chí Minh were systematised in 1989, under the leadership of Nguyễn Văn Linh. Hồ Chí Minh Thought, alongside Marxism-Leninism, became the official ideology of the CPV and the state in 1991. (AUTHORITY AND PRESERVATION OF PUBLIC IMAGE) The CPV's claim to legitimacy was retained following the collapse of communism in 1989 and the dissolution of the Soviet Union in 1991 by its commitment to the thoughts of Hồ Chí Minh, according to Sophie Quinn-Judge.

According to Pierre Brocheux, the author of $\mathrm{Ho}$ Chi Minh: a Biography, the current state ideology is Hồ Chí Minh Thought, with Marxism-Leninism playing a secondary role. While some claim that Hồ Chí Minh Thought is used as a veil for the Party leadership since they, according to this version, have stopped believing in communism, however this is false when considering that Hồ Chí Minh was an avid supporter of Vladimir Lenin and the dictatorship of the proletariat. (EQUALITY AND PROTECTION FOR THE WELFARE OF THE PROLETARIAT) Others see Hồ Chí Minh Thought as a political umbrella term whose main function is to smuggle in non-socialist ideas and policies without challenging socialist legality.

Since its foundation, the key ideology has been Marxism-Leninism, but since the introduction of a mixed economy in the late 1980s and 1990s, it has lost its monopolistic ideological and moral legitimacy. Marxism-Leninism, which is a classbased ideology, lost its legitimacy because of the mixed economy. As became clear because of the Đổi Mới reforms, the Party could not base its rule on defending only the workers and the peasants, which was officially referred to as the "WORKING CLASS- PEASANT ALLIANCE ". In the constitution introduced in 1992, the State represented the "workers, peasants and intellectuals" (EQUALITY, SOCIAL JUSTICE, AND WORLD OF PEACE ARE THE MOST CULTURAL VALUES)

Education

Indonesia

Education plays a big role among the people in Indonesia. It is the origin why people value conformity and honoring parents and elders. Just like the protagonist Ratna in the story "Meant for Each Other" by Abdul Muis. They have the habit of obeying the words of wisdom of their parents whatever the odds are. According to Law No. 2 1989 on the National System, the objective of the national education system was :

To establish a high-quality and self -reliant human being whose values are based on PANCASILA (i.e. State Ideology, spelled out in the 5 BASIC PRINCIPLES of the Republic of Indonesia: belief in One God (DEVOUT OF RELIGIOUS RITES) ; just and civilized humanity, including tolerance to all people (UNIVERSALISM); unity of Indonesia;(STABILITY OF SOCIETY) democracy led by wisdom of deliberation among representatives of the people; and social justice for all.

THE PRINCIPLES OF EDUCATION PROVISION ARE THE following:

Education is conducted democratically, equally and non-discriminatory based on human rights, religious values, cultural values, and national pluralism

Education is conducted as a systemic unit with an open system and multi-meanings

Education is conducted as a lifelong process of inculcating cultural values and for the empowerment of learners

Education is conducted based on the principles of modeling, motivation and creativity in the process of learning

Education is conducted by developing culture for reading and writing and arithmetic, for all members of the community

Education is conducted by empowering all components of the community through their participation in the implementation and quality control of the education services.

About 700 languages are spoken in Indonesia, of which EIGHT are considered the major ones (JAVANESE, SUNDANESE, MADURESE, BATAK, MINANG, BALINESE, BUGIS, and BANJAR ). Local languages are mainly used at the oral level.

THE NATIONAL EDUCATION SYSTEM CONSISTS OF SEVEN TYPES OF EDUCATION :

1) GENERAL EDUCATION - focuses on the expansion of general knowledge and improvement of student skills

2) VOCATIONAL EDUCATION prepares students for mastering a number of specific vocational skills needed for employment

3) SPECIAL EDUCATION -provides important skills and abilities for students with physical and/or mental diabilities

4) IN-SERVICE EDUCATION aims at increasing abilities required for job preparation as an official or a candidate for a government or a non-departmental government agency

5) RELIGIOUS EDUCATION prepares students to play a role which demands the mastery of religious knowledge and related subjects 
6) ACADEMIC EDUCATION - focuses primarily on improving the mastery of SCIENCES

7) PROFESSIONAL EDUCATION -prepares students primarily for specialized or JOB-RELATED knowledge and skills (ACHIEVEMENT, INTELLIGENT, AND COMPETENT PERFORMANCE OF INDONESIAN NATIONAL EDUCATION SYSTEM)

Malaysia

Education plays a big role among the people in Malaysia. It is the source why people value universalism and nationalism. Just like the protagonist Yusuf in the story "A Common Story" by Kassim Ahmad. They have always the inspiration to be faithful and loyal to their own country.

The Education Act, 1996 repealed the Education Act 1961. It is the parent legislation on education and covers all levels of education under the national education system (except international schools). The Act stipulates the use of the national language ( UNIVERSALISM, NATIONALISM \& EQUALITY) as the main medium of instruction, a national curriculum, and common public examinations. It provides for pre-school education, primary school education, secondary

school education, post-secondary education, teacher education, special

education, private education, and technical education. The Act gives

greater prominence to VALUES IN EDUCATION and aims to ensure relevance and quality in the education system. 1996

The Private Higher Education Institutions Act,

The Act for the first time, makes provision for the establishment of private universities, university colleges, branch campuses of foreign universities as well as the upgrading of existing colleges to universities. (MALAYSIA WANTS TO ENSURE NATIONAL SECURITY THROUGH QUALITY EDUCATION). This is in line with the goal to liberalise higher education to meet the increasing demand for tertiary education and for a highly educated and skilled human resource. To promote unity and UNDERSTANDING, UNIVERSALISM, TOLERANCE, AND EQUALITY among the multiethnic society, Islamic Religious Education, Moral Education and Malaysian Studies are made compulsory in all Private Higher Education Institutions.

Myanmar

Education plays a big role among the people in Myanmar. It is the root why people value achievement and personal success. Just like the protagonist U Nyan Sein in the story "The Kindergarten Teacher" by Aung Thinn, they have the habit of never giving up inspite of all the turmoil in life.
When Burma gained INDEPENDENCE, AUTONOMY AND SELF-DIRECTION in 1948, the government sought to create a literate and educated population, and Burma was believed to be on its way to become the first Asian Tiger in the region. However, 1962 coup d'etat isolated and impoverished Burma. All schools were nationalized and educational standards began to fall. Burmese replaced English as the medium of instruction at Burmese universities in 1965, with the passing of the New University Education Law a year earlier.(UNIVERSALISM AND NATIONALISM) This led to a rapid decline in English proficiency among the Burmese. English was reintroduced as a medium of instruction in 1982. In 1977, the 2 year regional college system was introduced by the Burmese government, as a way to disperse college students until they were about to graduate (the third and fourth years were spent at a traditional university), a system that was ended in 1981. Due to students' protest of 8888 Uprising, all universities were closed around Burma for 2 years. Since the 1990s, new structure of education system was weak as government faced crisis to universities' clash and set up a 6th months term for an academic year. The SPDC government arranged irregular commencement dates for universities and colleges, however, students were still in que and clash. Another series of students' strike in 1996 and 1998 resulted in another 3 years of closure. (STIMULATION, A DARING LIFE, AND CHALLENGE IN LIFE DUE TO AUTORITARIAN MILITARY'S OPPOSITION TO RELEASE OPPOSITION LEADERS AND NEVER TO FORGET GROSS HUMAN RIGHTS VIOLATIONS (Lockard 2009)

Philippines

Education plays a big role among the people in the Philippines. It is the reason why people value achievement. Just like the protagonist Dr. Leonardo Quitangon in the story "The House on Zapote Street" by Quijano de Manila, they have the habit of giving their best to do fulfill all the approved means in order to achieve all the approved goals like wealth and higher status.

The expansion in the availability of education was not always accompanied by qualitative improvements. Therefore, quality became a major concern in the 1970s and early 1980s. Data for the 1970s show significant differences in literacy for different regions of the country and between rural and urban areas. Western Mindanao Region, for example, had a literacy rate of 65 percent as compared with 90 percent for Central Luzon and 95 percent for Metro Manila. (ACHIEVEMENT AND SOCIAL RECOGNITION) A survey of elementaryschool graduates taken in the mid-1970s indicated 
that many of the respondents had failed to absorb much of the required course work and revealed major deficiencies in reading, mathematics, and language. Performance was poorest among respondents from Mindanao and only somewhat better for those from the Visayan Islands, whereas the best performance was in the Central Luzon and Southern Tagalog regions.

Other data revealed a direct relationship between literacy levels, educational attainment, and incidence of poverty. As a rule, families with incomes below the poverty line could not afford to educate their children beyond elementary school. (DETRIMENTAL TO THE NATIONAL SECURITY AND STABILITY OF SOCIETY) Programs aimed at improving work productivity and family income could alleviate some of the problems in education, such as the high dropout rates that reflected, at least in part, family and work needs. Other problems, such as poor teacher performance, reflected overcrowded classrooms, lack of particular language skills, and low wages. These problems, in turn, resulted in poor student performance and high repeater rates and required direct action (PRESERVATION OF PUBLIC IMAGE OF THE PHILIPPINE GOVERNMENT OF PRIORITIZING EDUCATION)

Vocational education in the late 1980s was receiving greater emphasis than in the past. Traditionally, Filipinos have tended to equate the attainment of education directly with escape from manual labor. Thus it has not been easy to win general popular support for vocational training.

Catholic and Protestant churches sponsored schools, and there were also proprietary (privately owned, nonsectarian) schools. Neither the proprietary nor the religious schools received state aid except for occasional subsidies for special programs. Only about 6 percent of elementary students were in private schools, but the proportion rose sharply to about 63 percent at the secondary level and approximately 85 percent at the tertiary level. About a third of the private school tertiary-level enrollment was in religiously affiliated schools.

In 1990 over 10,000 foreign students studied in the Philippines, mostly in the regular system, although there were three schools for international students--Brent in Baguio and Faith Academy and the International School in Manila. (ACHIEVEMENT, PERSONAL SUCCESS, AND SOCIAL RECOGNITION). These schools had some Filipino students and faculty, but the majority of the students and faculty were foreign, mostly American. Faith Academy served primarily the children of missionaries, although others were admitted as space was available.

Chinese in the Philippines have established their own system of elementary and secondary schools. Classes in the morning covered the usual Filipino curriculum and were taught by Filipino teachers. In the afternoon, classes taught by Chinese teachers offered instruction in Chinese language and literature. (TRADITION, RESPECT, AND COMMITMENT TO CHINESE CULTURE)

\section{Singapore}

Education plays a big role among the people in Singapore. It is the essential core why people value self-direction and independence. Just like the protagonist Salmah in the story "Bugis" by Alfian Sa'at, she has wanted to decide on herself to wear or not to wear tudung/cover on her hair. She is very young and beautiful, she wants to flaunt her hair in public but she is very much a Moslem.

Education has been both the key source of competitive strength and a necessity for the economic growth and social viability of Singapore as a nation since self-government in 1959. In a process of continual development and ongoing improvement, education policies and practices have been reviewed and refined through the years. Since the mid 1990s, the world has been constantly changing around us and this fact has challenged the Ministry of Education (MOE) to make fundamental paradigm shifts in the strategic direction of the education system so that it is geared to meet the needs of Singapore in the $21^{\text {st }}$ century (Gopinathan, 1999; Sharpe \& Gopinathan, 2002).

First, globalization (ACHIEVEMENT, AMBITION, AND SELF-RESPECT) is rapidly recasting the economic landscape and redefining the international workplace in which nations have to

operate. Second, technological change is proceeding at a rapid pace,

resulting in changes in the ways individuals live and work. Third,

INTELLECTUAL ACHIEVEMENT AND AMBITION SERVE AS capital that will increasingly become the basis for competitive advantage among companies and nations. Therefore, education in Singapore must equip successive generations to thrive in an intensely competitive global marketplace, to imbue them with MORAL ATTITUDES, enterprising and innovative mindsets, and to ensure they are technologically savvy, flexible and willing to continually learn and upgrade their skills. (ACHIEVEMENT, COMPETENT PERFORMANCE, AND SOCIAL RECOGNITION) To succeed in this endeavor, Singapore will be dependent on a HIGH QUALITY TEACHING FORCE with the values, instincts, life skills and 
competencies on which we entrust them with the heavy responsibilities of molding the lives of our young people.

British colonial creation that became part of Malaysia when that nation was created in 1963. However, conflicts between political leaders of the Chinese-dominated Singapore and of theMalaydominated Malay states that comprised Western Malaysia brought about Singapore's separation from Malaysia in 1965. Since that time, Singapore and the remaining components of Malaysia have gone their own ways as separate sovereign states.(SELFDIRECTION, AUTONOMY, INDEPENDENCE) By 1990, the ethnic composition of Singapore's 2.7 million citizens was $76 \%$ Chinese, 15\% Malay, $6.5 \%$ Indian, and $2.5 \%$ other groups.In religious affiliation, the populace was $28 \%$ Buddhist, $19 \%$ Christian, $16 \%$ Muslim, 13\% Taoist, 5\% Hindu, and 19\% nonreligious (Daume, 1991, p. 698).

In terms of territory, Singapore is minuscule 240 square miles and virtually devoid of natural resources other than a good seaport at the crossroads of the China-India sea-trade route. To survive and thrive economically, the nation has had to depend on the diligence of its people and the ingenuity of its political and economic leaders. The government of Singapore operates as a tightly controlled, secular, capitalistic meritocracy whose PROSPERITY, WEALTH, AND INTELLIGENCE have depended on efficiently serving the world of international commerce and industry, undisturbed by political dissent.

Since the mid-1970s, issues of moral values have been the center of a continuing debate in thepublic press, a debate engaging the active participation of government officials and the generalpublic. Open forums have been conducted by the government in an effort to STIMULATION AND EXCITING discussion about values and to inform the government of the public's views. The controversy has been of special concern to educators, since the formal and nonformal education systems are assigned much of the burden of implementing solutions that result from the debate. The youth subculture of alienation, HEDONISTIC, ENJOYING LIFE selfexpression fed by drugs and the rock music revolution was attractive and therefore potentially corruptive of Singapore youth: in the words of one official, "the philosophy of patched-up jeans and patached-up souls" was not the model to emulate. Official characterization then of the attitudes of Singapore's youths materialistic, unwilling to sacrifice or to put nation before self, even unfilial-implied that corruption had already taken root.In a 1980 survey of lifevalues of 1878 youths in secondary schools it was reported what characterized these youths were their selfishness, a value vacuum, and the possession of a "self-interested morality."
Thus, the central issue of the continuing debate became: What values should the political state adopt as guiding principles to unite the populace in pursuing a just and prosperous future? In 1979 a government-appointed committee on moral education reported that the principal objective of the nation's moral-education program "should be to produce GOOD, USEFUL, LOYAL, HONEST, AND BENEVOLENT citizens through inculcation of the desired moral values and social attitudes" (Ong Teng Cheong etal., 1979, p. 8). The committee report then quoted Prime Minister Lee Kuan Yew's description ofthe ideal Singaporean as one who can live, work, contend, and cooperate in a civilized way. Is he LOYAL and PATRIOTIC? Is he, when the need arises, a GOOD SOLDIER, ready to defend his country, and so protect his wife and children, and his fellow citizens? Is he FILIAL, RESPECTFUL OF HIS ELDERS, LAW-ABIDING, HUMANE, and RESPONSIBLE?... Is he a good neighbor and a trustworthy friend. Is he tolerant of Singaporeans of different races and religions/ Is he clean, neat, punctual,and well-mannered? (Ong Tong Cheong et al., 1979, p. 8)

By the early 1980s a new syllabus for primary and secondary schools in the required subject ofmoral education was prepared, and religious knowledge (including a comparative knowledge of RELIGIOUS BELIEFS) became a required subject focusing on the Bible, Buddhism, Hinduism, Islam, Confucian ethics, and Sikh studies (Gopinathan, 1988, p. 139). (In 1990 the religious knowledge offering would be changed from a compulsory to an elective subject.) By the latter 1980s the focus of the continuing debate became the question of what values should comprise the national philosophy and, particularly, how traditional Asian values should contribute to this philosophy (Thomas 1991).

\section{Thailand}

Education plays a big role among the people in Thailand. It is the origin why people value benevolence and concern for others' welfare and true friendship. Just like the protagonist Thong Muan in the story "As If It had Never Happened" by Witthayakon Chiangkun, she has been curious about the University students of Bangkok.

Thailand's National Education Act of 1999 prescribes that curriculum development be guided by the 'Conceptual Framework for Basic Education Curriculum' which contains information on the rationale for curriculum development, the characteristics of the basic education curriculum, its contents, and guidelines on education curriculum management. Ongoing socio-economic and global changes require that the basic education curriculum be continuously revised and updated. Other than changes in the global economy and the advances in science and technology, 
Thai society itself has undergone dramatic changes in its demographic, socio-cultural, economic, environmental and political characteristics which also now require new adjustments in the national curriculum and educational system. Recent assessments indicate that the curriculum offered little flexibility in content to meet the varying needs and conditions of localities. It also provided inadequate learning time for necessary basic courses (e.g. as for science and math, language, etc.), and did not allow for the satisfactory integration of teaching and learning processes. In general, Thai students were assessed as lacking the kinds of knowledge and abilities necessary for seeking further knowledge and future living. The foregoing limitations of Thai education were some of the considerations that went into the formulation of the 1999 National Education Act and the Conceptual Framework for Basic Education Curriculum.

Current reforms guided by these policy documents therefore aim to improve Thai education by, among others, making the curriculum more flexible to suit specific circumstances at local levels; more diversified in terms of its contents and programmes to reach and meet the needs of different groups of learners and develop their potentials; and more decentralized in terms of administration and management to allow the participation of schools, parents, local communities and various sectors

and stakeholders in curriculum development and the education system. Current reforms are also taking into account the new knowledge and information that have arisen in the areas of curriculum standards, subject matters and contents, learning approaches and pedagogy and

the basic learning principles advocated in the Delors Report.(NATIONAL SECURITY, STABILITY OF THEIR EDUCATION, SOCIAL ORDER, AND FAMILY SECURITY)

Viet Nam

Education plays a big role among the people in Vietnam. It is the root why people value self direction and independence. Just like the protagonist Ms. Phan in the story "An Unsound Sleep" by NhatTien, the young students intervened in the civil war among Catholics and Buddhists, instead of studying very well.

In 1998, the Education Law was approved by the National Assembly which clearly defined the objectives, contents and methods of general education and institutionalization of curriculum and textbooks in the new development period of the country. This is the fourth curriculum reform following those carried out in 1950, 1956 and 1981. It has set a vision for the development of the country's human resources until 2020( NATIONAL SECURITY, FAMILY SECURITY, AND SOCIAL ORDER and is oriented towards striking a balance and complementation in the formulation of the curriculum contents for the primary and secondary education, as well as vocational education to equip the citizens with the necessary skills and competences for Viet Nam's industrialization and modernization (ACHIEVEMENT, COMPETENT PERFORMANCE, AND SOCIAL RECOGNITION) $\underline{\text { Religious Aspect }}$

Indonesia

Religion plays a big role among the people in Indonesia. It is the origin why people value conformity and honoring parents and elders. Just like the protagonist Markaban in the story "Inem" by Pramoedya Ananta Toer. IT HAS BEEN PART OF THEIR SOCIAL NORMS AND CONVENTIONS TO HONOR THOSE WORDS OF THE PARENTS AND ELDERS ALTHOUGH THE INSTRUCTION/REQUEST IS ALREADY PART OF THE HUMAN RIGHTS VIOLATIONS.

Government policy on religious education in Indonesian schools was first implemented soon after the 1945 declaration of INDEPENDENCE. Initially the guidelines were not as rigid as they later became - where, for example, the present format makes religious study mandatory from the first grade of elementary school up to first year university level, and all schools without exception must have a minimum number of hours reserved for religious education. Before 1966 some variation was allowed, and students (or their parents) could choose to take a course on religion or an alternative course, eg. moral education. The present format, in which the policy is applied indiscriminately to all schools and courses are made compulsory for all levels of schooling, can be attributed to the political transformation in Indonesia that took place in 1966, that is, the bloody September 30, 1965 event. Under the Soeharto regime which followed all issues relating to religion underwent significant changes, including the policy on religious education.

In the context of national education, religious education is understood as meaning the study of one's own religion. It is a mono-religious education some would say instruction. Subjects taught in the courses are aimed at getting students to internalize their own religion. In its implementation in school, during the religion hours students are separated into different classrooms based on their religion to receive instructions about their own religion. The starting point is therefore explicitly exclusive, and when other religions are taught they tend to be taught from the perspective of a particular religion. While this mode of religious education has been challenged, especially after the 1998 political reform, as far as government policy is concerned there has been no significant change. In fact, some even perceive a move toward making the policy even more rigid.

The post-1998 reform period in general yielded significantly more political and social freedoms, prompting some schools to attempt to re-format their 
religious education programs while trying to follow the requirements of the national curriculum. These attempts have enjoyed differing degrees of success. In Yogyakarta, for example, a number of schools have tried to hold a single religion class for all students so they may learn the universal values of other religions together. (TOLERANCE, UNIVERSALISM, UNDERSTANDING, AND WORLD OF PEACE.

In one Islamic school there was an experiment at creating a more inclusive religious education subject at the high-school level. However, the success of this program depended on the particular teachers who took the initiative, and the program does not seem to have been institutionalized. A "religiosity education" program has been developed by the Archbishop of Semarang, Central Java, and was implemented by a few Catholic schools in Yogyakarta. Yet there have been some practical problems - for example the new course compromised the time for the teaching of the Catholic faith. The same Archbishop has also published a compilation of the teachings of many religions. Some schools add field trips to places of worship to the usual religious education curriculum. However, it is yet to be seen whether all these new experiments are ultimately successful.(Ahmad 2011). (TOLERANCE, UNDERSTANDING, PROTECTION FOR THE WELFARE OF DIFFERENT RELIGIONS OF INDONESIANS. WORLD OF PEACE WILL BE APPLIED IN ALL SITUATIONS TO AVOID CONFLICT AND CIVIL WAR)

\section{THE TEACHINGS OF ISLAM}

ISLAM means submission to the Will of God. Muslim is the one who surrenders himself to God. The greatest and last Prophet of God was Mohammad. The religion of Islam recognizes Abraham, David, Moses, and Jesus Christ as prophets. The Blessed Virgin Mary and the angels are also given due respect. (DEVOUT OF RELIGIOUS RITES)

The Five Pillars of Islam: The first pillar is the profession of faith "There is only one God, Allah, and Mohammad is His prophet. The second pillar is a prayer recited five times a day. The third is almsgiving to the poor.(ENHANCING SPIRITUAL LIFE AND BENEVOLENCE)

The fourth is fasting. This is done during Ramadan. An event commemorating Allah's revelations to Mohammad. Ramadan is the ninth month in the Islam calendar. During fasting, all Moslems, except the sick and the aged, abstain from eating, drinking, and smoking from sunrise to sunset. The last pillar is the pilgrimage to Mecca

The title HADJI (meaning "Pilgrim") is given to Muslims who have joined the Mecca pilgrimage. Islam allows polygamy as long as the man can support his wives and treats each one fairly. Alcoholic drinks are not allowed as well as gambling.
The Moslems do not eat pork and family ties are strong. (COMMITMENT TO CULTURE AND RELIGION)

Malaysia

Religion plays a big role among the people in Malaysia. It is the root why people in Malaysia value tradition and devout of religious rites, beliefs, and symbols. Just like the protagonist Kiman in the story "Grave Harvest" by Ajikik. It could be said that the Malaysian Constitution became the single most important modern institutional tool that has moulded and conditioned Malaysian Islam, including Islamic education. The Constitution has defined the sociopolitical space of Islam in Malaysian government and politics. This delineation of the 'Islamic/Muslim' socio-political space, as we observe today, into a rather special space, is rooted in a straightforward constitutional provision in which every Malay person is automatically defined as a Muslim. In other words, religion (read Islam) became the ethnic identifier for the Malays. As a result Malay politics has inevitably become an intra-Muslim factional contestation. Interethnic politics among the Malay, Chinese and Indian communities since INDEPENDENCE, SELFDIRECTION, AND CREATIVENESS have taken on the character of a struggle over identity politics.

Colonial Knowledge and the Reshaping of Islam, the Muslim and Islamic Education in Malaysia. The special position of Islam as provided in the Malaysian Constitution of 1957 is as follows:

- Islam is the religion of the Federation;

- There is no religious head for the whole Federation. The King continues to be the head of the Muslim religion in his own negeri and it is provided that he shall be the head of the Muslim religion in Malacca, Penang, in the Federal Territory and in Sabah and Sarawak. Each of the other states has its own ruler as the head of the Islamic religion in that state;

- Negeri law may control or restrict the propagation of any religious doctrine or belief among persons professing the Islamic religion; Most likely, this was one of the reasons why Singapore had left the Malayan Federation. Most of the Singaporean professed Buddhism and they had Chinese roots. (RESPECT OF TRADITION, COMMITMENT TO CUSTOMS/TRADITIONS, CULTURE AND RELIGION)

- Other religions may be practiced in PEACE and UNIVERSALISM, HARMONY and SECURITY in any part of the Federation. This means that every religious group has the right to manage its own religious affairs; to establish and maintain institutions for religious and CHARITABLE AND BENEVOLENT purposes; and to acquire and own property and hold and administer it in accordance with the law.

In spite of being given a special position Islamic law is in practice subordinate to the civil law. Its scope is limited to FAMILY SECURITY LAW and 
Muslim religious offences. Hence the Shari'ah courts have a limited jurisdiction. There is no provision in the Malaysian Constitution for the jurisdiction and POWERS of the Shari'ah courts or for the appointment and DISCIPLINE of their judicial and legal officers. It is therefore clear that in Malaysia, Islamic law is not applied to the whole community nor is it applied in its pure form. Various negeri legislations in Malaysia, in the main, deal with the administration of Muslim laws and not with the substantive Islamic laws.

It could thus be said that the status of Shari'ah law in Malaysia since INDEPENDENCE is largely symbolic, rather than substantive. It fulfils a bureaucratic purpose but not as a set of laws that function to inculcate fundamental Islamic values and way of life.

Furthermore, because the administration of Islamic matters and malay TRADITION AND CUSTOMS ARE not centralised at the Federal level but is under the jurisdiction of each negeri religious bureaucracy and its ruler, the interpretation of some parts of the Shari'ah laws differs from negeri to negeri. This INDEPENDENCE is fiercely guarded by each negeri to the extent that there have been occasions when the commencement date of the Ramadan fasting has differed in the various negeri because each used different methods to ascertain the arrival of the new moon; some used astronomical techniques while 130 Islamic Studies and Islamic Education in Contemporary Southeast Asia chose to physically sight the new moon. It could be said that the legal position of Islam in post-colonial Malaysia is thus characterised by fragmentation and pluralization. However this pluralization has a 'colonialmodern', not an 'Islamic' origin.

The plurality of Islamic teachings and legal practices in Malaysia is

further complicated by an equally pluralistic Islamic education system available in the country. Interest in Islamic education has been dominated by the belief that such education has a direct bearing on the future of the ummah, or Muslim community. Accor-dingly the federal government and the negeri governments have developed their own separate official policies for Islamic education, supposedly serving the interests of each entity.

In the national education system since 1956 Islam has been taught as single subject, namely 'Islamic Religious Knowledge.

It was, however, not a compulsory subject. However it has been observed that the subject has three major weaknesses. First, it lacks a comprehensive examination on the subject in an integrated manner, including cognitive, attitudinal and practical knowledge which has made it a 'lightweight' subject; second, it lacks a coherent and integrated, syllabus of what should be taught as "Islamic Religious Knowledge", including the ritual aspects such as prayer, zakat, pilgrimage and the other basic articles of faith (TRADITION, RESPECT, COMMITMENT TO CUSTOMS/TRADITIONS, CULTURE AND RELIGION; and third, there is a lack of comparative religious study. In short, teaching the subject is seen as paying lip service to the Federal government. Hence the ironic situation has developed in which a course on Islamic religious knowledge is absent of any Islamic religious instruction.

From the 1950s and 1960s at the negeri level both pondok and madrasah began to lose their influence in many parts of the country, particularly in the Malaydominated negeri of Kelantan, Terengganu, Kedah and Perlis. However, the more pertinent factors that thus far have not been investigated and elaborated are the internal workings of the different religious schools in the various negeri. These include the details of their organization, the type of pedagogy applied, the curriculum and syllabuses that have been adopted, the kinds of textbooks made available, the teachers' training and the employment opportunities of the school-leavers. This lacuna both in facts and analyses has rendered most discussions of Islamic education weak and hovering at a superficial, general level. The internal working of these religious schools at the grassroots is more complex and complicated than most have imagined. Apart from weaknesses in the curriculum, Malay parents are less willing to send their children to these schools because better job opportunities are available to their children through education offered by the government.

Yet at the same time there is an opposite trend. Since the 1970s with the revival of interest in Islam and eventually in the 1980 s through a conscious effort at 'Islamization' conducted by the Malaysian government since the 1980 s, Islamic religious education, both at the federal and negeri level, has received an unprecedented boost. The number of government-funded primary and secondary religious schools have increased many fold. Tertiary Islamic education has expanded, Islamic faculties in local public universities have been enlarged, and new Islamic university colleges specialising in Islamic education have been established to cater for the growing student population. (BENEVOLENCE, CONCERN FOR MOSLEM STUDENTS). This trend has reduced considerably the number of Malaysian students enrolling in Islamic tertiary institutions in the Middle East and South Asia.(Ahmad 2011).

$\underline{\text { Myanmar }}$

Religion plays a big role among the people in Myanmar. It is the light why people value benevolence concern for family, primary groups, and for other's welfare. Just like the protagonist Mother Nyo in the story "Mother's Merit" by Thu Maung, they have the habit of being generous, charitable and 
peaceful. Many people in Myanmar would like to please their god Buddha by offering food to monks and to the poor. Buddhism in Burma is predominantly of the Theravada tradition, practised by $89 \%$ of the country's population It is the most religious Buddhist country in terms of the proportion of monks in the population and proportion of income spent on religion. Adherents are most likely the dominantethnic Bamar (Burmans), Shan, Rakhine (A rakanese), Mon, Karen, and Chinese who are well integrated into Burmese society. Monks, collectively known as the Sangha, are venerated members of Burmese society. Among many ethnic groups in Myanmar, including the Bamar and Shan, Theravada Buddhism is practiced in conjunction with nat worship, which involves the placation of spirits who can intercede in worldly affairs.

Buddhists, although clearly professed by the majority of people in Myanmar, have their complaints regarding RELIGIOUS FREEDOM AND PRIVACY. A political party, the Democratic Karen Buddhist Army, split from the main Karen nationalist movement, the Karen National Union (KNU), after the Buddhists were denied to rebuild and repair the stupas at Manerplaw. The top leadership of the KNU were also dominated by Christians, although roughly $60 \%$ of the Karen are Buddhist. For instance, Aung San Suu Kyi, an icon of principled leadership and in defying the military leaders insisted on MODERATION, TOLERANCE, AND A BELIEF IN THE WORTH OF THE INDIVIDUAL. INSISTED ON DEMOCRATIC SPIRIT AND EQUITABLE DISTRIBUTION OF WEALTH DURING THE CORRUPT MILITARY REGIME in Myanmar.

$\underline{\text { Philippines }}$

Religion plays a big role among the people in the Philippines. It is the root why people value universalism and nationalism. Just like the protagonist Fil in the story "The Day the Dancers Came" by Bienvenido N. Santos, they have the habit of welcoming Filipino tourists in America. They long for the presence and camaraderie of Filipino visitors in America. The great majority of the Philippine population is bound together by common values and a common religion.

Philippine society is characterized by many positive traits. Among these are strong RELIGIOUS FAITH AND TRADITION, RESPECT FOR AUTHORITY AND SOCIAL POWER, and high regard for amor proprio (self-esteem) and SMOOTH INTERPERSONAL RELATIONSHIPS AND BENEVOLENCE. Philippine respect for authority is based on the special honor paid to elder members of the family and, by extension, to anyone in a position of power. This characteristic is generally conducive to the smooth running of society, although, when taken to extreme, it can develop into an authoritarianism that discourages independent judgment and individual responsibility and initiative. Filipinos are sensitive to attacks on their own selfesteem and cultivate a sensitivity to the self-esteem of others as well. Anything that might hurt another's self-esteem is to be avoided or else one risks terminating the relationship. One who is insensitive to others is said to lack a sense of shame and embarrassment, the principal sanction against improper behavior. This great concern for selfesteem helps to maintain harmony in society and within one's particular circle, but it also can give rise to clannishness and a willingness to sacrifice personal integrity to remain in the good graces of the group. Strong personal faith enables Filipinos to face great difficulties and unpredictable risks in the assurance that "God will take care of things." But, if allowed to deteriorate into fatalism, even this admirable characteristic can hinder initiative and stand in the way of progress.

Social organization generally follows a single pattern, although variations do occur, reflecting the influence of local traditions. Among lowland Christian Filipinos, social organization continues to be marked primarily by personal alliance systems, that is, groupings composed of kin (real and ritual), grantors and recipients of favors, friends, and partners in commercial exchanges.

Philippine personal alliance systems are anchored by kinship, beginning with the nuclear family. A FILIPINO'S LOYALTY AND BENEVOLENCE goes first to the immediate family; identity is deeply embedded in the web of kinship. It is normative that one owes support, loyalty, and trust to one's close kin and, because kinship is structured bilaterally with affinal as well as consanguineal relatives, one's kin can include quite a large number of people. Still, beyond the nuclear family, Filipinos do not assume the same degree of support, loyalty, and trust that they assume for immediate family members for whom loyalty is nothing less than a social imperative. With respect to kin beyond this nuclear family, closeness in relationship depends very much on physical proximity.

$\underline{\text { Singapore }}$

Religion plays a big role among the people in Singapore. It is the root why people value family security and sense of belonging. Just like the protagonist Helena in the story "The Martyrdom of Helena Rodrigues by S. Kon (1960). The Singaporean mothers have the tendency to become over-protective of their sons to the extent that they 
forget to give them chances to become INDEPENDENTand to decide for themselves.

The early Christians conquered the Ancient World by their innocent suffering, but they were forbidden to deliberately invite martyrdom. The Oriental temperament forged deliberate selfimmolation in the form of hunger-strikes and autoincineration into a potent psychological weapon. Christian martyrdom, as opposed to simple or unrefined domestic martyrdom, is suffered with sweet forgiveness and under veils of retirement. It does not employ the tactics of "Nobody-knows-whatI-suffer or I-work-my-fingers-to-the-bone-for-you"

\section{Buddhism}

More than three-fifths of Singapore's population subscribe to Buddhism. The Chinese Mahayana Buddhism is the most prevalent form here. Followers of Buddhism practice teachings of Morality, Concentration and Wisdom. Fengshui, which is the art and science of evoking positive energy, is all part of this religion. The largest Chinese Mahayana Buddhist temple in Singapore is the Kong Meng San Phor Kar See Monastery. Buddhism in Singapore is regulated by the Singapore Buddhist Federation. Other organisations such as the $\mathrm{Pu}$ Tuo Monastery help people set up businesses (BENEVOLENCE, ENHANCING THE WELFARE OF THE INGROUP, CONCERN FOR OTHERS' WELFARE, HELPFUL) such as vegetarian restaurants, art galleries, gift shops, and specialist Buddhist shops offering religious artifacts. Others like Tzu Chi and Kwan Im Welfare Society and The Metta Welfare operate free mobile clinics and other services all over the island to serve the elderly.

\section{Taoism}

Followers of Taoism adhere to the teachings of the ancient Chinese religious philosophy of Lao Tzu. It believes in RESPECTING HEAVEN, worshipping ancestors and being compassionate to all under heaven. Devotees make regular offerings of food and burn joss stick/paper in memory of those who have passed away. The concept of Yin Yang is derived from this religion. Thian Hock Keng, or the Temple of Heavenly Happiness, was built in 1842 in honour of the Sea Goddess Mazu. It is the one of the oldest Taoist temples in Singapore.

The most important Chinese festivals are Lunar New Year, Qingming Festival, Vesak Day, Hungry Ghost Festival and the Mid-Autumn Festival.

\section{Islam}

Followers of Islam profess to the teachings of Allah conveyed by Prophet Muhammad from the scriptural revelations of Quran, which contains wisdom of the past suitably blended with pointers for the future. Sixteen percent of Singapore's population believes in Islam, with the majority being Malays. The Majlis Ugama Islam Singapore (MUIS) is the supreme Islamic religious authority in Singapore. Other than building and administering mosques and coordinating the annual pilgrimage to Mecca, it looks after all the religious, social and welfare needs of Singaporean Muslims. Masjid Sultan is one of the oldest mosques in Singapore. The most prominent Islamic face of Singapore is Mr Yusof bin Ishak, the first President of Singapore, whose portrait is imprinted on currency notes that are still widely used today. CONFORMITY AND POLITENESS in not eating pork.

\section{Christianity}

Christians follow the teachings of Jesus, the Son of God. The life of Jesus, his message, suffering, death on a cross and resurrection are recorded in the Bible. Believers accept Jesus as their Messiah. The Armenian Church, the oldest Christian church in Singapore was completed in 1835. Christian churches of all denominations including Catholics and Protestants can be found in Singapore. Services are conducted in many languages during the day for the benefit of various nationalities.

The Roman Catholic population in Singapore comprises of Eurasians, Chinese, Peranakans and Indians. There are about 30 Catholic churches around the island. The Catholic Church is under the jurisdiction of the Holy See in Rome, and runs several schools and special homes. Protestant churches also hold many counselling services and anti-drug abuse programmes. (UNIVERSALISM, UNDERSTANDING, TOLERANCE, AND PROTECTION FOR THE WELFARE OF ALL PEOPLE.

\section{Hinduism}

Followers of Hinduism - the oldest religion in the world - believe that the supreme God takes various forms as 'Brahma' the Creator, 'Vishnu' the Preserver and 'Shiva' the destroyer. The most popular manifestations of God worshipped in Singapore are Ganesha, Rama, Krishna, Murgan, Hanuman, Durga, Mariamman, Lakshmi. The style and medium of discourse here is South Indian. The bulk of 30 temples is managed and administered by the Hindu Endowments Board and the Hindu Advisory Board. Sri Mariamman Temple, established in 1827 , is the oldest temple in Singapore. Every day, holy priests perform rituals at temples and chant ancient Vedic scriptures. Major Hindu festivals are Deepavali, Thaipusam, Navratri and Tamil New Year. 

Study

The mental perspective in the story is that the females in the story were the strong and decisive way a man should think while the weak and giving way that the males think should be that of a female. The male should be the protector and provider of the female that he loves.

Thailand

Religion plays a big role among the people in Thailand. It is the root why people value selfdirection and independence. Just like the protagonist Maha Bunman in the story "Lord Buddha, Help Me ?" 1975 by Suchit Wongthed, they have the habit of offering food to the monks thinking that they will have a better hierarchy in the next life. The story is a description of the hero's lost of faith in Buddhism and its encompassing moral power. Bunman's Buddhist amulets may not be genuine and that if he can deceive himself about the potency of his own amulets, he can also deceive himself about the potency of Buddhism and its definitions of reality. (Phillips, H.P. 1987).

In Thailand, Sangkha, or brotherhood of monks, is the third of the Three Treasures of Buddhism. The first is The Buddha, the second is Dharma. To "take on a yellow robe," or become a monk, is considered a highly meritorious act. The man's parents will surely be lifted to heaven by his act. (DEVOUT OF RELIGIOUS RITES/BELIEFS, AND SYMBOLS

Any man can become a Buddhist monk after he reaches 20 years of age. Before reaching that age, he may become only a samanera, or novice. However, ordination either as a monk or as a novice does not necessitate an everlasting vow. A monk or a novice may leave his monastic order at any time he likes, provided he goes through the proper rites. Thai custom encourages every man to spend a part of his life in a Buddhist monastery as a monk.(TRADITION, RESPECT, COMMITMENT TO CUSTOMS, TRADITIONS, CULTURE, AND RELIGION. There he learns Buddhist scriptures and follows a strict code of monastic regulations. He learns to train himself in self - restraint and self control against worldly temptation, and to DISCIPLINE AND CONFORMITY himself in the Buddhist way of life, free from all forms of hate and revenge. This discipline is regarded as a very important element of life, so much so that a man who once entered monkhood is considered a fully MATURE MAN AND BENEVOLENT, a learned man or khon Sukm(literally a "ripe man"). $\mathrm{He}$ is then ready to marry and live a full life. Those who never become monks are considered immature or khon dip ("unripe man).

Moreover, Buddhist monks are involved in all aspects of life among the Thai. They make their rounds early each morning with their bowls. This is not considered begging, but is giving people a chance to make merit by offering food. People learn to become generous when they learn to share. At the housewarming ceremony and other Thai rites, monks are usually invited to come to chant and to bless the house and the people by sprinkling sacred water. On Sabbath day at the monastery or wat, monks chant and tell stories of the many lives of Buddha or tell moral tales based on Buddhist scriptures.

For centuries, before formal education was enforced in 1898, monasteries provided free education for boys in Thailand. The monks served as teachers. The teaching monk, achan, taught literature, Mathematics, Science, and Religion and also acted as role model for his students. In fact, the Lord Buddha himself was highly revered as a Model Teacher. (Edmonds, I.G.andF. Watts, 1978).

For many Thai, perceive the monkly state as socially passive and solipsistic, without challenge. He does not necessarily have to do anything. For his biological existence is dependent upon what laypersons choose to give to him. The monk can simply become a man with nobody to depend on, nobody to know or to know him, nobody to serve or to serve him. A monk can simply be always isolated and lonely amid the din and chaos of Bangkok. (HEDONISM, SELF-INDULGENT)

Society is diseased. People compete with each other so much that the poor almost choke to death over their own jealousy. If all the money that is poured into sexual obsessions were used to help poor people then the prosperity of Thailand would increase. (ACHIEVEMENT, SELF-RESPECT, AND AMBITIOUS)

The story is a description of the hero's lost of faith in Buddhism and its encompassing moral power. The story is a brilliant presentation of the relationship between poverty and self-esteem. How a man becomes full in fighting the world. (ACHIEVEMENT AND COMPETENT PERFORMANCE) Thai society is decadent and morally shabby. The rich are so rich. They have so much to eat that they cannot even buy a glass of coffee to lubricate the engine of the body. Everyday morality is disappearing from men's hearts. Generosity is fading from people's hearts. While roughly $95 \%$ of the Thai people are practitioners of Theravada Buddhism, the official religion of Thailand, RELIGIOUS TOLERANCE, AND UNIVERSALISM is both customary in Thailand and protected by the constitution. By its very nature however, Buddhism, which is based on the teachings of the Buddha, "the enlightened one" (nee Siddhartha Gautama), is a compassionate and tolerant religion, the aim of which is the alleviation of suffering. Consequently, Thai people are very respectful of the religious beliefs of others and are very open toward discussing their Buddhist values with visitors. In fact, there are many opportunities in Thailand to visit Buddhist temples to learn about or study Buddhism and perhaps to learn to meditate. 

Study

Religion in Thailand pervades many aspects of Thai life and senior monks are highly revered; it is not uncommon to see their images adorning walls of businesses or homes or upon ornaments inside of taxi cabs. In many towns and villages the neighborhood wat (temple) is the heart of social and religious life. Buddhist holidays occur regularly throughout the year (particularly on days with full moons) and many Thai people go to the wat on these and other important days to pay homage to the Buddha and give alms to monks in order to make merit for themselves. Thai feels the SECURITY, SAFETY, HARMONY, AND STABILITY OF SOCIETY EVERYTIME THEY FELT THAT THEY HAVE BEEN ABANDONED AND ALONE

Vietnam

Religion plays a big role among the people in Vietnam. It is the root why people value self direction and creativeness. Just like the protagonist Old Blind in the story "The Cradles" by Mai - Ngu, they have the eagerness to rehabilitate their war-torn country with the help of each other.

The predominant religion in Vietnam is Buddhism, which is also on of the world's great religions. Buddhism was introduced into Vietnam under the Chinese domination, in the second century B.C., by Chinese immigrants and by Indian preachers coming by sea. Buddhism became the state religion of Vietnam under Ly Dynasty (1010-1214). Several kings took the cassock or retired into a pagoda after their abdication. Buddhist monks served as counselors to the king at court. Since the Tran Dynasty (1225-1440), Buddhism has lost the status of a state religion but nevertheless remained the dominant religion in Vietnam and a major cultural force.

The soul does not perish at death, but reincarnates in another existence and this goes on and on. The Buddhist's goal is to be freed from the circle of reincarnation and reach Nirvana,(Many Buddhists have beeen trying to become BENEVOLENT, HELPFUL, HONEST, FORGIVING, LOYAL, TRUE FRIENDSHIP TO BE FREED FROM REINCARNATION AND REACH NIRVANA which is a state of complete redemption and supreme happiness. Theoretically, any person may become a Buddha by suppressing craving and following the Eightfold Path, but those who actually attain Buddhahood are rare. THEY HAVE TO DETACH THEMSELVES FROM MATERIAL THINGS AND THAT IS BENEVOLENCE. There are two branches of Buddhism: Hinayana (Little Vehicle) also called Theravada Buddhism, which nourishes in Sri Lanka, Thailand, Cambodia, Laos, and Burma, and Mahayana (Great Vehicle) Buddhism which is found in China, Korea, Japan, and Vietnam. Most Vietnamese Buddhists belong to the Mahayana branch. The Theravada branch exists in communities of ethnic Cambodians and Vietnamese living in the Mekong Delta.

$\underline{\text { Social life }}$

$\underline{\text { Indonesia }}$

Social life plays a big role among the people in Indonesia. It is the root why people value power and social status. Just like the protagonist Ajo Sidi in the story "The Decline and Fall of Our Local Mosque" by A.A. Navis, they have the habit of praying and contemplating. They forgot to work hard while praying at the same time. Family is very important in Indonesia and it is very common for extended families that include grandparents, aunts, uncles and cousins to all live together in one place. Although this is true both in the cities and in the rural areas of Indonesia, it is becoming less common in city life.

Generally speaking, most Indonesian families are closely knit families and work hard to help each other. People have a responsibility to their families and especially to their elders. Indonesians are expected to respect the experience of their elders and follow their advice. They are also expected to look after their parents in old age.

Children learn from an early age how to help around the home. In rural areas they may work on farms when they are not at school. In the cities they may try to find a job, such as selling clothes at the market. (BENEVOLENCE, CONCERN FOR FAMILY, HELPFUL, \& TRUE FRIENDSHIP)

The pace of life in Indonesia is slower. People use the term jam karet which can be understood as 'time that stretches like rubber'. This concept reflects the way that Indonesians prefer to take things as they come, rather than plan every moment of their day. This means that things like parties or business appointments are not planned and kept in the same way that they are in Australia. (HEDONISM, GRATIFICATION FOR ONESELF, NEEDS AND PLEASURE, ENJOYING LIFE, AND SELFINDULGENT

Particularly in their social life, Indonesians prefer not to make detailed plans and be expected to arrive places at particular times. This is one of the reasons that Indonesian meals tend to be simple combinations of rice and sauces that can easily cope with the sudden arrival of a few more people. (STIMULATION AND A VARIED LIFE) 

Study

Sometimes in rural areas if there has been a very good harvest, the members of a kampung may decide to hire a travelling wayang show and celebrate. They may also pay the local gamelan orchestra to play at important events. In the cities, Indonesians prefer to meet at street stalls for coffee and conversation. People can spend hours just talking with friends and catching up on events. (SECURITY, HARMONY, AND SENSE OF BELONGING)

\section{$\underline{\text { Social Life }}$}

\section{$\underline{\text { Malaysia }}$}

Social life plays a big role among the people in Malaysia. It is the root why people value tradition and and respect. Just like the protagonist Imam in the story "Mariah."by Che Husna Azhari, they have the custom and belief for men seeking for second wife. It is to protect the widows and to propagate Islam in a bigger population. In addition to dress restrictions (above), the greatest behavioral note to make is on dining in Malaysia. If eating in public or with Muslims, remember Islamic law forbids pork products and alcohol; however there is little expectation that you follow these rules unless you are in public with Malays. Due to the large Chinese population, whose main protein is pork, pork is readily available and the locals are used to seeing people eat pork and in large cities few take any offense at it. If dining with Malays though try to avoid the pork. (STIMULATION, EXCITEMENT, CHALLENGE IN LIFE, \& DARING LIFE) Alcohol is also widely available to both the non-Muslims as well as to the tourists and again drinking alcohol is fine, but avoid drinking when in the presence of Muslims. Always consider the situation; on smaller islands where the overwhelming majority is Muslim, don't eat pork or drink alcohol, while in cities the population is more diverse and there is more flexibility on what you can eat or drink. If in doubt, don't order pork or alcohol.

When in the presence of the Chinese, remember that they can be very proud people and insulting them or putting a person down in anyway can be very offensive as the person will feel "shamed." In much the same way, the Chinese will rarely give you critical advice or insult you in fear of "shaming" you; this is especially true in business. Turning down a business offer in the wrong way may, unknowingly be an insult and could force your contact to feel so shamed that he will actually quit his job; if all hope is lost on a deal, allow your Chinese counterpart to gracefully exit the situation so he can save "face." (CONFORMITY AND POLITENESS) However, the opposite is also becoming more common and if you do (intentionally or unintentionally) insult another, that person may defend his honor by insulting you and will pursue a shouting match. Fortunately, this is more common among locals arguing over driving etiquette. (SABAH IS SEEN AS A PURELY BILATERAL CONCERN. THE SABAH CLAIM COMPLICATED ISSUES IN BILATERAL RELATIONSHIP * MUSLIM SEPARATIST REBELLION IN THE SOUTH AND FILIPINO LABOUR MIGRATION TO SABAH.

\section{$\underline{\text { Social Life }}$}

\section{$\underline{\text { Myanmar }}$}

Social life plays a big role among the people in Myanmar. It is the root why people value hedonism and gratification for oneself. Just like the protagonist Aye Aye in the story "Neighbours" by Moe Moe in1972. Under the British, ethnic minorities generally were able to retain some (AUTONOMY, SELF-DIRECTION, INDEPENDENCE) Negotiations for independence after World War II brought suspicions among the political leaders of several ethnic minorities that their status would be undermined. Immediately after SELF-DIRECTION, INDEPENDENCE in 1948, serious divisions emerged between Burmese and non-Burmese political leaders, who favored a less unified state. Between 1948 and 1962, armed conflicts broke out between some of these minority groups and the central government. Although some groups signed peace accords with the central government in the late 1980s and early 1990s, others are still engaged in armed conflict. The Wa have signed a peace agreement but have retained a great deal of autonomy and control of much of the DRUG TRADE (STIMULATION AND DARING LIFE) in northern Burma.

Military operations in ethnic minority areas and government policies of forced resettlement and forced labor (SOCIAL JUSTICE AND EQUALITY) have dislocated many ethnic groups, and have caused large numbers of refugees to flee to neighboring countries. At present there are around three hundred thousand refugees in Thailand, Bangladesh, and India, mostly from ethnic minorities.

In the 1960s narcotics was a big problems in Thailand, and narcotics was a big problem in BURMA. (STIMULATION AND DARING LIFE) Much of the opium that was translated into heroin in laboratories along the Thai-Burmese border and then shipped by caravan down into Thailand and exported, was raised in the Shan states of Burma. So the US worked out an assistance program with the 
Burmese. The US supplied them with helicopters for spraying weed-killer on opium plants, and gave them advice from the DEA people. The US tried crop substitution and things like that, and even had a road project going in Burma. The US tried to keep Burma more or less on the straight and narrow, despite the fact that it was a hopelessly run country, dictatorial. Ne Win was not exactly nature's nobleman, and he continued to run that country into the ground for quite awhile.(SOCIAL POWER, CONTROL AND DOMINANCE OVER PEOPLE AND RESOURCES AND AUTHORITY)

Alcohol was the first substance of abuse of American troops in Vietnam. Heroin abuse became significant in early 1970 when $90 \%$ to $96 \%$ pure heroin derived from the "golden triangle" of Thailand, Burma, and Laos became available countrywide. This pure heroin was so cheap that a significant "habit" could be maintained for $\$ 8$ to $\$ 10$ a day. The preferred route was "snorting" through the nostrils or smoking. Heroin reportedly displaced cannabis because it had no characteristic strong odor allowing detection, made time seem to go faster rather than slower as with marijuana, and was compact and easily transportable. Heroin did not so much replace marijuana as augment itsuse and that the real reason for the heroin epidemic was enormous profits that South Vietnamese officials could make by selling it to Americans. (PEOPLE OF MYANMAR USUALLY CONDUCTS HEROIN BUSINESS A DEVIANT/CRIME BEHAVIOR BECAUSE OF MONEY, SOCIAL POWER, DOMINANCE OVER RESOURCES.

Illicit worldwide opium production exceeded 4,000 metric tons in 1995 , enough to produce nearly 400 metric tons of heroin. Burma was the source of most of the heroin available in the United States, but opium production in Afghanistan had skyrocketed since 1990 and Colombia had surpassed Mexico as the largest producer of opium in the Western Hemisphere. (MYANMAR'S SAFETY, HARMONY, STABILITY OF SOCIETY, AND NATIONAL SECURITY WILL ALWAYS BE AT STAKE IF THEY WILL NOT STOP OPIUM/HEROIN TRAFFICKING)

Social Life

$\underline{\text { Philippines }}$

Social life plays a big role among the people in the Philippines. It is the root why people value universalism and nationalism. Just like the protagonist Fil and Tony in the story'

"The Day The Dancers Came" by Bienvenido N. Santos 1967 (Philippines Santos "memorialized the tenderness, nostalgia," and "bittersweet story" of Filipino manongs, a title or designation referring to male old-timers from the Ilocos region, living in the United States by creating tales based on "his memories" of his own "generation.(BENEVOLENCE, SMOOTH GROUP FUNCTIONING, CONCERN FOR FAMILY, HELPFUL, HONEST, FORGIVING, LOYAL, TRUE FRIENDSHIP, MATURE LOVED, AND SPIRITUAL LIFE - THOSE CULTURAL VALUES WERE VERY EVIDENT IN FILIPINO CULTURE LOCALLY OR INTERNATIONALLY.

Bonds of ritual kinship, sealed on any of three ceremonial occasions--baptism, confirmation, and marriage--intensify and extend personal alliances. This mutual kinship system, known as compadrazgo, meaning godparenthood or sponsorship, dates back at least to the introduction of Christianity and perhaps earlier. (BENEVOLENCE, ENHANCING THE WELFARE OF THE IN -GROUP, CONCERN FOR FAMILY, HELPFUL, LOYAL, TRUE FRIENDSHIP. It is a primary method of extending the group from which one can expect help in the way of favors, such as jobs, loans, or just simple gifts on special occasions. But in asking a friend to become godparent to a child, a Filipino is also asking that person to become a closer friend. Thus it is common to ask acquaintances who are of higher economic or social status than oneself to be sponsors. (FAMILY SECURITY, SOCIAL ORDER, RECIPROCATION OF FAVORS AND SENSE OF BELONGING) Such ritual kinship cannot be depended on in moments of crisis to the same extent as real kinship, but it still functions for small and regular acts of support such as gift giving.

A dyadic bond--between two individuals--may be formed based on the concept of utang na loob. (DEBT OF GRATITUDE, CONFORMITY, HONORING PARENTS AND ELDERS) Although it is expected that the debtor will attempt repayment, it is widely recognized that the debt (as in one's obligation to a parent) can never be fully repaid and the obligation can last for generations. Saving another's life, providing employment, or making it possible for another to become educated are "gifts" that incur utang na loob. Moreover, such gifts initiate a long-term reciprocal interdependency in which the grantor of the favor can expect help from the debtor whenever the need arises and the debtor can, in turn, ask other favors. Such reciprocal personal alliances have had obvious implications for the society in general and the political system in particular.

In 1990 educated Filipinos were less likely to feel obligated to extend help (thereby not initiating an utang na loob relationship) than were rural dwellers among whom traditional values remained strong. Some observers believed that as Philippine society became more modernized and urban in orientation, 
utang na loob would become less important in the political and social system. (UNIVERSALISM, UNDERSTANDING, AND TOLERANCE)

Social Life

$\underline{\text { Philippines }}$

Social life plays a big role among the people in the Philippines. It is the root why people value national security and social order. Just like the protagonist Clayton and Ms. Rosete in the story "Clay" written by Juan T. Gatbonton,1951. CONSCIOUS OF THE PROBLEM OF NATIONAL SECURITY, PRESIDENT MANUEL A. ROXAS GRANTED THE US CONTROL OF THE MILITARY AND NAVAL BASES AT CLARK AIR BASE AND SUBIC BAY NAVAL BASE, IN EXCHANGE FOR MILITARY AID. THE COUNTRY AT THIS TIME WAS ALSO FACED WITH A COMMUNIST UNREST IN THE RURAL AREAS. (AGONCILLO 2010).

Subservience to the dictates of the US, courting political disaster. Needless to say, culture during this period developed according to the ideological direction set by the U.S. As a former colony of the US, the Philippines upheld the line that the salvation of the world lay with free enterprise and American protection against communism. In 1951 was the granting of political independence did not in fact end American domination. On the contrary, many features of colonialism remain even today. The army camp was on the east side of the main street; the gray, two-story building of concrete and galvanized iron that was the army barracks in Candaba's main street. The Americans had built a bridge and gouged out a new road on the left bank of the river. The period from 1946 - 1960 was an era of effective American control of the Philippine economy, political life and military affairs.(BENEVOLENCE, HELPFUL, HONEST, FORGIVING, LOYAL, AND TRUE FRIENDSHIP. Clay symbolizes this type of person: Somebody who's always laughing and acting like a happy guy. However, the source of his laughter is meanness, not friendliness. He laughs at innocent people, takes advantage of them, uses them like his toys or pets.

It will be aware that bad memories persist from the days US Military Bases, when accused US Servicemen would escape from Subic and Clark before Filipino prosecutors could investigate or charge them.

$\underline{\text { Social Life }}$

$\underline{\text { Singapore }}$

Social life plays a big role among the people in Singapore. It is the root why people value selfdirection and creativeness. Just like the protagonist Sazalie and Salmah in the story "Bugis" by Alfian Sa'at, both of them want independent thought. They didn't like the society to control and to manipulate them so much.

As Singapore is a small and relatively modern amalgam of Chinese, Malay, Indian and European immigrants, the culture of Singapore expresses the diversity of the population as the various ethnic groups continue to celebrate their own cultures while they intermingle with one another. For example, one can find a Malay wedding taking place beside a Chinese funeral at a void deck, on the ground floor of a HDB apartment block. This can be said to be due to the policies of the HDB which tried to make sure all public housing have a diverse mix of races. However, Singapore has achieved a significant degree of cultural diffusion with its unique combination of these ethnic groups, and has given Singapore a rich mixture of diversity for its young age. (CULTURE SHOCK AND ETHNOCENTRISM DON'T EXIST IN A DIVERSE SOCIETY. EVERYBODY RESPECTS RESPECTIVE COMMITMENT TO CULTURE, CUSTOMS, TRADITIONS)

Singapore has several distinct ethnic neighborhoods, including Little India, Chinatown and Kampong Glam, formed by the Raffles Plan of Singapore in the early 19 th century to segregate the new immigrants into specific areas. Although the population are no longer segregated in distribution, mainly due to the policies of the Housing Development Board and the ruling People's Action Party, these ethnic neighborhoods retain unique elements of their specific culture. The usage of such neighborhoods is mostly commercial or for cottage industry specific to the culture of its ethnic neighborhood, and no longer plays a large part in housing the population, although it was once used for that purpose. Hence, these neighborhoods have patronage of all races who wish to either eat or buy something specific to that culture.( NATIONAL SECURITY IN SPITE OF DIFFERENT ETHNIC NEIGHBORHOODS, RECIPROCATION OF FAVORS AND SENSE OF BELONGING

For example, Little India is known and patronized by all races within the population for its thalis-South Indian "buffets" that are vegetarian and served on the traditional banana leaves. In other parts of the country, such segregation is discouraged by government policy. The policies of the Housing Development Board are designed to encourage a mix of all races within each housing district, with a quota system in place to achieve a minimum of minorities in each block. This effect can be observed in all parts of the country; for example a store devoted to selling Malay food might be right next to stores selling Chinese or Indian goods. The aim is to foster SOCIAL COHESION and national loyalty, which Lee Kuan Yew felt was crucial for sustaining 
Singapore after independence when he was Prime Minister. There is a weighty emphasis on RACIAL HARMONY, RESPECT, COMMITMENT TO CUSTOMS, TRADITIONS, CULTURE AND RELIGION and subsequent case study of historical events, such as the 1964 Race Riots.

Bugis in Singapore, was renowned internationally from the 1950 s to the 1980 s for its nightly gathering of transwomen, a phenomenon which made it one of Singapore's top tourist destinations during that period. In the mid-1980s, Bugis Street underwent major urban redevelopment into a retail complex of modern shopping malls, restaurants and nightspots mixed with regulated back-alley roadside vendors. Underground digging to construct the Bugis MRT station prior to that also caused the upheaval and termination of nightly transgender sex bazaar culture, marking the end of a colorful and unique era in Singapore's history. This change helped improve Singapore's international image as it began to be globally UNDERSTANDING, UNIVERSALISM)

When transvestites began to rendezvous in the area in the $1950 \mathrm{~s}$, they attracted increasing numbers of Western tourists who came for the booze, the food, the pasar malam shopping and the "girls". Business boomed and Bugis Street became an extremely lively and bustling area, forming the heart of Xiao Po. It was one of Singapore's most famous tourist meccas from the $1950 \mathrm{~s}$ to the $1980 \mathrm{~s}$, renowned internationally for its nightly parade of flamboyantly-dressed transwomen and attracted hordes of Caucasian gawkers who had never before witnessed Asian queens in full regalia.

The latter would tease, cajole and sit on visitors' laps or pose for photographs for a fee. Others would sashay up and down the street looking to hook halfdrunk sailors, American GIs and other foreigners on R\&R, for an hour of profitable intimacy. Not only would these clients get the thrill of sex with an exotic oriental, there would be the added spice of transgressing gender boundaries in a seamy hovel. (UNDERSTANDING, TOLERANCE, AND UNIVERSALISM)

\section{$\underline{\text { Social Life }}$}

\section{Thailand}

Social life plays a big role among the people in Thailand. It is the root why people value benevolence and concern for family. Just like the protagonist Thong Muan in the story "As If It Had Never Happened Before" by Witthayakon Chiangkun, The University students have the program in their curriculum of serving the people in countryside.
Meditation, one of the primary practices of Buddhism, is a means of self reflection in order to identify the causes of individual desire and ultimately alleviate ones suffering. Visitors can learn the fundamentals of this practice at a number of wats across the kingdom. Some temples, particularly in Chiang Mai, allow visitors to chat with monks in order to gain general knowledge about Buddhism or to study Buddhism more seriously. (THE SOCIAL POWER OF MONKS ARE THAT PEOPLE ARE WORRIED ABOUT THEIR SUBSISTENCE FOR THE DAY

While Theravada Buddhism may technically be considered a philosophy rather than a religion (there is no 'God') Thai Buddhism is infused with many spiritual beliefs which are likely the result of lingering animist and Hindu beliefs from centuries earlier. Most Thai homes and places of business feature a 'spirit house' just outside the building, where offerings are made to appease spirits that might otherwise inhabit their homes or workplaces. Furthermore, Buddhist monks are often brought to new homes and businesses to 'bless them', and Thai people frequently light incense and make prayers to both Buddha images and a host of Hindu gods whose shrines are located throughout Bangkok and the countryside. (TRADITION, RESPECT, DEVOUT OF RELIGIOUS RITES, BELIEFS, AND SYMBOLS LIKE BUDDHA)

The next largest religion in Thailand, Islam, is practiced by only about $4 \%$ of the population; the majority of Thai Muslims live in the most southerly provinces near the Malaysian border. Other religions in Thailand include Hinduism, Confucianism, Taoism, and Christianity, which are generally practiced by those living in Bangkok, where a multi-cultural population includes citizens of Indian, Chinese, Japanese, and European descent. (UNIVERSALISM, UNDERSTANDING OF DIFFERENT RELIGIONS, TOLERANCE, PROTECTION FOR THE WELFARE OF ALL PEOPLE)

$\underline{\text { Social Life }}$

Vietnam

Social life plays a big role among the people in Vietnam. It is the root why people value selfdirection and independence. Just like the protagonist Ms. Phan in the story "An Unsound Sleep" by Nhat -Tien. They have the habit of being faithful and loyal to Mahayana Buddhism in 1963. Vietnamese life is profoundly influenced by ancestor worship. Children learn at a very early age that they owe everything to their parents and their ancestors. Doing well in school and working hard honours one's parents and the family name. Respect for parents and ancestors is extended to all elders, whose life experiences are valued.(CONFORMITY TO 


\section{SOCIAL NORMS, OBEDIENCE, POLITENESS TO HONOR PARENTS AND ELDERS)}

Marriage and family are very important in Vietnam. In the countryside, parents often arrange marriages; divorce remains uncommon, though is more frequent in cities. In traditional Vietnamese families, roles are rigid. The man of the house is primarily responsible for the family's economic wellbeing and takes pride in his role as provider. Women are expected to submit to their husbands or to their eldest sons when widowed, and girls to their fathers. Older children help to look after younger siblings. Discipline is viewed as a parental duty, and spanking is common once children are past early childhood.(CONFORMITY OF THE SOCIAL NORMS, OBEDIENCE, SELF-DISCIPLINE, POLITENESS, HONORING PARENTS, AND LOYALTY)

The woman of the house is referred to as nôi tuong, "General of the Interior." She looks after her in-laws as well as her parents, husband and children. In rural areas, women also do much agricultural work. Vietnamese women live by the "four virtues": hard work, beauty, refined speech and excellent conduct. (STIMULATION AND CHALLENGE IN LIFE)

Communism in the 1960's brought big changes for women, who were suddenly given equal economic and political rights, as well as the right to choose their own husband. Years of warfare and dislocation in camps have also altered family roles. With so many men away at war, women took on many traditionally male duties, including managing factories and co-operatives. (SELF-DIRECTION AND INDEPENDENT THOUGHT)

More people are moving to cities, but most Vietnamese are still farmers. Houses are sometimes built on stilts to avoid flooding. Materials such as earth, straw and bamboo may be used for walls, and red clay tiles or sheets of corrugated metal for roofs. City homes are often made with brick, wood and/or tile. (STIMULATION AND CHALLENGE IN LIFE)

Table 1: Cultural Values of 35 Short Stories of Selected South East Asian Countries Based on the Ten Motivational Types of Values

\begin{tabular}{|c|c|c|}
\hline Cultural Values & Frequency & Percentage \\
\hline $\begin{array}{l}\text { Self Direction } \\
\text { - } \text { Creativity } \\
\text { - } \quad \text { Freedom }\end{array}$ & 4 & $11.43 \%$ \\
\hline $\begin{array}{l}\text { Stimulation } \\
\text { - Exciting life }\end{array}$ & 3 & $8.57 \%$ \\
\hline $\begin{array}{l}\text { Hedonesian } \\
\text { - Pleasure }\end{array}$ & 3 & $8.57 \%$ \\
\hline $\begin{array}{l}\text { Achievement } \\
\text { - Success } \\
\text { - Ambition }\end{array}$ & 6 & $17.14 \%$ \\
\hline $\begin{array}{l}\text { Power } \\
\text { - Authority } \\
\text { - Wealth }\end{array}$ & 2 & $5.71 \%$ \\
\hline $\begin{array}{l}\text { Security } \\
\text { - Social order }\end{array}$ & 4 & $11.43 \%$ \\
\hline $\begin{array}{l}\text { Conformity } \\
\text { - Obedience }\end{array}$ & 3 & $8.57 \%$ \\
\hline $\begin{array}{l}\text { Tradition } \\
\text { - Humility } \\
\text { - Devoutness }\end{array}$ & 3 & $8.57 \%$ \\
\hline $\begin{array}{l}\text { Benevolence } \\
\text { - Helpfulness }\end{array}$ & 4 & $11.43 \%$ \\
\hline $\begin{array}{l}\text { Universalism } \\
\text { - Social Justice } \\
\text { - Equality }\end{array}$ & 3 & $8.57 \%$ \\
\hline
\end{tabular}

The table shows the frequency and percentage distribution of cultural values of 35 stories from seleted South East Asian Countries. Four out of the
35 stories stories (11.83\%) are focused on selfdirection values such as creativity and freedom; three stories $(8.57 \%)$ embodied stimulation; four stories 
(11.83\%) tackled hedonesion; six stories (17.14\%) emphasized the value of achievement; two stories $(5.71 \%)$ presented power; four stories $(11.43 \%)$ are focused on security and social order; three stories $(8.57 \%)$ are anchored on the values of conformity and obedience; three stories $(8.57 \%)$ are related to tradition such as humility and devoutness; four stories $(11.43 \%)$ are centered on benevolence; and three stories $(8.57 \%)$ presented universalism specifically social justice and equity.

4) How were the cultural values among the selected Southeast Asian countries compared based on the ten motivational types of values as reflected in the short stories?

Conformity and honoring parents and elders are very dominant in the short stories of Indonesia and Malaysia. In the story "Meant for Each Other" by Abdul Muis - eighteen year old girls are already responsible in considering social norms and reputation. Ratna instructed her suitor Suparta to return to Djakarta. She said to him "When we are older we will surely meet again. If we are meant for each other, we will surely meet again." and "Inem" by Pramoedya Ananta Toer (Indonesia) Inem's mother wants her to marry Markaban after the harvest is over. But Inem is only eight years old. But they need the dowry. It is the only way they can get the money. "A Question of Dowry" by Siew Yue Killingley (Malaysia) The necklace represents the dowry in the story. The dowry symbolizes materialism of men in Hindu tradition. Chauvinism and superiority of men in India is part of their old culture. Conformity and honoring parents and elders were not given so much emphasis in countries like Myanmar, Philippines, Singapore, Thailand and Vietnam.

Achievement is very dominant in the short stories of Indonesia, Myanmar, Philippines, and Vietnam like in "The Kindergarten Teacher" by Aung Thinn (Myanmar). The leading character struggles against low budget and poverty but willing to teach almost all subjects; "The Carat 13Diamond" by Daw Khin Myo Chit (Myanmar) It was during the dark days of the Japanese occupation in Burma, It was difficult to believe that the couple had to live on the edge of starvation yet, they managed to get employment in a government office. "This Realm of Humans" by Khin Hnin Yu (Myanmar) Indeed, the wife has lived a poor life! Perhaps almost a miserable life in order to economize a lot but after several years, they have lived happily in their little bungalow. "Soldier" by Nugroho Notosusanto (Indonesia) Lance Corporal Tatang was a veteran of the revolution since during the Dutch offensive in 1947 and until the subsequent operations against the Communists in 1956. "The House On Zapote Street" by Quijano de Manila (Philippines) the major characters Lydia and Leonardo Quitangon are medical doctors yet mild mannered and unspoiled people; and "New Virtue" by Nguyen Ban (Vietnam) Everybody had suffered the war of the French colonialist invaders. She had done her best to get rid of soiled life and to create a new one. She was a new woman, painstaking and active, this was clearly shown in her daily work. It was not given so much emphasis in countries like Malaysia, Singapore, and Thailand.

$\underline{\text { Self-direction and creativeness are very dominant }}$ in the short stories of Singapore, Thailand and Vietnam, like in "An Unsound Sleep by Nhat - Tien (Vietnam) $\mathrm{Su}$, one of the major characters in this masterpiece has always been bringing good news of the underground struggles against the government. The youth gives a careful analysis of the situation in Central and South Vietnam. Su gives his assurance that after the revolution, there will be freedom of religion, faith, freedom of the press, and freedom of speech. The black markets and smuggling of illegal goods will be stopped. All the fraudulent capitalists and profiteers will be exterminated... "The Cradles" by Mai Ngu (Vietnam) One day the Old Blind got a tender green stemmed bamboo - tree to weave a basket for fishing. The daughter midwife asked him to make cradles for babies and to lull them to sleep. Old Blind wove cradles with all the skill of his fingers and love of his elated heart. Only now that he was on the shady side of seventy was he given a job to his liking. In "Bugis" by Alfian Sa'at (Singapore) A Malay woman walks in. She holds on to the strap of her handbag. She is wearing high-heeled shoes. She has high cheekbones. She is wearing spaghetti strap dress that shows her tights. But she has Adam's apple. The Malay lady is a man, "pondan" or transvestites. She has fake fingernails, fake wig, fake breasts, and fake shaven shins. "Lord Buddha, Help Me by Suchit Wongthred (Thailand) Maha Bunman reached the level of Parien III and enjoyed the title of Buddhist Scholar of the First Rank but he had resigned from the monkhood almost three months ago. He has left the monkhood to fight the world. Yet the world is so cruel to him. Self-direction and creativeness are not given so much emphasis in countries like Indonesia, Malaysia, Myanmar, and the Philippines.

Security and stability of society are very dominant in the short stories of Vietnam, Thailand, Singapore, and Philippines. There are four short stories that have discussed the mentioned cultural values. "My Milk Goes Dry" by Minh-Quan (Vietnam) It's because none of those Frenchmen is allowed to suck the breast of his mother. White men are not human beings, they are all devils. If a child is fed with animal milk, he is deprived of all human sentiments when he grows up. These barbarous people were always planning to corrupt the Annamite. "The Grandmother" by K. Surangkhanang (Thailand) The old grandmother had 
brought up with all due care her own daughter until she got married. But still had to depend on her old mother. Instead of being cared for, the old mother had to go out to peddle in order to support them all even the little grandchildren. "The Martyrdom of Helena Rodrigues" (Singapore) Both father and son gave in to Helena's wishes and sacrificed themselves as a woman would do to fit into society. Caroline played an important role that pushed George to move away from his mother and become more like a male but he falls to his mother in the end, and "Clay" by Juan T. Gatbonton (Philippines) Subservience to the dictates of the US, courting political disaster. Needless to say, culture during this period developed according to the ideological direction set by the U.S. As a former colony of the US, the Philippines upheld the line that the salvation of the world lay with free enterprise and American protection against communism. Security and stability of society were not given so much emphasis in countries like Indonesia, Malaysia, and Myanmar.

Schwartz' Benevolence and concern for family, primary groups, and for others' welfare are very dominant in the short stories of Indonesia, Malaysia, Myanmar, and Thailand. The four short stories are "Victoria and Her Kimono" by M. Shanmughalingam (Malaysia) The very amusing "Victoria and Her Kimono" might serve as an example of the manner in which the writer chooses to parody both the inherited legacy of colonialism and the dramatic confrontations of this. Such confrontations clearly marked the dawning of a new age of literary sensibility, resulting in the creation of authentically relevant and appropriate responses to the living experiences of ordinary men and women, who went about their everyday affairs alienated from and yet near enough the centre of the political nerves to sense and be affected directly by its policies. "Mother's Merit" by Thu Maung (Yangon, Myanmar) Mother Nyo is a devout Buddhist who does not pray long and loud every night. She does not attend sessions at meditation centres in order to reach a higher status of mind. She is also not the type to gather merit by giving Soon Kyway feasts for monks and guests on a monthly or even a bi-yearly basis. She in her own way lives her life with a charitable nature, a generous heart and a peaceful mind. "Sri Sumarah" (Indonesia) Sri Sumarah depicts powerful mother - daughter ties as stabilizing and self-assertive factors which provide women with the strength to endure misfortunes and adjust to changing times. "As If It Had Never Happened" by Witthayakon Chiangkun (Thailand). The narration pays indirect tribute to the students' energy, kindness, and naïve optimism. In their cheerful way they explain that "as school is now out, they have "the time to make the sacrifice of coming out to help improve the quality of the villagers' lives. Benevolence and concern for family, primary groups, and for others' welfare were not given so much emphasis in countries like Philippines, Singapore, and Vietnam.

The cultural values of stimulation and challenge in life are very dominant in the short stories of Vietnam, Thailand, and Philippines. The three short stories are "The Blind Alley" by Ma Van Khang (Vietnamese) Nihn suffered a lot during the French invasion. She dared not think of her shameful life. What was the good of thinking of it? It would only make her weep. She was already leading an easy life. "Michigan Test" by Wanit Jarungkit (Thailand) Because of growing economic and political uncertainty in Siam, and partly because of the semicolonial relationship with the US cemented in the 1960s, was the main contributor to the massive Thai migration in Southern California in the 1970s. "Children of the City" by Amadis Ma. Guerrero (Philippines) Victor, a third - grader, dropped out of school, to be employed as a newspaper boy. Victor's activist father was shot and killed when he was eight years old. Unfortunately, not long after his father's death, his mother abandoned him to be with her lover. Stimulation and challenge in life are not given so much emphasis in countries like Indonesia, Malaysia, Myanmar, and Singapore.

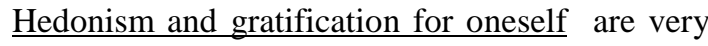
dominant in the short stories of Myanmar, Singapore, and Thailand. "The Effect of a Good Dinner" by Arthur Yap Singapore - More often than not, the husbands acquire new wives. It is never the policy for the wife to forbid her husband this little whim as long as he does not squeeze her allowance to rice powder. "Thong Proi The Rich Girl" by M.R. Kukrit Pramoj (Thailand) Thong Proi has decided to observe poor people. Ordinary people have been working all day under the scourging heat of the sun. People have been wearing shabbily torn clothes and they have experiencing hard lives. But is spite of difficult life, true happiness have always been there in their contented faces. "Neighbours" by Moe Moe (Inya) Myanmar - Intrusive, nosey, and gossiper kind of people are also like members of your own family. They care and they are willing to render a helping hand during difficult times. Hedonism and gratification for oneself were not given so much emphasis in countries like Indonesia, Malaysia, Philippines, and Vietnam.

Tradition, commitment to customs/traditions, culture and religion are very dominant in the short stories of Malaysia, Philippines and Singapore. The three short stories are "Mariah" by Che Husna Azhari(Malaysia) the Imam begged his loving, devoted wife named Cik Yam to forgive him, but asked for her permission to take a second wife. The virtuous wife said yes to the request, on condition of equality of treatment. "Grave Harvest" by Ajikik (Malaysia) - Highlights the modern values, religious teachings, and to criticize the ills of corrupt humanity 
in the Malay society. This relates also the hardships of the lower class or kampong life. The neighboring countries will understand better the Malaysian culture, lifestyles and problems. . . and "The Wedding Dance" by Amador T. Daguio - - LumnayShe does not want any other man than Awiyao. She has been a good wife. Awiyao has nothing to say against her. But unfortunately, seven harvests was just too long to wait for a child. She has prayed to Kabunyan so much. Still Kabunyan never blessed her a child. Well in fact, she has sacrificed many chickens during her fervent prayers. One of the best wives in the whole village is Lumnay so Awiyao does not want any other woman either. Tradition and commitment to customs/traditions, culture and religion were not given so much emphasis in countries like Indonesia, Myanmar, Singapore, Thailand, and Vietnam.

Universalism, nationalism, and protection for nature/environment, are very dominant in the short stories of Malaysia, Philippines, and Singapore. "A Common Story" by Kassim Ahmad Malaysia Yusuf must go back there in Malaysia to plant padi. $\mathrm{He}$ is bound up with the people there. He must go back to learn their language again. He has to learn their ways and live with them again. Perhaps, he will get back his soul. He wants his soul and the government cannot give it back to him. "The Tiger" by S. Rajaratnam (Singapore) The pregnant mother's disgust at the senseless killing of the pregnant tigress, which has left her undisturbed while she is bathing in the pool, is expressed positively in her cry for a doctor to attend to the birth of her child. Out of the brutal killing of the tigress has emerged a poignant birth - cry which is the mother's judgment on that brutality; and "The Day The Dancers Came" by Bienvenido N. Santos (Philippines) A story about an old timer Filipino in the USA. This story is a blend of irony and tenderness into the rootless and lonely lives of men residing in America but carrying their nationality like a winter coat they cannot discard. Universalism, nationalism, and protection for nature/environment were not given so much emphasis in countries like Indonesia, Myanmar, Thailand, and Vietnam.

Power, social status, control and dominance over people are very dominant in the short stories of Indonesia and Singapore. The Two short stories are "Monster" by Catherine Lim (Singapore) Sai Khong is ungrateful, indifferent, callous, insensitive son towards the Old Grandmother. He seems to be very busy with his work and golf course. and "The Decline and Fall of Our Local Mosque by A. A. Navis (Indonesia) Deals with yet a different world, the world of the rural village and the values of Islam. Navis is satirical, impious in the name of the greater piety, and has a thoroughly modern concern: that religion be rationalized, cleansed of superstition and egotism, and that it explains the present world as well as the next. Power was not given so much emphasis in countries like Malaysia, Myanmar, Philippines, Thailand, and Vietnam.

Although cultural values are often interdependent, they can be separated to study Southeast Asian societies. The individual level values theory has identified ten basic, motivationally distinct values that people in virtually all cultures implicitly recognize. Cultural values are one important, especially central component of our self and personality, distinct from attitudes, beliefs, norms, and traits. Values are critical motivators of behaviors and attitudes(Schwartz, 2012).

\section{CHAPTER 5}

Summary, Conclusions, And Recommendations

Summary of Findings

Elements that writers used to show cultural values in the chosen short stories

The relationship of the cultural values to the prevailing situations, conditions, and actual events during the time when the short stories were written.

The roles of the following aspects in the lives of Southeast Asian people as reflected in the identified cultural values in the short stories

Economy

Politics

Education

Religious Life

Social Life

Comparison of the cultural values among the selected Southeast Asian countries based on the ten motivational types of values.

Conclusions

1. The common elements of short stories used by the writers to bring out cultural values are plot, symbolism, characters, theme, setting, conflict, point of view.

2. The most effective element in bringing out cultural values are plot, symbolism, and characters.

3. The dominant cultural values per country are achievement, self-direction, and security.

4. Least cultural values per country are power and authority.

5. Dominant cultural values in Southeast Asia are Achievements, Self-Direction, Security, and Benevolence.

6. Least cultural values in Southeast Asia power and authority.

7. Common cultural values in Southeast Asia are stimulation, hedonism, conformity, respect of tradition, universalism/nationalism.

8. Role of economy in Southeast Asia's cultural values are the basic modes of production of coercion, capitalism, and peasant-intermediary industries. 
9. The usual effects of economic backwardness on Southeast Asian countries are aggression and territorial disputes, internal war, civil strife over religion, races, language and politics. Poverty, environmental deterioration and population explosion.economically, as the gap between the rich and the poor in Southeast Asian countries remains wide, cultural values influence their everyday attitude and behaviors towards economic realities of life.

10. Politically, some segments of ASEAN society are still marginalized due to government repression and/or dominance of Western educated elites who also control the economic resources of their countries. But the style of leadership will depend on the cultural values that they have lived and practiced educationally, religiously, and socially.

11.Common events like civil war, insurgencies, seccessionism, territorial/ethnic disputes will definitely be influenced by their respective cultural values since from the past to the present times.

Recommendations

The researcher presents the following recommendations:

1. Reading ASEAN short stories is a major activity of University students who wish to do well in their studies. Proficiency in reading brings about corresponding efficiency in writing because reading stimulates and develops the mind. Reading ASEAN short stories enriches the students' ideas and these ideas stimulate them in writing. University students, therefore, must be encouraged to read in order to write well. The students must stay at least an hour daily in the library reading Southeast Asian translated short stories.

2. Professors should be given as part of their advancement to have many meaningful seminars on how to teach World History, to teach and analyze fiction, and how to teach scientific writing.

3. Venues for communication like small group discussions, debates, and reports should be provided as exercises in the sequential or logical presentation of ideas using Southeast Asian short stories as possible topics highlighting the significant differences in terms of cultural values, social norms, religious perspectives, and political mores.

4. Professors should be encouraged to attend seminars/workshops on writing techniques to increase their Globalization/International knowledge and update their research and teaching methodologies and strategies.
5. Essay type of tests should be included in all subject areas to improve the students' skills in writing effectively.

6. The short stories of seven Southeast Asian countries presented in this study should be tried out by the Professors in order to encourage College students to appreciate the multicultural heritage and values of neighboring countries.

7. School publications and writing contests conducted by different universities should motivate students to write. They should encourage students to contribute creative outputs for publication.

8. Reading and writing must be planned. College students must be properly motivated. Students can write more effectively if they are shown model compositions about diverse Southeast Asian literatures.

9. The International Studies Department must meet the faculty for two purposes: a.) to discuss special problems on International Relations and comparative foreign policies of major powers and colonizers using world literature materials.

10. A conscientious use of the Southeast Asian short stories translated in English will surely make the College students discover further the comparison in their diverse cultural values and to authenticate the validity and practicality of this study.

\section{References}

1) Abad, G. H. (2005). The likhaan anthology of Philippine literaturein english from 1900 to the present. Quezon City: The University of the Philippines Press.

2) Abarquez, M. L. G. (2012). Evaluating the integrated literature - Skills framework in teaching reading and language in the primary grades. Unpublished master's thesis, University of the Philippines, Quezon City.

3) Abdullah, H., A. Adnan, and N. Rahman. (2012). The secondary school Englishlanguage Reading curriculum: A teacher's perceptions. Bandung: Indonesia University of Education.

4) Ahmad, K. B. and Jory, P. (2011). Islamic studies and Islamic education incontemporary Southeast Asia. Kuala Lumpur: YayasanIlmuwan Press.

5) Almond, B. (2010). Education for tolerance: Cultural difference and family values. Journal of Moral Education, 39 (2): 131-143.

6) Anavesa, J. M. (2012). Development of reading comprehension using selected songs. Unpublished master's thesis, University of the Philippines, Quezon City.

7) Anderson, B.R. O'G. (1985). In the mirror: Literature and politics in Siam in the American era. Bangkok: Editions Duang Kamol.

8) Andrew, H. (2012). Developing intercultural competence in university staff: Augmenting internationalisation. Melbourne: Deakin University Press.

9) Angelides, M. (1997). An introduction to Asian and Asian American fiction. Meramec: St Louis Community College Press.

10) Astrida, L. S. (2010). An Indonesian English translation of a short storyTerjadinyaselat. East Jakarta: Gunadarma University.

11) Athamesara, R., and Wallace, M. (2004). The Thai community curriculum as a model for multicultural education. International Education Journal 5 (1): 50-64.

12) Atkinson, D.R. and Sanchez, L.R. (2009). The relationships between Mexican-American acculturation, cultural values, 
gender, and help-seeking intentions. Journal of Counseling \& Development. 87.

13) Aveling, H. (1976). From Surabaya to Armageddon Indonesian short stories. Singapore: Toppan Printing Press.

14) Bain, C. E., Beaty, J. and Hunter, J.P. (1986). The Norton introduction to literature. New York: W.W. Norton \& Company, Inc.

15) Baltazar, H.M. (1997). Analysis of selected short stories of Jose Garcia Villa. Unpublished master's thesis, University of Centro Escolar, Manila.

16) Baritugo, M.R. et al.2007. Philippine Literature: An introduction to poetry, fiction, and drama. Manila: Book Antiqua Press.

17) Bayr, K. B., L. Brown, and George P. (1999). West meets east in Malaysia and Singapore. Fulbright-Hays summer seminars abroad program. Penang: Universiti Sains Malaysia.

18) Bethel, W.G., et al. 2005. Comparative study on the use of demographic and socio-economic information in coastal and fisheries management planning and conservation in Malaysia and the Philippines. Trinidad and Tobago: United Nations Development Programme.

19) Biber, P., Hupfeld, J. and Meier, L. (2008). Personal values and relational models. European Journal of Personality. (22): 609-628.

20) Bilsky, W. and Schwartz S.H.. (1994). Values and personality. European Journal of Personality (8): 163-181.

21) Blances, R.B. Background on Philippine Literature. Retrieved on May 14, 2014 from www.scribd.com/doc/230241463/Background-on-PhilippineLiterature

22) Boccuzzi, E. and Masavisut, N. (2008). In celebration of ASEAN's $40^{\text {th }}$ anniversary and SEA writers' $30^{\text {th }}$ anniversary. Bangkok: Amarin Printing and Publishing Press.

23) Braginsky, V. and Murtagh, B. (2007). The portrayal of foreigners in Indonesian and Malay literatures. New York: The Edwin Mellen Press.

24) Brooks, C., Purser, J.T. and Warren, R.P. (1975). An approach to literature. NJ: Prentice-Hall, Inc.,Englewood Cliffs.

25) Brown, S. P. Cultural Values and Personal Ethics Retrieved on May 14, 2014 from http://EzineArticles.com/?expert=Steven Phillip Brown

26) Bunanta, M. (2003). Indonesian folktales. Connecticut : Greenwood Publishing Press.

27) Burdick, S., et al. (2009). Education, values, and valuing in cosmopolitan perspective. Wiley Periodicals (39):5

28) Carpio, R. C. (2006). Crisscrossing through Afro-Asian literature. Pasig: Anvil Publishing Inc.

29) Carrier, W., Oliver, K. and O' Neal, R. (1980). Guide to world literature. Illinois: University of Chicago Press.

30) Castellanos, J., et al. (2008). Adherence to Asian cultural values and cultural fit in Korean American undergraduates' help-seeking attitudes. Journal of Counseling and Development. Vol. (86).

31) Chan, J. and Parr, G. (2012). Intercultural teacher education: challenges and ethical dilemmas on an international practicum. Melbourne: Monash University Press.

32) Chandler, D., et al (2004). The emergence of modernSoutheast Asia. Singapore: National University of Singapore Press.

33) Chavalit, K.M. (1997). Inthanon: an anthology of short stories by ASEAN writers. Bangkok: ASEAN committee on culture and information.

34) Chee, T. S. (1981). Essays on literature and society in Southeast Asia. Kent Ridge : Singapore University Press.

35) Chhuon, V., Hudley, C. and Macias, R. (2006). CambodianAmerican College Students: Culturalvalues and multiple words. Santa Barbara: University of California Press.

36) Chi, Feng-Ming. (1999). Reading as transaction in EFL: A thematic analysis. Department of foreign languages and literature. Taiwan: National Chung Cheng University.
37) Christiansen, X. L. C. and Silver, R.E.. (2012). Educational reforms, cultural clashes and classroom practices. Cambridge Journal of Education. 42 (2): 141-61.

38) Constantine, M., and Miville, M. (2007). Cultural values, counseling stigma, and intentions to seek counseling among Asian American college women. American Counseling Association. V. 52.

39) Crose, B. (2011). Internationalization of the higher education classroom: Strategies to facilitate intercultural learning and academic success. International Journal of Teaching \& Learning in Higher Education. 23 (3): 388-395.

40) Cruz, I.R. (2000). The best Philippine short stories of the twentieth century. Makati : Tahanan Books.

41) Davidson, A.K., and Inman, A.G. (2012) Predictors of cultural values conflict for Asian Indian women. Journal of multicultural counseling and development. V(40)

42) Day, T. and Liem,M.H.T. (2010). Cultures, at war. The cold war and cultural expression in Southeast Asia. MS University Press of Mississippi.

43) De Jesus, S.D.M. (2005). Elements in selected short storie of representative of Southeast Asian countries. Unpublished $\mathrm{PhD}$ 's dissertation, Centro Escolar University, Manila.

44) Dimalanta, O.A. and Mata, V.M. (2001). Philippine contemporary literature in English: Tradition and change (from the 20's to the present). Manila : UST Publishing House.

45) Dostal, J.M. (2004). Generalization and limitation of the Schwartz' social values scale. Ohio: Cleveland States University.

46) Dubas, Engels,J.J. and Roest, A. (2009). Value similarities among fathers, mothers, and adolescents and the role of a cultural stereotype: Different measurement strategies reconsidered. Journal of research on adolescence.19 (4) 812-833.

47) Durand, M.M. and Huan,N.T. (1985). An introduction to Vietnamese literature. New York : Columbia University Press.

48) Echols, J.M. (2009). Indonesian writing in translation. Indonesia: Equinox Publishing.

49) Edmonds, I.G. (1978). Buddhism: A first book. New York: Frabklin Watts.

50) Edulag, D. (2012). Analysis of the commonalities and diversities of traditionalfolkloric beliefs and practices in selected Southeast Asian countries: Implications to local culture for peace and unity. Unpublished PhD's dissertation, Centro Escolar University, Manila.

51) Elgin, M. (2010). Asian Values. California: Stanford University Press.

52) Erkaya, O. R. (2005). Benefits of using short stories in the EFL Context. Asian EFL Journal. 8 1-13.

53) Fernando, L. (1974). Twenty-two Malaysian stories. Singapore: Heinemann Educational Books.

54) Flores, E. M. (2002). Comics crash a survey of Filipino comics and its quest for cultural legitimacy. Quezon: University of the Philippines Press.

55) Frederick, W. H. 1983. Reflections on rebellion: Stories from the Indonesian upheavals of 1948 and 1965. Ohio: Center for International Studies.

56) Gopalakrishnan, S., E. Kessler, S. Khilji, D. Woi. 2013. Cross-culturalcomparison of cultural mythologies and leadershippatterns. South Asian Journal of Global Business Research. 3 (1): 79-101.

57) Gouveia, V., and M. Ros. 1999. Hofstede and Schwartz's models for classifyingindividualismattheculturallevel. Brazil: Experimental Social Psychology Laboratory.

58) Hakim, H.A. and Yassin. 2001. Anthology of ASEAN literature. Brunei: Asia Printers Press.

59) Halstead, J.and M. Taylor. 1996. Values in Education and Education inValues. Pennsylvania: Falmer Press.

60) Hamdani, H. 1983. Modern Malaysian stories. Kuala Lumpur: Percetakan Dewan Bahasa Dan Pustaka. 
61) Harris, E. 1993. Revitalizing and preserving cultural values: A qualitative study of two secondary schools. Houston: University Council for Educational Administration.

62) Hellwig, T. 1994. In the shadow of change: Women in Indonesian literature. Berkeley: University of California Press.

63) Hien, Mai Van. 1962. The white buffalo. Hanoi: Foreign Languages Publishing House.

64) Ingersoll, R.M. 2005. A comparative study of teacher preparation and qualifications in six nations. The Consortium for Policy Research in Education. US: Institute of Education Sciences.

65) Johns, A. H. 1979. Cultural options and the role of tradition. Canberra: Australian National University Press.

66) Johnson, D., J. Johnson. 1968. India through literature: An annotatedBibliography for teaching India. New Delhi: Educational Resources Center.

67) Jumsai, M.L.M. 2000. History of Thai literature. Bangkok: Sukhumvit Press.

68) Kanwar, A., and M. Taplin. 2001. Brave new women of Asia: How distance education changed their lives. Vancouver: Commonwealth of Learning.

69) Karlin, W., L.M. Khue and T. Vu. 1995. The Other Side of Heaven. Connecticut: The Curbstone Press.

70) Kendall, D. 2008. Sociology in our times: The essentials. Wadsworth Publishing.

71) Laygo, T.M. 1978. The Well of Time. Berkeley: Asian American Bilingual Center.

72) Lee, K-Y. 2012. Teaching intercultural English learning/teaching in world englishes: Some classroom activities in South Korea. English Teaching: Practice and Critique. 11 (4): 190-205.

73) Leichsenring, A. 2010. Values-based education in schools in the 2000s: The Australian experience. Unpublished master's thesis, Australian Federal Government.

74) Liem, A.D. and Y. Nie. 2008. Values, achievement, goals and individual-oriented and social-oriented achievement motivations among Chinese and Indonesian secondary school students. International Journal of Psychology 43 (5): 898903.

75) Lo, J.T-Y. 2010. The primary Social Education curricula in Hong Kong and Singapore: a comparative study. Research in Comparative \& International Education 5 (2): 144-55.

76) Logan, P. M. 2011. On culture: Edward B. Tylor

77) Lucero, R. D. The social content of contemporary Philippine poetry in English. Unpublished master's thesis, Centro Escolar University.

78) Ludwick, R. and M.C. Silva. 2000. Ethics Nursing around the world: Cultural values and ethical conflicts. On line Journal of Issues in Nursing volume 5 (3).

79) Lumbera, B. and C.N. Lumbera. 2007. Philippine literature A history and anthology. Rizal: Anvil Publishing, Incorporated.

80) Lumpas, R. 1996. Symbolism in Award-Winning Filipino short stories in English in the eighties. Unpublished master's thesis, Centro Escolar University, Manila.

81) Macionis, J. J. 2007. Society, the basics. $9^{\text {th }}$ edition. Upper Saddle River, N.J.: Prentice Hall.

82) Magno, C. 2010. Looking at Filipino pre-service teachers value for education through epistemological beliefs about learning and Asian values. The Asia-Pacific Education Researcher. 19 (1) 61-78.

83) Mahbubani, K. 1995. The Pacific way. Foreign affairs 74 (1): 100-11.

84) Manuel, A.R. 2010. Environmental literacy through songs and lyrics. Unpublished master's thesis, University of the Philippines, Diliman.

85) McGowen, C.S. and S. Moke. 1993. Teaching literature by women authors. Indiana University Press.

86) Mirci, P.S. 2010. In pursuit of educational justice and liberated hearts. Destech Publications, Inc. v 20.
87) Muhammad, N. 2009. A critical study of the educational system in Brunei Darussalam, in the light of Al-Attas. Unpublished Dissertation, University of Birmingham.

88) Mukherjee, D., M.A. Quayum and K. Singh. 2002. The Merlion and the hibiscus. Contemporary short stories from Singapore and Malaysia. New Delhi: Penguin Books India.

89) Nayan, G.A. 1995. The image of Filipino women in the Carlos Palanca Memorial Award-Winning short stories in English, 1973-1993. Unpublished master's thesis, University of Centro Escplar, Manila.

90) Oguz, E. 2012. Views of pre-service teachers on values and values education. Educational Sciences: Theory \& Practice Spring. 1320-1325.

91) Ortiz, W. P. 2008. Fictionalized history in the Philippines: Five narratives of collective amnesia. Children's literature in education 39: 269-280.

92) Ozturgut, O. 2012. Achievement gap and developing cultural competency skills for post - secondary teacher education program faculty. Missouri: National Study of Postsecondary Faculty.

93) Parlindungan, P. 2011. Using short stories to teach language skills. Journal of English Teaching. 1 (1): 14-27.

94) Perez, D. G. R. 1995. Filipino values in the selected short stories of Bienvenido N. Santos. Unpublished master's thesis, University of Centro Escolar, Manila.

95) Phillips, H.P. 1987. Modern Thai literature. Honolulu: University of Hawaii Press.

96) Qiang, Liu. 2004. Core Culture Values and Beliefs of Singapore. Nanyang Technology University.

97) Quisumbing, L.R. and F.P.Sta Maria. 1996. Values education through history. Peace and tolerance. Pasay City: UNESCO National Commission of the Philippines.

98) Schwartz, S.H. 2012. An overview of the Schwartz theory of basic values. Online Readings in Psychology and Culture, 2(1). http://dx.doi.org/10.9707/2307-0919.1116

99) Schwartz, S. H. 1999. A theory of cultural values and some implications for work. Applied Psychology: An International Review 48 (1): 23-47.

100) Schwartz, S.H. 2006. Basic human values Theory, measurement andapplications. Revue francaise de sociologies.

101) Shlensky, Jane. 1994. Short course in South Asian literature and culture. India: Educational Resources Information Center.

102) Sim, J.B.-Y. 2011. Social Studies and citizenship for participation in Singapore. Oxford Review of Education 37 (6): 743-61.

103) Smyth, D. 2000. The canon in Southeast Asian literatures. Great Britain: TJ International, Padstow, Cornwall.

104) Sobre-Denton, M.S. 2010. Theory reflections: Cultura value orientations. A cosmopolitan pedagogical framework to assess learning for global competency in Chicago's undeserved communities. International Journal of Intercultural Relations 40: 141-153.

105) Stiles, D.A. 2005. Societal influences on children's psychology: The schools in Iceland and Singapore promote prosocial values, positive self-concepts, and achievement in young adolescents. Oxford: Psychological Influences on Today's Children.

106) Sullivan, T. J. 2007. Sociology: Concepts and applications in a diverse world. Mishawaka, IN: Allyn \& Bacon.

107) Tan, C. 2012. Our shared values in Singapore. A Confucian perspective. Educational Theory 62 (4): 449-63

108) The Cultural and Social Centre \& Asian Pacific Council 1974. Asian and Pacific Short Stories.

109) Thomas, R. M. 1992. The nature of values: Education in Southeast Asia. Santa Barbara: University of California Press.

110) Tiempo, E.K. 2001. Literary criticism in the Philippines and other essays. Manila: De la Salle University Press.

111) Tin-Yau Lo, J. 2010. The primary social education curricula in Hongkong and Singapore: A comparative study. 
Research in Comparative and International Education. 5 (2).

112) Toer, P. A. 1999. Tales from Djakarta: Caricatures of circumstances and their human beings. New York: Southeast Asia Program.

113) Tope, L.R.R. 1998. Framing Southeast Asia Nationalism and the postcolonial text in English in Singapore, Malaysia and the Philippines. Quezon City: University of the Philippines Press.

114) Toth, M.D. 1971. Tales from Thailand. Tokyo: Charles E. Tuttle Company, of Ruthland, Vermont Press.

115) UNESCO. 1992. Education facing the crisis of values: Strategies for strengthening humanistic, cultural, and international values in formal and non-formal education. Paris, France.

116) Vathanaprida, S. 1994. Thai Tales. Colorado: Greenwood Publishing Group.

117) Veisson, M.T. 2010. Values of Estonian students, teachers, and parents. US-China Educational Review 6 (5): 67-75.

118) Wadley, S. 1975. Folk literature of South Asia. Journal of South Asian Literature 11 (1\&2).

119) Wang, Y. \& B. Yang. 2006. Exploring the effects of cultural values and beliefs on cross - cultural training. University of Minnesota Press.

120) Walean, H.A. 1992. A descriptive analysis of conversational strategies employed by Indonesian and native speakers of English. Unpublished master's thesis, University of the Philippines

121) Wei, T.T. 1989. Moral education in Singapore: A critical appraisal. Journal of Moral Education 23 (1)

122) Yeo, R. 1982. Singapore short stories. Singapore: Hoong Fatt Press.

123) http://www.amazon.it/Opium-Java-Enterprise-Indonesia1860-1910/dp/9793780495

124) https://answers.yahoo.com/question/index?qid=20070106092 729AAlGNh7

125) http://files.eric.ed.gov/fulltext/ED509127.pdf

126) http://www.hjenglish.com/nba/p583026/

127) http://www.freeessays.tv/b2175.htm

128) http://www.studymode.com/essays/Divergent-Cultures$1764060 . \mathrm{html}$

129) http://www.essaypride.com/essays.php?free_essay=5851404 \&title=Engineer

130) http://www.123helpme.com/search.asp?text=paragraphs

131) http://www.123helpme.com/search.asp?text=engineers

132) http://www.mediahex.com/Pitohui

133) http://www.hjenglish.com/meishi/p583026/

134) http://www.mediahex.com/Short_Story

135) http://referat-best.ru/Liter_glossary/section-23.html

136) http://hamiddin.com/wp-content/uploads/2012/09/MateriIntro-to-Lit-Prose-Poetry-and-Drama.pdf

137) http://soodarooinlove.blogspot.com/2004/12/brief-lecture-onhistory-of-short.html

138) http://www.studymode.com/essays/Polities-1512126.html

139) http://www.academia.edu/1066160/Looking_at_Filipino_pre service_teachers_value_for_educaton_through_epistemologi cal_beliefs_about_learning_and_Asian_values

140) http://www.docin.com/p-670601993.htm

141) http://www.asianinfo.org/asianinfo/malaysia/progeography.htm

142) http://www.travelbelle.com/malaysia.htm

143) http://www.iproperty.com.my/MM2h/overview.aspx

144) http://un.or.th/thailand/geography.html

145) http://www.geometry.net/detail/basic_c/climatic_regions_geo graphy_page_no_4.html

146) http://www.un.or.th/services/geography-2/

147) http://geography.howstuffworks.com/asia/geography-ofvietnam1.htm

148) http://mrstouristgeography.blogspot.com/

149) http://globserver.cn/en/vietnam/geography
150) http://www.asianinfo.org/asianinfo/myanmar/progeography.htm

151) http://globserver.cn/node/3611

152) http://www.indonesiapoint.com/geography-of-indonesia.html

153) http://www.asianinfo.org/asianinfo/indonesia/progeography.htm

154) http://www.asiaworldindonesia.com/indonesia-at-glance

155) http://mymyanmartravels.com/about myanmar.php

156) http://www.myanmarcartrade.com/about-myanmar

157) http://seangallaghersite.com/yahoo site admin/assets/docs/A rticle_Basic_Human_Values.22707.doc

158) http://www.yourmorals.org/schwartz.2006.basic\%20human\% 20values.pdf

159) http://www.studymode.com/essays/Basic-Human-Values843740.html

160) http://www.marimari.com/content/singapore/general_info/ge ography/geography.html

161) http://thephilippines.ph/the_philippines_guide/climate-of-thephilippines/

162) http://www.loc.gov/today/placesinthenews/archive/2010arch/ 20101018_philippines.html

163) http://jerrychan89522.blogspot.com/2010/04/geography-ofsingapore.html

164) http://singaporepackages.com/about singapore.htm

165) http://scholarworks.gvsu.edu/cgi/viewcontent.cgi?article=111 $6 \&$ context $=$ orpc

166) http://www.nafsa.org/_File/_/theory_connections_values.pdf

167) http://www.humbleisd.net/cms/lib2/TX01001414/Centricity/ Domain/2400/Cultural_Values_and_Knighthood_Notes.ppt

168) $\mathrm{http}: / /$ scholarworks.gvsu.edu/cgi/viewcontent.cgi?article=111 $6 \&$ context $=$ orpc

169) http://www.nafsa.org//File//theory_connections_values.pdf

170) http://www.humbleisd.net/cms/lib2/TX01001414/Centricity/ Domain/2400/Cultural_Values_and_Knighthood_Notes.ppt

171) http://www.digitaltermpapers.com/b2175.htm

172) http://www.aseanfic.org/asean/

173) http://www.123helpme.com/view.asp?id=64262

174) http://www.pgey.com/pdf/cultural-values-definition.html

175) http://www.studymode.com/essays/Divergent-Cultures1764060.html

176) http://en.wikipedia.org/wiki/Association_of_Southeast_Asian Nations

177) http://gened.kmutt.ac.th/paper/meterialGEN111_562/ASEAN.pptx

178) http://quizlet.com/64538586/flags-of-asean-countries-flashcards/

179) http://en.wikipedia.org/wiki/Association_of_Southeast_Asian _Nations

180) http://gened.kmutt.ac.th/paper/meterialGEN111_562/ASEAN.pptx

181) http://quizlet.com/64538586/flags-of-asean-countries-flashcards/

182) http://www.mjliebhaber.com/psyc354/articles/Almond2010Education\%20for\%20tolerance$\% 20$ cultural $\% 20$ difference $\% 20$ and $\% 20$ family $\% 20$ values.pdf

183) http://www.asiaeducation.edu.au/for teachers/professional le arning/languages/professionallearningproject/intercultural la nguage learning/learning program resources/ill res 5 back ground.html

184) http://panitikan.hostingsiteforfree.com/criticism/comicscrash htm

185) base.de/lehre\%5Clv_materialien.nsf/intern01/86A6F70E229 D92A6C1257871005977E8/\$FILE/Schwartz\%20$\%$ 20Cultural\%20Values, \%20Work\%20Values.pdf

186) http://wwwkrcmar.in.tum.de/lehre\%5Clv materialien.nsf/inte rn01/A80807EF667B9BDFC12576DB005BDA44/\$FILE/7 $\% 20-\% 20$ Cultural\%20Values,\%20Work\%20Values.pdf

187) http://files.eric.ed.gov/fulltext/ED492597.pdf

188) http://www.digitaltermpapers.com/b2175.htm

189) http://www.freeessays.tv/b2175.htm

190) http://www.pgey.com/pdf/cultural-values-definition.html

191) https://www.scribd.com/doc/32721186/Renato-ConstantinoThe-Miseducation-of-the-Filipino 
192) http://hrsbstaff.ednet.ns.ca/engramja/elements.html

193) https://dahliasagucio.wordpress.com/2013/11/09/elementsof-a-short-story/

194) http://ideasforenglish.files.wordpress.com/2012/11/shortstory-qwertyuiop.pdf

195) https://answers.yahoo.com/question/index?qid=20080122120 638AAYrkqK

196) http://bourguignon.weebly.com/uploads/3/7/9/3/3793303/con flict_and_character_handout.doc

197) http://msfellenglish.weebly.com/short-stories.htm

198) http://ideasforenglish.files.wordpress.com/2012/11/shortstory-qwertyuiop.pdf

199) https://answers.yahoo.com/question/index?qid=20080122120 638AAYrkqK

200) http://bourguignon.weebly.com/uploads/3/7/9/3/3793303/con flict_and_character_handout.doc

201) http://msfellenglish.weebly.com/short-stories.htm

202) http://hrsbstaff.ednet.ns.ca/engramja/elements.html

203) http://teacherweb.com/LA/AbneyElementary/GrossSmith/apt2.aspx

204) http://mystique-mel.blogspot.com/2011/04/literarystoryelements.html

205) http://www.ssdcougars.org/webpages/mrizzio/monthly.cfm?s ubpage $=711417$

206) http://www.enotes.com/topics/an-unsound-sleep

207) http://someonetyping.blogspot.com/2011/04/everythingsarranged-question-of-dowry.html

208) http://kmhouseindia.blogspot.com/2012/03/malaysia.html

209) http://en.wikipedia.org/wiki/Malaysia

210) http://malaysia4tours.blogspot.com/2010/11/history-ofmalaysia.html

211) http://www.kirjasto.sci.fi/shahnon.htm

212) http://www.upa.pdx.edu/IMS/currentprojects/TAHv3/Conten t/PDFs/1954_Geneva_Declaration_Indochina.pdf

213) http://www.upa.pdx.edu/IMS/currentprojects/TAHv3/Conten t/PDFs/1954_Geneva_Declaration_Indochina.pdf

214) http://vietnam--war.wikispaces.com/The+Vietnam+War+\%28home\%29

215) http://raoulnorotin.blogspot.com/2008/12/final-declarationsof-geneva-conference.html

216) http://vi.uh.edu/pages/buzzmat/geneva.htm

217) http://www.upa.pdx.edu/IMS/currentprojects/TAHv3/Conten t/PDFs/1954_Geneva_Declaration_Indochina.pdf

218) http://vietnam--war.wikispaces.com/The+Vietnam+War+\%28home\%29

219) http://militaryhistory.about.com/od/vietnamwar/tp/vietnam10 $1 . h t m$

220) http://www.brainia.com/essays/Vietnam/294243.html

221) http://triptriangle.com/page/Vietnam.html

222) http://www.news.nom.co/vietnam/wikipedia/

223) http://www.angusrobertson.com.au/books/opium-to-javajames-r-rush/p/9789793780498
224) http://1337x.to/torrent/95489/Opium-to-Java-RevenueFarming-and-Chinese-Enterprise-in-Colonial-Indonesia1860-1910/

225) http://www.amazon.it/Opium-Java-Enterprise-Indonesia$1860-1910 / \mathrm{dp} / 9793780495$

226) http://www.markedbyteachers.com/internationalbaccalaureate/world-literature/the-supremacy-of-fright-inthe-tiger-by-s-rajaratnam.html

227) http://ajarnjohn.com/about-fluency/our-stories/thong-proi/

228) http://en.wikipedia.org/wiki/Burmese_Way_to_Socialism

229) http://www.cyclopaedia.de/wiki/Burmese_Way_to_Socialis

230) http://www.cyclopaedia.info/wiki/Burmese-socialism

231) http://www.pearltrees.com/tfkempo/independantburma/id9975832

232) http://estrodariatnosihaloho.blogspot.com/2011/02/economyof-burma.html

233) http://countries.wikia.com/wiki/Republic_of_the_Union_of_ Myanmar

234) http://en.wikipedia.org/wiki/Burmese_Way_to_Socialism

235) http://www.quickiwiki.com/en/Communist_Party_of_Malaya

236) http://en.wikipedia.org/wiki/Malayan_Communist_Party

237) http://sgwiki.com/wiki/Bugis_Street:_transgender_aspects

238) http://en.wikipedia.org/wiki/Bugis_Street

239) http://sporelgbtpedia.shoutwiki.com/wiki/Bugis Street: trans gender aspects

240) http://thinkappleworm.blogspot.com/

241) http://thinkappleworm.blogspot.com/2009/07/martyrdom-ofhelena-rodrigueshow-are.html

242) http://en.wikipedia.org/wiki/Day the Dancers_Came

243) https://www.scribd.com/doc/82894902/The-Small-Key

244) http://en.wikipedia.org/wiki/The_Day_the_Dancers_Came_a nd_Other_Prose_Works

245) https://esteves101.wordpress.com/

246) https://www.scribd.com/doc/87428346/79961836-the-Houseon-Zapote-Street

247) http://www.studymode.com/essays/Children-Of-The-City1878897.html

248) https://www.scribd.com/doc/106846614/Children-of-theCity-by-Amadis-Guererro

249) http://www.answers.com/Q/What is a summary of Childre $\mathrm{n}$ of the City by Amadis Ma Guerrero

250) https://www.scribd.com/doc/250521317/Wedding-Dancedocx

251) http://www.sushidog.com/bpss/stories/clay.htm

252) http://burakatlangis.blog.com/

253) http://opinion.inquirer.net/80265/hellhole-in-manila

254) https://www.scribd.com/doc/250521317/Wedding-Dancedocx

255) http://www.asianinfo.org/asianinfo/indonesia/prohistory.htm

Appendices

Elements of Fiction Guide INEM by PRAMOEDYA ANANTA TOER (1952) Indonesia

\begin{tabular}{|c|c|}
\hline Characters & $\begin{array}{l}\text { INEM - She was just like all the other girls, except that she was thought to be rather pretty. } \\
\text { People liked her. She was polite, natural, intelligent and a good worker. Because of this she } \\
\text { quickly became well-known in the village and people began to say: "Inem would be a good } \\
\text { daughter-in-law to have." Inem's mother lived on what she earned making batik. In their } \\
\text { village women made batik when they weren't working in the fields. The poor made headbands } \\
\text { because they were easier to make and one got paid more quickly. Inem's mother made } \\
\text { headbands. } \\
\text { - Inem's FATHER was a professional cock-fighter. He gambled each day with his } \\
\text { winnings. If he lost, the winner took his rooster and anything from three farthings } \\
\text { to a dollar. If he won, he played cards with the neighbors for farthings. Sometimes } \\
\text { he was away for a month at a time. When he returned it meant that he had money } \\
\text { again. Father robbed people in the teak forest between Blora and the coastal town } \\
\text { of Rembang. Well, people heard a lot of stories about robbers, pirates, thieves and } \\
\text { murderers. }\end{array}$ \\
\hline
\end{tabular}




\begin{tabular}{|c|c|}
\hline Point of View & $\begin{array}{l}\text { - Innocent Eye - The story is told through the eyes of a child (his/her judgment being } \\
\text { different from that of an adult). } \\
\text { First Person - The story is told by the protagonist or one of the characters who } \\
\text { interacts closely with the protagonist or other characters (using pronouns I, me, we, } \\
\text { etc). The reader sees the story through this person's eyes as he/she experiences it } \\
\text { and only knows what he/she knows or feels }\end{array}$ \\
\hline Setting/Local color & $\begin{array}{l}\text { Intense and rooted in the reality of 1950s Javanese society and contemporary and recent } \\
\text { history. A.H. Johns has suggested that Pramoedya's intensity is capable of degenerating into } \\
\text { hysteria. The concern with money, and complete disregard for humane, CULTURAL } \\
\text { VALUES. Pramoedya is through and through Javanese in his cultural attitudes. }\end{array}$ \\
\hline Plot & 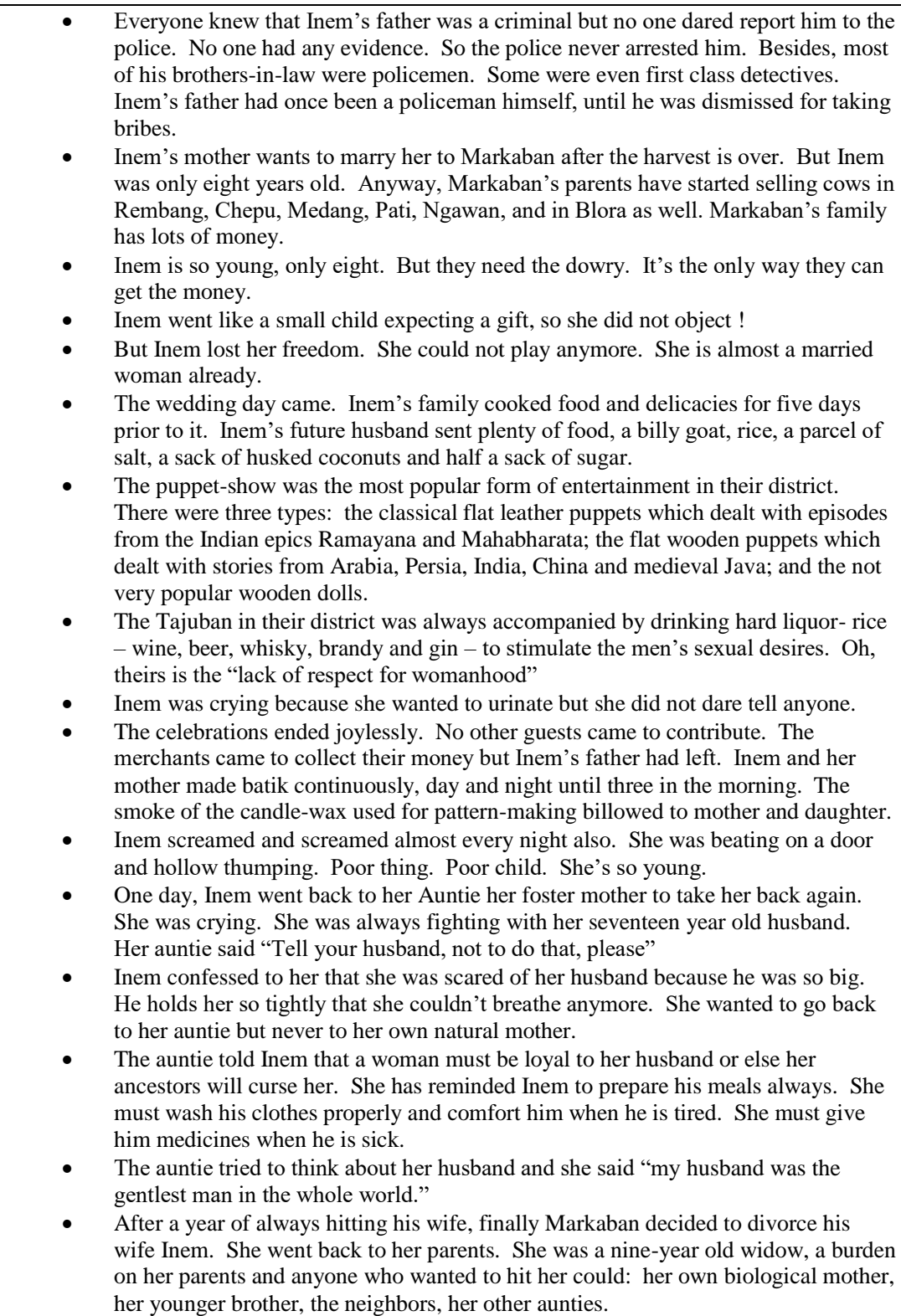 \\
\hline
\end{tabular}


Cultural Values in Selected Southeast Asian Countries As Reflected in Representative Short Stories: Comparative Study

\begin{tabular}{|c|c|}
\hline Conflict & $\begin{array}{l}\text { 1) Man vs. Man (physical) - The leading character struggles with his physical strength against } \\
\text { other men, forces of nature, or animals. } \\
\text { 2) Man vs. Circumstances (classical) - The leading character struggles against fate, or the } \\
\text { circumstances of life facing him/her. } \\
\text { 3) Man vs. Society (social) - The leading character struggles against ideas, practices, or } \\
\text { customs of other people. }\end{array}$ \\
\hline Symbol/s & $\begin{array}{l}\text { Inem's mother and the Auntie chewed betel. Inem was just eight years old not just } \\
\text { physically bad, but also not good for the health. And the would- be-husband } \\
\text { Markaban is just seventeen. They hope Inem gets a good man who can look after } \\
\text { her. They hope that the seventeen year old Markaban will learn to love the eight } \\
\text { year old Inem. } \\
\text { Inem was dressed in beautiful clothes. The hair on her forehead and in front of her } \\
\text { ears, as well as her eyelashes, was trimmed and carefully curled, then set with } \\
\text { mascara. The bun of hair behind her head was enlarged with teak bark and } \\
\text { ornamented with paper flowers called sunduk mentul. Her clothes were of satin. } \\
\text { Her skirt was genuine Solo batik. They hired from the Chinese merchant the gold } \\
\text { rings and bangles too. }\end{array}$ \\
\hline Theme/s & $\begin{array}{l}\text { The story is simply told, but extremely moving. It reveals Toer's profound disillusionment } \\
\text { with results of the Revolution: the concern with money, and complete disregard for humane, } \\
\text { CULTURAL VALUES. A. H. has written that “ Pramoedya is through and through Javanese } \\
\text { in his cultural attitudes. At the same time he finds much in his traditional culture repellent. } \\
\text { And it is this ambivalence - his isolation from and commitment to his Javanese traditions - } \\
\text { that is the source of much of the emotional intensity of his work". The story is united by a } \\
\text { nostalgia for an organic, caring community, which he realizes does not exist and possibly } \\
\text { never did. }\end{array}$ \\
\hline CULTURAL VALUES & $\begin{array}{l}\text { CONFORMITY, HONORING PARENTS AND ELDERS, LOYALTY, BEING } \\
\text { RESPONSIBLE, DISCIPLINED, POLITE, RESTRAINT OF ACTIONS, SOCIAL NORMS }\end{array}$ \\
\hline
\end{tabular}

Elements of Fiction Guide-SRI SUMARAH (1975) by UMAR KAYAM (Indonesia)

\begin{tabular}{|l|l|}
\hline $\begin{array}{l}\text { Characters } \\
\text { The central position occupied by a character. The device is } \\
\text { exceptionally important in that it } \\
\text { permits the author to focus on the } \\
\text { family and the individual, } \\
\text { particularly in the ways they } \\
\text { interact. }\end{array}$ & $\begin{array}{l}\text { Mrs. Martokusumo/Sri Sumarah ( graduated from Girls Homecraft Junior High School )was } \\
\text { happy to be betrothed to Mas Marto, a subdistrict supervisor for elementary schools. Sri } \\
\text { Sumarah was un obedient, understanding of her husband's weaknesses, patient, not stubborn } \\
\text { and respectful of his power. A young widow, still attractive, but did not want to remarry } \\
\text { anymore. Sri said that seclusion is a good thing for persons approaching middle age. She } \\
\text { saved all the money she made from sewing, she received proceeds from her rice field, so she } \\
\text { was able to send Tun to school alone. } \\
\text { Mas Marto was not an ideal Arjuna of the shadow plays, he was for Sri the man above all other } \\
\text { men. He was refined and gentle and always able to restrain his emotions as an educated }\end{array}$ \\
& $\begin{array}{l}\text { Javanese should. } \\
\text { Tun - The only child was only twelve years old and in the fifth grade when Mas Marto died. } \\
\text { Tun grew up to become intelligent, clever, and sociable. } \\
\text { Yos - The husband of Tun, he had lived in the same boarding house as Tun. He was so } \\
\text { grateful to receive a small amount of money from his mother-in-law. The money is enough to } \\
\text { rent a house in Jakarta for two years. He was a student and a prominent member of the } \\
\text { Konsentrasi Gerakan Mahasiswa, Indonesia, a Communist student group in Jakarta. } \\
\text { Ginuk - only four years old, poor child of Tun and Yos, born in the midst of such upheaval } \\
\text { Pak Mohammed - a landlord; a Darul Islam sympathizer; he has been grabbing up poor } \\
\text { farmer's lands }\end{array}$ \\
\hline
\end{tabular}


Cultural Values in Selected Southeast Asian Countries As Reflected in Representative Short Stories: Comparative Study

\begin{tabular}{|c|c|}
\hline Point of View & $\begin{array}{l}\text { Third-person point of vie is not a character in the story and can tell what any or all characters } \\
\text { are thinking and feeling }\end{array}$ \\
\hline Setting/Local color & $\begin{array}{l}\text { This short story challenges a variety of beliefs, communist and non-communist alike, about the } \\
\text { meaning of the rebellions of } 1948 \text { and } 1965 \text {, and about Indonesian society and values . } \\
\text { Traditional Javanese culture; a physical and ideological distance from the upheaval of } 1965 \\
\text { The present city of Jakarta had changed a great deal. The city felt much more busy. The city } \\
\text { became more overcrowded and much dirtier. Among the massive flow of people in the } \\
\text { kampong were not only Javanese but people from almost every other ethnic group as well. }\end{array}$ \\
\hline Plot & $\begin{array}{l}\text { If fate mocked Sri Sumarah about Tun being married at seventeen years of age, then she had to } \\
\text { answer fate dramatically. After that she approached Pak Mohammad, the rich farmer, and } \\
\text { pawned half of the small plot of rice land to him. Sri Sumarah did other jobs as well like } \\
\text { selling fried bananas in schools. } \\
\text { Signs of rising inflation had already been apparent in the subdistrict but suddenly it went out of } \\
\text { control. Sri was hit hard. Tun and Yos still did not have much of an income. How was she } \\
\text { going to help them? How was she going to come up with the money for the payments on her } \\
\text { loan if all she had to live on was her husband's meager pension? } \\
\text { - There's been a coup in Jakarta. For the past six months Tun and Yos and a number } \\
\text { of their friends had run from one city to the next, cities not too far from Jakarta. } \\
\text { They played a cat and mouse game with the army, which constantly staged cleanup } \\
\text { operations and chased them wherever they raid on their hiding place. Arrest, } \\
\text { murder, theft, revenge, more theft. Sri Sumarah wept how her son-in-law died. } \\
\text { The son of Sri Sumarah's neighbor had been screaming and crying due to a twisted } \\
\text { leg while playing soccer. Sri began to massage his foot slowly. Soon the boy had } \\
\text { fallen asleep. The boy's father slipped a } 100 \text { rupiah note into her hand. From that } \\
\text { night on Sri Sumarah was known as a masseuse. So, giving massages became the } \\
\text { main source of income for Sri. }\end{array}$ \\
\hline Conflict/s & - Woman VS herself/psychological and limitations \\
\hline Symbol/s & $\begin{array}{l}\text { The household must be peaceful so that the husband will feel "at home" beside his wife. So it } \\
\text { was that Sri discovered a new science, the science of keeping a home in perfect order. "If we } \\
\text { follow their wants, they will follow us, ..." }\end{array}$ \\
\hline Theme/s & $\begin{array}{l}\text { To focus with great intensity on the family and the individual... } \\
\text { To champion political doctrines; challenges a variety of beliefs, communist and non- } \\
\text { communist alike, about the meaning of the rebellions of } 1948 \text { and 1965, and about Indonesian } \\
\text { society and values }\end{array}$ \\
\hline
\end{tabular}


Cultural Values in Selected Southeast Asian Countries As Reflected in Representative Short Stories: Comparative Study

\begin{tabular}{|l|l|}
\hline CULTURAL VALUES & $\begin{array}{l}\text { BENEVOLENCE, CONCERN FOR FAMILT AND FOR OTHERS' WELFARE, HELPFUL, } \\
\text { HONEST, FORGIVING, LOYAL, TRUE FRIENDSHIP, SOIRITUAL LIFE }\end{array}$ \\
& \\
& \\
\hline
\end{tabular}

Elements of Fiction Guide THE SOLDIER BY NUGROHO NOTOSUSANTO (1956) Indonesia

\begin{tabular}{|c|c|}
\hline Characters & $\begin{array}{l}\text { Lance Corporal Tatang - was a veteran of the Revolution. } \\
\text { Hadijah - She is the wife of Tatang. She wanted to go to south with him. But her } \\
\text { husband told her - only the men can go. It's a dangerous area. Only the men can } \\
\text { go south. }\end{array}$ \\
\hline Point of View & $\begin{array}{l}\text { Omniscient Objective - The author tells the story in the third person. It appears as though a } \\
\text { camera is following the characters, going anywhere, and recording only what is seen and } \\
\text { heard. There is no comment on the characters or their thoughts. No interpretations are } \\
\text { offered. The reader is placed in the position of spectator without the author there to explain. } \\
\text { The reader has to interpret events on his own. }\end{array}$ \\
\hline Setting/Local color & $\begin{array}{l}\text { - In April } 1930 \text { the South Seas Communist Party was dissolved and was replaced by } \\
\text { the Communist Party of Malaya. }{ }^{[11} \text { While its primary responsibility was Malaya and } \\
\text { Singapore, the party was also active in Thailand and the Dutch East Indies, which } \\
\text { did not then have their own Communist parties. } \\
\text { Green rice-fields spread out in the valleys below. It was very hot in West Java. } \\
\text { The barracks had once been a Chinese shop-house. There were Chinese characters } \\
\text { over the front door. The corridor was lined with woven-bamboo walls. There were } \\
\text { nearly thirty rooms. Some had electricity, most had only oil lamps. } \\
\text { In } 1596 \text { the first Dutch ships dropped anchor in Banten (West Java). The Dutch } \\
\text { colonial occupation lasted } 350 \text { years. In } 1942 \text { the Japanese invaded, leaving in } \\
\text { 1945 at the end of World War II. } \\
\text { The Indonesian leaders Sukarno and Mohammad Hatta declared Indonesia's } \\
\text { independence as a republic in } 1945 . \text { In } 1949 \text { the Dutch finally acknowledged } \\
\text { Indonesia's independence. } \\
\text { Tatang joined the army during the Dutch First Offensive in 1947. It was now } 1956 . \\
\text { Nine years already. }\end{array}$ \\
\hline Plot & $\begin{array}{l}\text { - It was quiet. Tatang thought of such moments endured during the Revolution and } \\
\text { subsequent operations against the Communists in the Merapi Merbabu mountain } \\
\text { complex. } \\
\text { The attack began. A grenade lobbed into the car in the middle of the cutting. } \\
\text { Onom threw it out and it exploded behind them. They exchanged shots. Tatang } \\
\text { enjoyed the heavy scream of the } 12.7 \text { his own tension had gone as soon as he } \\
\text { pressed the trigger. He felt very safe behind the walls of the armoured car. They } \\
\text { were protected from low-flying bullets. } \\
\text { Tatang slowed down as he entered the dark corridor. He was suddenly very tired. } \\
\text { They had been in the area four months, and he was more appalled by the dirty, } \\
\text { stinking accommodation. } \\
\text { Tatang has been very worried about his wife. She is sick for three days already. } \\
\text { She looked fragile. There are no doctors in the south. } \\
\text { Their daughter Fatimah was as fragile as her mother. She caught tropical malaria in } \\
\text { a camp in Jakarta and died. } \\
\text { The wife wants them to be transferred to a better place with enough } \\
\text { accommodation. She wants to live decently. She was bitter about the badly } \\
\text { ventilated factory, a worse accommodation that caused the death of Fatimah, their } \\
\text { only child. } \\
\text { She married a soldier, not a mercenary. A regular soldier sacrifices everything he } \\
\text { - }\end{array}$ \\
\hline
\end{tabular}


Cultural Values in Selected Southeast Asian Countries As Reflected in Representative Short Stories: Comparative Study

\begin{tabular}{|c|c|}
\hline & $\begin{array}{l}\text { has for his ideals. The words protected him, like armour plating. } \\
\text { - The wife thought things would be different after the Revolution. She wanted to } \\
\text { have her own house. Or at least, airy quarters. } \\
\text { The struggle isn't over yet. There are still many dissident elements. The nation } \\
\text { needs national unity. } \\
\text { The wife wants a decent house to be given by the government. But the state is } \\
\text { poor. She wants to transfer to a better place like Bandung or Bogor or Magelang or } \\
\text { anywhere outside of Java. } \\
\text { The officer told Lance Corporal Tatang "You can go to town tomorrow." He gave } \\
\text { Tatang the piece of paper. "Your wife died this morning". }\end{array}$ \\
\hline Conflict & $\begin{array}{l}\text { 1) Man vs. Man (physical) - The leading character struggles with his physical strength against } \\
\text { other men, forces of nature, or animals. } \\
\text { 2) Man vs. Circumstances (classical) - The leading character struggles against fate, or the } \\
\text { circumstances of life facing him/her. } \\
\text { 3) Man vs. Society (social) - The leading character struggles against ideas, practices, or } \\
\text { customs of other people. } \\
\text { 4) Man vs. Himself/Herself (psychological) - The leading character struggles with } \\
\text { himself/herself; with his/her own soul, ideas of right or wrong, physical limitations, } \\
\text { choices, etc. }\end{array}$ \\
\hline Symbol/s & $\begin{array}{l}\text { Various sounds of communal living came through the walls. He then grimaced at the thought } \\
\text { of the smell of the latrine as sunset approached. }\end{array}$ \\
\hline Theme/s & $\begin{array}{l}\text { - Concerns with war, men without women, obscure codes of honour, and their } \\
\text { succinct, ironic style, suggest Hemingway. The armoured vehicle in "The Soldier" } \\
\text { (Panzer) is a symbol of the armour-plated role-playing of the chief protagonist, } \\
\text { whose world of action, warmth, light and masculinity is skillfully contrasted with } \\
\text { the cold, dark, sick world of his wife. Dedicated to "The soldiers of the Indonesian } \\
\text { Army who remain loyal to their vocation (dharma)" }\end{array}$ \\
\hline CULTURAL VALUES & $\begin{array}{l}\text { - } \\
\text { ACHIEVEMENT, PERSONAL SUCCESS, COMPETENT PERFORMANCE, } \\
\text { OBTAINING SOCIAL APPROVAL, INTELLIGENT, SELF - RESPECT, } \\
\text { SOCIAL RECOGNITION, AND AMBITIOUS }\end{array}$ \\
\hline
\end{tabular}

Elements of Fiction Guide THE DECLINE AND FALL OF OUR LOCAL MOSQUE BY A.A, NAVIS ( 1956) Indonesia

\begin{tabular}{|l|l|}
\hline Characters & $\begin{array}{l}\text { The Grandfather received nothing for looking after the mosque. He lived on the } \\
\text { alms he received from those attending Friday service. He was not the caretaker. } \\
\text { He was a knife - sharpener. People used to ask him to help them because he never } \\
\text { asked for payment. The men gave him cigarettes and sometimes, money. But } \\
\text { usually he received "thank you" and a smile. He didn't marry. He did not want to } \\
\text { be rich. He didn't want to have his own house. His whole life has been for God. } \\
\text { He did not want to kill the flies. But Ajo Sidi said that he was damned. He was fit } \\
\text { for hell. } \\
\text { Ajo Sidi - He was a garrulous old man }\end{array}$ \\
\hline
\end{tabular}




\begin{tabular}{|c|c|}
\hline Point of View & $\begin{array}{l}\text { Omniscient- The author can narrate the story using the omniscient point of view. } \\
\text { He can move from character to character, event to event, having free access to the } \\
\text { thoughts, feelings and motivations of his characters and he introduces information } \\
\text { where and when he chooses. There are two main types of omniscient point of } \\
\text { view: }\end{array}$ \\
\hline Setting/Local color & $\begin{array}{l}\text { - An old mosque, with a fishpond and four purification pools in front of it. } \\
\text { Now, women pull boards from the walls and floor when they run out of firewood at } \\
\text { night. Your impression now would be one of decayed sanctity. The decay } \\
\text { increases with each passing day, as the children run wild and the women keep their } \\
\text { fires alight. The world is more ignorant and careless than it was. }\end{array}$ \\
\hline Plot & $\begin{array}{l}\text { - } \quad \text { Ajo Sidi had made the old man so angry. } \\
\text { Grandfather said "I've never worried about tomorrow." If something good } \\
\text { happens, I say, Praise be to Allah. If something upsets me: God forgive me. If } \\
\text { something unusual happens, I say "God's will be done" } \\
\text { - He cried. Then, these were the hurting words of Ajo Sidi. Once upon a time - - - } \\
\text { - } \quad \text { Nhat did you do on earth? } \\
\text { Nothing, Lord. I prayed and recited your holy name continually. I don't know } \\
\text { Lord. I always read your holy book... } \\
\text { - Surprisingly, Haji Saleh was led by the beautiful angel to hell and many of his } \\
\text { friends. Some of them had been to Mecca fourteen times and could even claim to } \\
\text { be descended from the holy prophet Muhammad himself. } \\
\text { "Your faithful servants are all from Indonesia, a very fertile country. A very rich } \\
\text { country, full of minerals, oil and other natural resources. A country of rich } \\
\text { vegetation. A country rife with poverty. A contry owned by foreign interests. } \\
\text { Colonizers did terrible oppression. They took what you grow back to their own } \\
\text { countries. } \\
\text { The lord said "You didn't mind that your descendants would be poor too ? they } \\
\text { may be poor but they know the Koran by heart - It means nothing to you that they } \\
\text { are poor. } \\
\text { Then why did you remain in poverty, making no provision for those to come ? You } \\
\text { let others steal your property, while you fought amongst yourselves, you deceived } \\
\text { and oppressed each other. } \\
\text { I gave you a rich country. But you were lazy. You preferred contemplation. I told } \\
\text { you to work and pray. You only prayed. So you did nothing but praise me and } \\
\text { glorify my holy name. you must go back to hell ! Angels - put them back in the } \\
\text { lowest pits. } \\
\text { You did wrong in spending too much time on the cultivation of your soul. You } \\
\text { prayed because you were afraid of going to hell, but you forgot your fellow } \\
\text { Moslems and your family. You were put in the world to live as part of a } \\
\text { community, but you were too selfish. } \\
\text { That was Ajo Sidi's story, the story that had so greatly distressed the old man. } \\
\text { The next morning, Grandfather cut his throat wide open with a razor. } \\
\text { Ajo Sidi was totally irresponsible. He is gone to work. }\end{array}$ \\
\hline Conflict/s & $\begin{array}{l}\text { Man vs. Society (social) - The leading character struggles against ideas, practices, or customs } \\
\text { of other people. } \\
\text { - Man vs. Himself/Herself (psychological) - The leading character struggles with } \\
\text { himself/herself; with his/her own soul, ideas of right or wrong, physical limitations, } \\
\text { choices, etc. }\end{array}$ \\
\hline Symbol/s & $\begin{array}{l}\text { - Once there was an election. He told us about a frog whose only ambition in life } \\
\text { was to be a king. We called one of the politicians "the frog prince" } \\
\text { People did wrong in spending too much time on the cultivation of your soul. You } \\
\text { prayed because you were afraid of going to hell, but you forgot your fellow } \\
\text { Muslims and your family. You were put in the world to live as part of a } \\
\text { community, but you were too selfish. }\end{array}$ \\
\hline
\end{tabular}


Cultural Values in Selected Southeast Asian Countries As Reflected in Representative Short Stories: Comparative Study

\begin{tabular}{|l|ll|}
\hline Theme/s & $\begin{array}{l}\text { Deals with yet a different world, the world of the rural village and the values of } \\
\text { Islam. Navis is satirical, impious in the name of the greater piety, and has a } \\
\text { thoroughly modern concern: that religion be rationalized, cleansed of superstition } \\
\text { and egotism, and that it explains the present world as well as the next. }\end{array}$ \\
\hline CULTURAL VALUES & $\begin{array}{l}\text { SOCIAL POWER, CONTROL AND DOMINANCE OVER PEOPLE AND } \\
\text { RESOURCES, AUTHORITY, WEALTH }\end{array}$ \\
\hline
\end{tabular}

Elements of Fiction Guide MEANT FOR EACH OTHER by ABDUL MUIS (Indonesia) 1956

\begin{tabular}{|c|c|}
\hline Characters & $\begin{array}{l}\text { Ratna Djuita - boarded the express at Padalarang, an afternnon train from Djakarta to Bandung } \\
\text { Suparta, A young man, born in Sumedang, a medical student offered a vacant seat to Ratna in } \\
\text { Dutch language }\end{array}$ \\
\hline Point of View & Third person point of view \\
\hline Setting/Local color & $\begin{array}{l}\text { Padalarang (from Djakarta to Bandung) } \\
\text { Third class coach, perennially packed and there was no seat available for someone } \\
\text { - } \quad \text { Ratna's hometown in Tagogapu } \\
\text { - } \quad \text { Opindergarten Training School at Bandung-Karees } \\
\text { commercial trade in opium had far-reaching economic and political implications. } \\
\text { As in many of the Dutch territories in the Indonesian archipelago, the drug was } \\
\text { imported from elsewhere and sold throughout the island under a government } \\
\text { monopoly - a system of revenue "farms." These monopoly franchises were } \\
\text { regulated by the government and operated by members of Java's Chinese elite, who } \\
\text { were frequently also local officials appointed by the Dutch. The farms thus helped } \\
\text { support large Chinese patronage networks that vied for control of rural markets } \\
\text { throughout Java. } \\
\text { Late 1920s - Traditional values or to adopt Western notions of modernity }\end{array}$ \\
\hline Plot & $\begin{array}{l}\text { - Then, the police officer ordered the arrest of the Chinese people. A porter was } \\
\text { ordered to impound all their belongings. The officer had them brought into the } \\
\text { waiting room. } \\
\text { Finally, the Commissioner took out a pair of thick - soled silk Chinese shoes and } \\
\text { split the soles of the shoes and they discovered a thin package of opium } \\
\text { The Commissioner continued the search, and they examined the yellow cabbages } \\
\text { and they have split them, to their astonishment the cabbages contained smuggled } \\
\text { opium } \\
\text { It was already evening, it's only proper that girls in Java be escorted along a road at } \\
\text { night } \\
\text { Eighteen year old girls are already responsible of considering social norms and } \\
\text { reputation. Besides, the Directress of her dormitory was rigorously conforming to } \\
\text { conservative mores. }\end{array}$ \\
\hline
\end{tabular}


Cultural Values in Selected Southeast Asian Countries As Reflected in Representative Short Stories: Comparative Study

\begin{tabular}{|c|c|}
\hline & - $\quad$ Suparta asked Ratna if correspondence would interfere with her activities \\
\hline Conflict & - $\quad$ Man VS society's customs, traditions, and norms \\
\hline Symbol/s & $\begin{array}{l}\text { - Ratna instructed Suparta to return to Djakarta. She said to him "When we are older } \\
\text { we will surely meet again. If we are meant for each other, we will surely meet } \\
\text { again." } \\
\text { Opium represents and symbolizes the paramount imperial power in the Indonesian } \\
\text { archipelago, monopolized the importation and distribution of opium in Java almost } \\
\text { continually from the late } 17^{\text {th }} \text { century until } 1942 \text {. It abandoned the well-established } \\
\text { system of selling opium indirectly region - by - region through powerful Java- } \\
\text { Chinese opium farmers. }\end{array}$ \\
\hline Theme/s & $\begin{array}{l}\text { "Do not query much why things are as they are. All is God's will, and in His preordainment } \\
\text { alone lies certainty. Live in the fear of Allah, my son! Be firm in your heart. } \\
\text { - It was the responsibility of the Dutch to establish law and order. } \\
\text { - Love can wait for young people that time in the } 19^{\text {th }} \text { century }\end{array}$ \\
\hline CULTURAL VALUES & CONFORMITY, SOCIAL NORMS, HONORING PARENTS AND ELDERS, LOYALTY \\
\hline
\end{tabular}

Elements of Fiction Guide M A R I A H by CHE HUSNA AZHARI (1984) Malaysia

\begin{tabular}{|l|l|}
\hline Characters & $\begin{array}{l}\text { Mariah - she was a nasi seller in Molo. Every morning at seven sharp she would walk past the } \\
\text { market entrance into the village square and mesmerize the men with her swaying hips as well } \\
\text { as her nasi: nasi kerabu, nasi belauk and nasi dagang. Mariah also had another asset. She was } \\
\text { without a husband. There had been many suitors after her husband's untimely demise, but } \\
\text { Mariah had seemed uninterested. Mariah was tall and well-proportioned and moved } \\
\text { gracefully. In Molo, one does not go about without a kain lepas, to cover her head and part of } \\
\text { her torso, a two-metre traditional head and body cover favoured by womenfolk of Kelantan. } \\
\text { Imam - Quarrelsome couples who called at the Imam's place for arbitration would } \\
\text { be sobered by the domestic serenity of the Imam's abode. There was not a living } \\
\text { man in Molo who did not envy him for having such a devoted wife. Why couldn't } \\
\text { his wife bear children like other women? Fertility had nothing to do with men. } \\
\text { Cik Yam - Imam's wife, her culinary skills were the best attribute. Her } \\
\text { housekeeping was also a model to be followed by other womenfolk in the village. } \\
\text { Cik Gu Nab - One of the local women leaders. She was a teacher at a local } \\
\text { primary school }\end{array}$ \\
\hline
\end{tabular}




\begin{tabular}{|c|c|}
\hline Point of View & $\begin{array}{l}\text { Omniscient Objective - The author tells the story in the third person. It appears as though a } \\
\text { camera is following the characters, going anywhere, and recording only what is seen and } \\
\text { heard. There is no comment on the characters or their thoughts. No interpretations are } \\
\text { offered. The reader is placed in the position of spectator without the author there to explain. } \\
\text { The reader has to interpret events on his own. }\end{array}$ \\
\hline Setting/Local color & $\begin{array}{l}\text { Small village town of Molo- } \\
\text { Breakfast could be the various nasi, roti canai, or the myriad Kelantan breakfast tepung. } \\
\text { Kelantan; Pattani in Southern Thailand }\end{array}$ \\
\hline Plot & 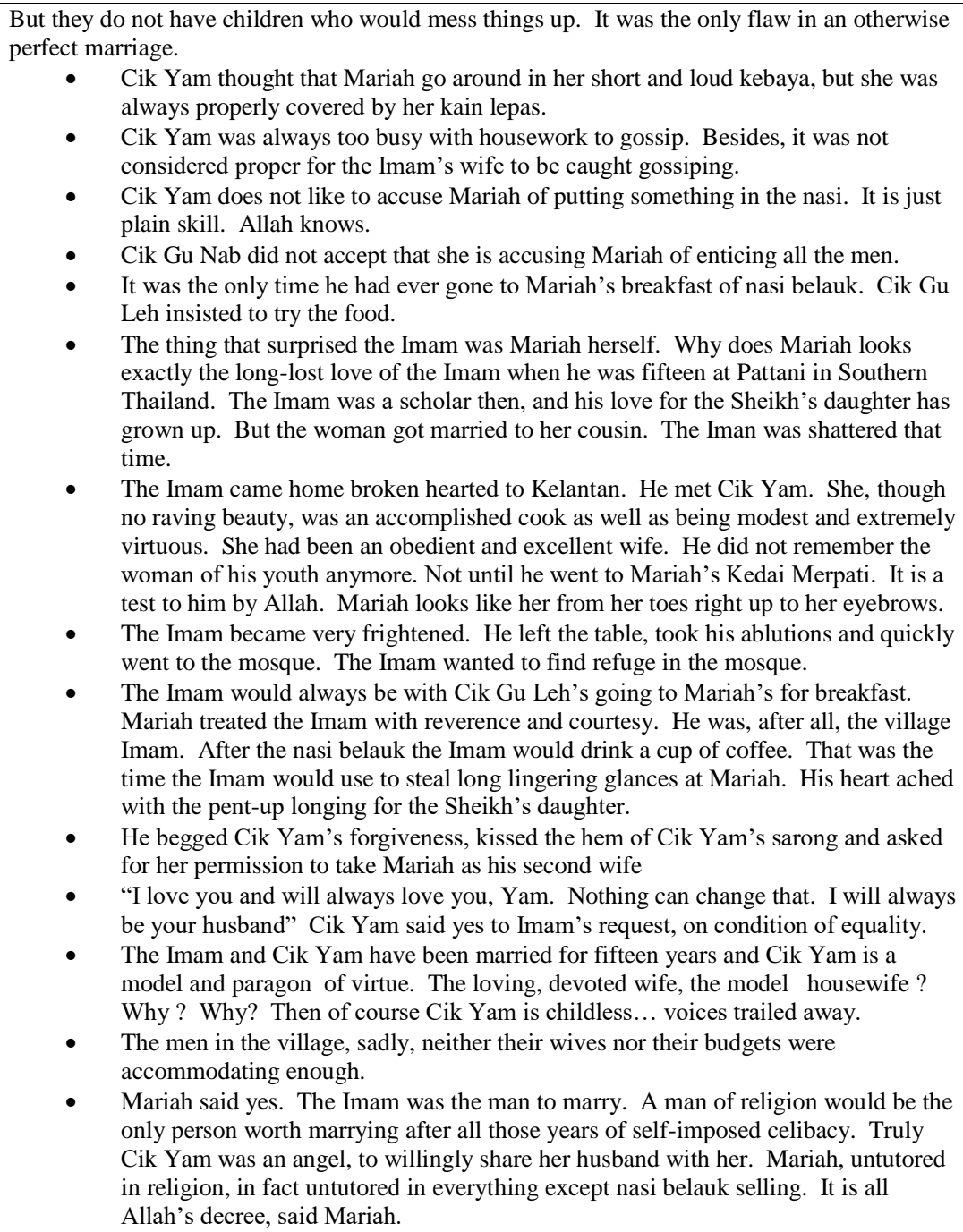 \\
\hline
\end{tabular}


Cultural Values in Selected Southeast Asian Countries As Reflected in Representative Short Stories: Comparative Study

\begin{tabular}{|c|c|}
\hline Conflict/s & $\begin{array}{l}\text { Man vs. Society (social) - The leading character struggles against ideas, practices, or customs } \\
\text { of other people. } \\
\text { Man vs. Himself/Herself (psychological) - The leading character struggles with } \\
\text { himself/herself; with his/her own soul, ideas of right or wrong, physical limitations, choices, } \\
\text { etc. }\end{array}$ \\
\hline Symbol/s & $\begin{array}{l}\text { O lady of excess who strips away my } \\
\text { Acts of devotion in every state. } \\
\text { There is no kindness in my wound } \\
\text { Either it is by abasement and it is } \\
\text { Attached to passion, or it is by } \\
\text { Might and it is attached to Kingdom. } \\
\text { If you're in your immunity, it } \\
\text { Protects us and if you're in the sea, } \\
\text { You come in the boat. }\end{array}$ \\
\hline Theme/s & $\begin{array}{l}\text { He begged his loving, devoted wife, the model housewife to forgive him, but asked for her } \\
\text { permission to take a second wife. The virtuous wife said yes to the request, on condition of } \\
\text { equality. }\end{array}$ \\
\hline CULTURAL VALUES & $\begin{array}{l}\text { TRADITION, RESPECT, COMMITMENT TO CUSTOMS/TRADITIONS/CULTURE AND } \\
\text { RELIGION }\end{array}$ \\
\hline
\end{tabular}

Elements of Fiction Guide VICTORIA AND HER KIMONO by M. Shanmughalingam (1984) Malaysia

\begin{tabular}{|c|c|}
\hline Characters & $\begin{array}{l}\text { Ramanan - The Form One English master, was tall, dark, and "hands on!" Hands for slapping } \\
\text { my misbehaving students' cheeks and shaping their characters rather than for hail and well } \\
\text { met, shaking. He strode into the school in his topi, closed coat, silver buttons, white long } \\
\text { sleeves shirt and long trousers, starched till they seemed brittle. } \\
\text { His temper was hotter than the tropics when there had been no rain for weeks. } \\
\text { - Mrs. Vickneswari Ramanan - was as fair as Ramanan was dark. They were called } \\
\text { the "kopi-susu couple." They had contrasting personalities. She applies talcum } \\
\text { powder in her face as soon as she wakes up. Fragrant white Jasmine flowers ringed } \\
\text { and perfumed the bun on her black hair. She has an exquisitely beautiful } \\
\text { handwriting that she becomes the calligraphic gladiator of the whole community. } \\
\text { Relatives and neighbours sought her out to narrate their messages through her. } \\
\text { However, they avoid her at funerals. She keeps a solemn face while whispering } \\
\text { jokes about the participants including the mourners, making those near her guffaw } \\
\text { and burst into a big laughter. }\end{array}$ \\
\hline Point of View & $\begin{array}{l}\text { Omniscient- The author can narrate the story using the omniscient point of view. He can move } \\
\text { from character to character, event to event, having free access to the thoughts, feelings and } \\
\text { motivations of his characters and he introduces information where and when he chooses. } \\
\text { There are two main types of omniscient point of view: }\end{array}$ \\
\hline
\end{tabular}




\begin{tabular}{|c|c|}
\hline Setting/Local color & $\begin{array}{l}\text { - Mr. Ramanan during Japanese invasion observed that this period of subsistence on } \\
\text { tapioca, cow herding and petty trading was the good news. The death railway in } \\
\text { the north, the reign of terror with the kempeitai informers, spies, physical abuse, } \\
\text { brutality, torture or imprisonment for a wide range of misdeeds (including the lesser } \\
\text { ones of listening to the BBC or failure to bow low enough at Japanese sentry } \\
\text { points), shortages of food and the hyper - inflation of their "banana" currency } \\
\text { which featured bananas on their notes. }\end{array}$ \\
\hline Plot & 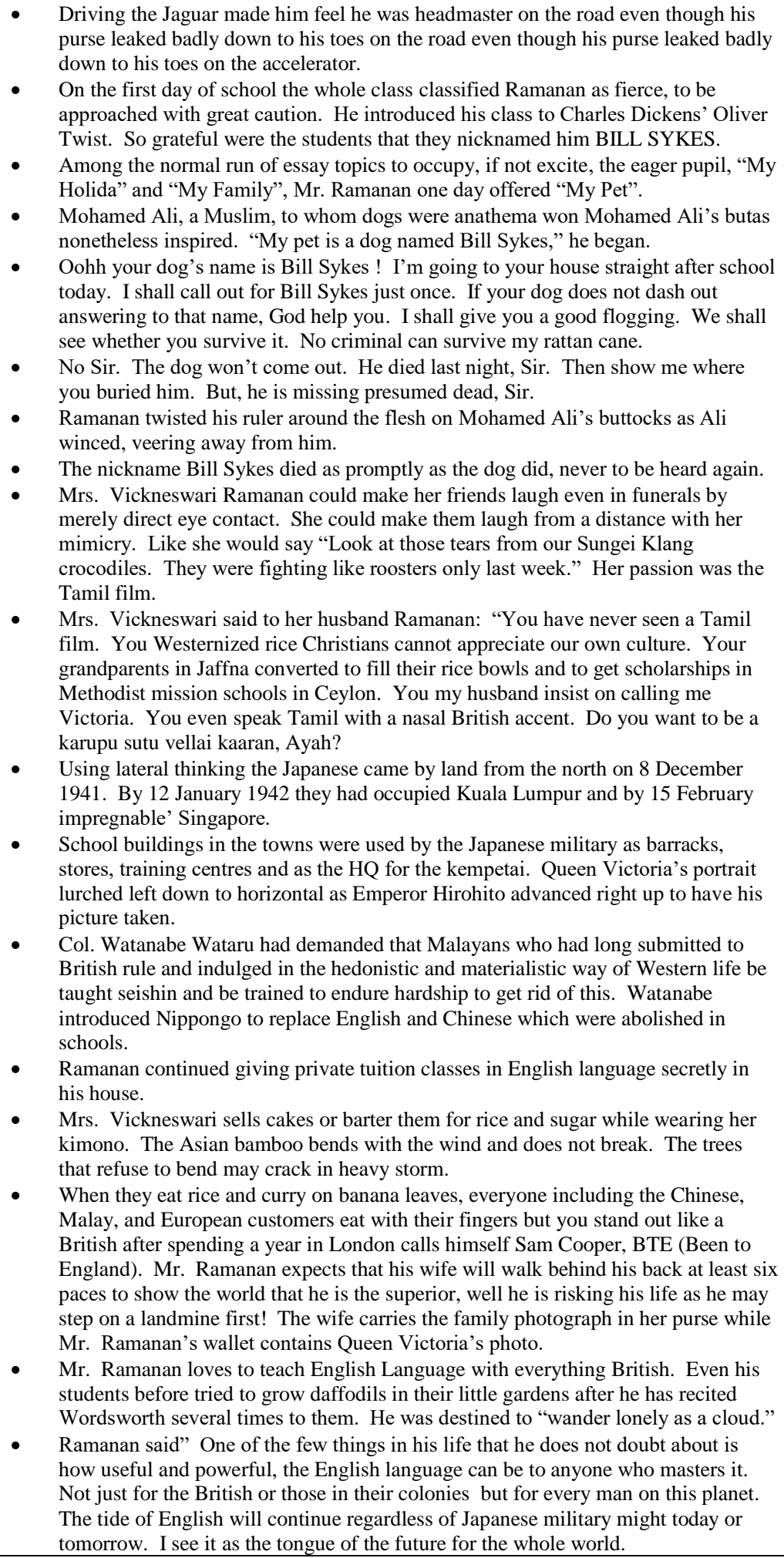 \\
\hline
\end{tabular}




\begin{tabular}{|c|c|}
\hline & 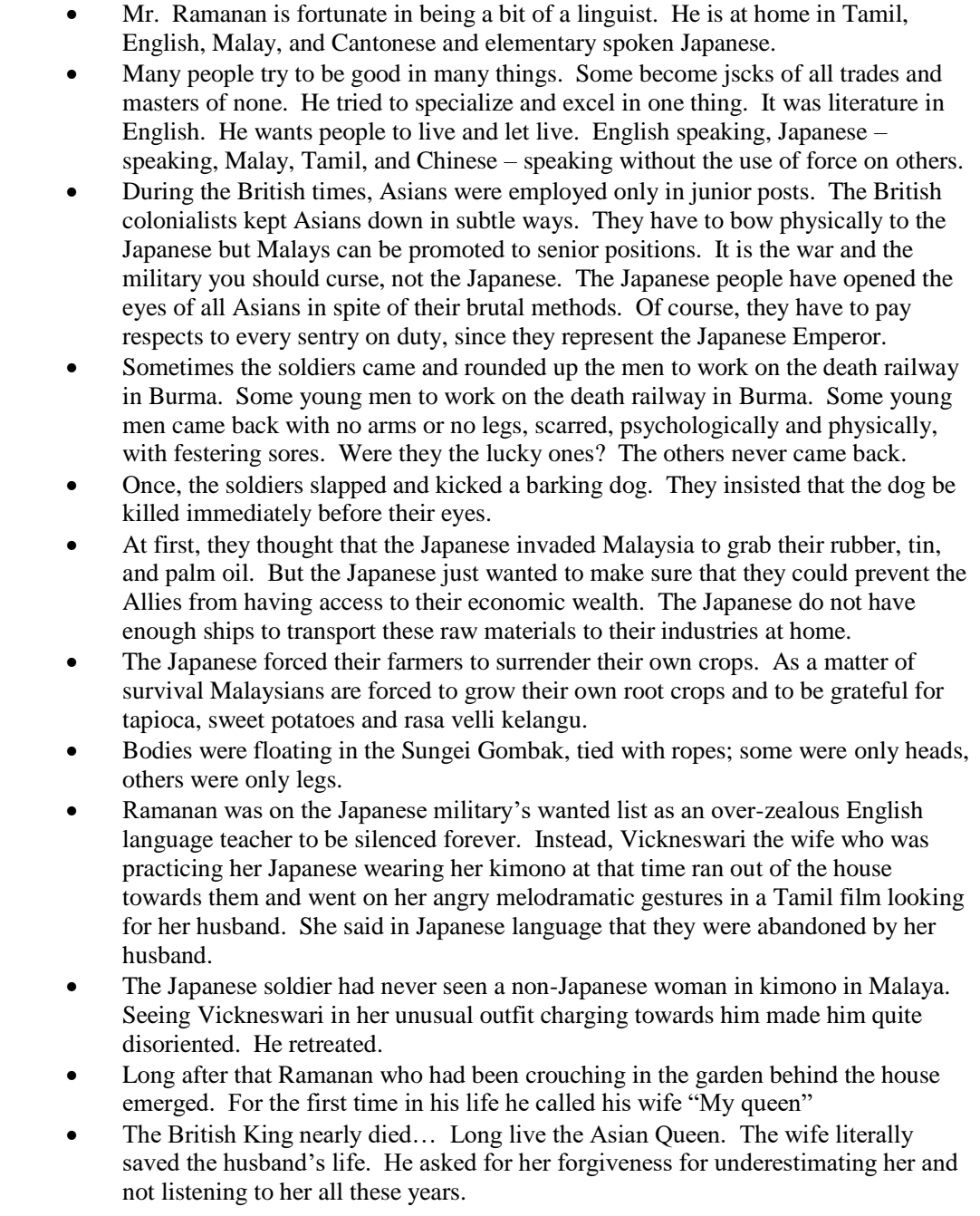 \\
\hline Conflict/s & $\begin{array}{l}\text { 1) Man vs. Man (physical) - The leading character struggles with his physical strength against } \\
\text { other men, forces of nature, or animals. } \\
\text { 2) Man vs. Circumstances (classical) - The leading character struggles against fate, or the } \\
\text { circumstances of life facing him/her. } \\
\text { 3) Man vs. Society (social) - The leading character struggles against ideas, } \\
\text { practices, or customs of other people. }\end{array}$ \\
\hline Symbol/s & $\begin{array}{l}\text { Queen Victoria's portrait lurched further left in late } 1941 \text { as the clouds of war } \\
\text { gathered over the Pacific. Japanese armed forces moved through Siam. } \\
\text { Every morning, every student and teacher had to stand at attention while facing east } \\
\text { towards Tokyo and sing Kimigayo. "May the Emperor's reign last ten thousand } \\
\text { years... }\end{array}$ \\
\hline
\end{tabular}




\begin{tabular}{|l|l|}
\hline Theme/s & $\begin{array}{l}\text { "Victoria and Her Kimono" might serve as an example of the manner in which the writer } \\
\text { chooses to parody both the inherited legacy of colonialism and the dramatic confrontations of } \\
\text { this. Such confrontations clearly marked the dawning of a new age of literary sensibility, } \\
\text { resulting in the creation of authentically relevant and appropriate responses to the living } \\
\text { experiences of ordinary men and women, who went about their everyday affairs alienated from } \\
\text { and yet near enough the centre of the political nerves to sense and be affected directly by its } \\
\text { policies. } \\
\text { It was indeed a happy reading! }\end{array}$ \\
\hline CULTURAL VALUES & $\begin{array}{l}\text { BENEVOLENCE, CONCERN FOR FAMILY, HELPFUL, HONEST, FORGIVING, } \\
\text { LOYAL, TRUE FRIENDSHIP }\end{array}$ \\
\hline
\end{tabular}

Elements of Fiction Guide A QUESTION OF DOWRY (1962) by SIEW YUE KILLINGLEY (Malaysia)

\begin{tabular}{|c|c|}
\hline Characters & $\begin{array}{l}\text { Mrs. Ramachandran is the mother of the woman who will be engaged to be married. Mrs. } \\
\text { Ramachandran goes here and there, as fast as her } 160 \text { pounds will allow her. She is worried } \\
\text { about her future doctor son-in-law. The young man should be able to know how to save for his } \\
\text { future family. } \\
\text { Mr. Ramachandran tries to explain that they don't have much money for the dowry and } \\
\text { money to pay for the necklace of their daughter. } \\
\text { - Sivasothie - She is chaste, innocent and modest person. She is working in the } \\
\text { kitchen for nearly two hours already. She seems to be a lucky girl to have a doctor } \\
\text { for her husband. } \\
\text { Thiruchelvam - He wants to talk with Mr. Ramachandran. He thinks he deserves a } \\
\text { reasonable dowry. Besides, he is a medical doctor anyway. }\end{array}$ \\
\hline Point of View & Third person point of view \\
\hline Setting/Local color & $\begin{array}{l}\text { Indian life in Malaysia, besides being remarkably authentic, has the added virtue of being } \\
\text { amusing. This short story presents social mores ironically, but overbalances on occasion into } \\
\text { rather facile satire. An English - educated Indian family underscores the curiously static } \\
\text { outlook and the comically inbred attitudes which result from a failure to respond fully to the } \\
\text { spirit of a multi - racial society. }\end{array}$ \\
\hline
\end{tabular}


Cultural Values in Selected Southeast Asian Countries As Reflected in Representative Short Stories: Comparative Study

\begin{tabular}{|l|l|}
\hline Conflict/s & \\
& \\
\hline Symbol/s & $\begin{array}{l}\text { Man VS society's customs } \\
\text { Hindu tradition. Chauvinism and superiority of men in India is part of their old culture. }\end{array}$ \\
\hline Theme/s & $\begin{array}{l}\text { Injures the aggrieved person with a view to coerce her to meet any unlawful demand for any } \\
\text { dowry or other property or valuable security. }\end{array}$ \\
\hline CULTURAL VALUES & $\begin{array}{l}\text { CONFORMITY, RESTRAINT OF ACTIONS, SOCIAL NORMS, HONORING PARENTS } \\
\text { AND ELDERS }\end{array}$ \\
& \\
\hline
\end{tabular}

Elements of Fiction Guide- A COMMON STORY by Kassim Ahmad(1959) Malaysian

\begin{tabular}{|l|l|}
\hline Characters & $\begin{array}{l}\text { Yusuf - has came back from Singapore. He could have made a fortune in the Malayan Civil } \\
\text { Service. But then, he has decided to come back in the life of the rubber - tappers in kampong. } \\
\text { His father has been discouraged that Yusuf wants to take care of their lands, their kampong, or } \\
\text { their people. Mother's Yusuf, poor woman, does not understand it either. But his mother has } \\
\text { been very happy to be reunited with her son after four years of his university education. }\end{array}$ \\
\hline Point of View & Third Person Point of View \\
\hline
\end{tabular}




\begin{tabular}{|c|c|}
\hline Setting/Local color & $\begin{array}{l}\text { He sees his kampong folk - illiterate, rubber - tappers or farmers for generations- with their } \\
\text { tattered clothes, their wrinkled faces and their coarse hands, and with nothing on their feet. } \\
\text { They have to walk miles, to their work. And they have to walk miles again to the little village } \\
\text { town to buy - to borrow on credit - their daily rations of sugar, coffee, salt and oil. They sell } \\
\text { the products of their sweat. } \\
\text { - His father has always been coming back from the sawah, (farm) drenched with } \\
\text { sweat, smelly, and dirty. His mother works under the flickering light of the } \\
\text { kerosene lamp till late into the night. } \\
\text { Then one day, the whole kampong has been fenced and they can not go out anytime } \\
\text { they like - even to tap their rubber or tend their padi. The Malayan Communist } \\
\text { Party wants to conquer their country! But soon enough, life in the village has } \\
\text { settled down to its new routine. } \\
\text { Malayan Communist Party was formed in } 1930 \text { - } 1989 \text { in Malaya, Singapore, } \\
\text { Thailand, Dutch East Indies ( Dutch radicals, trade unions of Chinese Communist } \\
\text { Party \& French Indo - China ) }\end{array}$ \\
\hline Plot & $\begin{array}{l}\text { - The young men will suddenly leave them in search of callings more adventurous } \\
\text { than ploughing or tapping. } \\
\text { Then, men kill one another and receive good money for it. Then, there will be } \\
\text { sorrow in the village and breakdown in the family's economy. } \\
\text { Land will be sold or mortgaged and the family will become the poorer for it. And } \\
\text { for long, they will receive a few green or red notes, from the forgotten young men. }\end{array}$ \\
\hline Conflict & - $\quad$ Man vs himself/psychological \\
\hline Symbol/s & $\begin{array}{l}\text { - Such is life - like a painting. There has to be contrast of colours and tones. Here is } \\
\text { shade and there is light. Here, too, are contrasts of joy and sorrow, of wealth and } \\
\text { poverty, of learning and ignorance. Therein lies its beauty, its freshness and its } \\
\text { dynamism. Without these, life would be a series of meaningless journeys through } \\
\text { boredom. } \\
\text { He thinks he nows. He lost his soul. He must go back there. He must go back } \\
\text { there in Malaysia to plant padi. That's where he belongs. He is bound up with the } \\
\text { people there. He must go back to learn their language again. He has to learn their } \\
\text { ways and live with them again. Perhaps, he will get back his soul. He knows what } \\
\text { he wants. He wants his soul and the government cannot give it back to him. } \\
\text { The main character is an early figure representing an embryonic form something of } \\
\text { the inner conflict with which Malaysians and Singaporeans have lived. }\end{array}$ \\
\hline Theme/s & $\begin{array}{l}\text { - Has a slight Hemingwayesque touch. It realizes that the ideal of cultural } \\
\text { integration in the many intellectuals in the early fifties. } \\
\text { - There is no place like home and debt of gratitude and also nationalism. } \\
\text { Bewildered by conflicting trends, the protagonist returns to his kampong, stirred by } \\
\text { a political faith whose goals lie in the future, and convinced at the same time that } \\
\text { the erosion of the original and enduring values of his community must be halted. }\end{array}$ \\
\hline CULTURAL VALUES & • $\quad$ UNIVERSALISM, NATIONALISM, EQUALITY \\
\hline
\end{tabular}

Elements of Fiction Guide- GRAVE HARVEST (1978) by AJIKIK-Malaysia 


\begin{tabular}{|c|c|}
\hline Characters & $\begin{array}{l}\text { Kimat - The caretaker of the cemetery of the villagers. Kimat's house is built on a family land } \\
\text { to the left of the cemetery. He has been an oversees worker to police force in Singapore } \\
\text { before. He has married a Singaporean and settled in the city. They have six children. Then, } \\
\text { Kimat has retired. He has decided to go back to his native land in Malaysia with one of his } \\
\text { sons. } \\
\text { His son Kiman, has worked in the village instead and got married. Kiman has taken cared of } \\
\text { the cemetery when his father died. } \\
\text { - Kimat and his son Kiman have decided to plant some more cashew trees in the } \\
\text { cemetery area so the children can enjoy the fruit. }\end{array}$ \\
\hline Point of View & Third person point of view \\
\hline Setting/Local color & $\begin{array}{l}\text { The cemetery is a large one, about five acres in size, but only one part of it is occupied. The } \\
\text { cemetery is quite near the village, beside the main road. } \\
\text { - Behind the cemetery is a rubber estate }\end{array}$ \\
\hline Plot & 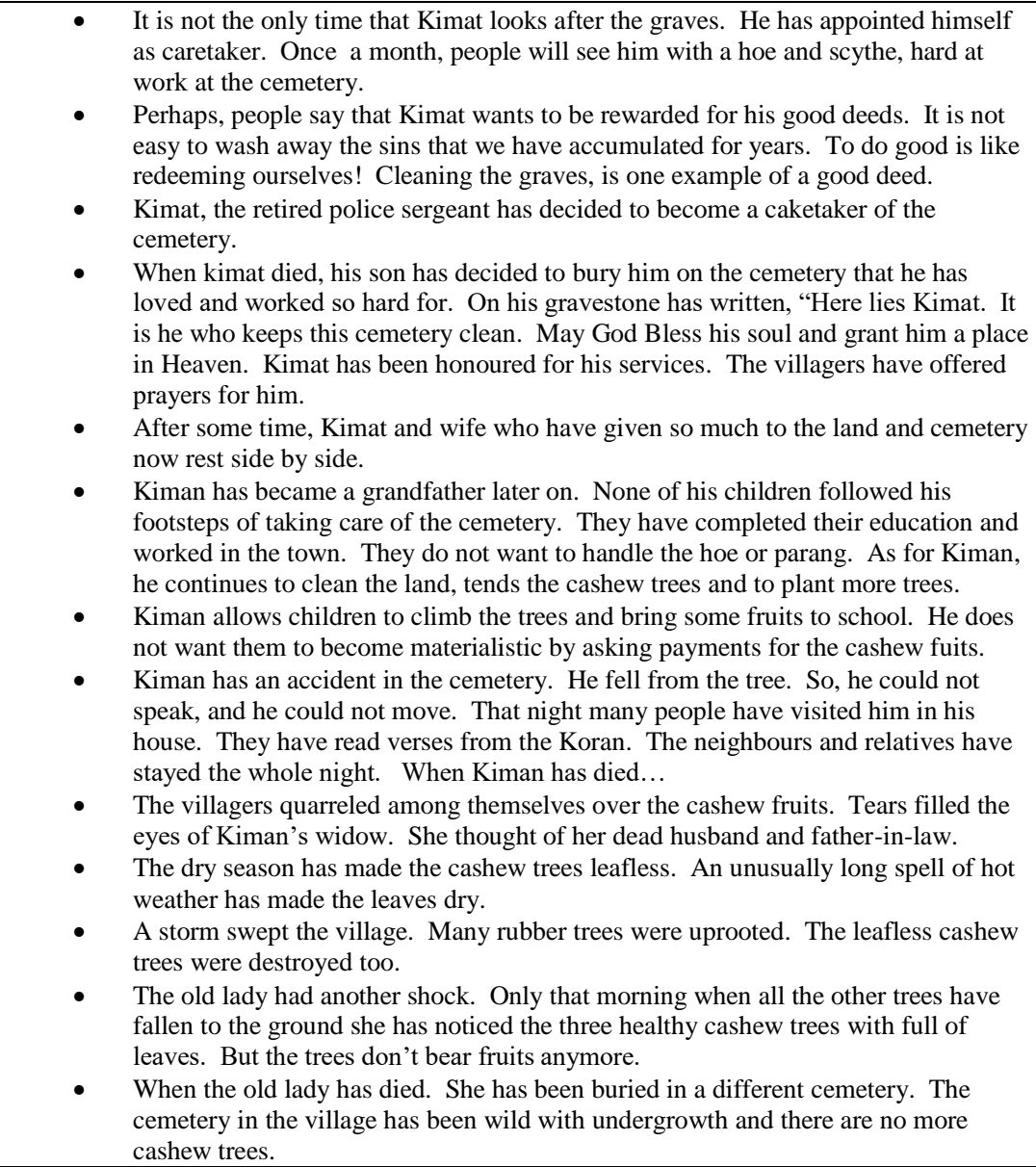 \\
\hline
\end{tabular}


Cultural Values in Selected Southeast Asian Countries As Reflected in Representative Short Stories: Comparative Study

\begin{tabular}{|c|c|}
\hline Conflict & - $\quad$ Man vs society's wickedness \\
\hline Symbol/s & $\begin{array}{l}\text { Kiman smiled just for a split second. He looked calm. Nobody knows that Kiman } \\
\text { has a dream! Kiman has deamt his father is there in the house. He has asked } \\
\text { Kiman to pluck some cashew nuts to give to the people in the mosque. It was } \\
\text { Friday. The next morning Kiman died. }\end{array}$ \\
\hline Theme/s & $\begin{array}{l}\text { Highlights the modern values, religious teachings, and to criticize the ills of corrupt humanity } \\
\text { in the Malay society. This relates also the hardships of the lower class or kampong life. The } \\
\text { readers will understand better the Malaysian culture, life styles and problems. }\end{array}$ \\
\hline CULTURAL VALUES & TRADITION, DEVOUT OF RELIGIOUS RITES/BELIEFS, AND SYMBOLS \\
\hline
\end{tabular}

Elements of Fiction Guide THIS REALM OF HUMANS by KHIN HNIN YU (1962) Myanmar

\begin{tabular}{|c|c|}
\hline Characters & $\begin{array}{l}\text { Ma Chit Hpo - She is lovable. She is very fair, a bit plumb, and her eyebrows are rather scant } \\
\text { but they stood starkly on her face because of her fair complexion. She was so careful about } \\
\text { money, so thrifty. She is saving for charity also. } \\
\text { - Schoolteacher - Ma Chit Hpo's husband } \\
\text { Ko Kyaw Myint - former classmate of the husband. His house was in Yangon. } \\
\text { His house was walled with crushed bamboo mats. The roof was tin and it was } \\
\text { unbearably hot. His wife looked haggard and old. }\end{array}$ \\
\hline Point of View & $\begin{array}{l}\text { First Person - The story is told by the protagonist or one of the characters who interacts } \\
\text { closely with the protagonist or other characters (using pronouns I, me, we, etc). The reader } \\
\text { sees the story through this person's eyes as he/she experiences it and only knows what he/she } \\
\text { knows or feels. }\end{array}$ \\
\hline Setting/Local color & $\begin{array}{l}\text { A finer, thicker type of cotton very popular during the } 1920 \mathrm{~s} \text {. } \\
\text { - Buddhist philosophy says that only when one can free oneself of attachments one } \\
\text { can find freedom and peace of spirit } \\
\text { - The military takeover in } 1962\end{array}$ \\
\hline
\end{tabular}




\begin{tabular}{|c|c|}
\hline Plot & 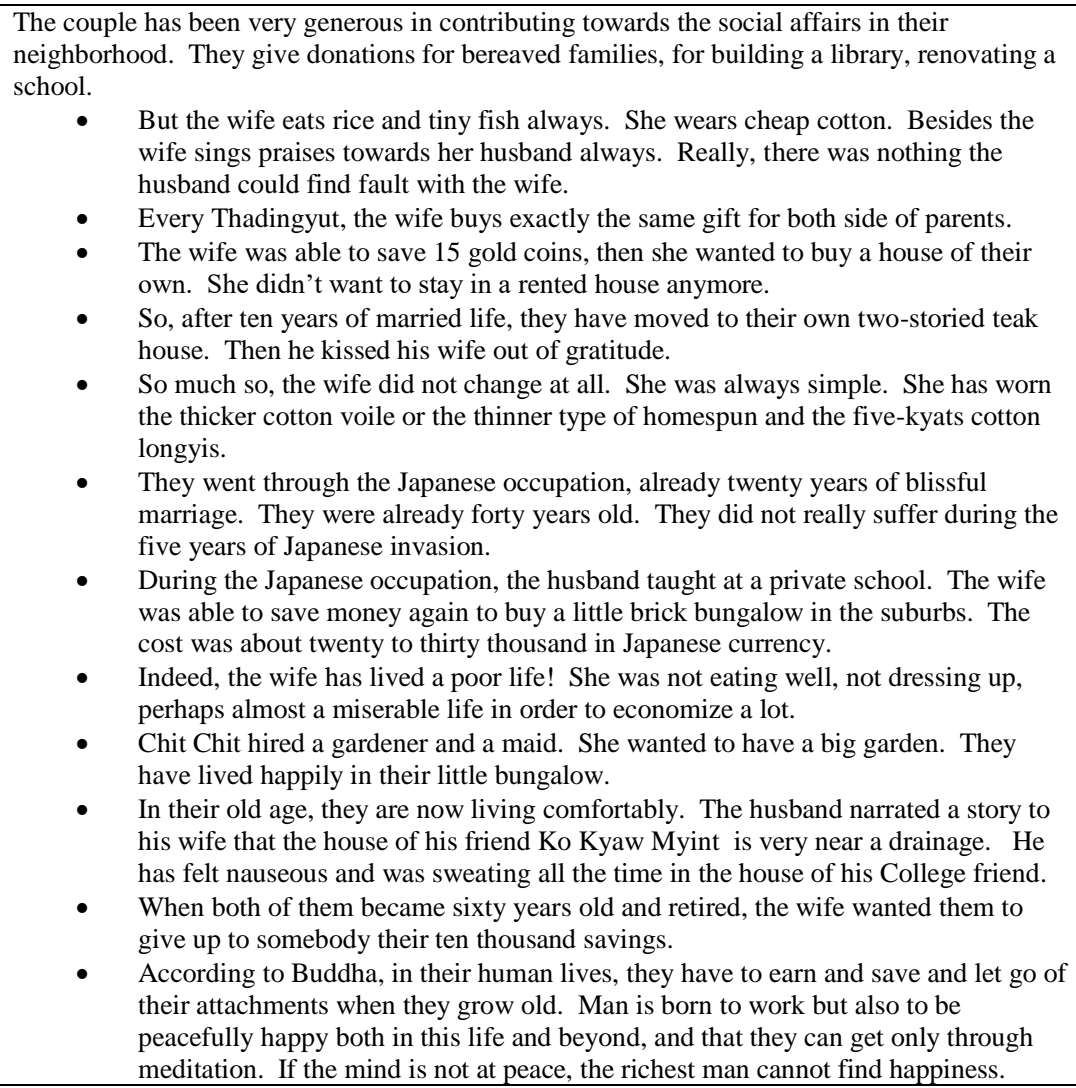 \\
\hline Conflict/s & $\begin{array}{l}\text { Man vs. Society (social) - The leading character struggles against ideas, practices, or customs } \\
\text { of other people. } \\
\text { 4) Man vs. Himself/Herself (psychological) - The leading character struggles with } \\
\text { himself/herself; with his/her own soul, ideas of right or wrong, physical limitations, } \\
\text { choices, etc. }\end{array}$ \\
\hline Symbol/s & $\begin{array}{l}\text { Buddhist philosophy says that the only way one can free oneself of attachments can one find } \\
\text { freedom and peace of spirit. }\end{array}$ \\
\hline Theme/s & $\begin{array}{l}\text { - If you die you stay so attached to the gold coins you will turn into an Oke Sar } \\
\text { Saunt. The spirits held in limbo to protect treasures enshrined in pagodas }\end{array}$ \\
\hline CULTURAL VALUES & $\begin{array}{l}\text { - } \quad \text { ACHIEVEMENT, PERSONAL SUCCESS, COMPETENT PERFORMANCE, } \\
\text { OBTAINING SOCIAL APPROVAL }\end{array}$ \\
\hline
\end{tabular}




\begin{tabular}{|c|c|}
\hline Characters & $\begin{array}{l}\text { Aye Aye - She complained to her husband about the nosey and intrusive neighbours. The } \\
\text { husband advised her to relax. } \\
\text { Ma Ma Nu - she calls her the moment she sees her going to bazaar to get her a chicken or } \\
\text { something else. She does not give back the money in payment for some things when she } \\
\text { comes back. In the long run Aye Aye has learned to forget her request to buy things in the } \\
\text { market. } \\
\text { Ma Mya Than - They usually go to the Government Shop to get their ration of rice or milk } \\
\text { powder. Ma Mya Than has already five children, messing up their things or pulling her son. } \\
\text { Aye Aye usually donates some yards of nylon because Ma Mya Than could not afford to buy } \\
\text { clothes anymore because of the five children. } \\
\text { Ma Tin Hlaing - she seems to be a quiet neighbor. But she turned out to be a gossiper. She } \\
\text { was able to tell her the dark secrets of her neighbours. Like for example, that heighbour's } \\
\text { husband does not show up. The husband has a second wife already. } \\
\text { And then the neighbor Ma Ma Nu wants to look young always because she is leaving together } \\
\text { with a son or nephew or something but not really has a blood relationship/kinship but } \\
\text { something else. }\end{array}$ \\
\hline Point of View & $\begin{array}{l}\text { First Person - The story is told by the protagonist or one of the characters who interacts } \\
\text { closely with the protagonist or other characters (using pronouns I, me, we, etc). The reader } \\
\text { sees the story through this person's eyes as he/she experiences it and only knows what he/she } \\
\text { knows or feels. }\end{array}$ \\
\hline Setting/Local color & $\begin{array}{l}\text { - The first first neighborhood was composed of prying, nosey, intrusive, gossiper, } \\
\text { thick skinned but just like family members kind of people. } \\
\text { - The second neighborhood is composed of uncaring, anti- social, and snobbish } \\
\text { people. }\end{array}$ \\
\hline Plot & 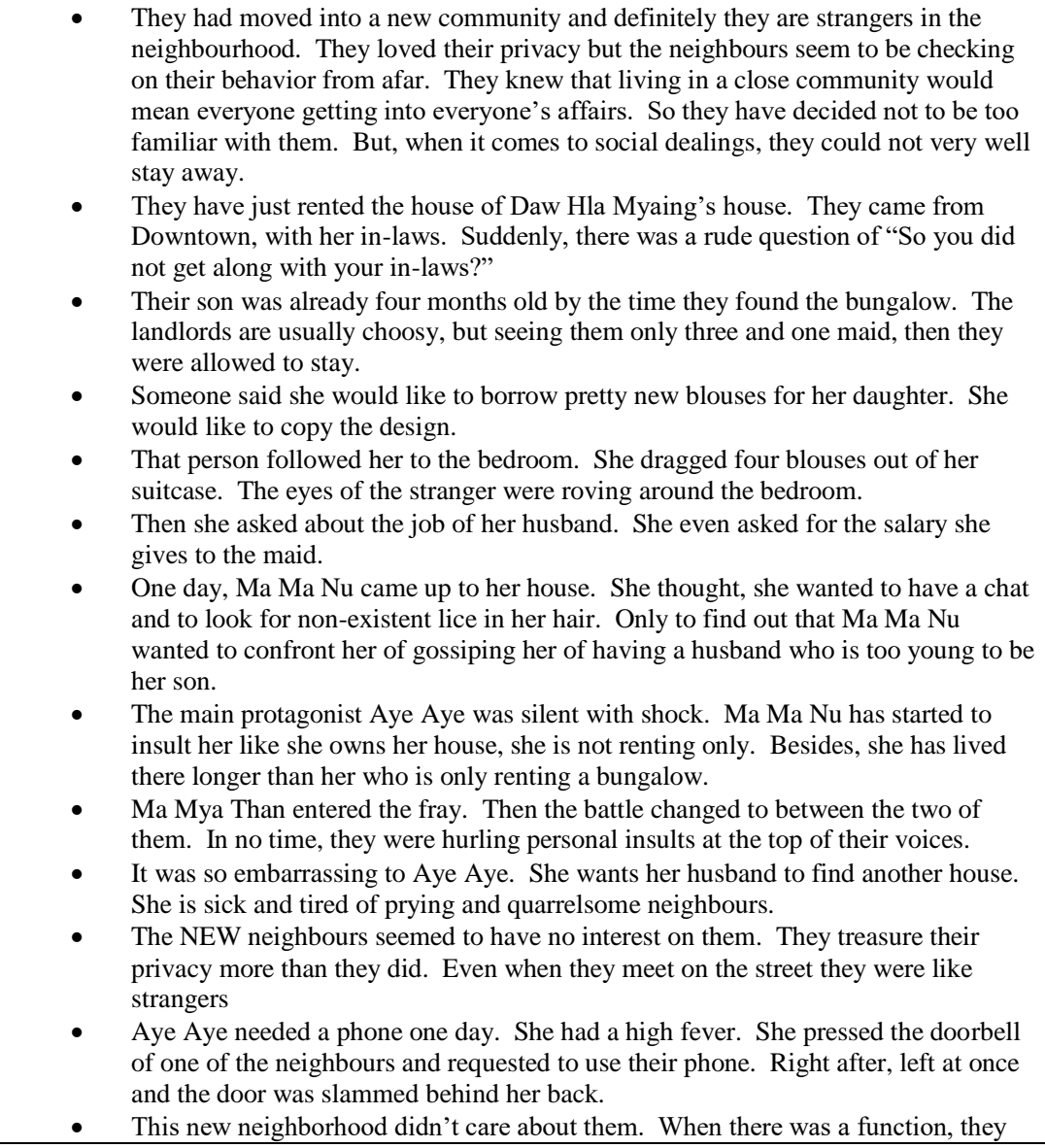 \\
\hline
\end{tabular}


Cultural Values in Selected Southeast Asian Countries As Reflected in Representative Short Stories: Comparative Study

\begin{tabular}{|c|c|}
\hline & $\begin{array}{l}\text { didn't invite them not even once. Nobody wanted their friendship. } \\
\text { One day, their Auntie was looking for them. But apparently, but even the people } \\
\text { next door don't know them. Aye Aye was thinking that her new neighbours were } \\
\text { anti-social people indeed or was she the one to be called as anti - social being? } \\
\text { Yes, the previous neighbours were prying and too inquisitive but they were just like } \\
\text { family to them. It was true. Whenever, she was sick, Ma Mya Than would hurry } \\
\text { over. Even Ma Ma Nu would bring over a bowl of soup. } \\
\text { Where they have lived before one of the neighbours could be relied upon to baby- } \\
\text { sit so Aye Aye has more time to become hedonist because of many free time. } \\
\text { The auntie told her nephew. Your wife seems to be unreasonable. She does not } \\
\text { like it there, she does not like it here also. Nothing pleases her... } \\
\text { Aye Aye was silent. She had no idea of what sort of neighborhood she wants to } \\
\text { live anymore. }\end{array}$ \\
\hline Conflict/s & $\begin{array}{l}\text { Man vs. Himself/Herself (psychological) - The leading character struggles with } \\
\text { himself/herself; with his/her own soul, ideas of right or wrong, physical limitations, } \\
\text { choices, etc. }\end{array}$ \\
\hline Symbol/s & $\begin{array}{l}\text { Intrusive, nosey, and gossiper kind of people are also like members of your own } \\
\text { family. They care and they are willing to render a helping hand during difficult } \\
\text { times. }\end{array}$ \\
\hline Theme/s & Love your neighbors as you love yourself \\
\hline CULTURAL VALUES & $\begin{array}{l}\text { HEDONISM, GRATIFICATION FOR ONESELF, NEEDS AND PLEASURE, ENJOYING } \\
\text { LIFE, AND SELF-INDULGENT }\end{array}$ \\
\hline
\end{tabular}

Elements of Fiction Guide MOTHER'S MERIT by THU MAUNG (1980) Yangon, Myanmar

\begin{tabular}{|l|l|}
\hline Characters & $\begin{array}{l}\text { Mother Nyo - She is a devout Buddhist who does not pray long and loud every night. She } \\
\text { does not attend sessions at meditation centres in order to reach a higher status of mind. She is } \\
\text { also not the type to gather merit by giving Soon Kyway feasts for monks and guests on a } \\
\text { monthly or even a bi-yearly basis. She in her own way lives her life with a charitable nature, a } \\
\text { generous heart and a peaceful mind. }\end{array}$ \\
\hline Point of View & $\begin{array}{l}\text { First Person - The story is told by the protagonist or one of the characters who interacts } \\
\text { closely with the protagonist or other characters (using pronouns I, me, we, etc). The reader } \\
\text { sees the story through this person's eyes as he/she experiences it and only knows what he/she } \\
\text { knows or feels }\end{array}$ \\
\hline
\end{tabular}


Cultural Values in Selected Southeast Asian Countries As Reflected in Representative Short Stories: Comparative Study

\begin{tabular}{|c|c|}
\hline Setting/Local color & $\begin{array}{l}\text { - } \quad \text { Yangon } \\
\text { - Heading towards a line of huts far beyond the stalks of harvested paddy in the bare } \\
\text { fields } \\
\text { - Monastery; temple; five houses in the compound }\end{array}$ \\
\hline Plot & $\begin{array}{l}\text { - When one of her friends said "Ma Khin Nyo, I always see you busy you would } \\
\text { hardly have time to sit at the shrine to pray." } \\
\text { Ma Khin Nyo answered "Well, I cooked and cleaned I keep my mind on Buddha's } \\
\text { teachings ... that is how she prays. } \\
\text { Her family has six members. But all the friends of her children and her husband's } \\
\text { crew, treat their home as a place to come and go as they please, to eat whatever } \\
\text { food there is, or even just to drop in to use the loo at anytime day or night. } \\
\text { - His mother loves to feed people, friends or acquaintances happen to pass by their } \\
\text { gate. She would invite them to have a taste of what was cooked that day. } \\
\text { Even the two elderly men who sell brooms would often come in their neighborhood } \\
\text { and they always look tired, what with the load they carry and the hot sun. she } \\
\text { would always insist they come in for a meal. It must be exhausting to walk for } \\
\text { hours under the blazing sun with their load. She wants them to save a bit also. } \\
\text { Once his mother called over a vendor in the train station. She bought two large } \\
\text { bamboo baskets from the old woman. The mother never bargains when she shops. } \\
\text { His mother has appreciated on how the basket has woven. It is worth the } \\
\text { handiwork. The mother has been thinking of the family of the old woman also. } \\
\text { Because of the mother's generosity, there, with high steps belying her age ran the } \\
\text { old woman heading towards a line of huts far beyond the stalks of harvested paddy } \\
\text { in the bare fields. }\end{array}$ \\
\hline Conflict/s & $\begin{array}{l}\text { Man vs. Society (social) - The leading character struggles against ideas, practices, or customs } \\
\text { of other people. }\end{array}$ \\
\hline Symbol/s & $\begin{array}{l}\text { Mother performs charity always. She is a devout Buddhist who does not pray long and loud } \\
\text { every night. She does not attend sessions at famous meditation centres in order to reach a } \\
\text { higher status of mind. She does not gather merit by giving feasts for monks and guests on a } \\
\text { monthly or even a bi-yearly basis. } \\
\text { - Although, she does not practice Buddhism religiously, she in her own way lives her } \\
\text { life with a charitable nature, a generous heart and a peaceful mind like she loves to } \\
\text { feed people. } \\
\text { She never reacts with aggression or bitterness to any suffering that she encounters. } \\
\text { She faces whatever fate brings with serenity and would smooth things out with } \\
\text { unruffled patience. The equanimity in the face of hardship is her way of } \\
\text { meditation and her method of seeking a higher state of mind. }\end{array}$ \\
\hline Theme/s & $\begin{array}{l}\text { A generous mother who loves to feed people, friends or acquaintances happen to } \\
\text { pass by, she would almost drag them into the house. "Hey, come in and have a } \\
\text { taste of what I cooked today," is something that you will hear from her all the time. }\end{array}$ \\
\hline CULTURAL VALUES & $\begin{array}{l}-1 \\
\text { BENEVOLENCE, CONCERN FOR FAMILY, PRIMARY GROUPS, AND FOR } \\
\text { OTHERS' WELFARE, HELPFUL, HONEST, FORGIVING, LOYAL, TRUE } \\
\text { FRIENDSHIP, MATURE LOVE, AND SPIRITUAL LIFE, ENHANCING THE } \\
\text { WELFARE OF THE IN-GROUP, SMOOTH GROUP FUNCTIONING, }\end{array}$ \\
\hline
\end{tabular}


Cultural Values in Selected Southeast Asian Countries As Reflected in Representative Short Stories: Comparative Study

\begin{tabular}{|c|c|}
\hline Characters & U Nyan Sein is an Art teacher. He teaches Reading and Writing also in the kindergarten. \\
\hline Point of View & $\begin{array}{l}\text { First Person - The story is told by the protagonist or one of the characters who } \\
\text { interacts closely with the protagonist or other characters (using pronouns I, me, we, } \\
\text { etc). The reader sees the story through this person's eyes as he/she experiences it } \\
\text { and only knows what he/she knows or feels. }\end{array}$ \\
\hline Setting/Local color & $\begin{array}{l}\text { Taundwin-gyi, Myanmar; Shwe In Taung Pagoda } \\
\text { 1960s }\end{array}$ \\
\hline Plot & $\begin{array}{l}\text { - The protagonist has just arrived for the opening of the new semester and } \\
\text { fortunately, she has a good evaluation in her teaching career. } \\
\text { One day, the teacher was drawing Master Tortoise, a popular Cartoon character on } \\
\text { the blackboard. } \\
\text { The teacher started to draw Master Rabbit also on the board. He was trying to } \\
\text { narrate a tale to the kids. } \\
\text { The teacher can teach Reading and Writing anytime. But as of the moment, he } \\
\text { wants his students to enjoy school. They must love coming to school. They should } \\
\text { not be afraid. } \\
\text { - Like, there was a boy crying out loud. He would often glance out of the window } \\
\text { looking at his grandmother, sitting under a nearby Tamarind tree. } \\
\text { - The teacher requested the grandmother not to show herself to the boy. The howls } \\
\text { of the boy shook the room. } \\
\text { - The teacher asked the class to cry so that it will be used up quickly. All the kids } \\
\text { went into a loud pantomime of crying. } \\
\text { - The boy stopped crying in amazement, looking around in confusion. } \\
\text { - U Nyan Sein went on with his tale. The boy started again to cry. And again the } \\
\text { whole class has joined him in crying aloud to use it all up. There were no more } \\
\text { tears from anyone, real or fake, after that. } \\
\text { The next day a new lesson started. The teacher asked each one to stand up, and to } \\
\text { announce his name. then he drew a 'ka' (First letter of the alphabet) on the black } \\
\text { board. } \\
\text { He was a good teacher. He is giving his best to his students. }\end{array}$ \\
\hline Conflict/s & $\begin{array}{l}\text { Man vs. Circumstances (classical) - The leading character struggles against fate, or the } \\
\text { circumstances of life facing him/her. }\end{array}$ \\
\hline Symbol/s & $\begin{array}{l}\text { U Nyan Sein was an Art teacher. He was also teaching Reading and Writing in the } \\
\text { kindergarten. Meaning, the teacher should be willing to teach almost all subjects. Aside from } \\
\text { the fact that he knows the art of child-rearing. }\end{array}$ \\
\hline
\end{tabular}


Cultural Values in Selected Southeast Asian Countries As Reflected in Representative Short Stories: Comparative Study

\begin{tabular}{|c|c|}
\hline Theme/s & $\begin{array}{l}\text { Despite a traditionally high rate of literacy and importance of learning in Myanmar, its } \\
\text { educational system is in a state of underdevelopment and uncertainty. Although enrollment in } \\
\text { primary schools is very high, the completion rate lags behind. Reports indicate that only one } \\
\text { third of all primary school children finish the first five years. Many students drop out due to } \\
\text { poverty, lack of support, and poor health. While school attendance is high in urban areas and } \\
\text { among male students, village schools in a vastly rural-agrarian country are handicapped by } \\
\text { poor attendance, especially among the female students. } \\
\text { Myanmar's educational system has been suffering from a proportionately declining budget. } \\
\text { While there has been a sizable increase in the number of schools, colleges, universities, and } \\
\text { teachers during the last five years, the percentage of total education expenditure declined from } \\
4.65 \text { percent in } 1995 \text { to } 2.52 \text { percent in } 1999 \text {. While the total budget rose from approximately } \\
7,000 \text { to } 1,000 \text { million kyats (approximately } 6.5 \text { kyats equal US } \$ 1.00 \text { ), the proportionate } \\
\text { decline implies that the present military rule does not give high priority to education, even } \\
\text { though it does declare its commitment to EF2000 Education For All by Year } 2000 \text {. } \\
\text { For several years Myanmar has also been actively participating in many world agencies } \\
\text { such as UNDP (United Nations Development Project), UNESCO (United Nations Economic, } \\
\text { Social, and Cultural Organization), and UNICEF (United Nations Children's Emergency } \\
\text { Fund). Even in this area of support by NGOs (nongovernmental organizations), as in the above } \\
\text { allocation by the Government' Ministry of Education budget, there is a slight proportionate } \\
\text { decline. While the UNDP allocation of } \$ 3.9 \text { million for primary education in Myanmar rose to } \\
\$ 5.9 \text { million in four years (1994-1998), it fell from } 14 \text { percent to } 12 \text { percent, proportionately. }\end{array}$ \\
\hline CULTURAL VALUES & $\begin{array}{l}\text { ACHIEVEMENT, PERSONAL SUCCESS, COMPETENT PERFORMANCE, OBTAINING } \\
\text { SOCIAL APPROVAL }\end{array}$ \\
\hline
\end{tabular}

Elements of Fiction Guide THE CARAT 13-DIAMOND by DAW KHIN MYO CHIT (1955) Myanmar

\begin{tabular}{|c|c|}
\hline Characters & $\begin{array}{l}\text { - } \quad \text { Ko Latt }- \text { He had a nice job, but his dreams of a bright and happy future was } \\
\text { shattered by the war. } \\
\text { - } \quad \text { First person Point of view, the impatient wife } \\
\text { - Their toddler only funny son }\end{array}$ \\
\hline Point of View & $\begin{array}{l}\text { - First Person - The story is told by the protagonist or one of the characters who } \\
\text { interacts closely with the protagonist or other characters (using pronouns I, me, we, } \\
\text { etc). The reader sees the story through this person's eyes as he/she experiences it } \\
\text { and only knows what he/she knows or feels. }\end{array}$ \\
\hline Setting/Local color & - It was during the dark days of the Japanese occupation in Burma. \\
\hline
\end{tabular}




\begin{tabular}{|c|c|}
\hline Plot & 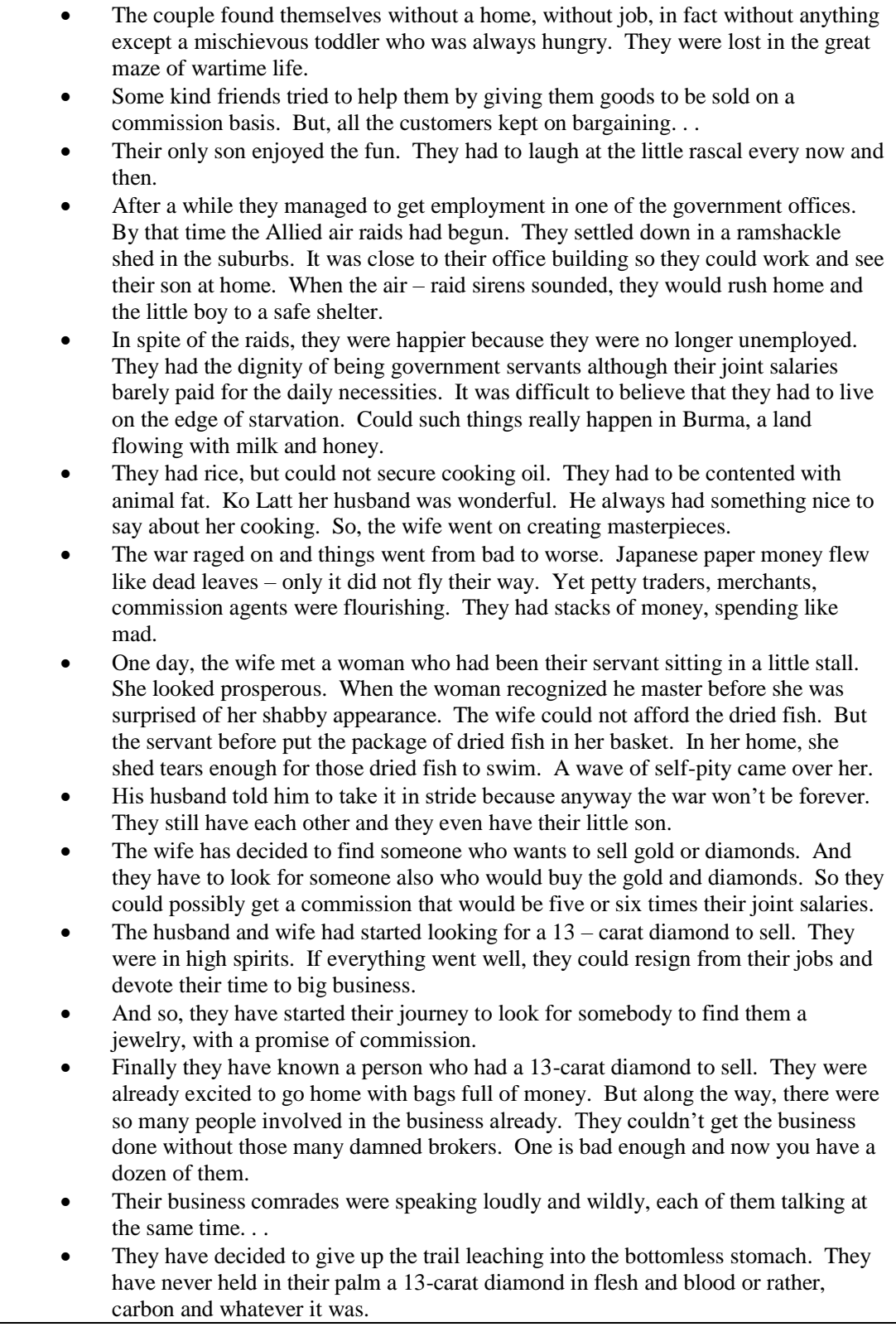 \\
\hline Conflict/s & $\begin{array}{l}\text { Man vs. Man (physical) - The leading character struggles with his physical strength against } \\
\text { other men, forces of nature, or animals. } \\
\text { Man vs. Circumstances (classical) - The leading character struggles against fate, or the } \\
\text { circumstances of life facing him/her. }\end{array}$ \\
\hline Symbol/s & $\begin{array}{l}\text { The worm in the ground knows every tooth of the harrow. The butterfly above preaches } \\
\text { patience. "Poverty, to say at the least, is very uncomfortable. }\end{array}$ \\
\hline
\end{tabular}


Cultural Values in Selected Southeast Asian Countries As Reflected in Representative Short Stories: Comparative Study

\begin{tabular}{|l|l|}
\hline Theme/s & People have to learn to count their many blessings in life. \\
& $\begin{array}{l}\text { ACHIEVEMENT, PERSONAL SUCCESS, COMPETENT PERFORMANCE, } \\
\text { INTELLIGENT, SELF-RESPECT, AMBITION }\end{array}$ \\
\hline CULTURAL VALUES & \\
\hline
\end{tabular}

Elements of Fiction Guide CHILDREN OF THE CITY by AMADIS MA. GUERRERO(More Recent Short Story, 1971) Philippines

\begin{tabular}{|c|c|}
\hline Characters & $\begin{array}{l}\text { Victor, a third - grader, dropped out of school, to be employed as a newspaper boy. Victor's } \\
\text { activist father was shot and killed when he was eight years old. Unfortunately, not long after } \\
\text { his father's death, his mother abandoned him to be with her lover. } \\
\text { Tio Pedring - Older brother of the mother of Victor. Tio Pedring made plans to employ } \\
\text { Victor as a newsboy with the assurance of help. Tio Pedring that time was a newspaper agent. } \\
\text { He did not mention of resuming the boy's interrupted schooling. } \\
\text { Nacio - Enjoys a popularity among newspaper boys and friendly to Victor. He taught Victor } \\
\text { to keep a sharp eye for customers, how to swiftly board a bus or jeep and alight from it while } \\
\text { still in motion ... }\end{array}$ \\
\hline Point of View & Third person point of view \\
\hline Setting/Local color & $\begin{array}{l}\text { - The story happened in the late 1980s. Everything occurred in the dark perilous } \\
\text { busy streets of Manila. } \\
\text { - In one of the shanties that stood in Intramuros; along the Boulevard; Rizal } \\
\text { monument in Luneta, Ermita district, Blumentritt area, Boulevard district, and } \\
\text { Avenida Extension } \\
\text { - An organized defiance, and the setting up of picket lines in piers against shipping } \\
\text { management, with the strikers and their families subsisting on funds raised by } \\
\text { student, labor and civic-spirited elements. } \\
\text { The Boulevard by night began to attract the boy, the bars filled with foreign sailors, } \\
\text { for a military exercise to be held within a few days }\end{array}$ \\
\hline Plot & $\begin{array}{l}\text { The story is about the life of Victor, an eight year old boy whose father was involved in a } \\
\text { company menace because of unjust salaries and compensations. His father joined the } \\
\text { employee's strike and there he met his death when he was shot by the police officers managing } \\
\text { the chaos in the strike. Victor was shocked to know the sudden death of his father on a } \\
\text { newspaper. He and his mother were in deep pain upon hearing his father's death. } \\
\text { Soon, her mother had a new husband. She left Victor to his older brother. There, he was } \\
\text { trained to be a newspaper boy in the dangerous streets of Avenida. He met there many children } \\
\text { doing just like what he is. In those dark street he learned how to curse-say bad words and } \\
\text { smoke cigarette because he was influenced by a group of unmannered teenagers. He found } \\
\text { himself alone in the street, sometimes being beat up by bullies. } \\
\text { The story ended when the author realized how cruel the world is... } \\
\text { "... And Victor, swirled the life of the city: this city, flushed with triumphant charity } \\
\text { campaigns, where workers were made to sign statements certifying they received minimum } \\
\text { wage, where millionaire politicians received Holy Communion every Sunday, where mothers } \\
\text { taught their sons and daughters the art of begging, where orphans and children from broken } \\
\text { homes slept on pavements and under darkened bridges, and where best friends fell out and } \\
\text { betrayed one another." }\end{array}$ \\
\hline
\end{tabular}


Cultural Values in Selected Southeast Asian Countries As Reflected in Representative Short Stories: Comparative Study

\begin{tabular}{|c|c|}
\hline Conflict & $\begin{array}{l}\text { One evening four months after the strike began, the silence of the piers was broken by the six- } \\
\text { by-six trucks. They ran over three strikers and shot to death two more men. } \\
\text { - That evening at the appointed hour he went over to the newspaper's building in } \\
\text { downtown, and was greeted by the sight of scores of barefooted newsboys } \\
\text { awaiting the call to duty. The noise of their conversation, loud with putang-ina } \\
\text { filled the newspaper's building. } \\
\text { The destination of Victor was Blumentritt. Perhaps it wasn't so difficult after all to } \\
\text { sell a newspaper. The customers included a dressmaker, a barber, a pharmacist, } \\
\text { and a beautician. } \\
\text { - Victor was able to see young scavengers, slept inside their pushcarts. } \\
\text { - On his second night on the job, Victor met a group of street boys who began to beat } \\
\text { him up and got all his newspapers ! } \\
\text { His best friend Nacio met his death - violently; he had been run over by a car. } \\
\text { Victor grieved for his friend, and from that time on he became even more taciturn } \\
\text { and withdrawn. } \\
\text { The ring-leader, went over to him and, as a kind of peace offering, held out a } \\
\text { cigarette. Take it. It is very nice to smoke, and it is easy. } \\
\text { Man vs circumstances/fate }\end{array}$ \\
\hline Symbol/s & $\begin{array}{l}\text { In this city, flushed with triumphant charity campaigns, where millionaire politicians received } \\
\text { Holy Communion every Sunday, where orphans and children from broken homes slept on } \\
\text { pavements and under darkened bridges, and where best friends fell out and betrayed one } \\
\text { another. }\end{array}$ \\
\hline Theme/s & $\begin{array}{l}\text { The city, flushed with charitable projects, where millionaire politicians continuously enriching } \\
\text { themselves at the expense of the lower class sector, where street children slept on pavements } \\
\text { and under darkened bridges. }\end{array}$ \\
\hline CULTURAL VALUES & STIMULATION, CHALLENGE IN LIFE, DARING LIFE \\
\hline
\end{tabular}

Elements of Fiction Guide CLAY by JUAN T. GATBONTON (Post-War) Philippines (1951)

\begin{tabular}{|l|l|}
\hline Characters & $\begin{array}{l}\text { Clayton but everybody called him Clay. Clay was one of the army mechanics. He talked too } \\
\text { fast that many natives could not understand him. } \\
\text { Ms. Rosete was a teacher at the high school }\end{array}$ \\
\hline Point of View & First person point of view stands out as a character and refers to himself or herself, using "I" \\
\hline
\end{tabular}




\begin{tabular}{|c|c|}
\hline Setting/Local color & $\begin{array}{l}1951 \text { - The granting of political independence did not in fact end American domination. On } \\
\text { the contrary, many features of colonialism remain even today. } \\
\text { The army camp was on the east side of the main street; the gray, two-story building of } \\
\text { concrete and galvanized iron that was the army barracks } \\
\text { Candaba's main street. The Americans had built a bridge and gouged out a new road on the } \\
\text { left bank of the river } \\
\text { The period from } 1946 \text { - } 1960 \text { was an era of effective American control of the Philippine } \\
\text { economy, political life and military affairs. }\end{array}$ \\
\hline Plot & $\begin{array}{l}\text { - The teenager introduced the American friend Clay to Ms. Rosete his crush. After a } \\
\text { while, Clay was already striking his fist against the shoulder of the teenager, he was } \\
\text { very happy! } \\
\text { Old Clay had a good time! He told the teenager that he won't be understood } \\
\text { because the teenager was still very young only sixteen. } \\
\text { The girls of most of the soldiers were there. In a corner, a woman was sitting on a } \\
\text { soldier's lap. She was giggling shrilly. } \\
\text { The high school boy heard Clay said "The little babe's just playin' hard to get, } \\
\text { that's all. She can't stay away from me anymore" }\end{array}$ \\
\hline Conflict & - $\quad$ Man VS other people's practices \\
\hline Symbol/s & $\begin{array}{l}\text { Galvanized iron that was the army barracks } \\
\text { Clay symbolizes this type of person: Somebody who's always laughing and acting like a } \\
\text { happy guy. However, the source of his laughter is meanness, not friendliness. He laughs at } \\
\text { innocent people, takes advantage of them, uses them like his toys or pets } \\
\text { Ms. Rosete is an example of a sweet, pure, good person who is used by Clay. He } \\
\text { talks about her as if she is his possession or plaything } \\
\text { The main character is the most innocent person at all. He is young and at first he } \\
\text { thinks that Clay is a true friend. When he overhears how Clay talks about Ms. } \\
\text { Rosete, he finally realizes that Clay is bad. After that, he wants nothing more to do } \\
\text { with Clay. }\end{array}$ \\
\hline Theme/s & $\begin{array}{l}\text { Subservience to the dictates of the US, courting political disaster. Needless to say, culture } \\
\text { during this period developed according to the ideological direction set by the U.S. } \\
\text { - As a former colony of the US, the Philippines upheld the line that the salvation of } \\
\text { the world lay with free enterprise and American protection against communism. }\end{array}$ \\
\hline CULTURAL VALUES & NATIONAL SECURITY, STABILITY OF SOCIETY, SAFETY AND HARMONY \\
\hline
\end{tabular}

Elements of Fiction Guide-THE HOUSE ON ZAPOTE STREET by Quijano de Manila (Philippines) 1968

\begin{tabular}{|l|l|}
\hline Characters & $\begin{array}{l}\text { Dr. Leonardo Quitangon, a soft-spoken, mild - mannered, cool-tempered Caviteno medical } \\
\text { doctor. } \\
\text { Lydia Cabading - a medical intern and looked like a sweet unspoiled girl, but there was a } \\
\text { slight mystery about her. }\end{array}$ \\
$\begin{array}{ll}\text { Pablo Cabading, Lydia's father was a member of the Manila Police Department. This father } \\
\text { had been known to threaten to arrest young men who stared at his daughter Lydia on the streets } \\
\text { or pressed too close against her on jeepneys. An Ilocano, he looked every inch an agent of the } \\
\text { law, looked younger than his inarticulate wife, who was actually two years younger than him. } \\
\text { Mother Anunciacion Cabading - A mousy woman unable to speak save at her husband's } \\
\text { bidding. }\end{array}$ \\
\hline
\end{tabular}


Cultural Values in Selected Southeast Asian Countries As Reflected in Representative Short Stories: Comparative Study

\begin{tabular}{|c|c|}
\hline Point of View & $\begin{array}{l}\text { Third-person point of view. The author makes comments or describes his characters vividly } \\
\text { like Quijano de Manila's description of the antagonist "the drama of the jealous father" }\end{array}$ \\
\hline Setting/Local color & $\begin{array}{l}\text { The house of Zapote Street is in the current architectural cliché, a person standing in the sala } \\
\text { can see the doors of the bedrooms and bathroom just above his head. } \\
\text { Lydia and Leonardo wed at the Cathedral of Manila, with Senator Ferdinand Marcos and Mrs. } \\
\text { Delfin Montano, wife of the Cavite governor as sponsors. Then the newlyweds went to live on } \\
\text { Zapote Street. }\end{array}$ \\
\hline Plot & $\begin{array}{l}\text { - The entire household revolved in submission around Pablo Cabading. The } \\
\text { daughter, mother, the foster-son, the maids and even the dogs trembled when he } \\
\text { lifted his voice. In 1946, he had shot dead two American soldiers he caught } \\
\text { robbing a neighbor's house in Quezon City. } \\
\text { Pablo Cabading couldn't bear to see Lydia and Leonardo rise and go up together to } \\
\text { their room. The patriarchal father said " Lydia, you sleep with your mother } \\
\text { tonight. She has a toothache. So, Leonardo went to bed alone and the incident } \\
\text { would always be repeated with several reasons. } \\
\text { Leonardo became anxious to take his wife away from that house. The father said } \\
\text { "If she goes with you, I'll shoot her head before your eyes." } \\
\text { - Pablo Cabading got his submachinegun and trained it to Gene Quitangon (brother } \\
\text { of Dr. Leonardo) "Produce my daughter at once or I'll shoot you all down! } \\
\text { The entire room on Zapote Street was spattered with blood. Lay Mrs. Cabading, } \\
\text { shot in the chest and stomach but was still alive. Lydia was shot in the heart, and } \\
\text { Leonardo was shot in the breast, they are both dead. And, Cabading shot himself } \\
\text { fatally, two times. }\end{array}$ \\
\hline Conflict/s & - $\quad$ Man VS himself/psychological \\
\hline Symbol/s & $\begin{array}{l}\text { Lydia was always clasping a large crucifix. There was no expression on her face. } \\
\text { - The drama of the jealous father... }\end{array}$ \\
\hline Theme/s & $\begin{array}{l}\text { A father guilty of incestuous desire for his own daughter. } \\
\text { Love, Freedom \& Sacrifices }\end{array}$ \\
\hline CULTURAL VALUES & $\begin{array}{l}\text { ACHIEVEMENT, INTELLIGENT, PERSONAL SUCCESS, OBTAINING SOCIAL } \\
\text { APPROVAL }\end{array}$ \\
\hline
\end{tabular}




\begin{tabular}{|c|c|}
\hline Characters & $\begin{array}{l}\text { Filemon Acayan - Filipino, fifty years old, a U.S. citizen, He has been a corporal in the US } \\
\text { Army, training at San Luis Obispo. In 1945, after his work in the US Army, he worked in a } \\
\text { hospital as a menial. He has been in charge of the human embryos inside their bottles. He has } \\
\text { always having nightmares because of those fetus and infants. So much so, he decided to look } \\
\text { for another pleasant job as a policeman in the post office in } 1945 \text {. He has no more immediate } \\
\text { family even in the Philippines. Fil wants to join the company of dancers from the Philippines, } \\
\text { show them around, walk with them in the snow, answer their questions, tell them about the } \\
\text { changing seasons in the US. He enjoys eating adobo and the best stuffed chicken with Tony in } \\
\text { their apartment. Fil shows greater mastery in their dialect. He has always been florid, } \\
\text { sentimental, and poetic. Fil is also very sentimental... he can not easily let go of the things. } \\
\text { He is perhaps stuck in the past that after years of not being able to visit his beloved country, he } \\
\text { thought things wouldn't change. } \\
\text { But he has been unfortunately wrong in his expectations. } \\
\text { The erasure of all the recorded concert will help Fil to accept that time never stops. Beautiful } \\
\text { memories will always be in our hearts and minds. It is a kind of sentimentality that he wants } \\
\text { to have a record of memories of the Filipino young dancers, but he ends up losing them all } \\
\text { instead. But then again, maybe it was for the best. } \\
\text { - Tony Antonio Bataller - a retired porter and unfortunately has been bedridden most } \\
\text { of the time for the last two years. His face has been healing from severe burns. He } \\
\text { has not been feeling alright. He thinks it's cancer or leprosy. He has shared a lot } \\
\text { with Fil. They have tried to be merry on Christmas days, most of the times get } \\
\text { drunk and they become loud. Fil loves to recite poems in his dialect and Tony } \\
\text { curses all the railroad companies of America. But, they didn't talk last Christmas, } \\
\text { they have decided not to celebrate last time. }\end{array}$ \\
\hline Point of View & Third person point of view \\
\hline Setting/Local color & Chicago; sleep valley, drowsy gray; snowy morning in Chicago; New York \\
\hline Plot & $\begin{array}{l}\text { Many times, Fil stares at Tony moaning, crying and screaming because of the severe pain in } \\
\text { his abdomen. Tony will usually scream that he's dying. } \\
\text { - Fil has arrived at the Hamilton Hotel, to see the Philippine dancers. Fil has been } \\
\text { amazed to remember how beautiful Philippine girls are. They are all very young. } \\
\text { But there are few elderly men and women who must have been their chaperons or } \\
\text { well-wishers like him. } \\
\text { Fil wants to ask them: Ilocano ka ? Bicol ka? Paisano? Comusta? But, suddenly } \\
\text { he feels that he is an outsider. Suddenly he feels that he doesn't belong there. The } \\
\text { age is in his face already. His hands is already horny, Fil doesn't like to shake } \\
\text { hands with the boy who stands close to him. He seems to be friendly but Fil has } \\
\text { decided to put his hands in his pocket. How he wishes Tony is with him. Tony } \\
\text { knows more how to socialize with those young people. Once in a while, Fil hears } \\
\text { them talking in their own native dialects. Fil could really feel the nostalgia of the } \\
\text { misa de gallo, barrio fiestas and evening on the plazas. Fil smells their fragrance } \\
\text { also of camia, ilang-ilang, and dama de noche. } \\
\text { He wants to invite those young people to have a free tour of Chicago. He wants to } \\
\text { take them around the lakeshore drive, gardens and parks, museums, department } \\
\text { stores, planetarium. And finally, he wants to offer a dinner at his apartment on } \\
\text { West Sheridan Road - to eat pork adobo and chicken relleno. He wants to say } \\
\text { "how about it, paisanos?" } \\
\text { Alas, he has now the courage to invite them. Fill has started with the boys: "May I } \\
\text { invite you to my apartment?" The boys turned down Fil's invitation. He } \\
\text { approached the group of girls, but they have answered him "Thank you, but we } \\
\text { have no time" } \\
\text { At long last, Fil has decided not to invite the young people anymore. "Let them } \\
\text { have fun on their own schedule." Fil wants to invite those youth because he } \\
\text { remembers the good old days when he was exactly like them many years ago. } \\
\text { Perhaps, they have been advised carefully not to talk with strangers, to be extra } \\
\text { careful in New York and Chicago, beware of old-timers, most of them are bums. } \\
\text { To his dismay, none of the dancers take notice of him or accept his invitation to } \\
\text { come over to his apartment }\end{array}$ \\
\hline Conflict & Man VS himself/psychological \\
\hline Symbol/s & $\begin{array}{l}\text { Filemon's dream of Tony telling him what to do in case of a shipwreck "Say in a ship... I } \\
\text { mean, in an emergency, you're stranded without help in the middle of the Pacific or the } \\
\text { Atlantic, you must keep floating till help comes..." This line pertains to the scene that } \\
\text { happened in the Hamilton Hotel when he has tried to be friendly and accommodating with the } \\
\text { Filipino dancers, yet he has been rejected, and thus left him feel so much loneliness. } \\
\text { - Relating this with the dream, it means that he should not let himself feel so down } \\
\text { with the burden of loneliness that he is carrying. "He must keep floating till help } \\
\text { comes." Help can pertain to someone comforting him, perhaps it can be Tony. } \\
\text { "Now, let me teach you how to keep afloat" Those words were not Tony's words. } \\
\text { Perhaps, the voice who said this could be his own, telling him that the only one } \\
\text { who can help him to not break down emotionally is himself. Take things in }\end{array}$ \\
\hline
\end{tabular}


Cultural Values in Selected Southeast Asian Countries As Reflected in Representative Short Stories: Comparative Study

\begin{tabular}{|l|l|}
\hline \multicolumn{1}{|l|}{} & stride... \\
\hline Theme/s & $\begin{array}{l}\text { A story about an old timer Filipino in the US. This story is a blend of irony and tenderness } \\
\text { into the rootless and lonely lives of men residing in America but carrying their nationality like } \\
\text { a winter coat they cannot discard. } \\
\text { About loneliness, alienation, homesickness, all postwar maladies. }\end{array}$ \\
\hline CULTURAL VALUES & \begin{tabular}{c} 
UNIVERSALISM, NATIONALISM, SOCIAL JUSTICE, EQUALITY \\
\hline
\end{tabular} \\
\hline
\end{tabular}

Elements of Fiction Guide- THE WEDDING DANCE by AMADOR T. DAGUIO 1953 (Philippines)

\begin{tabular}{|l|l|}
\hline Characters & $\begin{array}{l}\text { Lumnay - She does not want any other man than Awiyao. She has been a good wife. Awiyao } \\
\text { has nothing to say against her. But unfortunately, seven harvests was just too long to wait for } \\
\text { a child. She has prayed to Kabunyan so much. Still Kabunyan never blessed her a child. Well } \\
\text { in fact, she has sacrificed many chickens during her fervent prayers. One of the best wives in } \\
\text { the whole village. She had been very proud of her husband's humour. } \\
\text { Awiyao - He has been a good husband to Lumnay. He does not want any other woman either. } \\
\text { He had a sense of lightness in saying things, which made people laugh. Just like Lumnay, he } \\
\text { would always offer pigs to Kabunyan only for them to have a child with Lumnay. But still, } \\
\text { Kabunyan does not see them fit to have a child. } \\
\text { Madulimay - She is not as strong as Lumnay in planting beans, not as fast in cleaning jars, not } \\
\text { as good in keeping a house clean. }\end{array}$ \\
\hline Point of View & $\begin{array}{l}\text { Third person point of view } \\
\text { Setting/Local color }\end{array}$ \\
& $\begin{array}{l}\text { Early families are dependent to farming as a means of sustaining their daily needs. Rice } \\
\text { paddies, dikes, mountain ranges, and rice field. }\end{array}$ \\
\hline
\end{tabular}


Cultural Values in Selected Southeast Asian Countries As Reflected in Representative Short Stories: Comparative Study

\begin{tabular}{|c|c|}
\hline Plot & $\begin{array}{l}\text { - Awiyao did not want to force Lumnay to join his second wedding ceremony. He } \\
\text { didn't have a choice. He needed to be subservient to their culture of a man should } \\
\text { have an offspring. } \\
\text { The moment that Awiyao has married Madulimay then, Lumnay would go back to } \\
\text { her parents. Never again would he hold her face. } \\
\text { According to their culture, life is not worth living without a child. Tribal people } \\
\text { would mock a childless man behind his back. } \\
\text { - A man has to have a child so that his name will live in their tribe. } \\
\text { Awiyao made a promise to Lumnay to go back to her arms when he failed to have a } \\
\text { child with Madulimay. Both of them will vanish from the life of their tribe. } \\
\text { She would go to the chief of the village, to the elders, to tell the it was not right. } \\
\text { Awiyao was hers. Let her be the first woman to complain, to denounce the } \\
\text { unwritten rule that a man may take another woman. }\end{array}$ \\
\hline Conflict/s & - $\quad$ Man vs. society's customs \\
\hline Symbol/s & $\begin{array}{l}\text { The gongs of the dancers clamorously called in her ears through the walls. } \\
\text { The beads are worth twenty fields given to Lumnay, they stand for the love of } \\
\text { Awiyao for Lumnay } \\
\text { Awiyao not long ago, decided to throw his spear on the stairs of her father's house } \\
\text { in token of his desire to marry her. } \\
\text { - The unwritten law demanded that all their men in their tribe must have a child } \\
\text { Before, she would dance like a bird tripping for grains on the ground, beautifully } \\
\text { timed to the beat of the gangsas } \\
\text { - She would stretch her hands like the wings of the mountain eagle. Was not their } \\
\text { love as strong as the river? }\end{array}$ \\
\hline Theme/s & $\begin{array}{l}\text { Respect for old customs, tradition and unwritten rule in the tribal groups in the northern } \\
\text { Philippines }\end{array}$ \\
\hline Cultural Values & $\begin{array}{l}\text { TRADITION, RESPECT, COMMITMENT TO CUSTOMS/TRADITIONS, CULTURE AND } \\
\text { RELIGION }\end{array}$ \\
\hline
\end{tabular}

Elements of Fiction Guide BUGIS by ALFIAN SA'AT (Singapore) 1997

\begin{tabular}{|l|l|}
\hline Characters & $\begin{array}{l}\text { Salmah - decides to wear her tudung again. } \\
\text { Sazalie - The boyfriend of Salmah. He likes to have to pierce his eyebrows with ornaments } \\
\text { like silver. He likes to hear dirty jokes. He likes playing skateboarding. }\end{array}$ \\
\hline Point of View & $\begin{array}{l}\text { Third person point of view - the author butts in or throws his weight around or makes } \\
\text { comments or tells his characters what to do in the story and obviously intrudes, the author is } \\
\text { said to be subjective. }\end{array}$ \\
\hline
\end{tabular}




\begin{tabular}{|c|c|}
\hline Setting/Local color & $\begin{array}{l}\text { The MRT train stops at Bugis St. In the afternoon, the train is not so crowded and everyone } \\
\text { finds a seat. There are Caucasians, Bangladeshis, Filipinos, Thais, Chinese, Malays, Indians } \\
\text { looking for their seats. Multi society, multi-racial, multi-religious, multi-lingual, multi-cultural } \\
\text { Singapore. } \\
\text { - Outram park; Chinatown; the pirated VCD shops } \\
\text { A Malay woman walks in. She holds on to the strap of her handbag. She is } \\
\text { wearing high-heeled shoes. She has high cheekbones. She is wearing spaghetti } \\
\text { strap dress that shows her tights. But she has Adam's apple. The Malay lady is a } \\
\text { man, "pondan" or transvestites. She has fake fingernails, fake wig, fake breasts, } \\
\text { and fake shaven shins. } \\
\text { In the mid-1980s, Bugis Street underwent major urban redevelopment into a retail } \\
\text { complex of modern shopping malls, restaurants and nightspots mixed with } \\
\text { regulated back-alley roadside vendors. Underground digging to construct the Bugis } \\
\text { MRT station prior to that also caused the upheaval and termination of nightly } \\
\text { transgender sex bazaar culture, marking the end of a colourful and unique era in } \\
\text { Singapore's history. } \\
\text { Bugis has been cleaned up, dolled up decently for the tourists. }\end{array}$ \\
\hline Plot & $\begin{array}{l}\text { Tudung is the scaf that good Moslem girls wear. She kisses her mother's hand to win her trust. } \\
\text { Later on she sees her boyfriend in school. } \\
\text { - So young, but they want to find romance. The old ones call it "cinta monyet" or } \\
\text { monkeys in love. } \\
\text { - Islamic tradition demands that women should be concealed when they come out in } \\
\text { public. Although a lot of women don't follow these rules, some have still retained } \\
\text { the age-old values of the Islamic religion. }\end{array}$ \\
\hline Conflict & - $\quad$ Man VS the customs of her society \\
\hline Symbol/s & $\begin{array}{l}\text { When transvestites began to rendezvous in the area in the 1950s, they attracted increasing } \\
\text { numbers of Western tourists who came for the booze, the food, the pasar malam shopping and } \\
\text { the "girls". Business boomed and Bugis Street became an extremely lively and bustling area, } \\
\text { forming the heart of Xiao Po. It was one of Singapore's most famous tourist meccas from the } \\
\text { 1950s to the 1980s, renowned internationally for its nightly parade of flamboyantly- } \\
\text { dressed transwomen and attracted hordes of Caucasian gawkers who had never before } \\
\text { witnessed Asian queens in full regalia. } \\
\text { The latter would tease, cajole and sit on visitors' laps or pose for photographs for a fee. } \\
\text { Others would sashay up and down the street looking to hook half-drunk sailors, } \\
\text { American GIs and other foreigners on R\&R, for an hour of profitable intimacy. Not only } \\
\text { would these clients get the thrill of sex with an exotic oriental, there would be the added spice } \\
\text { of transgressing gender boundaries in a seamy hovel. }\end{array}$ \\
\hline Theme/s & $\begin{array}{l}\text { Bugis in Singapore, was renowned internationally from the } 1950 \text { s to the } 1980 \text { s for its } \\
\text { nightly gathering of trans women, a phenomenon which made it one of Singapore's top tourist } \\
\text { destinations during that period. } \\
\text { In the mid-1980s, Bugis Street underwent major urban redevelopment into a retail complex } \\
\text { of modern shopping malls, restaurants and nightspots mixed with regulated back-alley } \\
\text { roadside vendors. Underground digging to construct the Bugis MRT station prior to that also } \\
\text { caused the upheaval and termination of nightly transgender sex bazaar culture, marking the } \\
\text { end of a colourful and unique era in Singapore's history. This change helped improve } \\
\text { Singapore's international image as it began to be globally recognised. } \\
\text { - Islamic tradition demands that women should be concealed when they come out in } \\
\text { public. Although a lot of women don't follow these rules, some have still retained } \\
\text { the age-old values of the Islamic religion. }\end{array}$ \\
\hline CULTURAL VALUES & $\begin{array}{l}\text { SELF - DIRECTION, INDEPENDENT THOUGHT, CREATIVE, AUTONOMY, } \\
\text { INDEPENDENCE, INTELLIGENT, PRIVACY }\end{array}$ \\
\hline
\end{tabular}




\begin{tabular}{|c|c|}
\hline Characters & $\begin{array}{l}\text { Helena Rodrigues is a sweet girl. Helena has the meek gentle face of a nun, and the force of } \\
\text { personality of an Empress Tzu His. Helena trains her husband to recite every morning a } \\
\text { complete programme of his actions and company for the whole day. } \\
\text { Aloysius - The husband of Helena died of complications following the perforation of a } \\
\text { duodenal ulcer. "Stress and tension" the doctors said, were the causal factors. } \\
\text { The Only Uncle - He is always busy. Nobody can expect for him to have time and sympathy } \\
\text { for his fatherless nephew. }\end{array}$ \\
\hline Point of View & $\begin{array}{l}\text { The Martyrdom of Helena Rodriguez is told by the brother-in-law of Helena whose } \\
\text { disapproval of her provides the moral viewpoint. (First person point of view stands out as a } \\
\text { character and refers to himself using "I" }\end{array}$ \\
\hline Setting/Local color & $\begin{array}{l}\text { The early writers were influenced by the "thirties literature" of England. Short-story writers } \\
\text { have read and learned from the masters of fiction. }\end{array}$ \\
\hline Plot & $\begin{array}{l}\text { The widow Helena has decided to devote the rest of her life to bring up little George. She } \\
\text { brings up George to believe that to insult his mother's devotion to him is the ultimate } \\
\text { blasphemy. } \\
\text { - George is now sixteen. He has acquired his driving license, and the keys of the } \\
\text { family car. One day, George has decided to visit his uncle while his mother is in } \\
\text { the salon. } \\
\text { The uncle says he wants to invite George to a dinner. But George is worried about } \\
\text { his mother. He is thinking that his mother is going to be alone in the evening. } \\
\text { George can't leave his mother to become lonely in the evening. } \\
\text { George has discovered something. His mother has been commuting by bus to visit } \\
\text { the most remote, the most phone-gossipy aunts. } \\
\text { George has grown older. He has reached his last years of schooling, then he passed } \\
\text { his examinations. After becoming a conscientious student, he entered a relative's } \\
\text { firm. } \\
\text { - George has fallen in love with Caroline Adams. She has a fine sense of humour. } \\
\text { Helena, asks for more time of George's company. She increases her tender } \\
\text { enjoyment of the presence of her only son. But George is already contemplating to } \\
\text { get married. } \\
\text { Now, Helena has developed nervous symptoms, palpitations, tremors of the heart. } \\
\text { Doctor de Cruz, a family friend told George that his mother's heart is not strong } \\
\text { anymore. } \\
\text { - Within his mother's house, George still has no independent will-power. } \\
\text { There will be a long honeymoon in Penang. } \\
\text { Helena has a psychosomatic weapon, she is diagnosed a seizure of the heart. } \\
\text { George called off the wedding. He doesn't want to see Caroline anymore. He has } \\
\text { given up his job to take care of his mother. He wants to become a devoted son for } \\
\text { the rest of his life. } \\
\text { George has unfortunately taken a lot of barbiturates to keep him awake in his nightly vigils of } \\
\text { taking care of his mother. He has far exceeded the quantity prescribed. People found George } \\
\text { lying dead on the bathroom floor. } \\
\text { Helena has transferred into a comfortable nursing home, where she was soon universally loved } \\
\text { and attended on for her sweet unselfish ways. } \\
\text { Helena occasionally voiced her gentle wonder that her brother-in-law does not come to visit } \\
\text { her. }\end{array}$ \\
\hline
\end{tabular}




\begin{tabular}{|c|c|}
\hline Conflict & $\begin{array}{l}\text { Man vs. Himself/Herself (psychological) - The leading character struggles with } \\
\text { himself/herself; with his/her own soul, ideas of right or wrong, physical limitations, choices, } \\
\text { etc. } \\
\text { Mental= The females in the story were the strong and decisive way a man should think while } \\
\text { the weak and giving way that the males think should be that of a female. The male should be } \\
\text { the protector and provider of the female that he loves. Both father and son gave in to Helena's } \\
\text { wishes and sacrificed themselves as a woman would do to fit into society. Caroline played an } \\
\text { important role that pushed George to move away from his mother and become more like a } \\
\text { male but he falls to his mother in the end. } \\
\text { Emotional= Helena has taken on the emotional roles of up-bringing George that should have } \\
\text { been his fathers. As a result George's gender role was reversed from the child to care-taker } \\
\text { when he grew up to support his mother that eventually led to his death. He also denied his } \\
\text { emotional feelings for Caroline to take care of her because to him it would be the ultimate sin } \\
\text { to insult his mother or cause her harm } \\
\text { Spiritual= George was trapped in the females world spiritually where he had to obey and make } \\
\text { the best out of it under his mothers care. She raised him to fear and fear for her at the same } \\
\text { time, which should be how female view males, the dominant ones. } \\
\text { Psychological aspects of the four characters= } \\
\text { Females: Aloysius and George both were controlled by Helena thought she was 'kind' in her on } \\
\text { way of securing her own future. 'Teaching' both of them to be 'good' using her cunning mask. } \\
\text { Caroline was similar to Helena in a way that she tried to 'teach' George how to get away from } \\
\text { his mother but using a less cunning style and more direct and true. } \\
\text { Males: Aloysius and George both were devoted to Helena because of her 'teachings' and } \\
\text { therefore took on the roles of the female for the as the dependent and weak while the females } \\
\text { became the power over them. Thought George was treated as a male by Caroline, in the end he } \\
\text { did not emerge victorious against his mother. } \\
\text { These are how the gender roles of the story were reverse because of one factor that changed } \\
\text { them, Helena. }\end{array}$ \\
\hline Symbol/s & $\begin{array}{l}\text { Christian martyrdom, as opposed to simple or unrefined domestic martyrdom, is suffered with } \\
\text { sweet forgiveness and under veils of retirement. Helena's strength was that she never } \\
\text { complained, nor gave an appearance of complaint. } \\
\text { - The devoted mother is now a Lady Dracula } \\
\text { - The Medusa presence which has dominated the whole life of George makes him } \\
\text { crazy now. } \\
\text { - The day approached, the banns were called. } \\
\text { "The martyrdom of Helena" or is it The selfishness of Helena? }\end{array}$ \\
\hline Theme/s & $\begin{array}{l}\text { The aim of introducing the theme of Christian martyrdom at the beginning soon becomes clear } \\
\text { as the author proceeds chillingly to link the theme to the story's conclusion, a conclusion } \\
\text { whose inevitability in no way affects one's sense of being deeply disturbed at the end of it. } \\
\text { The story demonstrates a concern for and understanding of some of the forces that animate a } \\
\text { society. }\end{array}$ \\
\hline CULTURAL VALUES & $\begin{array}{l}\text { FAMILY SECURITY, SAFETY, HARMONY, STABILITY OF SOCIETY, NATIONAL } \\
\text { SECURITY, RECIPROCATION OF FAVORS, SENSE OF BELONGING }\end{array}$ \\
\hline
\end{tabular}


Elements of Fiction Guide THE EFFECT of a GOOD DINNER by ARTHUR YAP (1963) Singapore

\begin{tabular}{|c|c|}
\hline Characters & $\begin{array}{l}\text { Grand - uncle wanted to have a concubine. He had his money that time he wanted to have a } \\
\text { second wife. } \\
\text { Grand - auntie - was too afraid to accept the second wife because they were not in good terms } \\
\text { as her cousin. }\end{array}$ \\
\hline Point of View & "The Effect of a Good Dinner, told completely in the third person point of view. \\
\hline Setting/Local color & $\begin{array}{l}\text { The Moon Festival seems more insipid. Marriage in those days was by the process of match- } \\
\text { making. The two persons to be married need not know each other, but after a quietly nervous } \\
\text { meeting, they should. } \\
\text { Their background is uncomplicated. They came over from China at a very early } \\
\text { age with their parents. One day, they were married. Gradually, they prospered. } \\
\text { They had many children. }\end{array}$ \\
\hline Plot & $\begin{array}{l}\text { There is a story about grand-uncle and grand-aunt. They are not very loving. She is always } \\
\text { busy with something: washing cups, babies, or stitching and sewing. He decided to buy his } \\
\text { eldest son a bicycle, his eldest daughter a portable radio, his wife a jade bangle, and himself a } \\
\text { car. } \\
\text { - Life seems to be complacent. There is neither domestic tragedy nor sublimation. } \\
\text { Match-making has nothing much to commend it. Though divorces are never heard } \\
\text { of, this does not lend evidence to the belief that these married people are happy and } \\
\text { contented. } \\
\text { More often than not, the husbands acquire new wives. It is never the policy for the } \\
\text { wife to forbid her husband this little whim as long as he does not squeeze her } \\
\text { allowance to rice-powder. } \\
\text { Men have certainly all the means and women have all the understanding. } \\
\text { - Her only misgiving might be that she might not feel amiable towards the new wife. } \\
\text { The greater and silent misgiving would be that the new wife might not be amiably } \\
\text { disposed towards her, and what with her fresher appeal, her comparative youth and } \\
\text { his new allegiance, the woman usually stood in mortal dread of a domestic turmoil. } \\
\text { Her consolation would be that life itself, like some table game, would still have } \\
\text { built-in surprises. } \\
\text { The war also came, but it did not last forever. When the better years came, the } \\
\text { grand-uncle wanted the grand-aunt's cousin, a comparatively young woman as the } \\
\text { second wife. } \\
\text { The grand-aunt's dislike for her cousin was not merely personal. Their two } \\
\text { families have never been cordial or kind with each other. They have been bitter } \\
\text { among each other. They will have a loss of face if the grand-uncle will marry the } \\
\text { wife's cousin. They do not have friendly social relationships. So much so, the } \\
\text { immediate family members like the matriarch, relatives, and friends brought a } \\
\text { petition. } \\
\text { After a calming effect of dinner and a soothing effect on their emotions, an old man } \\
\text { was presented with the decision that he should not pursue his desire to marry the } \\
\text { cousin, but that he could have, as second wife, any other decent woman he should } \\
\text { choose. }\end{array}$ \\
\hline
\end{tabular}


Cultural Values in Selected Southeast Asian Countries As Reflected in Representative Short Stories: Comparative Study

\begin{tabular}{|c|c|}
\hline Conflict & $\begin{array}{l}\text { Man vs. Society (social) - The leading character struggles against ideas, practices, or customs } \\
\text { of other people. }\end{array}$ \\
\hline Symbol/s & $\begin{array}{l}\text { The first wife has to have a cup of tea given and served by the new/second wife. } \\
\text { And the new wife will receive one of these three unlegislated things: a poisonous } \\
\text { glare, a look of relief, and a look of total resignation. }\end{array}$ \\
\hline Theme/s & $\begin{array}{l}\text { Exposes the hypocrisy of that generation regarding concubinage in prose that is ironic and } \\
\text { sharp in an understated manner. } \\
\text { - Custom and tradition are the easiest things to kill. } \\
\text { - It is never unfashionable for a person to have a concubine. }\end{array}$ \\
\hline CULTURAL VALUES & $\begin{array}{l}\text { HEDONISM, GRATIFICATION FOR ONESELF, NEEDS AND PLEASURE, ENJOYING } \\
\text { LIFE, SELF-INDULGENT }\end{array}$ \\
\hline
\end{tabular}

Elements of Fiction Guide MONSTER by CATHERINE LIM (1966) Singapore

\begin{tabular}{|l|l|}
\hline Characters & $\begin{array}{l}\text { Old grandmother of seventy lies on her bed. She is very sad because her daughter - in -law } \\
\text { wants to get rid of the things in her room like her table, her cupboard, her bed, her altar... } \\
\text { Karen - The daughter-in-law of the old grandmother. She is the wife of Sai Khong. She } \\
\text { wants to get rid of the bed of the old grandmother because it has lots of bugs and filth. The } \\
\text { bugs have already invaded the room of the grandchildren. She wants to put in a decent bed } \\
\text { with a comfortable mattress instead of hideous four-poster with its carvings and that filthy mat } \\
\text { and the rusty tin she uses as a pillow. The old bed is the ugliest thing with all the weird } \\
\text { carvings and full of bugs and vermin. Karen calls the bed The Monster } \\
\text { Sai Khong - indifferent, callous, insensitive and ungrateful son towards the Old Grandmother. } \\
\text { He seems to be very busy with his work and golf course. }\end{array}$ \\
\hline Point of View & $\begin{array}{l}\text { Third person point of view } \\
\text { Setting/Local color }\end{array}$ \\
& $\begin{array}{l}\text { Semi-detached house in such a prestigious housing estate of Karen. She says the house is new } \\
\text { and lovely. But because of the filthy old grandmother the house looks like a Chinatown slum. }\end{array}$ \\
& \\
&
\end{tabular}


Cultural Values in Selected Southeast Asian Countries As Reflected in Representative Short Stories: Comparative Study

\begin{tabular}{|c|c|}
\hline Plot & $\begin{array}{l}\text { - The old grandmother says she is only a poor widow. Her sons and daughters do not } \\
\text { care for her. They argue with one another about whose turn it is to take her in. Her } \\
\text { children think she cannot understand the foreign language they speak. } \\
\text { The grandmother feels the pain so much because apparently, her children do not } \\
\text { want her anymore because she is already old and very sick. } \\
\text { The daughter-in-law wants to convert the room as a study and music room for the } \\
\text { children. The room will be a study room for Carol and Ricky. She said "It's so } \\
\text { important to have one's children properly educated these days. There's so much } \\
\text { competition in society today" } \\
\text { They are talking in low whispers. They are talking in their foreign language as } \\
\text { usual thinking she could not understand the essential meaning. } \\
\text { The doctor says it would be better if old grandmother will be brought to hospital. } \\
\text { The old grandmother wants to say that she wants to die on that huge treasured bed. } \\
\text { That monster, is worth a little fortune. Many American and European tourists love } \\
\text { old carved things. They just have the old antique bed be renovated. It could } \\
\text { possibly be a collector's item. } \\
\text { - Sai Khong, the biological son of the old lady assures his wife that her last few days } \\
\text { will be comfortable. She has the best attending doctor. } \\
\text { Her end is near, so they decided to take turns in visiting her everyday. }\end{array}$ \\
\hline Conflict & $\begin{array}{l}\text { 1) Man vs. Man (physical) - The leading character struggles with his physical strength against } \\
\text { other men, forces of nature, or animals. } \\
\text { 2) Man vs. Circumstances (classical) - The leading character struggles against fate, or the } \\
\text { circumstances of life facing him/her. }\end{array}$ \\
\hline Symbol/s & $\begin{array}{l}\text { "Monster" is the ruthless and cruel treatment of the physiological children towards their old } \\
\text { and sick mother. }\end{array}$ \\
\hline Theme/s & $\begin{array}{l}\text { The younger generation copes well enough, and in "Monster" they do so by manifesting } \\
\text { snobbery which is a form of social discrimination at the expense of the old grandmother. But } \\
\text { it is not the old or the poor, as people being discriminated against, who always lose out. }\end{array}$ \\
\hline CULTURAL VALUES & $\begin{array}{l}\text { POWER, SOCIAL STATUS, WEALTH, PRESTIGE, AUTHORITY, SOCIAL } \\
\text { RECOGNITION }\end{array}$ \\
\hline
\end{tabular}

Elements of Fiction Guide THE TIGER by S. Rajaratnam (Singapore) 1978

\begin{tabular}{|c|c|}
\hline Characters & $\begin{array}{l}\text { - Fatima - a Malay pregnant woman. For some reason, unlike the anxious villagers } \\
\text { around Fatima is compassionate and sympathetic towards the tiger after she is out } \\
\text { of danger, whereas the villagers are aggressive to the possible threat of a tiger and } \\
\text { behave in an irrational manner. Firstly, Fatima watches as Mamood and the men } \\
\text { walk she was averse to having the tiger killed } \\
\text { Mamood, with his youthful face was all for hunting the tiger at once. He said } \\
\text { "Somebody has to kill the tiger before it kills us" }\end{array}$ \\
\hline Point of View & Third person point of view \\
\hline Setting/Local color & $\begin{array}{l}\text { Has a rural setting with cruel villagers to animals } \\
\text { - } \\
\text { a narrow body of water separates Singapore from Malay Peninsula (mountains } \\
\text { - Kampongs: small isolated villages throughout } \\
\text { countryside } \\
\text { - People: subsistence farmers: depend on the crops they grow and animals } \\
\text { they raise for survival } \\
\text { - Singaporeans: live with a delicate balance with nature }\end{array}$ \\
\hline
\end{tabular}




\begin{tabular}{|c|c|}
\hline Plot & $\begin{array}{l}\text { - Fatima and the tiger watched one another, she frightened and it suspicious. The } \\
\text { tiger showed no signs of really wanting to attack her. Fatima noticed the surprising } \\
\text { changes of mood in the animal's eyes. } \\
\text { - The tiger showed no signs of going away she grew desperate. } \\
\text { - The headman said, "For the peace and safety of the women and children the tiger } \\
\text { must be hunted down and destroyed without delay." } \\
\text { - Fatima did not like to kill the tiger. She explained: "The tiger was not more than } \\
\text { twenty yards away from me and it could have sprung at me easily, but it didn't. At } \\
\text { first its eyes glared at me but later they were gentle and bored. There was nothing } \\
\text { fierce or murderous about it." } \\
\text { - Then, they heard the faraway crack of a rifle. Then came the roar of the tiger, full } \\
\text { of pain, agony and defiance. } \\
\text { - After the big tiger was shot twice they had to spear it before it was really killed. } \\
\text { Then, they saw three of the tiniest tiger - cubs. Their eyes were scarcely open. No } \\
\text { wonder the mother tiger fought like one possessed. Mamood says that he could sell } \\
\text { the cubs for a good price. } \\
\text { Then Fatima moaned in pain. She needs a midwife immediately ! }\end{array}$ \\
\hline Conflict & - $\quad$ Man VS himself \\
\hline Symbol/s & $\begin{array}{l}\text { - Fatima was against the idea of killing the tiger as she had sympathy for it, on the } \\
\text { contrary the villagers are aggressive enough to kill the beast instead of protecting } \\
\text { themselves from it, which shows no possible threat. Overall, Fatima experiences a } \\
\text { connection with the tiger which leads her to feel compassionate towards the tiger } \\
\text { unlike the villagers who find a need to become violent as they did not take the time } \\
\text { to analyze the situation for a more rational solution. } \\
\text { In conclusion, if one takes the time to review and balance the pros versus cons of } \\
\text { the situation at the presence of fear, a more reasonable outcome is able to take place } \\
\text { which does not include violence. }\end{array}$ \\
\hline Theme/s & $\begin{array}{l}\text { - Illegal hunting of endangered species } \\
\text { The pregnant mother's disgust at the senseless killing of the pregnant tigress, which } \\
\text { has left her undisturbed while she is bathing in the pool, is expressed positively in } \\
\text { her cry for a doctor to attend to the birth of her child. Out of the brutal killing of } \\
\text { the tigress has emerged a poignant birth - cry which is the mother's judgement on } \\
\text { that brutality. } \\
\text { Rajaratnam does a well job to show the different views of two opposite reaction to fear, on one } \\
\text { hand there is Fatima who stays level headed at the immediate sight of a tiger and on the other } \\
\text { hand there are the villagers who exaggerate the fear and are shown to be impulsive. Also, } \\
\text { Fatima demonstrates sympathy and compassion for the tiger as she realizes it means no harm } \\
\text { whereas the villagers show violence and aggressiveness towards the tiger as they believe it is } \\
\text { their best option to safety. Therefore, fear is able to influence and control one's wisdom by } \\
\text { compelling them to undoubtedly carry out sudden decisions. }\end{array}$ \\
\hline CULTURAL VALUES & $\begin{array}{l}\text { UNIVERSALISM, PROTECTION FOR NATURE/ENVIRONMENT, UNDERSTANDING, } \\
\text { TOLERANCE, SOCIAL JUSTICE, EQUALITY, WORLD OF PEACE }\end{array}$ \\
\hline
\end{tabular}

Elements of Fiction Guide AS IF IT HAD NEVER HAPPENED by WITTHAYAKON CHIANGKUN (1974) Thailand

\begin{tabular}{|l|l|}
\hline Characters & $\begin{array}{l}\text { Thong Muan, fourth grade, she could actually see only the village, the ricefields, water - } \\
\text { buffaloes, and the children tending them. } \\
\text { Headman Mi came out to meet the group. Mi had always been regarded as the most respected } \\
\text { person in the village, since His Majesty's Government had appointed him headman and } \\
\text { everyone had to obey him. }\end{array}$ \\
\hline
\end{tabular}




\begin{tabular}{|c|c|}
\hline Point of View & $\begin{array}{l}\text { Witthayakon uses the device of telling the story through the person of an innocent little girl, } \\
\text { called Thong Muan, to make gentle, sardonic fun of his educated Bangkok contemporaries in } \\
\text { the early stages of their politicization. } \\
\text { Innocent Eye - The story is told through the eyes of a child (his/her judgment being } \\
\text { different from that of an adult). }\end{array}$ \\
\hline Setting/Local color & $\begin{array}{l}\text { Bone - dry rice field the dilapidated houses of her village, the tiny temple, and the clapboard } \\
\text { schoolhouse, which had only a floor and a roof. }\end{array}$ \\
\hline Plot & 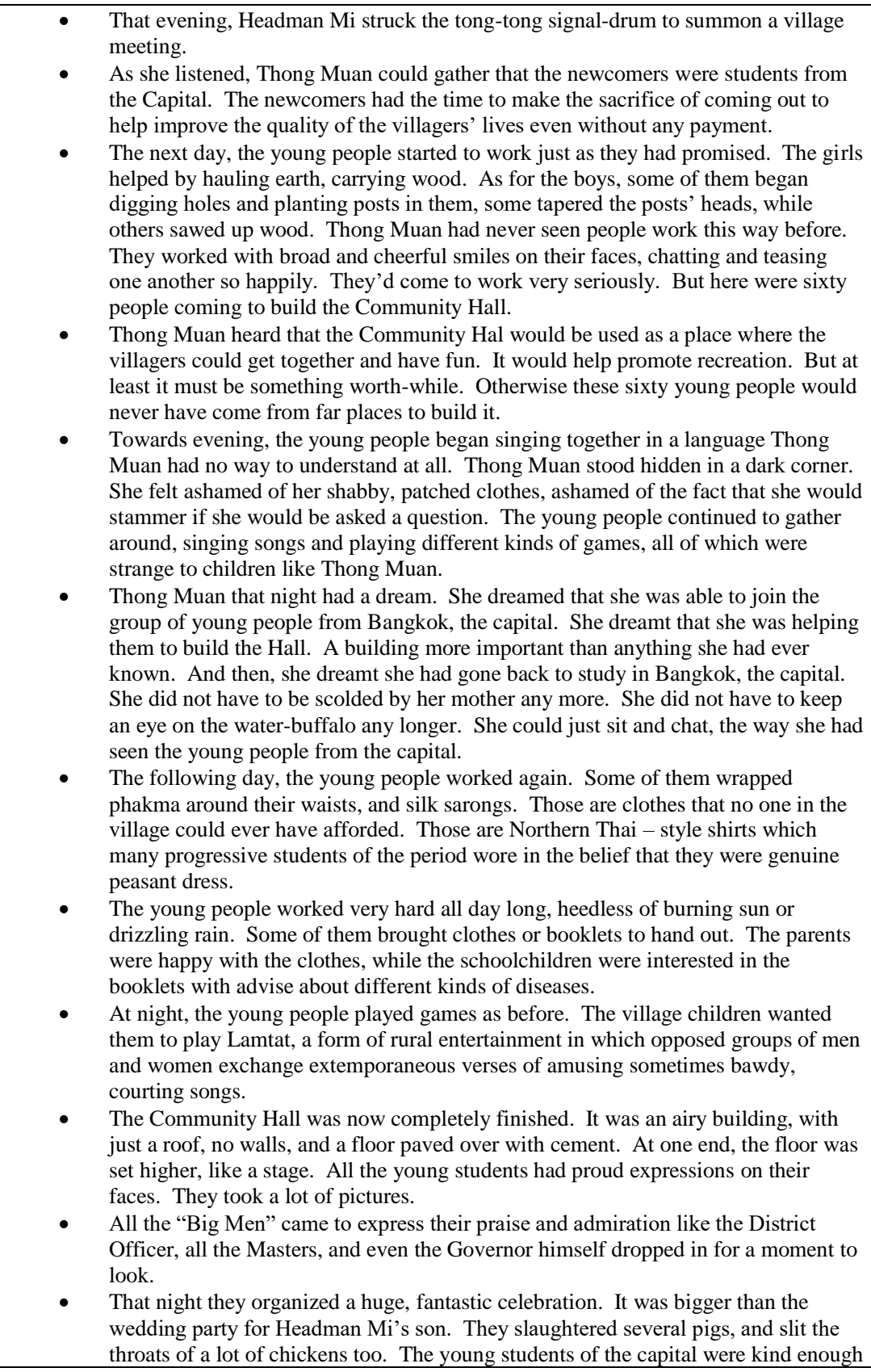 \\
\hline
\end{tabular}




\begin{tabular}{|c|c|}
\hline & $\begin{array}{l}\text { to invite the villagers to join them. But only Headman Mi and Teacher, no one } \\
\text { dared to go. No one in the village had clothes good enough to wear. And no one } \\
\text { wanted to face the District Officer's critical stare. } \\
\text { In the afternoon, when Thong Muan finished her chores, she went off to the } \\
\text { Community Hall. Actually, no one really knew what they could use the } \\
\text { Community Hall for. Headman Mi preferred to use the courtyard of his own home } \\
\text { rather than wasting time and tiring himself by the walk to the Hall. He was also } \\
\text { afraid that if he used it often, the Hall would get run down; and then, when the } \\
\text { District Officer dropped for an inspection, he would criticize him for his } \\
\text { negligence. } \\
\text { The teacher did not want to use it either. He would only say that when school } \\
\text { opened again, he would probably have the children put on some kind of show there. } \\
\text { But every now and then the school was closed, and everyone knew that he simply } \\
\text { did not want to do anything at all. } \\
\text { And so the Community Hall, which they had labored to build with such hope and } \\
\text { faith, just stood there, with no one to care for it. } \\
\text { Thong Muan, every time she gets time off from her chores, she goes to the } \\
\text { Community Hall to relax. It gives her a feeling of warmth when she thinks about } \\
\text { "them." She often wonders what they are doing now in the Capital. Do they ever } \\
\text { think back to what they built for love? } \\
\text { She would like to have built walls too - they would have helped against the rain. If } \\
\text { there were walls, the Community Hall could also be used for storing rice. Then the } \\
\text { people would not rush to sell their rice when the price was not yet right. }\end{array}$ \\
\hline Conflict & $\begin{array}{l}\text { Man vs. Circumstances (classical) - The leading character struggles against fate, or } \\
\text { the circumstances of life facing him/her. To depict the oppressive realities of } \\
\text { contemporary rural life and to create an atmosphere of menace. }\end{array}$ \\
\hline Symbol/s & $\begin{array}{l}\text { - The Community Hall was now completely finished. It stood majestically in the } \\
\text { middle of the rice-fields, like a monstrous wild animal. } \\
\text { The rainstorm has now subsided outside. But it has not died down in her heart. } \\
\text { Thong Muan feels a sudden wave of loneliness. And from her eyes ooze clear, pure } \\
\text { tears. They well up in the sockets of her eyes and trickle down over her cheeks. } \\
\text { Then fall to the dark cement floor. } \\
\text { The fact that the Thong Muan's village is still described almost like the contented, } \\
\text { harmonious Ur-Thai community. } \\
\text { "Masters" are official or unofficial parts of the security bureaucracy which trained } \\
\text { by the Americans for counterinsurgency purposes in 1960s and 1970s. }\end{array}$ \\
\hline Theme/s & $\begin{array}{l}\text { We see the relationship between metropolitan and rural Siam during the late 1960s from a } \\
\text { parallel, if contrasting, perspective. It describes the descent on an isolated Northeastern village } \\
\text { of a group of idealistic Colloge student "volunteers" who come to build a "Community Hall" } \\
\text { as part of some government-sponsored rural development program. } \\
\text { The narration pays indirect tribute to the students' energy, kindliness, and naïve optimism, but } \\
\text { also mocks them from the moment they arrive in the village in their big orange-yellow bus, } \\
\text { singing "We've Come to Develop, Working Together for Our Country's God. In their } \\
\text { cheerful way they explain that "as school is now out, they have "the time to make the sacrifice } \\
\text { of coming out to help improve the quality of the villagers' lives." } \\
\text { Blissfully confident of their superior knowledge of what is good for the villagers, they build } \\
\text { their Community Hall, for which the village has not asked, and for which, it turns out, it has no } \\
\text { use. Abandoned by all but an occasional stray water-buffalo, once the College students have } \\
\text { left, it becomes a "ruin" at the very moment of its completion. }\end{array}$ \\
\hline CULTURAL VALUES & $\begin{array}{l}\text { BENEVOLENCE, ENHANCING THE WELFARE OF THE IN-GROUP, SMOOTH GROUP } \\
\text { FUNCTIONING, CONCERN FOR FAMILY, PRIMARY GROUPS, AND FOR OTHERS' } \\
\text { WELFARE, HELPFUL, HONEST, FORGIVING, LOYAL, TRUE FRIENDSHIP, MATURE } \\
\text { LOVE, AND SPIRITUAL LIFE }\end{array}$ \\
\hline
\end{tabular}

Elements of Fiction Guide THE GRANDMOTHER by K. SURANGKHANANG (Thailand) 1974 


\begin{tabular}{|c|c|}
\hline Characters & $\begin{array}{l}\text { The Grandmother - a peddler of cooked dumplings. The old woman has a wrinkled face and } \\
\text { with hearing difficulty already. She usually sells } 50 \text { tapioca dumplings around the village } \\
\text { market. She put some golden fried garlic and red and green hot peppers on top of the shining } \\
\text { dumplings. } \\
\text { She has a grown - up daughter who had married and had children of her own, on whom she } \\
\text { could not depend for anything } \\
\text { Every afternoon, when she gets home, she will mix together whatever left-over for subsistence } \\
\text { - The eldest son is a monk. The old woman had to force herself to feel that her son } \\
\text { had no more place in her life } \\
\text { - The second daughter was married to an orchard owner with two big wooden } \\
\text { houses. But Piam required the old mother to cut down weeds in the ditches of the } \\
\text { orchards. The daughter said that the old mother should never be treated as princess. } \\
\text { The third son, every night this son would come home nearly every evening drunk } \\
\text { and start beating his wife and children. If the old woman will intervene, he would } \\
\text { push her so hard that she would be sent reeling. } \\
\text { The fourth daughter was ashamed and embarrassed to accommodate her old mother } \\
\text { in her dwelling house. Her in-laws are all people of blue blood and rich. } \\
\text { Phew was her fifth child. She was married to a lazy man who did not like to work. } \\
\text { He could never stay long at one job. When they have money, they would quietly } \\
\text { spend it themselves without letting her get some share. }\end{array}$ \\
\hline Point of View & The Third - person point of view can tell what all characters are thinking and feeling. \\
\hline Setting/Local color & $\begin{array}{l}\text { In Thailand, peddlers, especially women, carry their loads in two baskets which hang from the } \\
\text { two twisted - up ends of a pole (mai-khan). The saraek are the strings of rattan which form the } \\
\text { slings for those baskets. } \\
\text { - In the neighborhood of Samsen Nai, Bangsue, usually hears familiar hawking of } \\
\text { "Sakoo-sai-moo ... miang - lao } \\
\text { To a roadside grocery store, the Grandmother sat down and cry "Sakoo-sai-moo ... } \\
\text { miang -lao, buy hot sakoo-sai-moo, my ladies. (A kind of dumpling made of } \\
\text { tapioca paste with stuffing made of pork and peanuts. They are eaten with parsley } \\
\text { or lettuce. } \\
\text { Another kind of dumpling with nearly the same kind of stuffing wrapped in pickled } \\
\text { cabbage-leaves, to be eaten with fried popped rice }\end{array}$ \\
\hline Plot & $\begin{array}{l}\text { The old woman remained sitting there until the sun was high and the market stalls had nearly } \\
\text { all packed up. Still Grandmother could not sell anything. } \\
\text { - She had been walking since early chilly morning and then through the hot } \\
\text { afternoon. Little by little she sold them. } \\
\text { She would always untie the knot to count her money to be invested in sakoo-sai- } \\
\text { moo and miang-lao } \\
\text { - Before going home, the old woman bought two salted eggs, one salted pla-too and } \\
\text { five well-ripened freckled bananas } \\
\text { The Grandmother finally went home. The mother told her four children "Your } \\
\text { Grandmother is back. Go and ask for some sweets. Then the children consumed } \\
\text { all the ten miang-lao that was left. } \\
\text { - With all her good deeds and the offerings to the monks, she might be born again a } \\
\text { great king's daughter in her next life } \\
\text { Little did the old woman realize it, but the one monk who came to receive the } \\
\text { offerings would say at her back "Hasn't she got anything else except salted eggs } \\
\text { and freckled bananas? } \\
\text { - Often she cried, wishing for death to come soon to escape from all this misery } \\
\text { - None of the people who crossed the bridge would ever suspect that deep down } \\
\text { below them was the deathbed of a poor old woman. }\end{array}$ \\
\hline Conflict & Man vs. circumstances of poverty \\
\hline
\end{tabular}


Cultural Values in Selected Southeast Asian Countries As Reflected in Representative Short Stories: Comparative Study

\begin{tabular}{|c|c|}
\hline Symbol/s & $\begin{array}{l}\text { The Grandmother offers food to the monks especially during holy days. } \\
\text { - Those bare feet, which had never worn shoes, stepped on the gravel road } \\
\text { - } \quad \text { She had chewed three or four mouthfuls of pounded betel nut } \\
\text { hawk her wares lifted the pole onto her shoulder, she passed by shops, houses, to } \\
\text { - In Thailand, one-satang coins are copper, the five - satang nickel, the tens and } \\
\text { twenty-fives silver. One baht has } 100 \text { satangs. } \\
\text { - The hawker is an old woman. She's dirty. } \\
\text { - Tla-too - a fish of the same family as mackerel, one of the cheapest in Thailand } \\
\text { - Two salted eggs and pla-too are to be offered to the monks } \\
\text { was nature's law that ripe fruits will finally fall off the branch, and this old creature } \\
\text { wape fruit... so old, so ripe ! }\end{array}$ \\
\hline Theme/s & $\begin{array}{l}\text { The old grandmother had brought up with all due care her own daughter until she got married. } \\
\text { But still had to depend on her old mother. Instead of being cared for, the old mother had to go } \\
\text { out to peddle in order to support them all. } \\
\text { - Life is full of suffering or conflict (thukkhang), life is non - self (anatta) } \\
\text { Only by overcoming these earthly cravings and our ignorance can we attain } \\
\text { Nirvana, the Awakening or the Enlightenment. }\end{array}$ \\
\hline CULTURAL VALUES & $\begin{array}{l}\text { FAMILY SECURITY, SAFETY, HARMONY, STABILITY OF SOCIETY, NATIONAL } \\
\text { SECURITY, SOCIAL ORDER, RECIPROCATION OF FAVORS, SENSE OF BELONGING }\end{array}$ \\
\hline
\end{tabular}

Elements of Fiction Guide: Lord Buddha, Help Me? By Suchit Wongthred Thailand (1975)

\begin{tabular}{|c|c|}
\hline Characters & $\begin{array}{l}\text { Maha Bunman - Reached the level of Parien III and enjoyed the title of Buddhist Scholar of } \\
\text { the First Rank but he had resigned from the monkhood almost three months ago. He has left } \\
\text { the monkhood to fight the world. Yet the world is so cruel to him. } \\
\text { Thaan Phra Khruu Waj's - He was apologetic to Bunman because he could not offer food on } \\
\text { that day. All of the monks were invited them to a noonday meal by an Air force captain living } \\
\text { behind the monastery. So much so, they did not go out on their begging rounds on that day. } \\
\text { Thaan's comment that Bunman can work in the morgue because he had resigned from the } \\
\text { monkhood. Thaan Phra's comment is primarily a recognition that things must be difficult for } \\
\text { his guest. }\end{array}$ \\
\hline Point of View & Third person point of view \\
\hline Setting/Local color & $\begin{array}{l}\text { The monastery/ritual hall is in Chinese style located in Mahachaj Road; temple in Bangkok; } \\
\text { Rajadamnern Avenue- a broad boulevard is universally recognized as Bangkok's most } \\
\text { handsome thoroughfare } \\
\text { The city is full of products that have caused the loss of the country's trade balance. It is full of } \\
\text { places of entertainment that are excessive, places of sex that are the causes of vice and crime. } \\
\text { All these are poisons which destroy the political leaders who are responsible for the country } \\
\text { Mahaa Bunman could have lived at the temple as a temporary guest or temple boy. } \\
\text { Some Bangkok temples house more guests than monks }\end{array}$ \\
\hline
\end{tabular}




\begin{tabular}{|c|c|}
\hline Plot & $\begin{array}{l}\text { For many Thai, perceive the monkly state as socially passive and solipsistic, without } \\
\text { challenge. He does not necessarily have to do anything. For his biological existence is } \\
\text { dependent upon what laypersons choose to give to him. } \\
\text { - The monk can simply become a man with nobody to depend on, nobody to know or } \\
\text { to know him, nobody to serve or to serve him } \\
\text { A monk can simply be always isolated and lonely amid the din and chaos of } \\
\text { Bangkok } \\
\text { Mahaa Bunman is trembling from hunger. His last few coins had been spent that } \\
\text { morning on a cup of coffee and half a package of Khled Thong cigarettes. His } \\
\text { religion degree should have helped him get a job without any difficulty. But it was } \\
\text { all wrong. Nowadays, employers want people with university degrees, not with } \\
\text { Parien certificates. } \\
\text { A monk's major deal of the day must begin by 11:00 A.M. and, when completed, } \\
\text { the monk can eat no solids again until the following morning. By 1:00 P.M., any } \\
\text { leftovers from this meal would presumably be available to visitors and hangers-on. } \\
\text { He has always been virtuous, both privately and publicly, but he is suffering from } \\
\text { starvation now } \\
\text { Everyone works like mad to earn his living. Nobody cares about anyone else. He } \\
\text { thinks of the shabby room he rents. He hasn't paid this month's rent yet. } \\
\text { Mahaa Bunman never thought that the life of a layman would be so difficult and } \\
\text { miserable. The world is so confusing. It is turmoil, indecency, and without justice. } \\
\text { He thought, he might as well become a thief, a terrorist, a bank robber, a purse } \\
\text { snatcher. Oh why did he leave the monkhood? } \\
\text { In the end Mahaa Bunman has thrown his four Buddha amulets, various } \\
\text { personifications of the Lord Buddha. He feels relieved around his neck. No more } \\
\text { obligation. No more faith. Perhaps, he is ready now to commit deviant or criminal } \\
\text { behavior in order to survive. The morality has deteriorated in Thai society. } \\
\text { Society is diseased. People compete with each other so much that the poor almost } \\
\text { choke to death over their own jealousy. If all the money that is poured into sexual } \\
\text { obsessions were used to help poor people then the prosperity of Thailand would } \\
\text { increase. }\end{array}$ \\
\hline Conflict & - $\quad$ Man vs his society; Man vs himself \\
\hline Symbol/s & $\begin{array}{l}\text { - Yellow robes of a monk mean his essential goodness } \\
\text { - Beencaangkhapradit is a series of extremely elaborate body movements for } \\
\text { showing respect to senior monks and Buddha images } \\
\text { Mahaa is an honorific for a learned monk } \\
\text { - The Luang Phauau (may mean a monk who is highly knowledgeable about the } \\
\text { supernatural) Somdej, Somkauau, Kring, Kampaeaeng Kayeeng are various } \\
\text { personifications of the Lord Buddha which the amulets symbolize. All had come } \\
\text { from Wat Mahathat at Sanam Luang. }\end{array}$ \\
\hline Theme/s & $\begin{array}{l}\text { The story is a description of the hero's lost of faith in Buddhism and its encompassing moral } \\
\text { power } \\
\text { - The story is a brilliant presentation of the relationship between poverty and self- } \\
\text { esteem } \\
\text { - How a man becomes full in fighting the world } \\
\text { Thai society is decadent and morally shabby. The rich are so rich. They have so } \\
\text { much to eat that they cannot even buy a glass of coffee to lubricate the engine of } \\
\text { the body. Everyday morality is disappearing from men's hearts. Generosity is } \\
\text { fading from people's hearts. } \\
\text { Politically speaking, one group of people has tried to spend several thousand } \\
\text { million to build an electronic machine just to send two people to walk on the moon, } \\
\text { while several thousand people are waiting for help to survive with a little less pain } \\
\text { and poverty }\end{array}$ \\
\hline
\end{tabular}


Cultural Values in Selected Southeast Asian Countries As Reflected in Representative Short Stories: Comparative Study

\begin{tabular}{|l|l|}
\hline CULTURAL VALUES & SELF-DIRECTION, AUTONOMY, INDEPENDENCE \\
& \\
\hline
\end{tabular}

Elements of Fiction Guide MICHIGAN TEST by WANIT JARUNGKIT-ANAN (1974) Thailand

\begin{tabular}{|c|c|}
\hline Characters & $\begin{array}{l}\text { Told in the first person of a foolish and funny student. Surely middle class, surely nationalist, } \\
\text { to a large extent. } \\
\text { Mae Jumjim - his lady friend advised him to ask help from a famous, sacred statue of } \\
\text { Brahma(whose location itself, in front of downtown Bangkok's tourist - filled, prostitute - } \\
\text { ringed Erawan Hotel). }\end{array}$ \\
\hline Point of View & $\begin{array}{l}\text { - Told in the first person by an amiable, empty headed Bangkok student, it describes } \\
\text { the absurd misadventures that befall him in his quest for a passport and visa to join } \\
\text { his brother and sister-in-law in California. Officials at the American embassy and } \\
\text { USIS inform him that the visa is conditional on passing the "Michigan Test" for } \\
\text { English language proficiency. }\end{array}$ \\
\hline Setting/Local color & $\begin{array}{l}\text { "Michigan Test" is the story in which individual Americans actually appear. But, interestingly } \\
\text { enough, although they are calmly ridiculed, they are marginal to the tale and to Wanit's } \\
\text { subversive concerns. The overt target of his satire is Bangkok's new middle class, which, } \\
\text { partly because of growing economic and political uncertainty in Siam, and partly because of } \\
\text { the semi colonial relationship with the US cemented in the 1960s, was the main contributor to } \\
\text { the massive Thai migration to Southern California in the 1970s. } \\
\text { - It is not by chance that Wanit makes his hero a luk jin - - the child of a first - } \\
\text { generation immigrant from China. This identification is sociologically correct. } \\
\text { Much of bangkok's new middle class is Sino-Thai, of recent Chinese descent. The } \\
\text { contrast between two migrations : the first of hardworking, poverty - stricken men, } \\
\text { fleeing famine and oppression, and seeking a productive better life; Second of idle, } \\
\text { well-to-do youths, with nothing on their minds but getting "a whiff of snow" and } \\
\text { enjoying the comforts of American consumer culture. }\end{array}$ \\
\hline Plot & $\begin{array}{l}\text { - The six things one had to submit when applying for a visa (1) A passport. (2) A } \\
\text { letter of certification from a financial guarantor (3) A letter from the guarantor's } \\
\text { bank attesting to his financial status (4) The I -20 (5) photos (6) his transcript } \\
\text { According to the new regulations the American embassy had laid down, it seemed } \\
\text { like everyone had to take the Michigan Test, except those who had already passed } \\
\text { the TOEFL. } \\
\text { He was advised to ask Ganesha's help. The elephant - headed Hindu god Ganesha, } \\
\text { still the object of devotions in Buddhist Siam, is believed by some to be an } \\
\text { effective god of obstacles. } \\
\text { The rustle of paper filled the whole auditorium. Everyone was set to work on the } \\
\text { exam. His rotten English was no help in making head or tail of them. Then, he } \\
\text { made his decision that his big and fertile Thailand was a better place to live than } \\
\text { America. } \\
\text { "Every one of you here is applying to become a slave of American imperialism... } \\
\text { You're the ones responsible for implanting rotten values in our society and } \\
\text { widening class differences! You're the ones who go off to bring back a degenerate } \\
\text { culture from America to Thailand! Why are you all heading for America? Is there } \\
\text { really no place in Thailand where you can study? Or are you planning to tear up } \\
\text { banknotes for fun? The truth is you don't have the wit to make a living in } \\
\text { Thailand. So you want to get a whiff of snow and then come back and show off as } \\
\text { if you now belonged to a different class of people. And now, you're being made to } \\
\text { take an exam in a language which is not even your mother tongue. }\end{array}$ \\
\hline
\end{tabular}


Cultural Values in Selected Southeast Asian Countries As Reflected in Representative Short Stories: Comparative Study

\begin{tabular}{|c|c|}
\hline Conflict & $\begin{array}{l}\text { Man vs. Society (social) - The leading character struggles against ideas, practices, } \\
\text { or customs of other people. }\end{array}$ \\
\hline Symbol/s & $\begin{array}{l}\text { The overt target of his satire is Bangkok's middle class, which because of growing economic } \\
\text { and political uncertainty in Siam, and partly because of the semi colonial relationship with the } \\
\text { US cemented in the 1960s, was the main contributor to the massive Thai migration in Southern } \\
\text { California in the 1970s. }\end{array}$ \\
\hline Theme/s & $\begin{array}{l}\text { - But in the face of impending humiliation, inspiration strikes. Jumping to his feet in } \\
\text { the crowded examination hall, he comically denounces his fellow examinees : } \\
\text { "Every one of you here is applying to become a slave of American imperialism..." } \\
\text { I tried to remember the sorts of phrases the new generation of writers uses. } \\
\text { "You're the ones responsible for implanting rotten values in our society and } \\
\text { widening class differences! You're the ones who go off to bring back a degenerate } \\
\text { culture from America to Thailand... the truth is you don't have the wit to make a } \\
\text { living here in Thailand. So you want to get a whiff of snow and then come back and } \\
\text { show off as if you now belonged to a different class of people..." }\end{array}$ \\
\hline CULTURAL VALUES & STIMULATION, CHALLENGE IN LIFE, DARING LIFE \\
\hline
\end{tabular}

Elements of Fiction Guide THONG PROI THE RICH GIRL Thai 1954 by M.R. Kukrit Pramoj

\begin{tabular}{|c|c|}
\hline Characters & $\begin{array}{l}\text { Thong Proi - is the youngest daughter in the large family of a couple running a business in } \\
\text { Chao Ched. She is aware that she is very fortunate. Her parents believe that Thong Proi must } \\
\text { have done many good things in her previous life. } \\
\text { San - A young man who has an interest on Thong Proi. San is the assistant district officer of } \\
\text { their town. }\end{array}$ \\
\hline Point of View & Third person point of view \\
\hline Setting/Local color & Ban Phaen and Bangkok \\
\hline Plot & $\begin{array}{l}\text { Thong Proi has grown up to be one of the most beautiful young women in the district. Her } \\
\text { parents have taken cared of her so much. She does not do jobs around the house that girls of } \\
\text { her age have done. } \\
\text { - } \\
\text { Ordinary men have been discouraged to love her because she has never done a bit } \\
\text { of woman's work. } \\
\text { Their wives have to help them earn a living. The future wives should be able to } \\
\text { share the work as well as leisure. None of the important men in the village has } \\
\text { chosen her to be offered with marriage proposal. } \\
\text { Thong Proi has been sent to Bangkok to have a decent education. She has } \\
\text { possessed money, however she fails to realize its true value. Life in Bangkok } \\
\text { becomes dull and boring to Thong Proi. } \\
\text { - Thong Proi does not know yet how to differentiate true happiness from suffering. } \\
\text { Thong Proi has met a man named San. } \\
\text { The two young people fall in love with each other and they have decided to be } \\
\text { married. } \\
\text { - Unfortunately, Thong Proi begins to get bored of her marriage. She becomes tired } \\
\text { of her husband. Ironically, the husband has always been faithful to his vow. } \\
\text { Thong Proi has decided to observe poor people. Ordinary people have been } \\
\text { working all day under the scourging heat of the sun. People have been wearing } \\
\text { shabbily torn clothes and they have experiencing hard lives. But in spite of difficult } \\
\text { life, true happiness have always been there in their contented faces. } \\
\text { She has attracted some of the young and handsome men, but her husband has been } \\
\text { pretending not to notice her callousness. She begins to see her husband as an old } \\
\text { piece of furniture which needs to be stored away. }\end{array}$ \\
\hline
\end{tabular}


Cultural Values in Selected Southeast Asian Countries As Reflected in Representative Short Stories: Comparative Study

\begin{tabular}{|c|c|}
\hline & - In the third year of marriage, Thong Proi becomes very ill. \\
\hline Conflict & Man VS herself/psychological \\
\hline Symbol/s & $\begin{array}{l}\text { Empty life - Life has been cruel and meaningless to Thong Proi. } \\
\text { Thong Proi hit the surface of the water, she let herself sink without making the } \\
\text { slightest effort to save herself never to be drowned }\end{array}$ \\
\hline Theme/s & $\begin{array}{l}\text { Her life was like that of a caged bird who does everything to make her happy. She lived a } \\
\text { meaningless life. Hinayana Buddhism, to explore the mystery of karma, the sin of Buddhism's } \\
\text { philosophy. }\end{array}$ \\
\hline CULTURAL VALUES & HEDONISM, GRATIFICATION FOR ONESELF, ENJOYING LIFE, SELF-INDULGENT \\
\hline
\end{tabular}

Elements of Fiction Guide NEW VIRTUE by NGUYEN BAN (Vietnamese) 1962

\begin{tabular}{|c|c|}
\hline Characters & $\begin{array}{l}\text { The widower - He was lonely and in low spirits. His father, his younger brother, and his wife } \\
\text { who was then pregnant, had been killed by bombing during a terrorist raid in } 1952 \mathrm{in} \mathrm{H.} \\
\text { Village. } \\
\text { The woman - She was about twenty -five years old, she was dressed in black - black tunic, } \\
\text { black satin trousers and black overcoat; she wore a large conical hat and held a basket in her } \\
\text { hand. }\end{array}$ \\
\hline Point of View & Third person point of view \\
\hline Setting/Local color & $\begin{array}{l}\text { In a train running on the last night of the lunar year. Drug store, the small ware shop the Nhan } \\
\text { Dan bookshop, the department store at Gia Lam and Lac Dao } \\
\text { Hanoi Muc Nam Quan Construction Site } \\
\text { Tet Festival; The Restoration of Peace }\end{array}$ \\
\hline Plot & $\begin{array}{l}\text { In a train on the last night of the lunar year, the train stopped. A dozen passengers, all army } \\
\text { men except a married couple, got into their coach, a spick and span and fashionable coach. } \\
\text { The husband was in high spirits, then he decided to tell a story. } \\
\text { - It was at the end of 1954, the year of the restoration of peace. He enjoyed the Tet } \\
\text { Festival at his work place and not at home -his house had been burnt down by the } \\
\text { French. His father, his younger brother and the pregnant wife were killed by } \\
\text { bombing during a terrorist raid in } 1952 \text {. } \\
\text { Then. He decided to go out for a walk on the eve of the Tet. The road was } \\
\text { completely dark, when he saw a woman. The woman was about twenty-five years } \\
\text { old. She was dressed in black satin trousers and black overcoat. She wore a large } \\
\text { conical hat and held a basket in her hand. }\end{array}$ \\
\hline
\end{tabular}




\begin{tabular}{|c|c|}
\hline & $\begin{array}{l}\text { - She had a very charming oval-shaped face, curved eyebrows, fascinating eyes and } \\
\text { red lips. Why she walked on that cold and rainy night, the last night of the year ? } \\
\text { The woman asked him to escort her going to D.C. He told the woman to spend the } \\
\text { night in his house and then, they will take the first trip in the morning. } \\
\text { - She said "A woman never sleeps just anywhere. } \\
\text { - Thus, they went down town, side by side. Arriving in the middle of the town, side } \\
\text { by side. Arriving in the middle of the town, she suddenly walked close to the man } \\
\text { as if they were lovers. Then, they saw a policeman coming. The police asked for } \\
\text { their papers. Knowing that she had no papers on her, he began to doubt her identity } \\
\text { and refused to recognize her as his acquaintance. } \\
\text { - } \text { After one year and a half later... } \\
\text { - He met her again with one of his colleagues in his work. She was introduced as } \\
\text { their prospective errand - girl for distribution of books and reviews. He } \\
\text { remembered that she was the very woman he met on the eve of the Tet Festival. } \\
\text { For three times, he would always tell her to accept the truth already. } \\
\text { In } 1952 \text {, she was captured in an enemy raid and fell into the hands of a sergeant of } \\
\text { the } 2^{\text {nd }} \text { bureau. (French Intelligence Service). She was nineteen. Then the sergeant } \\
\text { disposed of her to a French lieutenant for three thousand piastres. } \\
\text { Six months later the lieutenant was killed and she was left alone in Hanoi. Then } \\
\text { she met him on the outskirts of the town on the eve of the Tet Festival. } \\
\text { Later on, she worked at the Hanoi Muc Nam Quan railway construction site and } \\
\text { was rewarded many times. } \\
\text { Everybody had suffered the war of the colonialist invaders, though their sufferings } \\
\text { were different. She had done her best to get rid of soiled life and to create a new } \\
\text { one. She was a new woman, painstaking and active, this was clearly shown in her } \\
\text { daily work. } \\
\text { Eventually, she has enjoyed the Tet Festival in her native village, with her husband } \\
\text { and her child. }\end{array}$ \\
\hline Conflict & $\begin{array}{l}\text { Man vs. Circumstances (classical) - The leading character struggles against fate, or the } \\
\text { circumstances of life facing him/her. }\end{array}$ \\
\hline Symbol/s & $\begin{array}{l}\text { Why she didn’t enjoy a rest, she replied, "I have rested a long time in the past; now } \\
\text { - I must make up for the lost time; and this is not enough } \\
\text { - She enjoys the Tet Festival in her native village, with her husband and her child }\end{array}$ \\
\hline Theme/s & She has done her best to get rid of soiled life and to create a new one. \\
\hline CULTURAL VALUES & ACHIEVEMENT, PERSONAL SUCCESS, INTELLIGENT \\
\hline
\end{tabular}




\begin{tabular}{|c|c|}
\hline Characters & $\begin{array}{l}\text { Old Phan - a beggar, he would usually buy a small bottle of alcohol and dry shrimps in the } \\
\text { afternoon. He used to be a porter who usually carried loads from several storehouses in } \\
\text { Cholon } \\
\text { Miss Phan - earned her living as a greengrocer at the city market. Before seven in the } \\
\text { afternoon, she came slowly down the street carrying two baskets of fruit. Ms. Phan is } \\
\text { eventually the wife of Su, both of them are Buddhist demonstrators in May } 1963 \text {. } \\
\text { Su- He has always been bringing good news of the underground struggles against the } \\
\text { government. The youth gives a careful analysis of the situation in Central and South Vietnam. } \\
\text { Su gives his assurance that after the revolution, there will be freedom of religion, faith, } \\
\text { freedom of press, freedom of speech. The black markets and smuggling of illegal goods will } \\
\text { be stopped. All the fraudulent capitalists and profiteers will be exterminated. }\end{array}$ \\
\hline Point of View & Third person point of view \\
\hline Setting/Local color & $\begin{array}{l}\text { Thien - Thai - A lot of people go on a pilgrimage there; marketplaces; temples; Lo-Gom } \\
\text { hamlet; Central and South Vietnam }\end{array}$ \\
\hline Plot & $\begin{array}{l}\text { - } \\
\text { "An Unsound Sleep" takes place in Vietnam during the Vietnam War. The main } \\
\text { concern of the story is how people's lives are changed by political censorship and } \\
\text { war. The story traces the Phan family's downfall after a daughter and her husband } \\
\text { participate in Buddhist demonstrations. Nhât Tiên skillfully incorporates } \\
\text { descriptions of the local lifestyle and historical facts in his fiction. } \\
\text { - The story begins in early afternoon in what is typically a boisterous, poor part of } \\
\text { town. Old Phan is watching beggars and finishing off some dry shrimp and alcohol. } \\
\text { He gets up to leave for the marketplace, then spots a rather cheap eating place. } \\
\text { Again drinking alcohol and eating dry shrimps, he hears someone yelling about a } \\
\text { fire at Lo-Gom hamlet. After expressing surprise, he finishes up his food and drink } \\
\text { and heads for a park. He hears news of revolution in his state of half-sobriety. } \\
\text { Afterward Old Phan heads for home. } \\
\text { - After a day's work as a porter for numerous storehouses in the marketplace Cholon, } \\
\text { Old Phan usually sits on his doorstep enjoying a drink and peanuts. However, since } \\
\text { the Buddhist demonstration, his daughter has been coming home from her } \\
\text { greengrocer job later and later. Old Phan is very annoyed by the fact that dinner has } \\
\text { been left to grow cold lately because his daughter, Miss Phan, is always late. He } \\
\text { grows very impatient with her increasing lack of punctuality, when she used to get } \\
\text { home before 7:00 p.m. }\end{array}$ \\
\hline Conflict & - Man vs society's political ideology different from his own perspective \\
\hline Symbol/s & $\begin{array}{l}\text { - Nhât-Tien's concise but ample prose style is still evident. He conveys the local } \\
\text { flavor through vivid and vibrant descriptions of urban life in war-torn towns and } \\
\text { cities of Vietnam during the early 1960's. The author favors descriptions of } \\
\text { everyday, banal sights and activities, such as beggars eating filthy rice and Old } \\
\text { Pham's penchant for rice alcohol with dry shrimps, not to mention his dwindling } \\
\text { monetary flow because of that penchant. These details are banal and mundane; } \\
\text { however, because they are part of the fabric of Vietnamese life and unfamiliar to } \\
\text { Western readers, they may seem exotic. These details are one of the salient features } \\
\text { that produce the overall effect of the local and ethnic milieu of "An Unsound } \\
\text { Sleep." } \\
\text { As demonstrated by his portrayal of the lowest class of people in war-torn Vietnam, } \\
\text { the author's sympathies lie with the common person. His choice of subject is a } \\
\text { literary convention or technique used to deliver a larger message that the poor and } \\
\text { unrepresented are being trampled on by the government, the well-to-do, and the } \\
\text { privileged. }\end{array}$ \\
\hline
\end{tabular}




\begin{tabular}{|c|c|}
\hline & $\begin{array}{l}\text { - Old Pham and his daughter are character types that represent their socioeconomic } \\
\text { class and the proletariat. The old man and his daughter are not unique and } \\
\text { important as individuals but as representatives, as stand-ins, for the masses. The } \\
\text { author uses these character types in order to convey his critical view of the political } \\
\text { suppression of the Buddhist demonstrations. The reader can see that Nhât is much } \\
\text { more sympathetic with the politics of North Vietnam than with the supposedly } \\
\text { democratic South Vietnam. } \\
\text { - Nhât uses a basic literary convention of a simple family, socioeconomic class, } \\
\text { political struggle, and locality to create a profile sketch of the overall sentiment and } \\
\text { popular discontentment of the time in a country fighting a civil war. }\end{array}$ \\
\hline Theme/s & $\begin{array}{l}\text { The dominant subject matter is war and government oppression. Though not clearly stated by } \\
\text { Nhât, the setting is various towns in South Vietnam during the earlier part of the war and } \\
\text { during the presidency of Ngo Dinh Diem (1955-1963). "An Unsound Sleep" creates a story } \\
\text { around the Buddhist demonstrations that actually took place in South Vietnam during } 1963 \text {. } \\
\text { One of the primary reasons that the Buddhist demonstrations were severely suppressed was } \\
\text { because the members of the Diem family (which was similar to the Kennedy family in the } \\
\text { United States in terms of fame and fortune) were Roman Catholics who fervently disapproved } \\
\text { of the monks' suicides. Catholics were a minority in Vietnam during that time, amounting to } \\
\text { no more than } 10 \text { percent of the population. However, they predominated in government } \\
\text { positions because Diem was Catholic. The Buddists' resettlement resulted from Diem's severe } \\
\text { discrimination against them. } \\
\text { Miss Phan and Su are portrayed as taking part in the Buddhist demonstrations. Although Nhât } \\
\text { does not identify the demonstrations, they are most likely the May, 1963, demonstrations } \\
\text { against Diem. The demonstrators are fired on by police. Miss Phan and Su are arrested and } \\
\text { imprisoned along with thousands of high school and grade school students who are involved in } \\
\text { protests against the Diem government. Although Diem is never mentioned by name in the } \\
\text { story, readers familiar with the history of the Vietnam War will recognize what regime was... }\end{array}$ \\
\hline CULTURAL VALUES & $\begin{array}{l}\text { SELF-DIRECTION, CREATIVE, AUTONOMY, INDEPENDENCE, INTELLIGENT, } \\
\text { PRIVACY }\end{array}$ \\
\hline
\end{tabular}

Elements of Fiction Guide THE CRADLES by MAI NGU (Vietnam) 1962

\begin{tabular}{|l|l|}
\hline Characters & $\begin{array}{l}\text { Old Blind - He lives on the bank of the river for a long time. He is too poor and an alien in the } \\
\text { village. He has no plot of land of his own and lived by his clever hands as a carpenter. His } \\
\text { talents are to make a bamboo seat, to mend a worm-eaten bed or a rickety chair. He has been } \\
\text { a coffin-maker for children. } \\
\text { The adopted daughter who eventually became a dutiful midwife in their village. }\end{array}$ \\
\hline Point of View & $\begin{array}{l}\text { Third person point of view } \\
\text { Setting/Local color }\end{array}$ \\
$\begin{array}{l}\text { A little thatch-hut in the shade of a dense clump of bamboo-trees, high-trunked male bamboos } \\
\text { and green tender-barked bamboos. } \\
\text { At that time the rate of infant mortality nearly equaled the birth rate. Diseases and } \\
\text { famine wrested the babies right from their mothers' arms. It was said that they } \\
\text { were born not to grow up but to return to the earth. Those who could be snatched } \\
\text { from the jaws of death led a wretched life full of all kinds of sufferings. That was } \\
\text { the darkest days under the rule of the French colonialists and the landlords. } \\
\text { Oh! How lovely and invaluable was the present society. By the time he had woven } \\
\text { the eighty fourth cradle, the State Shop in the town placed orders with him for } \\
\text { many hundreds of them. }\end{array}$ \\
\hline
\end{tabular}




\begin{tabular}{|c|c|}
\hline Plot & $\begin{array}{l}\text { - That winter, a terrible small-pox plague spread to his village. Children died } \\
\text { without having time for proper burial and they were buried without coffins. } \\
\text { The old man's adopted girl was also tortured by small-pox. He only sat there } \\
\text { staring at the poor child, his face bathed in tears. It was a miracle how the girl } \\
\text { escaped death. But she was cured. } \\
\text { By the fifth year of the Resistance War enemy troops reached the other bank of that } \\
\text { small river. Bullets rained on the village. His optic nerve paralysed by the terrific } \\
\text { blast of a shell exploding nearby, the old man was struck blind. } \\
\text { The adopted child decided to work to keep the old man. She also served the } \\
\text { resistance as a messenger for the village committee, a guide for the guerillas and a } \\
\text { ferrywoman for the troops. } \\
\text { The old blind man managed to ferry troops across the river. His little hut became a } \\
\text { shelter for the travelling cadres. } \\
\text { Two years after the restoration of peace, the adopted girl was just twenty years old. } \\
\text { She was sent by the village Committee to a midwife training course, and when it } \\
\text { was over, she returned to her village to take charge of its maternity house. The } \\
\text { brick watch-station behind Old Blind's hut where the dead and dying children had } \\
\text { been taken to waiting for their burial, was built a Maternity House. } \\
\text { Everyday the Old Blind he strained his ears listening to the babies' cries and, was } \\
\text { able to say that it was a boy or a girl, if strong or weak and could foretell its } \\
\text { character. } \\
\text { One day the Old Blind got a tender green stemmed bamboo-tree to weave a basket } \\
\text { for fishing. The midwife asked him to make cradles for babies. Old Blind wove } \\
\text { cradles with all the skill of his fingers and love of his elated heart. Only now that } \\
\text { he was on the shady side of seventy was he given a job to his liking. } \\
\text { None of the children in their village is willing to carry the trade of the Old Blind } \\
\text { because they want to go all over the land and do bigger work. If the old man } \\
\text { disappears, all the cradles will remain. The babies when they grow up, will leave } \\
\text { those cradles to other new-born babies. }\end{array}$ \\
\hline Conflict & $\begin{array}{l}\text { Man vs. Circumstances (classical) - The leading character struggles against fate, or } \\
\text { the circumstances of life facing him/her. }\end{array}$ \\
\hline Symbol/s & $\begin{array}{l}\text { - The cold wind carried to him the children's cries in the desolate watch-station. The } \\
\text { shrieks of the dying pierced the air like those of wild cats in a graveyard. } \\
\text { Like an artist who had reached the summit of his art he was all the time pondering } \\
\text { over his work. } \\
\text { The sacred cradle was their birthplace, their country, the immense land of their } \\
\text { motherland, the cradle which had lulled them to sleep, protected and brought them } \\
\text { up. } \\
\text { The old blind would laugh happily and would say that this was not owing to his } \\
\text { hands but to the bamboo trees. }\end{array}$ \\
\hline Theme/s & $\begin{array}{l}\text { A bamboo - cradle will be swinging in the centre of every house like a boat on the river. } \\
\text { When the Old Blind sat weaving, his hair and beard covered by whittling, he } \\
\text { looked like a deity among his little followers in a Chinese painting. }\end{array}$ \\
\hline CULTURAL VALUES & SELF-DIRECTION, AUTONOMY AND INDEPENDENCE \\
\hline
\end{tabular}

Elements of Fiction Guide THE BLIND ALLEY by MA VAN KHANG (1962) Vietnam

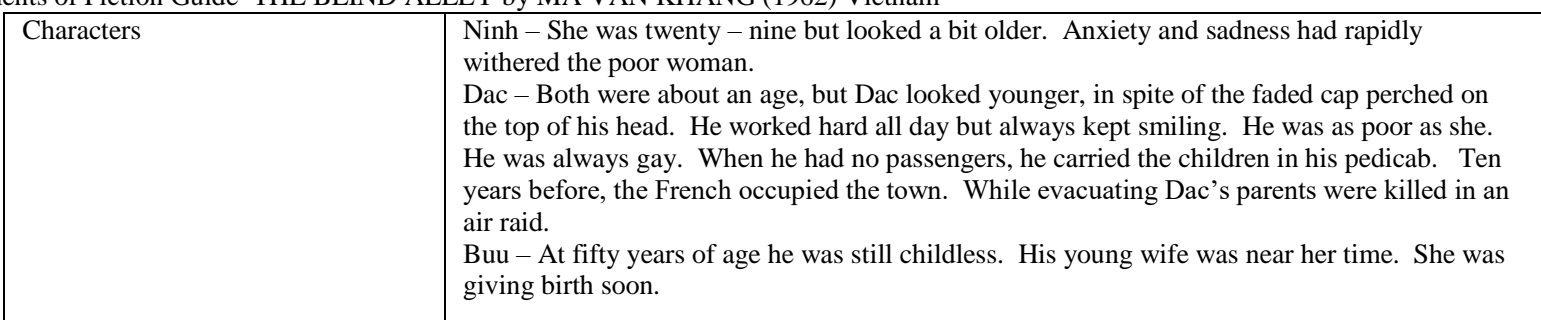


Cultural Values in Selected Southeast Asian Countries As Reflected in Representative Short Stories: Comparative Study

\begin{tabular}{|c|c|}
\hline Point of View & Third person point of view \\
\hline Setting/Local color & $\begin{array}{l}\text { The blind alley was hardly known to the people of the town. Old people said that this quarter } \\
\text { was previously inhabited by the soldiers' wives; someone said that during the French } \\
\text { occupation, it was frequented by opium - smokers. }\end{array}$ \\
\hline Plot & $\begin{array}{l}\text { Ninh brought Dac a soup -tureen full of rice, salted vegetables and sweet and seasoned soup. } \\
\text { She entered his room for the first time since her arrival there four months ago. Everything was } \\
\text { in disorder. } \\
\text { - Thirteen years ago, Ninh left her native village to earn her living elsewhere. Ninh } \\
\text { worked hard daily on the stopes. At night she had to sleep under the floor of a } \\
\text { house built on piles, full of gadflies, dog-ticks, mosquitoes, and bugs. } \\
\text { Every day there were miners who died of ill-treatment and sickness. She left Coc } \\
\text { coal -mine for another town. She went from bad to worse. Arrested and raped by } \\
\text { the policemen then she was sold to the Mai Huong coffee-house, at that time a } \\
\text { prostitute den where she had to work as a waitress. She had to lead a shameful and } \\
\text { exhausting life for six years. } \\
\text { Her beauty lost its bloom so she was turned out on the pavement. Just as that time } \\
\text { the town was liberated. } \\
\text { Through the assistance of the officials and townsfolk, she learnt bamboo weaving. } \\
\text { She dared not think of her shameful life. What was the good of thinking of it ? it } \\
\text { would only make her weep. She was already leading an easy life. } \\
\text { At dawn, Mrs. Buu gave birth to a child. The delivery was painful because she } \\
\text { was over forty years old. } \\
\text { The talk was lively. Talk as well as laughter is contagious. The conversation } \\
\text { moved from the child to the people present. } \\
\text { Ten years before, Dac endured all manner of sufferings and miseries during the } \\
\text { French occupation. He even lost his wife and only child. He left Tran Sam to } \\
\text { forget his miserable life. } \\
\text { Dac woud go away. The Office of Labour needed some coal-miners. But after } \\
\text { three days, Dac came back to fetch Ninh. He was going to marry Ninh. Both of } \\
\text { them could become coal-miners. }\end{array}$ \\
\hline Conflict & $\begin{array}{l}\text { 1) Man vs. Man (physical) - The leading character struggles with his physical strength against } \\
\text { other men, forces of nature, or animals. } \\
\text { 2) Man vs. Circumstances (classical) - The leading character struggles against fate, or the } \\
\text { circumstances of life facing him/her. }\end{array}$ \\
\hline Symbol/s & $\begin{array}{l}\text { That day, the blind alley was very animated. The neighbors returned one another's call. } \\
\text { Cakes, tins of milk, clothes, and medicines given by groups of women, representatives of old } \\
\text { men and of the town-quarter administration, filled the little table. } \\
\text { - The blind alley has undergone a change. But when the men leave for work, the } \\
\text { blind alley is very animated. And the same cat warms herself by the fire. }\end{array}$ \\
\hline Theme/s & $\begin{array}{l}\text { - The child was the joy and also the gem of so many other joys. It changed the life of } \\
\text { the blind alley. }\end{array}$ \\
\hline CULTURAL VALUES & STIMULATION, CHALLENGE IN LIFE, A DARING LIFE \\
\hline
\end{tabular}




\begin{tabular}{|c|c|}
\hline Characters & $\begin{array}{l}\text { "Thu" First - person narrator - Her guardians would comment on her that there was no hope } \\
\text { for her anymore. She was an untamed child, disobedient, unfeeling, a liar, and had all the bad } \\
\text { qualities possibly inherent in a naughty child. In so doing, her heart was wounded and } \\
\text { paralyzed, she was indeed an unfortunate niece. } \\
\text { Uncle - A learned man for he talked and talked of the East and the West, of the past and the } \\
\text { present, with no intermission and without consulting any book }\end{array}$ \\
\hline Point of View & $\begin{array}{l}\text { First person point of view stands out as a character and refers to himself or herself, using "I" } \\
\text { - The author butts in or throws his weight around or makes comments or tells his } \\
\text { characters what to do and obviously intrudes, the author is said to be subjective. }\end{array}$ \\
\hline Setting/Local color & $\begin{array}{l}\text { Central Vietnam } \\
\text { Two aspects of French colonial policy are significant when considering the attitude of the } \\
\text { Vietnamese people, especially their educated minority, toward the colonial regime: one was } \\
\text { the absence of any kind of civil liberties for the native population, and the other was the } \\
\text { exclusion of the Vietnamese from the modern sector of the economy, especially industry and } \\
\text { trade. Not only were rubber plantations, mines, and industrial enterprises in foreign hands- } \\
\text { French, where the business was substantial, and Chinese at the lower levels - but all other } \\
\text { business was as well, from local trade to the great export-import houses. The social } \\
\text { consequence of this policy was that, apart from the landlords, no property-owning indigenous } \\
\text { middle class developed in colonial Vietnam. Thus, capitalism appeared to the Vietnamese to } \\
\text { be a part of foreign rule; this view, together with the lack of any Vietnamese participation in } \\
\text { government, profoundly influenced the nature and orientation of the national resistance } \\
\text { movements. }\end{array}$ \\
\hline Plot & $\begin{array}{l}\text { Not until a woman becomes a mother for the first time, she will have the realization that } \\
\text { nursing a baby with one's own milk is the best than all the canned milk in the market. } \\
\text { - It's because none of those Frenchmen is allowed to suck the breast of his mother. } \\
\text { White men are not human beings: they are all devils. If a child is fed with animal } \\
\text { milk, he is deprived of all human sentiments when he grows up. These barbarous } \\
\text { people were always planning to corrupt the Annamite! } \\
\text { The orphan prayed earnestly to God, Buddha, Christ, the Spirit of the Mountains, } \\
\text { the Spirit of Rivers, Providence, Ulysses, Gandhi, Sir Happiness and Sir Fortune } \\
\text { on Chinese calendar to have mercy on her and help her and to safeguard her } \\
\text { human nature. In her sweet dream, one after the other, they caressed her head and } \\
\text { aid, "Don't worry, I will help you..." } \\
\text { The youth was asked by the auntie to take some of their pigs to the market to be } \\
\text { sold. } \\
\text { In the train, there was an old woman asking for alms. The youth wanted to be } \\
\text { charitable in spite of having drunk cow's milk. She still has a human nature. } \\
\text { - Come the time she had her own children, she kept her vow that all the children had } \\
\text { drunk milk from her breasts until they were able to eat rice. Even the fifth child } \\
\text { was fed for six months, when suddenly her milk began to go } \\
\text { Thu relied on her mother's intuition to breast - feed all her children so to keep all } \\
\text { the babies healthy, less susceptible to diseases, and able to recover quickly from } \\
\text { sickness. } \\
\text { Whenever she would held her children to her arms, all her grief receded, all her } \\
\text { disappointments disappeared, all the sorrows which lay heavy in her heart seemed } \\
\text { to float away. All the hard trials of the past, became unimportant, she became } \\
\text { armed to face and overcome all the future difficulties in life. } \\
\text { Finally, the sixth baby had nothing to suck, her milk had gone completely dry. } \\
\text { Suddenly, Thu remembered her husband's words "Is your milk still nutritive } \\
\text { enough to warrant mourning over it?" }\end{array}$ \\
\hline Conflict & Man vs. himself/psychological \\
\hline Symbol/s & $\begin{array}{l}\text { - Unable to turn over a new leaf, even a rag can be used to wipe up dust, but that } \\
\text { youth is less useful tan a rag! Rubbish - no more, no less. } \\
\text { "It's owing to those three Frenchmen" A customary way of mentioning the French } \\
\text { in South Vietnam (riddle) } \\
\text { "These three Frenchmen are liars, dishonest, plundering, raping, seizing other } \\
\text { people's land. They are merciless beyond imagination, and they never flinch from } \\
\text { any cruelty. Why are they so barbarous?" }\end{array}$ \\
\hline
\end{tabular}


Cultural Values in Selected Southeast Asian Countries As Reflected in Representative Short Stories: Comparative Study

\begin{tabular}{|l|l|l|}
\hline & $\begin{array}{l}\bullet \quad \text { "Annamite" old name for the Vietnamese } \\
\text { Emperor T'sin Tche Hwang never sucked his mother's breast, so he remained } \\
\text { unmoved even by a river of bloodshed or a mountain of corpses } \\
\text { But Mencius and Confucius, the celebrated philosophers, had sucked the milk of } \\
\text { their mothers untl four years of age. So had Jesus Christ. }\end{array}$ \\
\hline Theme/s & $\begin{array}{l}\text { Child rearing and the mother's love of all her children. The tender attention of the mother to } \\
\text { all her own children. } \\
\text { The Indochina Peninsula was colonized by the French in the mid }-19^{\text {th }} \text { century } \\
\text { until } 1954\end{array}$ \\
\hline CULTURAL VALUES & $\begin{array}{l}\text { FAMILY SECURITY, SAFETY, HARMONY, STABILITY OF SOCIETY, SOCIAL } \\
\text { ORDER }\end{array}$ \\
\hline
\end{tabular}

Table 2: Raw Data of Cultural Values of 35 Short Stories of Selected South East Asian Countries Based on the Ten Motivational Types of Values

\begin{tabular}{|c|c|c|c|c|c|c|c|c|c|c|c|c|c|c|c|c|c|c|c|c|c|c|c|c|c|c|c|c|c|c|c|c|c|c|}
\hline & & & lones & & & & & lays & & & & Mya & $\mathrm{nm}$ & & & & Phil & ippi & nes & & & Sing & zapo & & & & Thai & ailanc & & & & Vietr & tnam & \\
\hline & 1 & 2 & 3 & 4 & 5 & 1 & 2 & 3 & 4 & 5 & 1 & 2 & 3 & 4 & 5 & 1 & 2 & 3 & 4 & 5 & 1 & 2 & 3 & 4 & 5 & 1 & 2 & 3 & 4 & 5 & 1 & & 34 & 45 \\
\hline $\begin{array}{l}\text { Self Direction } \\
-\quad \text { Creativity } \\
-\quad \text { Freedom }\end{array}$ & & & & & & & & & & & & & & & & & & & & & $\checkmark$ & & & & & & $\checkmark$ & $\checkmark$ & & & & $\checkmark \checkmark$ & & \\
\hline $\begin{array}{l}\text { Stimulation } \\
\text { - Exciting life }\end{array}$ & & & & & & & & & & & & & & & & $\checkmark$ & & & & & & & & & & & & $\checkmark$ & $r$ & & & & $\checkmark$ & \\
\hline $\begin{array}{l}\text { Hedonesian } \\
\text { - Pleasure }\end{array}$ & & & & & & & & & & & & $\checkmark$ & & & & & & & & & & & $\checkmark$ & & & & & & & $\checkmark$ & & & & \\
\hline $\begin{array}{l}\text { Achievement } \\
\text { - } \quad \text { Success } \\
\text { - Ambition }\end{array}$ & & & $\checkmark$ & & & & & & & & $\checkmark$ & & & $\checkmark \checkmark$ & & & & $\checkmark$ & & & & & & & & & & & & & $\checkmark$ & & & \\
\hline $\begin{array}{l}\text { Power } \\
\text { - Authority } \\
\text { - Wealth }\end{array}$ & & & & $\checkmark$ & & & & & & & & & & & & & & & & & & & & $\checkmark$ & & & & & & & & & & \\
\hline $\begin{array}{l}\text { Security } \\
\text { - Social order }\end{array}$ & & & & & & & & & & & & & & & & & $\checkmark$ & & & & & $\checkmark$ & & & & & $\checkmark$ & & & & & & & $\checkmark$ \\
\hline $\begin{array}{l}\text { Conformity } \\
\text { - Obedience }\end{array}$ & $\checkmark$ & & & & $\checkmark$ & & & $\checkmark$ & & & & & & & & & & & & & & & & & & & & & & & & & & \\
\hline \begin{tabular}{ll}
\multicolumn{2}{l}{ Tradition } \\
- & Humility \\
- & Devoutness
\end{tabular} & & & & & & $\checkmark$ & & & & $\checkmark$ & & & & & & & & & & $\checkmark$ & & & & & & & & & & & & & & \\
\hline $\begin{array}{l}\text { Benevolence } \\
\text { - Helpfulness }\end{array}$ & & $\checkmark$ & & & & & $\checkmark$ & & & & & $\checkmark$ & & & & & & & & & & & & & & $\checkmark$ & & & & & & & & \\
\hline $\begin{array}{l}\text { Universalism } \\
\text { - } \quad \text { Social Justice } \\
\text { - } \quad \text { Equality }\end{array}$ & & & & & & & & & $\checkmark$ & & & & & & & & & & $\checkmark$ & & & & & & $\checkmark$ & & & & & & & & & \\
\hline
\end{tabular}

